\title{
Black Rainbow \\ stories of Māori and Pākehā working across difference
}

\author{
Rachael Fabish
}

A thesis submitted to Victoria University of Wellington

in fulfilment of the requirements for the degree of

Doctor of Philosophy in Social Anthropology

Victoria University of Wellington 


\section{Abstract}

This thesis examines the impacts of colonialism on the interpersonal experiences of Māori (indigenes) and Pākehā (settlers) involved in anarchist organising in Wellington, Aotearoa New Zealand. This research contributes to literature on urban Māori identity, processes of Pākehā change, and 'biculturalism as lived'. It also contributes to international literature on indigene-settler relations, whiteness studies, activist studies and anti-oppressive praxis. The central research question is: how do Māori and Pākehā work together across difference? This question was also considered when developing a collaborative methodology, in response to Kaupapa Māori (indigenous) critiques of 'traditional' research. This involved establishing and working closely with Black Rainbow, a collective of five Māori and two Pākehā activists (including myself). We met over twelve months and recorded our discussions, as 'interactive interviews'. These discussions have been transformed into 'stories' showing the rich shared meaning-making that occurred while we told tales of our experiences in the anarchist 'scene'. The Black Rainbow discussions show the difficulties of working across difference in Pākehā dominated communities, where Pākehā often undermine or tokenise Māori identity, respond insensitively to Māori members' concerns and fail to share power.

Throughout this thesis I build on Uma Narayan's work, arguing that 'insiders' epistemic privilege' is based on lived experience and tied to identity, yet 'repressive authenticity' is often used to dismiss urban Māori identity and therefore, their epistemic privilege. Further, insiders' epistemic privilege is experienced through emotional reactions, yet Māori ways of expressing emotion are often invalidated. Black Rainbow allowed Māori members to validate each other's epistemic privilege, especially through humour. It also allowed a place for careful listening for Pākehā members. I argue that this listening is not passive, but also involved 'learning to be affected' by the 'epistemological discomfort' at the heart of 'processes of Pākehā change'. I see this as the emotional cost of truly accepting insiders' epistemic 
privilege, and I propose that sitting with this discomfort, shifts some of the emotional burden onto Pākehā, as well as the threat to identity that Māori may experience when working across difference. 
This thesis is dedicated to the members of Black Rainbow. 


\section{Acknowledgements}

I would like to thank the following people and organisations: my supervisors, Brigitte Bönisch-Brednich and Maria Bargh, for your sharp minds, kind support and great senses of humour; the staff and students of the School of Social and Cultural Studies and Te Kawa a Māui/School of Māori Studies, Victoria University of Wellington, particularly Bronwyn McGovern, Riki Mihaere, Tanja SchubertMcarthur, Catherine Trundle, Arama Rata, Erina Okeroa, Awanui Te Huia, Krissi Jerram, Miki Seifert and Ocean Mercier; The Victoria Doctoral Assistanceship and The Research Trust of Victoria University for their financial support; the members of the anarchist community for inspiring and challenging me; my mother, Maree Lovergrove, for your love, help and taking me on all those walks and, finally, A.J. 'Sonny' Vollweiler for being the medicine to all my worries, for your sparkly eyes and all your endless correcting of my grammar and spelling. 


\section{Contents}

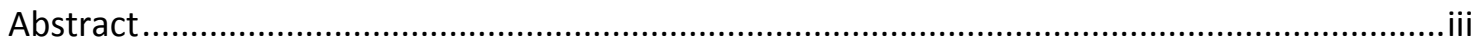

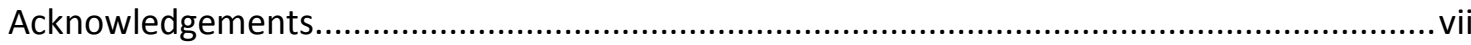

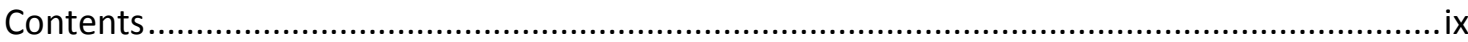

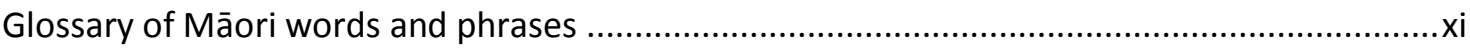

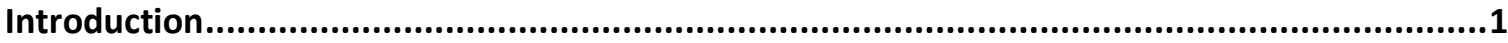

'Mess-finding' in the Wellington anarchist scene............................................................. 2

Questions arising from my experience of disjuncture ................................................... 6

Fitting Black Rainbow into wider debates about Māori-Pākehā relations ....................... 9

Relating across difference in the anarchist circles....................................................... 13

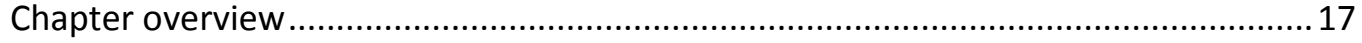

\section{Chapter 1}

Methodology: ‘Learning to be affected’ by Kaupapa Māori .............................................23

Kaupapa Māori research: a response to Māori concerns..............................................25

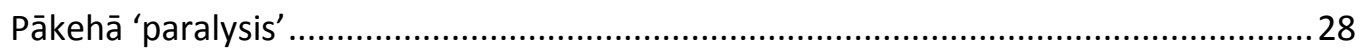

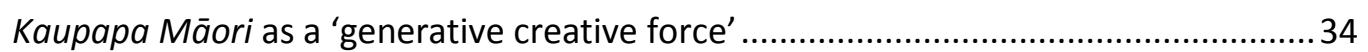

'Working at the interface' between anthropology and Māori studies...........................37

Anti-oppressive praxis as a place to stand at the interface with Kaupapa Māori ..........40

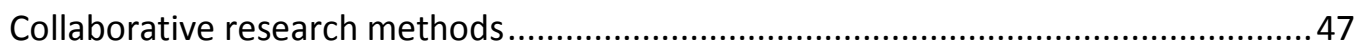

Reflections on positioning in collaborative research.....................................................56

\section{Chapter 2}

A Black Rainbow Story: How I have written this thesis

Why write stories?

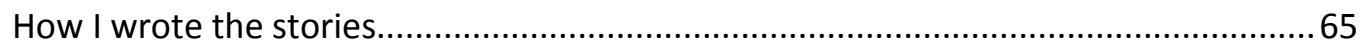

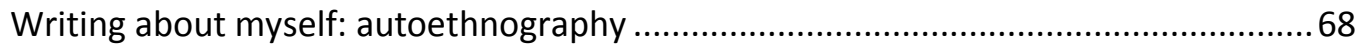

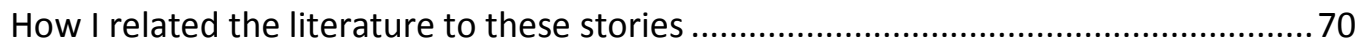

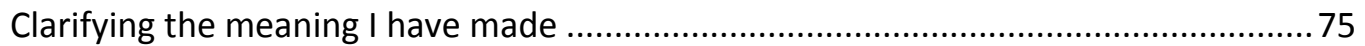

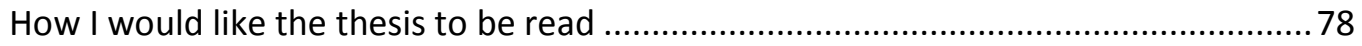

\section{Chapter 3}

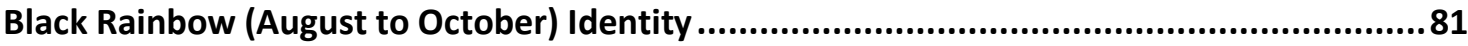

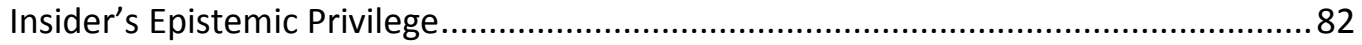

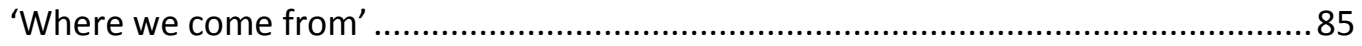

Humour and insider's epistemic privilege …............................................................... 102

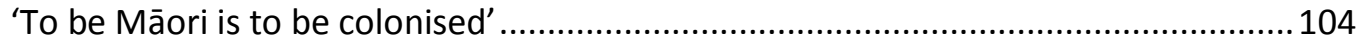


'Cool, a "real" Māori told you'

\section{Chapter 4}

Black Rainbow (November to March) Relationships

Emotional sources of epistemic privilege 129

Threatened relationships: Microaggressions and failure to relate. 131

Talking relationships: Identity, emotions, power

\section{Chapter 5}

Black Rainbow (April to June) Power-sharing

Telling stories, sharing jokes, making meaning 179

Stories from the anarchist scene: tino rangatiratanga, power and responsibility .....182

A Black Rainbow Story

\section{Processes of Pākehā Change}

'Learning to be affected' while working across difference...

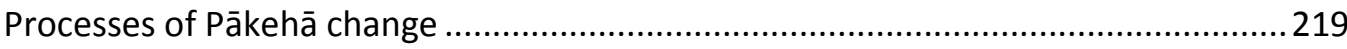

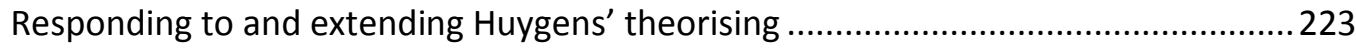

Critiques of whiteness studies and white decolonisation workshops .........................226

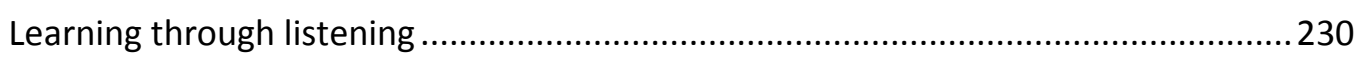

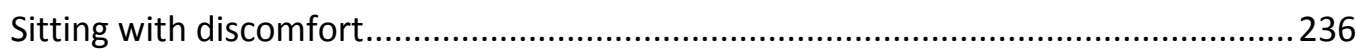

'Learning to be affected' unmakes Pākehā identity and opens opportunities for

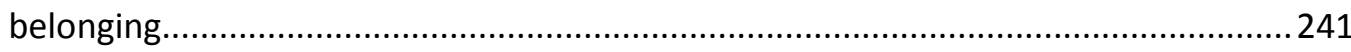

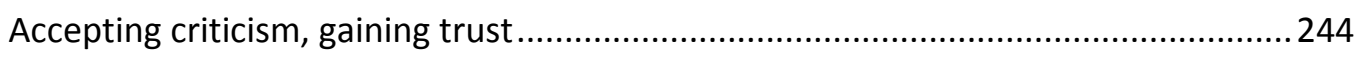

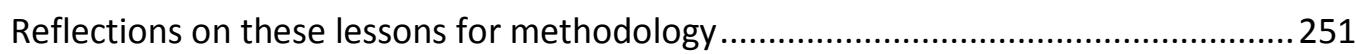

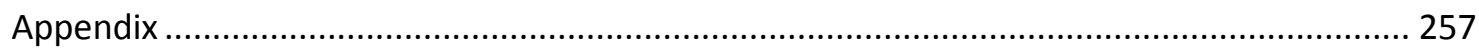

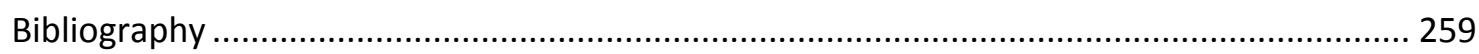




\title{
Glossary of Māori words and phrases
}

\author{
āke, ake ake \\ forever \\ aroha \\ aroha ngā tangata \\ haka \\ affection, sympathy, charity, compassion, love, empathy \\ respect for the people \\ posture dance - vigorous dances with actions and \\ rhythmically shouted words \\ hapū \\ kinship group, subtribe, section of a large kinship group \\ he kānohi kitea \\ a face seen \\ hīkoi \\ march \\ hui \\ meeting or conference \\ iwi \\ extended kinship group, tribe, nation, people \\ kaitiakitanga \\ guardianship, stewardship, trustee \\ karakia \\ karanga \\ incantation, ritual chant, prayer \\ a ceremonial call of welcome to visitors onto a marae at \\ the beginning of a pōwhiri. \\ kaua e mahaki \\ don't be humble, it seems to mean the opposite in Cram's \\ use (2001) \\ kaua e takahia \\ te mana o te tangata \\ do not trample the power of the people \\ kaupapa \\ foundation, agenda, topic, philosophy \\ Kaupapa Māori \\ Māori ideology or philosophy \\ kawakawa \\ pepper tree, used for ceremonies and medicinal purposes \\ kia tūpato \\ be careful \\ Kiwi \\ a flightless native bird, commonly used to mean New \\ Zealander \\ kōhanga \\ Māori language immersion preschool centres \\ mana \\ prestige, authority, power, influence, spiritual power \\ mana motuhake \\ separate identity, autonomy \\ Mana Motuhake o Tūhoe \\ autonomy of the Tūhoe nation \\ manaakitanga \\ hospitality, kindness \\ manaaki ki te tangata \\ take care of the people
}




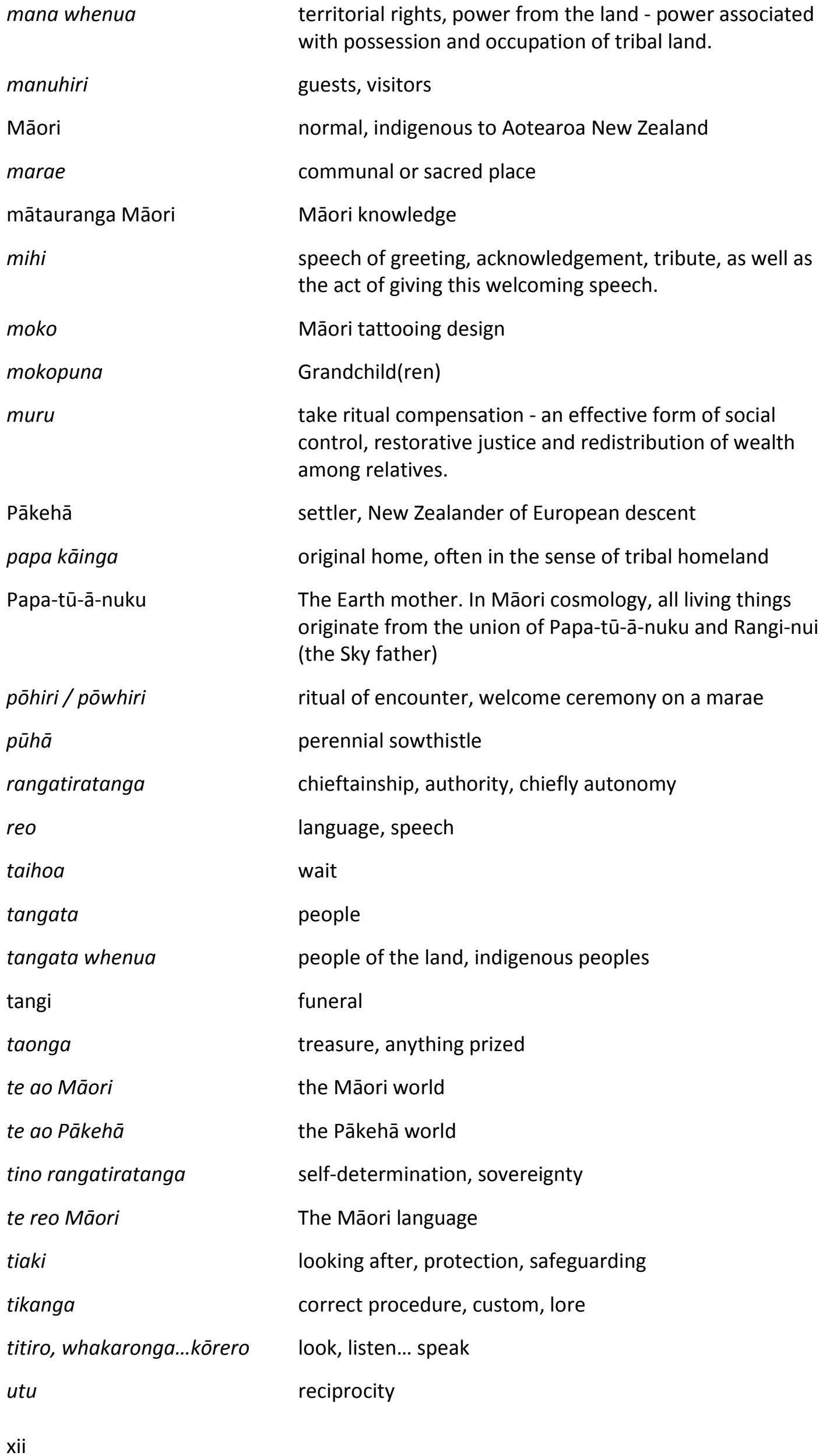

reciprocity originate from the union of Papa-tū-ā-nuku and Rangi-nui (the Sky father)

ritual of encounter, welcome ceremony on a marae

perennial sowthistle

chieftainship, authority, chiefly autonomy

language, speech

wait

people

people of the land, indigenous peoples

funeral

treasure, anything prized

the Māori world

the Pākehā world

self-determination, sovereignty

The Māori language

looking after, protection, safeguarding

correct procedure, custom, lore

look, listen... speak 


$\begin{array}{ll}\text { wahine } & \text { woman } \\ \text { waiata } & \text { song, chant } \\ \text { wairua } & \text { spirit } \\ \text { wānanga } & \text { Māori tertiary institution } \\ \text { wero } & \text { challenge, stab, sting } \\ \text { whaikōrero } & \text { oratory, formal speeches usually made by men during a } \\ & \text { pōhiri } \\ \text { whakamā } & \text { be ashamed, shy, bashful, embarrassed } \\ \text { whakapapa } & \text { genealogy } \\ \text { whānau } & \text { extended family } \\ \text { whanaungatanga } & \text { relationship, kinship } \\ \text { whāngai } & \text { adopt, nurture, raise } \\ \text { whenua } & \text { land }\end{array}$




\section{Introduction}

$30^{\text {th }}$ of August, 2008

Sitting on a couch in the 'yellow room' of 128 community centre after the global 'Day of Action' demonstration, I find myself out of touch and drifting away from the debrief meeting happening around me. The other members of the October $15^{\text {th }}$ Solidarity crew seem so happy, talking about what a success the day has been-well organised, good media presence, no trouble with the police. I feel like I was at a whole other protest. What I saw was one of the few Māori women at the demo handed a big tino rangatiratanga flag ${ }^{1}$ to wave, while white anarchists on mega phones chanted things like: 'This is Māori land, this is Tühoe land! ${ }^{2} \bar{A} k e$, ake ake!'3 and 'One solution: Revolution'. I feel awkward and embarrassed and don't know how to say that I think it was actually a pretty weird protest, especially to these people who are so pleased with the results of their hard work.

I'm a newbie to this group, to this community, I don't really get how it works. During the months I've been working with October $15^{\text {th }}$ Solidarity, in the lead-up to this demo calling for the state to 'Drop the Charges' for the 18 defendants of the Operation 8 case, there has been a lot of talk about supporting tino rangatiratanga ${ }^{4}$ and Mana Motuhake o Tūhoe. ${ }^{5}$ With these issues cutting to the heart of Māori struggles, I've been a little confused about why there weren't more Māori involved in this organising. But the more experienced members of October $15^{\text {th }}$ Solidarity crew seemed so confident, I assumed they had the necessary relationships with

\footnotetext{
${ }^{1}$ A symbol of Maori sovereignty.

${ }^{2}$ Central Wellington, is not in fact Tūhoe land (which is centred in the Bay of Plenty), but Te Ātiawa/Taranaki ki Te Upoko o Te Ika land.

${ }^{3}$ Forever.

${ }^{4}$ Māori self-determination.

${ }^{5}$ The autonomy of the Tūhoe nation.
} 
Māori leaders, thinkers, activists and that these communities would connect up with ours on the day of the demo. Instead, the turn out for the protest had been a hundred-odd, mostly Pākehā, anarchist types. All I can think is: 'If we're supposed to be supporting Māori, why didn't Māori support this demo? Surely this means we are doing something wrong?'

Now this thinking seems clearly naive, but at the time it sparked an important change process in me. What disturbed me most, as I sat on that couch, and in the coming days and weeks, was that I did not know how to do it any better. As I started to worry that there was no clear network of accountability between this activist community and Māori (indigenous) counterparts, I realised, too, that I had no idea where to start looking for one. This brought home the painful reality that I knew very little about the Māori world. I had begun to realise how monocultural I am. I felt I did not have my 'feet on the ground' in this country, where I grew up; I had been walking around in the 'white wash'. It became real to me that, if the big problem Māori face is colonisation, this is my big problem too, because I am a part of that colonisation. After all, I operate almost purely within Pākehā (settler) frameworks; anyone interacting with me experiences another subtle assimilative pressure, which confirms Pākehā dominant norms. It's personal.

\section{'Mess-finding' in the Wellington anarchist scene}

This thesis is about Māori and Pākehā people working together across difference within anarchist circles in Wellington, Aotearoa New Zealand. It centres on Black Rainbow, a collective of five Māori and two Pākehā activists (including myself) and shares our stories about working in the anarchist 'scene'. It all began with that moment on the couch at the 128 community centre, which I have come to understand as what Karen Potts and Leslie Brown meant by the 'mess-finding' involved in the questioning stage of research: 
[L]ived experience of self and others can also provide a valid point of departure for a research topic... Sometimes the question finds us. Sometimes questions are more like hunches, experienced tensions, or disjunctures sensed in our own lives (2005: 266-267). From the story above, you (the reader) will get a sense of the disjuncture I experienced. Trying to make sense of these tensions, I began to speak with Māori members of the wider anarchist scene about this and heard many express frustrations about being marginalised and tokenised in this Pākehā dominated community, especially when it came to organising around 'Māori issues'. This community did not seem to be living up to its own social justice values and claims of supporting tino rangatiratanga. I was only just beginning to glimpse the impacts of colonisation and internalised racism on my own identity, however I felt sure that in order for this community to truly be a space that Māori enjoyed participating in, Pākehā had to take personal and collective responsibility for change. Yet, in the Pākehā activists around me, I saw a complex combination of efforts towards that change and resistance to it. It was certainly a 'mess' I found.

The Wellington based anarchists and activists, loosely orbiting 128 Radical Community and Resource Centre (128 Abel-Smith street, central Wellington), are a collection of like-minded people with varying degrees of involvement in a range of small groups working around specific projects (See David Gaeber's 2009 ethnography on anarchist organising practices and David Foote 2009 for a more local ethnography, based in Hamilton). While these groups all work independently of each other, there is much crossover of membership which leads to a sense of belonging to a wider 'scene'. Further, there are some attempts at community building and both 'community' and 'scene' are words used by individuals to describe this network. Although I did not realise at the time, this community was already beginning to decline when I joined it in December 2007.

A few months earlier, on October $15^{\text {th }}$, Operation 8 saw hundreds of police raid the small Tūhoe community of Rūātoki, in the Bay of Plenty, as well as several other 
homes around the North Island, including the 128 community centre (see October $15^{\text {th }}$ Solidarity, Keenan 2008, Devadas 2008, Morse 2010a). Five people involved with the Wellington anarchist community were among those who were arrested and spent a month in prison. These raids were the result of months of surveillance of Māori, anarchists, environmentalists and anti-war activists under the Terrorism Suppression Act 2002. While terrorism charges were never laid, eighteen people faced arms charges. This led to the 2012 trial of only four people; Tāme Iti, Rangi Kemara, Emily Bailey and Urs Signer, with Iti and Kemara being sentenced to two and a half years of imprisonment, and Bailey and Signer receiving a sentence of nine months home detention. Given the violence and racism of the police action in Rūātoki, the impact of Operation 8 on the Wellington anarchists perhaps seems trivial, however it did have an effect.

I now see the community I came to as a traumatised one. Before Operation 8 , the anarchist networks had already been fractured and reduced by the fall-out resulting from several instances of sexual abuse. The difficulty of trying to support survivors and reintegrate the accused left many of those remaining within the scene drained and disillusioned. On top of the Operation 8 surveillance, there was also the discovery of a police informant and a corporate spy active in the community. This further corroded trust in the scene and many new members (myself included) went through a period of feeling under suspicion.

As a newer member, however, who joined this community only after the Operation 8 arrests, it is difficult for me to fully appreciate the pain and exhaustion of that time (a sense of this can be gained from the discussion in chapter three, 'Black Rainbow (August to October): Identity'). In her article, 'The process is the punishment: Operation 8 two years on', Valerie Morse, writes about the trauma of prison and the dragging legal processes, as well as what she calls the 'community implosion' that followed her arrest. She poignantly admits: 
In the aftermath of the raids, I struggled to come to terms with what I had become a part of; I made many mistakes along the way including speaking for other people, disempowering people, not behaving collectively, and failing to educate myself about basic ideas and protocols. People in our community struggled to survive, to feel valued in what they were doing and to be safe (2010b: 50).

In this trying time, friendships were damaged and bridges were burnt. This included connections with activists outside of the anarchist scene. At the commemoration of October $15^{\text {th }}$ 'Never Forget' (October $9^{\text {th }} 2013$ ), Kiritapu Allan argued that before Operation 8 a great deal of trust had been developed between various activiststino rangatiratanga groups, Pākehā decolonisation groups and Treaty educators, anarchists. This trust had been building since the early 2000s, especially during the period of protest following government moves to confiscate substantial tracts of Māori land under the Foreshore and Seabed Act (2004), and was relationshipsbased, developed through both sharing 'dreams' and 'time in the trenches'. Allan described Operation 8 as destroying that trust, as people pulled back into themselves and stopped communicating. This is part of a common conclusion that 'the state won' in the sense that it broke down these activist networks.

One supporter of the arrestees commented that communication was made difficult during this time by the 'enforced silence' surrounding October $15^{\text {th }}$-caused by the suppression orders and police surveillance. Within this environment, it was clear that challenging the arrestees on their behaviour or politics, or even asking questions about what happened during their time in Rūātoki, could have legal consequences. This space of silence was hard to live within. It also meant that people had to create their own stories about what had happened and whyprobably in quite different ways and with quite different meanings. This thesis represents some of those stories and meanings that came out of this climate. The issues and experiences discussed in this thesis also extend beyond the specifics and events around October $15^{\text {th }}$, however it remains part of that story, so I want to 
acknowledge the pain that this thesis sits within and make it clear that there are other stories that are not told here.

\section{Questions arising from my experience of disjuncture}

As you will see reading the stories in this thesis, the challenges the October $15^{\text {th }}$ Solidarity crew faced over how Māori and Pākehā relate to each other around Māori issues are not unique to that collective, but rather similar challenges arise in various situations, in and out of the anarchist community. My experience with the

October $15^{\text {th }}$ Solidarity collective, however, represents a moment of disjuncture for me, from which the questions that lead to this thesis arose. Out of my dawning recognition of my own ignorance, monoculturalism and privilege, and a dissatisfaction with the way that the anarchist scene seemed to be marginalising Māori members, I became deeply interested in how Māori and Pākehā individuals are affected by colonisation. How do we interact within it? How can we shift those interactions towards something 'better'?

I wanted to gain a greater understanding of how things were in our community. What are some of the attitudes among the general anarchist scene towards decolonisation, Pākehā and Māori culture, Māori issues and how best to engage with Māori struggles? How are Māori individuals actually treated in this community? What are their experiences and analyses? What are some of the pressures or factors that contribute to marginalisation of Māori? What are some of the factors that prevent Pākehā anarchists from committing to or advancing tino rangatiratanga and decolonisation? Why does it seem so difficult for Pākehā anarchists to recognise their own power? Why does understanding these issues politically not necessarily lead to changes in behaviour? Where are the places of hope? Can we create spaces that are truly Māori centred? While these questions are focus on the anarchist community to which I belong, they also have implications for the wider public in Aotearoa New Zealand, and other settler societies. At the 
heart of my thesis is questions about how Māori and Pākehā relate to each other personally-both individually and in groups.

Once I became interested in exploring these questions through research for a $\mathrm{PhD}$, new questions arose about how to position myself as a Pākehā researcher working with this sensitive topic. How can I do responsible research with Māori and Pākehā in a way that responds to the challenges presented by Kaupapa Māori (indigenous) researchers? How can I do research that benefits wider Māori and non-Māori audiences, as well as my research participants? Can research act as an intervention? These questions pushed me towards a collaborative style of research and the Black Rainbow was formed as a collective within which all members could act as researchers and participants, to explore our questions together (see Chapter one, 'Methodology: "Learning to be affected" by Kaupapa Māori' for more on these issues).

Many of the people who eventually joined Black Rainbow were the same people I had been speaking with about these issues since I first experienced that moment of disjuncture within the October $15^{\text {th }}$ Solidarity crew, so the questioning we did within this collective was largely a continuation of those earlier discussions. I was aware that there is power in who asks the questions and wanted to allow the questions to continue to emerge throughout the research, rather than fixing them early on. Here is a brainstorm list Black Rainbow created together and worked with, as a basis of our discussions:

- Things that happen in activist groups that are seen as neutral, but are actually cultural

- 'Neutral' spaces and earnest, superficial 'biculturalism'

- Why do we have these discussions?

- Strategies for dealing with Pākehā taking up space being 'bicultural'

- Where are people coming from?

- Intimate relationships between Māori and Pākehā 
- Insecurity about Māori identity

- When you first noticed your ethnicity

- Activist ideology and supporting tino rangatiratanga

- Crossovers between class and identity politics

- Identity and essentialism

- Trauma of colonisation

- Why were there so few Pākehā that Māori wanted to work with in this group?

Through working in Black Rainbow, which was a Māori majority group, new questions arose for me about the complexities of contemporary Māori identity and how Pākehā change can occur through working in a Māori centred environment. How do urban Māori understand and experience their identities? How are those identities limited and misunderstood within Pākehā centred environments? How can I (as a participant) move out of Pākehā 'paralysis' (Tolich 2002), confront my white privilege, and move towards Māori culture without appropriating it? Can taking this journey and describing the experience help other Pākehā to take similar journeys into decolonisation? How does working in the Māori centred activist group transform Māori and Pākehā members? These questions speak to issues around how Māori and Pākehā experience personal decolonisation; however, how we relate to each other and work together, especially in various social justice contexts, remains a central question. During the writing up stages of this research thesis, I have come to contain all of this 'messy' questioning within the two simple questions:

- How do Māori and Pākehā work together across difference?

- How can Pākehā work better with Māori? 


\section{Fitting Black Rainbow into wider debates about}

\section{Māori-Pākehā relations}

By looking closely at the interpersonal relationships between Māori and Pākehā, the discussions of the Black Rainbow collective contribute to wider debates about Māori-Pākehā relations, which are often centred on 'biculturalism' and the Treaty of Waitangi. Aotearoa New Zealand pursues a politics of biculturalism, a vague and contested term, which also runs alongside a 'de facto multiculturalism' (Jo Smith 2007: 68) and disguises Pākehā monoculturalism (Butt 2005). The Treaty of Waitangi is often seen as the source of the bicultural pressures of the nation. Given that the 1840 signing by Crown representatives and Māori leaders of iwi (tribes) amounted to 'two peoples' agreeing to two very different treaties-the English language 'Treaty of Waitangi', in which Māori ceded sovereignty to the Queen, and the Māori language 'Tiriti o Waitangi', in which Māori retained their rangatiratanga ('autonomy' or 'political authority') (Royal Commission on Social Policy 1988: appendix I - IV, Biggs 1989, McDowell and Webb 1998, Winiata 2005, Mikaere 2011), it is perhaps not surprising that we also see different understandings of 'biculturalism', which vary greatly in terms of who holds the power in the relationship (Butt 2005). Mason Durie has pointed out that there is a 'bicultural continuum', ranging from mere cultural exchange within the mainstream to fully independent Māori organisations (1995). Richard Hill notes that, while the Treaty is important, it is not the origin of these tensions between the Crown and Māori, which are standard for settler states: 'Government policies aimed at suppressing, appropriating and assimilating the political economy and culture of indigenous peoples, and ongoing but adaptive struggle by indigenes for self-determination, are integral to the history of colonialism and post-colonialism' (Hill 2009: $x$-xi).

Within this postcolonial struggle, 'biculturalism' debates often equate Pākehā with the state and Māori with iwi, however, these national level discourses also have a 
complex connection to our everyday identities and interpersonal relationships, as Jo Smith points out in her discussion of 'biculturalism' and 'multiculturalism':

Whenever these two terms circulate, they do so at the service of a nation-building agenda and involve some form of identity positioning within the categories of Māori (or tangata whenua [people of the land]), Pākehā (a settler identity distinct from European identity and in relation to Māori), or migrant.

Discourses of biculturalism and multiculturalism rarely enable the possibility of simultaneous identity positions across these categories. Such identity categories are embedded in a history of meaning that can never quite express the constantly shifting parameters of identification characterizing the everyday (Smith 2007: 69).

It is this complex everyday experience of 'biculturalism' as lived, at some distance from the centres of national power that dominate these debates (but also shaped by them), that the Black Rainbow discussions illuminate.

It is helpful to note that within these powerful discourses, there are at least 'three possible biculturalisms: of the self, of public procedure, or as a mode of intercultural contact' (MacLean 1996: 111). On the level of the self, Māori people are often considered to have 'bicultural' identities, formed by the demands of the political economy embedded in western norms, while Pākehā generally remain overwhelmingly 'monocultural' (Walker 2004). Evans argues that this monoculturalism is partly disguised by what Witi Ihimaera calls 'Pākehā-Style Biculturalism': the use of Māori cultural tropes to embellish the dominant culture, fulfilling Pākehā yearnings for identity (2006). The pressures on Pākehā to develop 'bicultural' selves by learning Māori language and norms are relatively few, and it is perhaps worth noting here that my PhD thesis reflects my own monoculturalism and the western norms of Victoria University of Wellington. These identity issues complicate inter-cultural contact between 'bicultural' Māori and 'monocultural' Pākehā, as Alison Jones (1999) observed in classrooms, where Pākehā students expect to 'share' with Māori in a way that will be ultimately unifying. This presupposes an equal cultural exchange, rather than recognising that Māori already have a deep understanding of Pākehā culture and therefore, stand to gain little. 
While these discussions of 'bicultural Māori' and 'monocultural Pākehā' are useful, as Smith points out, they 'never quite express the constantly shifting parameters of identification characterizing the everyday' (Smith 2007: 69). One of the contributions the Black Rainbow stories make is showing the complex experiences of self, for both Māori and Pākehā, formed by colonisation and shaped by the expectations of others. By telling these stories, this thesis adds to literature on contemporary Māori identity (Durie et. al. 1995; Durie 1998; 2005a; Meredith 1999; Bell 2004; Borell 2005; McIntosh 2005; Van Meijl 2006; Harris 2008; Webber 2008; Gwynne 2009; González 2010; Houkamau and Sibley 2010; Rata 2012; Gagné, 2013) as well as Pākehā identity (MacLean 1996; Pearson and Sissons 1997; King 1999; Fleras and Spoonley 1999; Bell 1999; 2004; 2006; 2009; McCreanor 2005; Gibson 2006; Mitcalfe 2008). This thesis differs from much of this previous work, in that it looks at these identities working in relation to each other.

Avril Bell, following Ranginui Walker, points out that 'Māori and Pākehā are constitutively related terms':

Both terms, which come from the Māori language, only come into use to name and distinguish groups of people following contact between the hapū [subtribes] and iwi of Aotearoa and the European, Australian and American explorers, whalers, missionaries, traders, colonial administrators, military and settlers who began arriving following Captain James Cook's voyage of 1769 (2004: 4).

Yet Māori and Pākehā identities tend to be studied separately. This can in part be seen as the result of what Augie Fleras and Paul Spoonley describe as 'a clear bifurcation' between Māori and Pākehā that occurred in the 1980s, as 'Māori moved to exclude Pākehā from iwi and protest politics' for carrying too much colonial 'baggage' (1999: 86-87). This lead to a time of increased identity formation for both groups, as 'Being Pākehā was defined as a counterpoint to the new politics of Māori identity' (ibid.). Several Pākehā activists responded by creating the 'Treaty 
educators movement', to prepare the Pākehā public for a future based on tino rangatiratanga (Huygens 2007, Otter 2007, Margaret 2010a).

Despite this 'bifurcation' in activist movements and identity politics however, Māori and Pākehā continue to work together in various contexts, whether paid or unpaid. These identities rub up against each other and are created, at least in part, through that contact. While the anarchist scene is a Pākehā dominated (both numerically and culturally) activist community, it continues to attract young Māori. Members of Black Rainbow point out that these Māori activists tend to be marginalised on several fronts-'Pākehā-fied' culturally, queers, vegans, punks, and so on. Because Māori and Pākehā are already working together, I believe it is important to look at how. How are these identities experienced relationally when we work together across difference? And how could our relationships be improved?

There are relatively few academic sources that concentrate on the relationship between Māori and Pākehā in the everyday (as opposed to elites). Joan Metge and Patricia Kinloch's classic, Talking Past Each Other: Problems of Cross-cultural Communication (1999) and journalist Carol Archie's popular, Skin to Skin: Intimate True Stories of Māori-Pākehā Relationships (2005) offer some beginnings, however, neither develops a full critical analysis. By contrast, Avril Bell's heavily theoretical work, Relating Māori and Pākehā: The Politics of Indigenous and Settler Identities (2004) describes contemporary Māori and Pākehā identity claims, especially those drawing on notions of essentialism and hybridity, as grounded in colonial relations. Bell also explores theories of intersubjectivity, ultimately seeking 'non-dominating relations' through an appeal to the ethics of Emmanuel Lévinas and a politics of 'disappointment'. I follow Bell, in that: 'My primary focus is on colonisation as a relation. It is this relation that structures Māori and Pākehā identities as colonised and coloniser, indigene and settler' (Bell 2004: 11). What my research with Black Rainbow adds is an ethnographic view of how these identities and colonial relations play out in the messy details of the everyday. This includes reflections on my 
personal experience as a Pākehā attempting to enact 'non-dominating relations' through this work.

\section{Relating across difference in the anarchist circles}

This research thesis allowed me to take the time to reflect deeply on issues of cross-cultural communication that trouble my own anarchist community. However, the implications of this research are much wider than this small activist scene. Therefore, I have not written this thesis in a way that prioritises anarchist theory. Never-the-less, it is worth taking a brief look at anarchist beliefs and practices as background to this research. I believe this anarchist community is a particularly generative site to study how Māori and Pākehā work together across difference on an interpersonal (as opposed to official) level, because an anarchist emphasis on personal and collective responsibility moves the debate away from elites and towards the 'ground'. Further, shared basic assumptions within this community about prioritising social justice and rejecting racism allows for research that focuses on the more subtle forms of injustice. While we are all exposed to racist language in New Zealand (McCreanor 2005), I find studies of overt racism less interesting and productive than looking at the things we may find 'hard to see'.

Anarchism is most commonly understood as a political theory of society without state. The basic value of freedom is strongly affirmed, the state is seen as prohibiting freedom and therefore, anarchists advocate building communities without the state. This rejection of representational politics places an emphasis on personal responsibility, as individuals and collectives, to negotiate our colonial situation. 'Reconciliation' is not something the government can do 'for us'. Therefore, researching Māori-Pākehā relating within the anarchist scene naturally draws the eye towards the everyday. 
This anti-statism also opens up the potential for alliances with indigenous struggle-as the illegitimacy of the state is already assumed, anarchists may be more accepting of tino rangatiratanga as a viable alternative. The recent mobilisation of Māori activists in the anti-globalisation movement (see Bargh 2007) also created a natural point of solidarity for anti-capitalist anarchists. Further, internationally, anarchists today are often interested in indigenous critiques of society and alternative ways of organising, particularly the Zapatista movement (See Graeber 2007). Leonard Williams notes that the younger generation of anarchists are largely disinterested in the classic works of anarchist theorists and are just as likely to be informed by movements in 'indigenous, feminist, ecological and culture-criticism thinking' (2007: 298. See, for example, Ferguson 2011).

This generation gap, however, has also created tensions within anarchist circles. Many of us join anarchist communities because we are interested in antiauthoritarian organising and opposing oppression, and may be more connected to tino rangatiratanga struggles than those who are particularly wedded to anarchist political economic theory. In his article 'Anarchism as the Spirit of Contemporary Anti-Capitalism? A Critical Survey of Recent Debates' (2012), Chamsy el-Ojeili discusses a growing number of anarchist academics who are deconstructing the tradition in a post-modern light, highlighting the need to abandon the remnants of Enlightenment humanism, and he argues that this represents 'an inheritance in question', where emerging anarchism sits awkwardly with the anarchism of yesterday. For example, anarchism traditionally assumes that people are inherently good-resisting inequality and working co-operatively given the chance-and elOjeili argues that combining this 'anarchist universalism with assertive status group identity politics remains a tricky and unresolved problem' (ibid: 8). Similar issues surround anarchism's traditional anti-statism, as el-Ojeili points out: 'the obvious awkwardness of attempting to combine anarchism and its historical attention to the state with a Foucauldian desire to jettison outdated analysis of sovereign power for a focus on the ubiquity and micro-quality of contemporary power' (ibid: 10). While I have not engaged with these debates in academic anarchism in this thesis, it 
is worth noting that these same debates are also playing out 'on the ground' in anarchist organising, and the experiences and analyses of members of Black Rainbow reflect those debates.

It is the 'ground' that I am particularly interested in-how do these issues of universalism versus diversity feed into our everyday practice? I have often heard debates in anarchist circles about who has the 'right' or 'wrong' politics around identity. I am less interested in these abstractions and more interested in what allows us to work together. The anarchist tradition typically promotes a prefigurative politics, where means are as important as ends. Consensus decisionmaking is prioritised to the degree that it has become central to the definition of anarchism, for example, David Graeber writes that 'Anarchism has tended to be an ethical discourse about revolutionary practice' (2004: 6). Elsewhere he argues that 'this is a movement about reinventing democracy. It is not opposed to organization. It is about creating new forms of organization. It is not lacking in ideology. Those new forms of organization are its ideology' (Graber 2002: 70. Emphasis in the original).

At first glance, Graeber seems to neatly avoid the 'inheritance in question' problem that el-Ojeili points out, between universal claims and an acknowledgement of difference, by emphasising organising practices as the central ideology of the movement. In his study of anarchist organising, Direct Action: An Ethnography (2009), however, we can see that notions of the universally good subject are often the basis of consensus-seeking and this can be challenged in heterogeneous groups. After a detailed discussion of the workings and benefits of consensus, Graeber admits:

[I]t is very common to see a pattern of exaltation followed by burn-out. Those drawn into the world of horizontal organizing will often find the experience amazing, liberating, transformative; it will open their eyes to entirely new horizons of human possibility. Six months later, they may just as well quit in disgust. Or the 
groups they were working with may dissolve in bitter recriminations. The recriminations are almost never about the process itself, however. In America, at least, in nine cases out of ten, they turn on arguments about race-and, secondly, class and gender (ibid: 332).

He goes on to explain:

Consensus operates on a principle of trust...The reason racism, sexism, and other forms of what activists like to call "internalized forms of oppression" are so difficult to deal with is precisely because one is not conscious of them. They are simultaneously absolute evils, and so fundamental to the nature of our society that they form inescapable aspects of the subjectivity of anyone who grew up within it. They cannot be defeated just by trust in others' good intentions (ibid: 352).

Graeber's observations certainly ring true with my experience of anarchist organising in the Wellington community, as can be seen in the multiple fractures described above. This signals to me the urgent need for the anarchist movement to find ways to build trust across difference. I have found Uma Narayan's article, 'Working together across difference: Some considerations on emotions and political practice' (1988) very useful in this regard and I find further justification for my research with Black Rainbow in her comment that:

Dialogue between members of a group that has a heterogeneous composition in terms of factors like class, race, ethnicity, gender, sexual preference etc, and in coalitions of such heterogeneous groups, is often hard to sustain, despite the presence of common interests and political goals... I think it would be a helpful practice for groups with heterogeneous components to talk about ways in which dialogue between people who share and people who do not share the experience of a certain form of oppression can be damaged because the emotions, and hence the sense of self, of the members of the oppressed group are unintentionally violated by non-members of the oppressed group who participate in the dialogue (1988: 31. Emphasis in the original).

While, as I mentioned, I believe this is particularly important for anarchist organising, this need for discussion about how people relate from within and without experiences of oppression is needed any place Māori and Pākehā work 
together, and brings the discussion back to the wider implications of my research with Black Rainbow.

\section{Chapter overview}

Narayan's work became a central guide for me throughout this thesis. It is through her article that I came to articulate all the questions that arose as 'mess finding' in anarchist circles, in the simple questions: 'How do Māori and Pākehā work together across difference? How can Pākehā work better with Māori?' It is with reference to these questions and to Narayan's thought that I will outline the thesis here.

Chapter one, 'Methodology: "Learning to be affected" by Kaupapa Māori', tracks the development of my methodology and research design, which arose out of the central questions of this thesis: 'how do Māori and Pākehā work together across difference?' and 'how can Pākehā work better with Māori?' Answering these questions in terms of research practice meant looking closely at developments in indigenous methodologies - particularly Kaupapa Māori (research based in Māori philosophy), Māori concerns about conventional western research, and the resulting Pākehā 'paralysis' over working with Māori. Responding to this delicate academic climate and striving to position myself as a Pākehā researcher working with Māori, I found it useful to delve into the 'pleasures' and 'pains' of engagement and look at how anthropology has been 'affected' by Kaupapa Māori critique. I expect that this discussion will also be useful for other emerging non-Māori researchers. While Kaupapa Māori critiques certainly represent a boundary marking around who can or should do research with Māori communities, I suggest that they also offer an invitation to radically rethink the way we do research. For me, responding to these challenges involved carrying out collaborative research within my own activist community. I drew on 'anti-oppressive' praxis as a place to stand at the 'interface' with Kaupapa Māori research and employed a combination of Participatory Action Research, 'interactive interviewing' and auto-ethnography to 
create a research design that allowed all members of Black Rainbow to be treated as 'participant-researchers'. I argue that this collaborative approach involves a continual 'learning to be affected', as an antidote to Pākehā 'paralysis' (Tolich 2002).

In chapter two, 'A Black Rainbow Story: How I have written this thesis' I discuss the challenges of taking this collaborative approach into authorship. Here I justify my choice to tell stories (as a method of 'writing against culture' which resists generalisation and also shows the shared creation of meaning), the process through which I wrote these stories and how I have related them to academic literature and my own analysis. In doing this, I also speak of how I responded to a participant's concerns about an early chapter draft, which seemed to prioritise the academic literature over that of the members of Black Rainbow. This turned my attention towards finding ways to affirm participant knowledge in the form as well as the content of the thesis, however I remain within the tension: can we realistically tell a story and 'say what we have come to say', without speaking over the participants?

The following three chapters present the stories from my year of research with Black Rainbow, arranged chronologically, but also selected to explore the themes of 'identity', 'relationships' and 'power-sharing' that seemed most prominent at different moments of our time together. Avril Bell notes that ' $[t]$ he working of a kaleidoscope provides a useful metaphor for the way in which theories and 'cases' are brought together' in her thesis and I would like to borrow this metaphor to make a similar point here that '[e]ach chapter represents a turn of the kaleidoscope' (2004: 21). As the kaleidoscope turns and creates a different arrangement of colours, so the Black Rainbow discussions move backwards and forwards across these issues of identity, relationships and power-sharing, offering different views of these issues. In this way, the stories told about Black Rainbow's time together are chronological and roughly thematically organised, yet they are not linear. While tracing the different meanings that Black Rainbow made together 
as a group, I also discuss my own reflections on these themes, particularly with reference to Uma Narayan's work on insiders' epistemic privilege (1988).

The first of these chapters, chapter three, 'Black Rainbow (August to October): Identity', tells three stories, one for each of our first three meetings together. 'Where we come from' was a discussion in which we shared personal histories and struggles with 'insecure' cultural identity. From these stories I began to develop an awareness of insiders' epistemic privilege, seeing these as the foundations of both 'insiders' epistemic privilege' and 'outsider' carelessness, and also the way the use of humour can indicate this gap in understanding. In 'To be Māori is to be colonised', Mara ${ }^{6}$ (one of the members of Black Rainbow) tells her story, showing her understanding of how structural racism, as well as relational encounters shaped her Māori identity. Finally, in "“Cool, a real Māori told you”: undermining Māori identities' members of Black Rainbow discuss their experiences working in the October 15th Solidarity crew. They speak of Pākehā usurping Māori roles and dismissing the concerns of Māori members of the anarchist scene, in favour of 'real Māori' outside it. Drawing on Narayan, I suggest this undermining of community members' Māori identity also denies their insider's epistemic privilege, and shows an outsider's inattention to the complexities of cultural identity and to the emotional costs of this dismissal.

Chapter four, 'Black Rainbow (November to March): Relationships', tells stories from the next few months of research with Black Rainbow, in which we made a deliberate attempt to build our relationships within the group. To show this relationship development, this chapter begins and ends with 'snapshots' of group outings. Between these are two discussions from meetings, the first shows a time when I felt our relationships within the group were threatened by my inability to actively respond to 'racial microaggressions'. The next, longer story is a discussion among Black Rainbow about cross-cultural romantic relationships. This discussion

\footnotetext{
${ }^{6}$ This is a pseudonym.
} 
builds on the previous chapter, as it shows how relational identity is, how cultural stereotypes affect our relationships and the roles we play within them and how complex identities require subtle power negotiations within relationships. We also spoke about how different cultural values around emotional expression can impact on relationships. The idea that Pākehā culture tends to see emotional upset as hindering good communication has implications for the recognition of insiders' epistemic privilege, which Narayan argues is most often experienced through emotional reactions.

Chapter five, 'Black Rainbow (April to June): Power-sharing', tells of the final phase of our recorded time together as a group. This chapter centres around two stories from meetings - the first where we discuss possible actions the group could carry out, particularly writing a 'zine (a small independent publication) about experiences within the anarchist scene and the second where we tell each other stories as a basis for writing that 'zine. When choosing to tell stories as a way of affecting change, members of the group spoke about resisting generalisations, letting the stories themselves validate or challenge readers, and yet I noted that in practice, the group moved fluidly backwards and forwards between storytelling and creating analysis. I suggest that humour plays an important role in creating a 'joking consensus' and allowed Māori members of Black Rainbow to validate each other's insider's epistemic privilege without creating 'fixed' generalisations. This validation is important, because as the previous two chapters show, Māori concerns can be dismissed in Pākehā dominated spaces when they are not seen as 'real Māori' or are framed as 'overemotional'. The Black Rainbow discussion in this chapter adds further reasons for the dismissal of Māori concerns, such as a culture that sees criticism as an attack. The dismissal of Māori concerns has clear implications for power-sharing, and here members of Black Rainbow talk about the greater burden of responsibility being placed on Māori in collectives discussing tino rangatiratanga or attempting to enact tikanga (correct procedure), yet finding themselves constrained, tokenised or invisible. 
The 'Black Rainbow' chapters centre on the shared meanings created by the group. By contrast, my final discussion, 'Processes of Pākehā Change: 'learning to be affected' while working across difference', turns towards the personal learning I have taken from working with Black Rainbow. Here I look at how working with Māori has worked a change in me, especially through listening to Māori and accepting criticism. I argue that this listening is not a passive process, but involves 'learning to be affected' by the 'epistemological discomfort' at the heart of 'processes of Pākehā change'. I see this as the emotional cost of accepting insiders' epistemic privilege, and I propose that sitting with this discomfort shifts some of the emotional burden onto Pākehā, as well as the threat to identity that Māori may experience when working across difference. 


\section{Chapter 1}

\section{Methodology}

\section{'Learning to be affected’ by Kaupapa Māori}

At the heart of my motivations for returning to university and undertaking research with Māori were questions about how Māori and Pākehā work together across difference and how Pākeha can work better with Māori. Although these questions arose out of my experiences in anarchist circles, once I began to pursue this project I quickly came to understand that these questions would also be intimately linked to the methodology I use to research them. Because I wanted to match my methods to the social justice aims of my research, I wanted to create a methodology deeply responsive to Māori concerns. When looking for an appropriate method for answering my research question, this meant asking explicitly, how can Pākehā researchers work better with Māori?

This question is particularly important because I am working in an academic moment when settler researchers have been unsettled, as Norman K. Denzin and Yvonna S. Lincoln note, 'During the "Decade of the World's Indigenous Peoples" (1994-2004), a full-scale attack was launched on Western epistemologies and methodologies. Indigenous scholars asked that the academy decolonize its scientific practices' (Denzin and Lincoln 2008: 3). Nearly ten years after the 'Decade of World's Indigenous Peoples' much work still needs to be done to find appropriate methodologies for non-indigenous researchers. Without a well-trod path to follow, I was forced to be a little innovative and I came to understand that this $\mathrm{PhD}$ thesis would have a strong methodological focus. 
Therefore, along with the usual aims of a methodology chapter-to introduce you (the reader) to the research I carried out, outlining my research methods and the thinking behind them - I also hope to satisfy several other aims, including positioning myself as a Pākehā researcher within the current academic climate in Aotearoa New Zealand. The boundary setting represented by Kaupapa Māori maxims like 'by Māori, for Māori' (Smith 1999) has contributed to what Martin Tolich has named 'Pākehā paralysis', which amounts to the fear of studying Māori topics. Responding to this complex intellectual environment, I look at how anthropology has been affected by Kaupapa Māori critique, drawing on my own experiences as a student working across two disciplines. It is not my intention to attempt to comment on all that Kaupapa Māori research is or could be, but rather to focus here on my own personal experience of learning about Kaupapa Māori in a particular place (Te Kawa a Māui-Māori studies at Victoria University of Wellington), as well as the relationship between the two departments I worked with and my position within that dynamic.

When I decided to return to university and learn more about Māori culture, I automatically gravitated towards anthropology. My masters' thesis was in religious studies, but I effectively had a minor in anthropology and it seemed a natural place for me to return to. I spoke to Prof. Brigitte Bönisch-Brednich about the PhD programme and found her supportive and inspiring. However, I also knew that I wanted Māori supervision, so I sought out Dr. Maria Bargh in Te Kawa a Māui (Māori studies). While still working part time, I took an anthropology methodology course (ANTH 408) and a Māori studies methodology course (MAOR 408) to prepare for further study. Much of my research design was developed within those two courses. While both my supervisors and departments have been very supportive of me, I was also aware of the history of antagonism between anthropology and Māori studies, and my research design grew within these tensions. 
My experience of interdisciplinary research across anthropology and Māori studies allows me to reflect on the contested relationship between these two disciplines. By discussing openly and honestly how this has affected me, I am also interested in showing some of the 'pain' and 'pleasure' of engagement, in the hope that this will be of use to other emerging researchers. Likewise, I hope to encourage non-Māori researchers to respond to the invitation from Kaupapa Māori to radically rethink the way we do research. For me, this has involved exploring collaborative methods of working with Māori. The final aim of this chapter, therefore, is to demonstrate the collaborative process of simply developing a research methodology-as I have attempted to tell the story of how I came to my research design in a way that acknowledges the genealogy of ideas and the people who have influenced my research.

\section{Kaupapa Māori research: a response to Māori concerns}

When I first went to see Maria Bargh about the possibility of working together, she suggested I read Linda Tuhiwai Smith's Kaupapa Māori classic Decolonizing Methodologies: Research and Indigenous Peoples (1999). 'In fact,' Maria said, 'you may want to purchase it'. She also suggested I take Ocean Mercier's course, 'Ta Te Māori Rangahau/Methodology of Māori Research' (MAOR 408). I did both those things and found myself suddenly in a world of challenging ideas. Kaupapa Māori is one form of Māori research, which arose out of Māori concerns about traditional research and may be defined as 'Māori research by, with and for Māori [that] is about regaining control over Māori knowledge and Māori resources' (Cram 2001: 37). As such, it is an important development springing from a wider Māori movement of revitalisation and politicisation during the 1970s and 1980s and has been described by Russell Bishop as the 'operationalization of self-determination (tino Rangatiratanga)' (1998: 201). 


\section{Māori concern over whose knowledge is reproduced in research}

In his article 'Freeing ourselves from neo-colonial domination in research: a Māori approach to creating knowledge' (1998), Russell Bishop concisely outlines several concerns Māori people have about research. Bishop argues that the colonisation of Aotearoa New Zealand and the resulting dominance of Pākehā have led to 'the development of a tradition of research into Māori people's lives that addresses concerns and interests of the researcher's (who are predominantly non-Māori) own making, defined and accountable in terms of the researcher's own cultural worldview' (ibid: 200). Research carried out under this tradition has maintained colonial values and power, while 'undervaluing and belittling Māori knowledge' (ibid.). Bishop associates this with the development of a 'social pathology research approach' which assumes that Māori culture is inferior throughout the research process: 'Such practices have perpetuated an ideology of cultural superiority that precludes the development of power-sharing processes and the legitimization of diverse cultural epistemologies and cosmologies' (ibid.). This domination of research by non-Māori has also led to the distortion of Māori beliefs and practices. Instead of Māori having authority over their own experiences, they have been appropriated by 'experts' who 'misrepresented Māori understandings and ways of knowing by simplifying, conglomerating, and commodifying Māori knowledge for "consumption" by the colonizers' (ibid.). This distortion has led to many commonly held myths about Māori having traction in Aotearoa New Zealand today.

As a response to these concerns, Kaupapa Māori research is based on the assertion that Māori systems of knowledge are as valid as their western counterparts. This creates a scholarship that 'starts from te ao Māori [the Māori world] and extends outwards to te ao Pākehā [the Pākehā world], rather than the other way around', yet is capable of weaving both traditions together (Irwin 1994: 28). Linda Tuhiwai Smith notes that this creates a 'localized critical theory', which involves both an analysis of power structures under colonisation and a revitalisation of Māori epistemological and metaphysical traditions (1999: 185-189. See, for example, Royal's use of whakapapa (genealogy) as an analytical framework, 1998). 


\section{Māori concerns about who researchers are accountable to}

Because mainstream research has not served Māori communities well, Bishop notes that: 'Māori people are deeply concerned about who researchers are answerable to. Who has control over the initiation, procedures, evaluations, construction, and distribution of newly defined knowledge?' (1998: 200). Bishop notes that the preoccupation with neutrality and objectivity in research reflects western cultural preferences. This ideal of objectivity has 'distanced Māori from participation in the construction, validation, and legitimization of knowledge' (ibid: 201). All of this comes back to the concern Māori people have about who directly gains from the research.

Kaupapa Māori researchers have responded to these concerns about accountability by arguing for Māori control over research with Māori. With an emphasis on 'research by Māori', identity is clearly an important issue and Smith notes that, 'Kaupapa Māori research, as currently framed, would argue that being Māori is an essential criterion for carrying out Kaupapa Māori research' (1999: 187). However, it seems the individual researcher is not the sole focus of this concept of Māori controlled research. Bishop emphasises collectivity, with communities participating in research that they initiate and evaluate, for their own benefit. This means research that responds to Māori research needs, rather than the interests of nonMāori. Therefore, transformative research is prioritised, with the hope of improving the material and spiritual wellbeing of Māori people.

Māori norms and relational ethics (tikanga) are another notable foundation of Kaupapa Māori research. This use of Māori customary practice not only validates 'taken for granted' ways of being for Māori communities, it also provides strategies for responding to concerns about accountability in research. For example, Smith notes: 
[T] he importance of the concept of whanau [extended family] as a supervisory and organizational structure for handling research. Bishop refers to this as a 'research whanau of interest'. Irwin refers to a 'whanau of supervisors'. For both Bishop and Irwin, the whanau provides the intersection where research meets Māori, or Māori meets research, on equalizing terms (1999: 185. Italics in the original).

Fiona Cram (2001) has offered seven practical guidelines for Kaupapa Māori research. First is 'respect for people' (2001: 42), aroha nga tangata, which breaks down the hierarchical position of the researcher and instead allows the participants to control the interaction (see Irwin 1994 for 'rituals of encounter'). Secondly, 'he kanohi kitea' (ibid: 43) emphasises the need for face-to-face meetings which establish relationships. Third is 'titiro, whakaronga...korero' (ibid: 44) - watching and listening over a period of time (to develop shared understandings) should form the basis of any comment on a community. Fourth is 'manaaki ki te tangata' (ibid: 45), which encompasses collaboration and reciprocity. Fifth, 'kia tupato' (ibid: 46) refers to cultural safety and the need for reflexivity over our insider/outsider roles. Sixth is 'kaua e takahia te mana o te tangata' (ibid: 47)- avoiding harm to the mana (power or prestige) of participants, which involves keeping the community informed and in some control of the research, rather than merely taking information from them. Finally 'kaua e mahaki' (ibid: 48) warns against flaunting one's knowledge as an 'expert'. Rather knowledge should be made accessible and shared in empowering ways. Cram's face-to-face approach highlights the Kaupapa Māori response to Māori concerns about traditional research, especially over who researchers are accountable to and who directly gains from the research.

\section{Pākehā 'paralysis'}

By challenging the epistemology, practices and identity of researchers, Kaupapa Māori researchers essentially pulled the foundations out from under anthropology in Aotearoa New Zealand. When I first came to speak to Brigitte Bönisch-Brednich about doing a PhD involving Māori, she gave me Martin Tolich's article 'Pākehā 
"Paralysis": Cultural Safety for Those Researching the General Population of Aotearoa' (2002) to demonstrate the current academic climate. In this article Tolich wrote about the way that non-Māori were responding to the rise of Kaupapa Māori research, its critique of western methodologies and its emphasis on 'by Māori for Māori'. He characterised this response as 'Pākehā paralysis' - where nonMāori are unable to engage with Māori in research because they cannot work through the complexities of identity politics. Countless non-Māori researchers have simply taken this challenge as a reason to disengage, rather than finding generative ways to respond to those challenges. Tolich has observed that 'Many Pākehā colleagues in New Zealand universities are either oblivious to the complexity of these issues or they are paralysed, recognising it as a political minefield' (ibid: 167). The 'too hard' nature of this 'minefield' has led to a general situation where students are being taught to avoid working with Māori participants both in Māoricentred research and general population studies. According to Tolich:

Pākehā social science students are warned off contemplating researching Māori in second-year research methods courses, and this message is sustained in postgraduate education. In year-two courses undergraduates are first exposed to the short history of Pākehā research "on" Māori. The story goes that in the nineteenth century Governor George Grey, Percy Smith, Elsdon Best and Augustus Hamilton abused their roles as researchers... The results of this nineteenth century research "on" Māori skewed Māori attitudes to research.... One hundred-odd years later during the Māori renaissance of the 1970s Māori critiques of Pākehā-centred research on Māori once more came to a head. Here, well intentioned Pākehā researchers were run out of Māoridom. Notable Pākehā researchers like historian Michael King and anthropologist Joan Metge, to name two, were dislodged from entrenched positions as scholars of Māori (ibid: 168-170).

Unfortunately, this story encourages a kind of black and white thinking that reduces complex issues and encourages paralysis rather than looking for ways through. Joan Metge, for example, weathered challenges to her role with support from the Māori community she worked among and she remains widely respected within Māori academic circles (see Metge 2010). This relates to another problem I see with this 
black and white thinking - that it reduces the issues to the colour of one's skin. I have often heard naive complaints that Kaupapa Māori excludes Pākehā who may know a lot, while Māori who may not know much about their culture get to do research with Māori, just because they have 'a brown face'. Sitting in the Māori Methodology classroom, I came to realise just how inaccurate this image is. The emerging Māori researchers there did not have a 'free pass' to Māoridom and their identity negotiations around Kaupapa Māori research seemed far more complicated than my own (see George 2010; Gwynne 2009).

As one of the students in the social science classrooms in the late 1990s and early 2000s, however, I was unaware of these nuances. I can attest to Tolich's argument that non-Māori students are being encouraged not to engage with Māori in research. I had deeply internalised that message and used fears of overstepping as a reason to avoid engagement with Māori issues for most of my adult life. Once I tentatively started trying to engage, I was told I was 'brave' and warned by a number of friends and colleagues about the dangers of such research. I now find it alarming to think about the impact of these messages in majority white classrooms. To me this elegant and brutal term 'Pākehā paralysis' has come to signify both my struggles around doing research with Māori and my difficulty engaging with Māori issues in radical politics. It is my observation that Pākehā paralysis is alive and well among activists as well as academics. The same kind of cultural boundary marking represented by Kaupapa Māori within the academic world has also occurred within activist and social justice spheres. Moreover, a large number of Pākehā activists are products of tertiary education in the social sciences. Many of the conscientious Pākehā activists I know struggle to make any comment or decision around Māori issues.

The paralysing sting of Kaupapa Māori

While I had internalised these messages, it was not until reading Smith's

Decolonizing Methodologies (1999) that I began to understand the meaning behind 
them. It was painful and enlightening reading. It was also threatening; her description of anthropology is scathing:

Some, such as anthropology, made the study of us into 'their' science... (1999: 11).

Indigenous people have been, in many ways, oppressed by theory. Any consideration of the ways our origins have been examined, our histories recounted, our arts analysed, our cultures dissected, measured, torn apart and distorted back to us will suggest that theories have not looked sympathetically or ethically at us... For indigenous people, most of the theorizing has been driven by anthropological approaches (ibid: 38 ).

The ethnographic 'gaze' of anthropology has collected, classified and represented other cultures to the extent that anthropologists are often epitome of all that is bad with academics. Haunani Kay Trask accuses anthropologists of being 'takers and users' who 'exploit the hospitality and generosity of native people' (ibid: 67).

Feeling the full power of this challenge helped me to appreciate the 'paralysed' response of many non-Māori anthropologists. I could feel the sting of Kaupapa Māori. Moreover, in my experience this image of anthropologists as 'takers and users' is still very real. A friend from Māori studies recently told me that when she tells Māori about my research she does not like to say what department I am in, because she knows what the response will be to anthropology. Similarly, I am sometimes introduced as 'This is Rachael, she's an anthropologist, but she's alright'.

\section{What are we afraid of?}

Therefore, it is perhaps not surprising that the main Pākehā narratives of Māori research focus on anxiety, shame and avoidance. Danny Butt talks about this as a fear of 'what lies beneath':

The fear is institutionalised in stories I have heard more than once about research directors suggesting that academics "avoid dealing with Māori issues", to avoid having to negotiate with Māori over cultural ownership. But what in New Zealand is not a Māori issue? 
What part of New Zealand culture is not implicated in the colonial project of making the land into "New Zealand"? (2010).

I am interested in examining this fear, because as Butt's comments show, it allows many non-Māori to avoid truly taking responsibility for the ongoing colonisation of Aotearoa New Zealand. Personally, I experience this paralysis around three main fears: fear of being an 'expert', fear of my own ignorance and fear of my own internalised racism. In the first year of my PhD project I spoke about these fears at the 2010 Contemporary Ethnography Across the Disciplines (CEAD) conference:

It is very difficult to attempt to educate myself at a high academic level about Māori perspectives and experiences while also trying to avoid becoming another white 'expert' on Māori. This is not a role I want, yet I have often found myself quoting academic literature to my fellow activists and-perhaps even more disturbing - find more and more that I am listened to as someone who is seen to know something about the Māori world. Of course, I find this so deeply troubling in part because I feel like I know very little and am afraid of my own ignorance. Until a few years ago I had avoided involvement in activism around Māori issues because I have felt like a clueless white girl who had nothing to contribute. However, confronting that ignorance has been the major push behind my recent desire to do research with Māori. How could I have gone so many years without recognising the extent of my white privilege, or how ill equipped I am to meet Māori on their own terms? This ignorance fascinates but terrifies me. Not only is ignorance a fairly awkward attribute to wear in academic study, I am also acutely aware that it is dangerous. No matter how I position myself in this project, by writing a thesis, I will in some way be representing Māori and with blind spots a mile wide, I am likely to get it wrong.

Because knowledge production carries power, my ignorance has the potential to perpetuate racist perceptions of Māori. Early in my research project I attempted to turn an essay I had written into a 'zine (a small independent publication), a resource for other anarchists. The essay presented the summaries of a series of interviews with Wellington anarchists on the topic of biculturalism and the implications of activist organising in a colonised country. Every time I sat down to write my own personal piece on the topic, to include in the 'zine, I found myself unable to write. After a while I realised that part of the problem was that I was afraid of 'sounding' racist. Not because I was saying 
anything anti-Māori, but because I suspected that Māori generally experience a continuous flow of little disappointments with Pākehā, and I felt sure that there would be many subtle ways in which the racism I have been surrounded by since birth would come through (see Frankenberg 1993; McCreanor 2005; Shamblin 1996; Sue et al., 2007). It was then I realised, of course I would sound racist, I am racist.

This internalised racism does not cancel out the antiracism that I am also informed by, rather the two sit together within the contradictions and dialogues of the mind. However, any racism I have absorbed is harder to look at and therefore more important to confront. That is the reality I have to live with, work with, work around and attempt to shift. This is a lifelong task and it would not be solved in time to produce that little 'zine. I can now see that it is living with my own racism honestly and painfully that offers the only hope of breaking it down (Fabish 2010).

I am sharing these personal fears about research, not only in the interest of reflexivity, but rather because exploring them allowed me to understand the current state of 'Pākehā paralysis' in Aotearoa New Zealand. This is an interesting time for anthropology in Aotearoa New Zealand-a time, I would argue, when anthropology has been deeply affected by Kaupapa Māori. Overcoming this paralysis is the central problem I have attempted to solve while creating my methodology and I have been leaning into this fear as a way of moving through it. I have found the concept of 'learning to be affected', which I took from J.K. GibsonGraham and Gerda Roelvink, useful for this confronting and dismantling of my Pākehā paralysis. In 'An Economic Ethics for the Anthropocene' Gibson-Graham and Roelvink suggest that:

Unlike the well-defended critical stance, the open reparative posture is conducive to learning, itself a transformative process, and perhaps especially to the kind of bodily learning that Latour (2004) calls "learning to be affected"... We are interested in thinking about learning to be affected as an ethical practice, one that involves developing an awareness of, and in the process being transformed by, co-existence (2009: 324-325).

From this use of 'learning to be affected', I take the meaning that instead of trying to intellectualise how to ethically position myself as a researcher within colonial 
New Zealand, I can turn towards the reality that I am already being shaped by this colonial situation, this co-existence of Māori and non-Māori, within a white dominant culture. To focus on this, not only as it has been personally formative thus far - the fact of my ignorance and internalised racism - but how co-existence also continues to transform, allows for a certain openness to the potential generative effects of Kaupapa Māori.

\section{Kaupapa Māorias a 'generative creative force'}

This emphasis on the transformative powers of 'learning to be affected' brings me to the joys of engagement. Because it is my intention to encourage further engagement with Māori, I had better articulate the 'pleasures' as well as the 'pains'. I realised this at the next CEAD conference, while listening to Te Ahukaramū Charles Royal speak about his passion for creative opportunities and the importance of seeing tino rangatiratanga as a 'generative creative force', to counter deficit models of Māori (Royal 2012). I came to see that failing to clearly state the joys of engagement, leaving an emphasis on my fears, only reinforces notions of Māori as a problem.

The standard story that Tolich describes being taught in social science classrooms does just this-focusing on the problems with engagement and the paralysing effects of Kaupapa Māori. However, a challenge of this nature also invites a response, not only a retreat. There are many places where Kaupapa Māori researchers and theorists invite non-Māori to 'step up' to their challenge. Smith notes that a 'strategy of avoidance may not be helpful to anyone' (1999: 177) and points out several options that are available for non-Māori researchers, including tiaki (mentoring) and whāngai (adoption) models for engagement, which focus on Māori authority and long term relationships. Although the place of Pākehā researchers is still being debated, Fiona Cram notes that 'One growing opinion is that non-Māori cannot conduct Kaupapa Māori research but non-Māori can support 
a Māori research kaupapa' (Cram 2001: 38). Inspired by Cram's comment that 'what is good for Māori is often good for people in general so perhaps there will be something here for all' (2001: 38), I approach Kaupapa Māori as an invitation to radically rethink the way we do research. This is something I often discussed with Kristin Jerram, who frames this argument in more poetic terms:

$[T]$ he challenge set out by Māori academics such as Smith can be seen as a wero [challenge], laid down as a part of the pōhiri [ritual of encounter] process, where a branch is placed between the tangata whenua and manuhiri [guests] groups so that the tangata whenua can assess the intentions of the manuhiri. The manuhiri can respond by taking up the wero or by leaving it there. Manuhiri who want to cultivate a mutually beneficial relationship will choose to pick up the branch, to accept the challenge, with the knowledge that they are on someone else's marae [communal place] (Jerram 2012: 28).

\section{The joys of engagement}

Therefore, it is with an emphasis on the joys of engagement that I want to discuss my search for a place to stand in relation to Kaupapa Māori research. Deciding to do research with Māori led me to engage with Māori dominated spaces, which I had previously shied away from. This included auditing several papers taught at $\mathrm{Te}$ Kawa a Māui (Māori studies at Victoria University of Wellington) and eventually tutoring for the department, completing three years of Te Ara Reo Māori (Māori language) through Te Wānanga o Aotearoa and attending Kei Tua o te Pae: the challenges of Kaupapa Māori research in the $21^{\text {st }}$ century hui (Pipitea Marae, Wellington 5-6 May, 2011). As well as the formal learning gained in these spaces, I also experienced the subtle learning that comes from being decentred, culturally deskilled and the feelings of awkwardness that comes with this (see my final discussion for more on the 'affects' of working across difference). Being in Māori dominated spaces also revealed how 'white' the anthropology department is by contrast. Despite my awkwardness, I have found these various Māori spaces overwhelmingly welcoming and supportive and I have been offered some beautiful friendships. One group of friends I am particularly grateful for is the women in our 
small Māori studies postgraduates writing group, Erina Okeroa, Awanui Te Huia, Krissi Jerram, and Arama Rata, who continually challenged and inspired me throughout my research. These women helped 'keep me honest' and it is through this relational connection that my accountability to the Māori academic community feels most real.

One of the great pleasures of working with the Māori studies department is being within an inspiring, stimulating environment, at the forefront of indigenous research. When Royal spoke about tino rangatiratanga as a 'generative creative force' it immediately reminded me of being in Māori studies classrooms. Mason Durie points to this in his notion of 'discovery' as one of the principles of working at the cultural interface where 'two knowledge systems have moved together in directions not possible by recourse to one system only' (2004: 11). This also makes me think of the recognition I felt when I read Joan Metge's comment that 'association with Māori encourages flexibility of mind' (Metge, 2010: 6). In this supportive and generative environment, I was able to begin to search for ways I could work at the interface with Kaupapa Māori.

Kaupapa Māori as the foundation for a new Kaupapa Pākehā? For our final assignments in MAOR408 we were asked to write what impact $T \bar{a} T e$ Māori Rangahau / Methodologies of Māori Research (MAOR408) had on our understanding of research (see Fabish 2009). For me, the impact had been profound and I found it difficult to write something that reflected this. I was also terrified of disappointing the course coordinator, Ocean Mercier, of whom I was still in awe. When she returned our essays, I saw that Mercier had written: 'I look forward to seeing you develop a Kaupapa Pākehā way of doing research in the Treaty house!' I am not entirely sure what a 'Kaupapa Pākehā way' would look like, or if it is something I would claim, however I think this phrase is very interesting in

\footnotetext{
${ }^{1}$ Quoted with permission from Ocean Mercier.
} 
that it clearly positions my work as non-Māori but in partnership with Māori. This is an exciting possibility to try to imagine for an anthropology of this place.

Joan Metge makes an argument in Korero Tahi: Talking Together (2001) that instead of finding new ways to organise group meetings, we should recognise and draw on the indigenous practices of this place. The same argument can be made for finding methods of engaged anthropology. What better place to start than by responding to the methods developed by Kaupapa Māori academics? This relates to Maria Bargh's comment that 'the future of New Zealand Studies rests on it becoming more deeply of this place. To do that there needs to be a fostering of more nuanced visibility of Māori theorising and a further examination of genealogies tracing the relationship between people and ideas' (2009: 10). Likewise, Butt argues that 'for us to build a New Zealand Studies worth its name, we need to be listening to Māori, and producing work that they will listen to.... We need to be prepared to learn what they want to hear. These are basic conversational manners' (2004). Butt recommends Smith's Decolonizing Methodologies as the 'text that should be seen as the paradigm for New Zealand Studies' (ibid.). Thus, he takes what has been a source of avoidance and fear and makes it foundational to future of research in this place. Likewise, Kaupapa Māori research texts could become foundational for anthropology in Aotearoa New Zealand.

\section{'Working at the interface' between anthropology}

\section{and Māori studies}

This is not really a departure, but rather part of a growing trend towards an acknowledgement of the shared genealogy of ideas between Kaupapa Māori and anthropology in this place. Amiria Henare demonstrates that, 'The beginnings of Māori participation in what would become anthropology, not only as subjects but 
as analysts of their own culture, may be traced back to the early nineteenth century' (2007: 94). This strong history of Māori contributions to anthropology in Aotearoa New Zealand could also be understood as continuing within those university departments that Henare describes as receiving the 'exodus from the discipline' -Māori studies and Education (ibid: 105). Kaupapa Māori research is intimately linked to the methodologies of the social sciences, as made especially clear by Alice Te Punga Somerville, who writes from outside those traditions:

In Aotearoa at least, although in some other places too, the bulk of research and writing about the relationship between indigenous knowledges, research methodologies, and the colonial project has been produced by scholars who are trained in and/or based in the social sciences, including (and especially) education... What about the humanities? (2011: 62).

It is clear reading Linda Tuhiwai Smith's Decolonizing Methodologies (1999), for example, that Smith is not merely 'attacking' western methods for the sake of it, but rather she is a researcher earnestly struggling to find a way to transform those methods into something she can use.

Peggy McIntosh has identified as a distinct feature of white privilege that 'I can choose to ignore developments in minority writing and minority activist programs' (1990: para. 8). By moving away from research with Māori, Pākehā anthropologists working with other vulnerable communities merely shift the problems elsewhereto less vocal and mobilised groups who might become subjects of study. Further, if Pākehā turn towards only studying ourselves, we end up re-inscribing white dominance (see Ahmed 2004). I think it is crucially important to resist these privileged positions and I see this as an exciting time when non-Māori anthropologists may engage rigorously with the contribution Kaupapa Māori makes to methodology debates. I would like to see anthropology in Aotearoa New Zealand continue to move towards, rather than away from, Māori studies, in ways that are not dominating, but instead are collaborative. Taking up this challenge to respond to Kaupapa Māori is part of the contribution I hope to make, by experimenting with ways this can be done. 
For my own research as a PhD student the options for collaboration were somewhat limited, because it is expected that I produce a thesis that is solely my own work. I was not able to co-write, as Alison Jones and Kuni Jenkins do in their article 'Rethinking collaboration: Working the Indigene-Colonizer Hyphen' (2008). Debates about whether non-Māori researchers can 'do' Kaupapa Māori usually suggest the inclusion of Pākehā working as part of a research team which remains under Māori control (see Smith 1999; Cram 2001), however this path was not available to me either. Therefore, while I attempt to respond to Kaupapa Māori, I never expected to position myself within it. This is not only a matter of identity, but also one of skill-I simply do not have the understanding of Māori perspectives and protocols needed for Kaupapa Māori research. Instead I follow the example set by Norman Denzin and Yvonna Lincoln:

[I]n arguing for a dialogue between critical and indigenous theories, Denzin and Lincoln recognize that they are outsiders to the indigenous colonized experience. We write as privileged Westerners. At the same time, we seek to be "allied others", fellow travellers of sorts, antipositivists, friendly insiders who wish to deconstruct from within the Western academy and its positivist epistemologies... We value autoethnographic, insider, participatory, collaborative methodologies. These are narrative, performative methodologies - research practices that are reflexively consequential, ethical, critical, respectful, and humble (2008: 6).

Here I find Mason Durie's notion of 'working at the interface' especially useful (2004). While Durie focuses on indigenous scientists who 'live at the interface' (ibid: 8), his principles offer guidance for 'allied others' working alongside Kaupapa Māori. Durie's first principle is mutual respect or 'mutual mana enhancement' (ibid: 10). This not only recognises the validity of both knowledge systems, but also that '[p]ractitioners of one system are not necessarily equipped to interpret meanings that arise from the other' (ibid.). While giving each other this space, collaborators can each contribute their different elements to 'jointly create a new construct' (ibid.). Durie's second principle, shared benefits, addresses the question raised 
above about who directly gains from the research. This includes treating Māori people as active participants, rather than passive research respondents, and prioritising research that benefits their communities. Durie notes that the next principle, human dignity or 'aroha ke ti tangata', is an important principle not only for how researchers treat research participants, but also how researchers treat each other and could be applied to how we work across departments (ibid: 11). The cultural identity, beliefs and practices of others should not be compromised or appropriated in research. Therefore, the notion of human dignity 'has ethical connotations and particular implications for the way projects are designed, implemented, and applied' (ibid.). Finally, the principle of discovery encourages exploration and highlights the innovation that can arise from 'two knowledge systems that have moved together' (ibid.). This concept of discovery also emphasises the fact that indigenous theory and methods have something fresh to offer the academy, as it moves forward into the future.

\section{Anti-oppressive praxis as a place to stand at the interface with}

\section{Kaupapa Māori}

As an emerging researcher, coming from a background in religious studies (which is interdisciplinary) and anthropology (which is still recovering from 'paralysis') and now increasingly influenced by Kaupapa Māori research methodologies, I initially found it difficult to name the ground upon which I stood at the interface with Kaupapa Māori research. I knew I needed to position myself within western research traditions, to find a 'Kaupapa Pākehā way' I could live with and this led me to explore a range of techniques, such as participatory action research, autoethnography and interactive interviewing, techniques which shared some of the principles of Kaupapa Māori (I will discuss my research design in detail below). However, it took me a while to find an over-arching methodology I could name as my foundation. 
Finally, my friend Mara (who later became one the participants in this research and who you will become quite familiar with throughout this thesis), suggested I read Research as Resistance: Critical, indigenous and anti-oppressive approaches (Brown and Strega 2005). Anti-oppressive research can be understood as a product of Durie's principle of 'discovery', having developed out of 'social identity theories' with their foundation in various oppositional social movements around racial, queer, indigenous and ability/disability identities (Moosa-Mitha 2005). Kaupapa Māori theorists, such as Linda Tuhiwai Smith, are clearly part of the intellectual genealogy of the proponents of anti-oppressive theory and research. This catch-all, 'anti-oppressive research', is also interesting for my research, because it relates to social identity movements I am 'inside' of-such as queer and feminist-as well as those I am 'outside' of-such as disability and indigeneity. Here I found an antioppressive framework that resonates with my personal political beliefs and allowed me a place to stand at the interface. In their article 'Becoming an anti-oppressive researcher' Karen Potts and Leslie Brown summarise their praxis thus:

Being an anti-oppressive researcher means that there is political purpose and action to your research work. Whether that purpose is on a broad societal level or about personal growth, by choosing to be an anti-oppressive researcher, one is making an explicit, personal commitment to social justice. Anti-oppressive research involves making explicit the political practices of creating knowledge. It means making a commitment to the people you are working with personally and professionally in order to mutually foster conditions for social justice and research. It is about paying attention to, and shifting, how power relations work in and through the processes of doing research (2005: 255).

Potts and Brown suggest three tenets as underpinning anti-oppressive theory and practice, which have become the epistemological, ontological and practical foundations for my work also. I will outline these here and briefly mention how I see them as in keeping with Kaupapa Māori's response to Māori concerns about research. 


\section{'Anti-oppressive Research Is Social Justice and Resistance In}

Process and In Outcome' (Potts and Brown 2005: 260).

Having developed out of oppositional social movements, a focus on social justice and resistance remains central to anti-oppressive research. This demands a praxis that is transformative in means as well as ends-to use the well-worn anarchist sentiment. Within the context of this thesis, this could be rephrased as decolonisation in process and in outcome. Therefore, rather than solely a critique or a method of inquiry, Potts and Brown argue for an anti-oppressive methodology as a kind of 'social work' or method of intervention (2005: 258). This includes a strong personal commitment to social justice transformation within ourselves, our communities and our institutions. Central to anti-oppressive research is a recognition of systems of oppression and an awareness of our complicity within them. As anti-oppressive researchers, we are encouraged to confront our own privilege, within an acknowledgement that we are all potentially both oppressor and oppressed. Within the scope of this thesis, which is primarily focused on decolonisation, this means recognising my power and privilege as a member of the colonising culture. Indeed, recognising colonial power has been a central task of this thesis. It is crucial to see oppression as being played out through engagement in social relations, activities and practices-including research.

The acknowledgment that research can be a site of oppression echoes Bishop's (1998) comments about the concerns Māori have about research maintaining colonial power, and the suggestion that research can act as a social justice intervention echoes the aims of Kaupapa Māori for transformative research. This research can only claim to be an intervention if it enacts power-sharing in its processes and evaluation. This includes a commitment to participants benefiting from the experience of the research. Thus, this seems to be an appropriate response to Māori concerns about who researchers are answerable to and who benefits from the research. The Kaupapa Māori response to those concerns has been to prioritise Māori control of research. In contrast, I initiated the research in 
this thesis and I hold a great deal of control over how it has been designed, carried out and written up. While attempting to develop collaborative methods, which allow as much power-sharing as possible with the participants, this tenet reminds me that I need to remain honest about the power I hold and the constraints of writing a PhD thesis.

\section{'Anti-oppressive Research Recognizes That All Knowledge Is} Socially Constructed and Political' (Potts and Brown 2005: 261). In her article 'Situating anti-oppressive theories within critical and differencecentred perspectives' (2005), Mehmoona Moosa-Mitha described anti-oppressive theory as being based in an epistemological assumption that there are multiple ways of knowing, and therefore multiple knowledges, because knowledge is subjective and based in lived experience. This understanding grew out of social identity movements, with the recognition that experiences of privilege and oppression situate knowledge in the social location of the knower. Further, subaltern knowledge (which is gained by living with oppression) is understood as subjugated, in that subaltern people 'are always translating from one sort of knowledge to another' (Moosa-Mitha 2005: 66). This point is often made about Māori experience; Ranginui Walker for example argues that the political economy demands that Māori learn to function within Pākehā norms and often bridge 'two worlds', translating back and forth between two, while Pākehā remain overwhelmingly monocultural (2004).

In recognising the political and socially constructed nature of knowledge, this research tenet demands the question-'whose knowledge is constructed through our research projects?' and expects that ownership of knowledge is maintained by 'those who experience it, who need it' (Potts and Brown 2005: 261). Recognising that knowledge production can be oppressive and/or a means of resistance, anti- 
oppressive research is reframed as 'a political process to co-create and rediscover knowledge'(ibid: 262). Moosa-Mitha makes the important point that:

[N]ot everything is knowable; for example, subaltern knowledge is owned by and belongs to particular marginalized communities. The researcher holds the attitude of a learner, of one who is a "not-knower," but, through the act of empathetic imagination and by possessing critical self-consciousness, comes to gain a sense of what the Other knows. The researcher is reflexive in her practice, whereby the knowledge of the subaltern or subjugated is used to reflect dominant practices and assumptions in which the researcher herself is complicit (Moosa-Mitha 2005: 66-67. My emphasis).

This seems an appropriate epistemology for non-Māori researchers who want to align themselves with Kaupapa Māori theorists' affirmation of Māori ways of knowing and their critique of positivism. Kaupapa Māori researchers are clearly constructing and extending subaltern knowledge as they write. By contrast, the question remains 'whose knowledge is constructed' through my research? By positioning myself as a 'learner' and recognising the rightful owners of knowledge, this approach attempts to avoid the appropriation and misrepresentation of Māori knowledge by outsider 'experts'.

The main thing for me is that the realities of the participants I am working with are prioritised. My reading of Kaupapa Māori sits behind of my emphasis on insiders' epistemic privilege throughout this thesis. Responding to Māori concerns over 'whose knowledge is constructed', I decided not to privilege international debates within anthropology around power and identity. Instead, I have allowed the Black Rainbow discussions themselves to make the major contribution in this thesis to academic knowledge on Māori and Pākehā identity and power. I made a deliberate political and ethical decision to 'tread lightly' in those chapters, restraining myself from offering further analytic guidance. My contribution to contemporary anthropological debates about power, collaborative research methodology and the politics of representation can be found within Chapters 1, 2 and 5, where I discuss 
how I have worked to facilitate the inclusion of Black Rainbow discussions in an academic text, and where I reflect on lessons learnt throughout the process. Even in these chapters, however, I want to make it clear how the knowledge presented was constructed-through the people and events that have influenced my thinking, as well as the decisions I have made (see the next chapter, 'A Black Rainbow Story: How I have written this thesis').

\section{'The Anti-oppressive Research Process Is All about Power and} Relationships' (Potts and Brown 2005: 262).

Moosa-Mitha outlined the ontological assumptions of anti-oppressive theory as grounded in the subjective, differential and specific nature of oppression (2005: 6465). She points out that the 'social identity theorists' were attempting to move away from theorising around the oppression experienced by groups under a singular social identity (such as race or gender), towards a recognition of the multiplicity and intersectionality of identity locations (for example, women of colour). Social identity theorists highlight the existence of social hierarchies and the power relations inherent in them, where the white, heterosexual, able-bodied man is the assumed norm and anyone holding an identity that differs from this norm experiences structural, relational and cultural oppression. Thus, while emphasising specificity, anti-oppressive theorists simultaneously acknowledge the constancy of systems of oppression and therefore also recognise collective experiences and justice claims. This makes this approach both critical and difference-centred.

The implication for research is that participants are treated as active agents. Rather than attempting to fit them into normative categories, space is made for differences in self-identity and responses to oppression. Moosa-Mitha notes that: 'the self is also deeply dialogical or relational where it affects and is also affected by the multitude of relationships and experiences of oppression that it faces in society' 
(2005: 66). Power relations are seen as always shifting within relationships and these dynamics need to be attended to within research:

In anti-oppressive research, constant attention is given to these relations, and care is taken to shift power from those removed from what is trying to be "known" to those closest to it - that is, those people with epistemic privilege or lived experience of the issue under study (Potts and Brown 2005: 263).

This is a complex process of negotiation and therefore Potts and Brown advocate a 'no research without relationships' (ibid.) rule.

By focusing on power and relationships, anti-oppressive approaches seem to mirror Māori concerns about who researchers are accountable to. Also, the emphasis on self-definition within anti-oppressive praxis seems like a suitable response to Māori concerns that their experiences have been appropriated and their beliefs misrepresented by traditional research. Moreover, this ontological stance that stresses intersectionality and letting participants represent their own experiences of oppression is particularly relevant to my research, where the participants represent diverse Māori and Pākehā realities and experience multiple and overlapping oppressions at the intersections of gender, sexuality and class as well as ethnicity. They are also highly politicised and hold their own analysis about their positions within these structural realities. Working together across our similarities and differences involves attention to complex power dynamics. Kaupapa Māori researchers have employed tikanga as a means of managing the relationship negotiations necessary in research. While those customs are not appropriate for me, I was encouraged by this use of 'taken for granted' ways of being when carrying out research within my own anarchist community and I have worked hard to follow the ethical practices expected there (see Graeber 2009). Working with my friends also means relationships with participants exist before the research begins, making the personal stakes high for me. Those relationships take precedence over the research outcome. 
Overall, anti-oppressive approaches seem to parallel the guidelines for research laid out by Fiona Cram (2001), whose emphasis on collaboration and reciprocity was an inspiration as I sought to undertake research within my own community. 'Antioppressive' became a term I could apply to my own work. By showing how antioppressive praxis can respond to concerns raised by Māori about research I am not suggesting that it be used to side step Kaupapa Māori research. Rather I find it a good place to stand at the interface with Kaupapa Māori. Reading and re-reading works on Māori methodology helps me to test and challenge my ideas about research. It is a continual process of 'learning to be affected' by Māori academic work.

\section{Collaborative research methods}

It was Ocean Mercier who first suggested that I follow the lead of Miki Seifert's (2011) collaborative work and centre my research on my own anarchist community. This allowed me to respond to the Kaupapa Māori research emphasis on collaborative, insider research. Moreover, it resonated with the desire expressed by many of my friends in the anarchist scene to work in a collective that was uplifting and supportive, rather than exhausting and painful. Having been driven back to study with the nagging question 'surely we could be doing this better', this provided an exciting opportunity to try. This offered to not only create a focused situation within which to study cross-cultural interactions, but also provided the greatly needed opportunity for us to reflect on and transform alienating organising practices existing in our activist community.

I began forming a collective in July 2010 and we met roughly monthly until September 2011. This group brought together five Māori people and two Pākehā (including myself). I had initially conceived of this being a 'women's group' - so that cultural difference could remain the focus, without gender differences 'muddying the water'-however the group that formed can best be described as a 
'marginalised genders' group (including cis-women, transgendered and genderqueer people). We met at people's homes, always beginning with a shared meal and we organised according to the anarchist practices we are familiar with, including consensus decision making. At our first meeting we were joking around about how every collective in the anarchist scene has 'black' in its name-'Black Star Books', 'Black Cardigans Library Collective', 'The Black Sheep Animal Sanctuary' - and 'Black Rainbow' was suggested as a particularly nonsensical twist on this theme. We quickly decided 'Black Rainbow' would be the name of our collective. ${ }^{2}$ During our initial meetings we also spoke about what we would like to get out of this group, brainstormed ideas we could address and set ground rules for how we would treat each other. We decided by consensus to audio record the meetings and to make it a closed group. While we stopped meeting regularly after the yearlong recording period ended, we continue to come together periodically, to socialise and to support each other in specific work.

\section{Participatory Action Research}

Drawing on Participatory Action Research, I was able to argue that all of the members of Black Rainbow were 'participant-researchers', including myself. I found Stephen Kemmis and Robin McTaggart's article 'Participatory Action Research: Communicative Action and the Public Sphere' (2005) particularly useful, as they describe Participatory Action Research based on the idea that people are better at solving their own problems than outside researchers are, an assertion that fits with the principles of Kaupapa Māori research and anti-oppressive praxis described above. The use 'participant-researchers' allowed members of Black Rainbow to determine the direction of the research, while I could also fully participate in this group as a member (not merely an outside researcher). Participatory action research is also based on the idea of opening up space for conversation-through which people can transform the way they see their world, the way they interact and, hopefully, their social scene. Out of this may arise a more just and satisfying

\footnotetext{
2 It was only later I learnt of the connection to 'Black Rainbow' (1987), painted by the renowned artist Ralph Hotere in reference to the sinking of the Rainbow Warrior.
} 
society (see also McGuirk 2012 for an overview of action research employed in Aotearoa New Zealand).

\section{Interactive Interviewing}

Another model that I drew heavily upon comes from Ellis and Berger's 2003 article 'Their Story/My Story/Our Story: Including the Researcher's Experience in Interview Research'. This helped me develop data collection methods to suit the collaborative context, by emphasising reciprocal discussion, rather than interrogation. I employed Ellis and Berger's notion of 'interactive interviews' to apply to the meetings of the collective. Ellis and Berger use this term to describe interviews where researchers share elements of themselves during the interview process, creating a discussion with participants, giving space for different voices and reflecting life as lived. They argue that these kinds of techniques have proven to be especially useful for dealing with sensitive topics, and so seemed suitable for working across difference around the painful topic of colonisation. By extending this idea of the interactive interview to group meetings, I could record discussions between members of the collective in something akin to a cross between a focus group and participant observation, while maintaining the assertion that all members are participant-researchers. The focus of this method then becomes the understandings that are constructed among the group through this interaction.

Both Participatory Action Research and the idea of 'interactive interviewing' allowed me to understand Black Rainbow as a site for 'co-theorising' (see Huygens, 2007). While participants knew from the outset that my interest was in how Māori and Pākehā work together in our scene, one of my aims for this research was that this collective should define its own questions and set about answering them as a group. In the interest of more fully including members of Black Rainbow in the cotheorising process, I made the audio recordings of meetings readily available and, at the suggestions of Ingrid Huygens, I wrote a one page summary of the discussion of each meeting. Arama Rata suggested members take turns, in pairs, leading 
meetings-by proposing a topic for discussion or activities and facilitating discussions - as a way of shifting ownership of the project towards all the members of the group. This approach was enthusiastically taken up by Black Rainbow. Allowing the research to be directed by the group (or perhaps a better way to put it is: responsive to the group), my research questions had to remain fluid and continued to evolve throughout the time we worked together, as well as while I was analysing and writing about the material we gathered. In this thesis I endeavoured to track the meanings we made together. This was not one coherent narrative, but several inter-related ones that developed alongside each other, challenging and changing each other.

Black Rainbow was not only a space for theorising however, but also a site of action and embodied learning. This project group is quite different from typical Participatory Action Research projects-in which all the members of the group go out and interview or survey members of their community or organisation, then analyse the data together and use it as a basis for a plan to improve their ways of working. Instead, within our meetings or 'interactive interviews', participants drew on their own experiences within the anarchist scene (and wider society) to try to describe and understand how it works and suggest possible strategies for change. I originally imagined these discussions would develop into a central project, determined by consensus among the group, which could be more clearly labelled the 'action' part of the research. Right from the very early meetings of the group, there was some desire expressed to write a 'zine. This need for action by some members, however, also came up against resistance from others, who were frustrated with the action-focused anarchist scene and wanted to take our time building relationships and discussing experiences instead. There were also differences in levels of time, energy and commitment available to give to this project. Therefore, Black Rainbow remained largely a discussion and support group. This did not mean 'all talk', however; in order to build relationships within the group and also to find different ways of thinking about colonisation, we visited art galleries and museums, joined protest marches and ran a small poster campaign as 
a collective. Further, even though Black Rainbow was not a very mobilised group, just by forming we had an impact on the wider anarchist community. People were talking about us and our conversations impacted on other discussions wherever members of Black Rainbow were active in other collectives and communities.

Moreover, I would argue that Black Rainbow also 'did something' within the group itself. I was inspired by the Participatory Actions Research model-the 'spiral of self-reflective cycles' (planning, acting, observing, reflecting, re-planning etc)when planning to study the way that our collective worked together across difference. I also found this model to be too prescriptive, however, as I did not want to 'train' members of Black Rainbow' in the complex processes Kemmis and McTaggart suggest. Although I shared Kemmis and McTaggart's article with the group, I did not want members to feel as though they needed any qualifications for membership other than their own experience and insight. Instead, an intention for creating deliberate space for reflection played out informally, through ongoing discussions about how we wanted the group to run and checking back in after seeing how things went. That is not to say that all of our difficulties were resolved or that everyone in the group was happy with the way things went all of the time. Indeed, we struggled-group dynamics, power imbalances, personality differences and the artificial nature of the group (being set up for the research) often contributed to awkwardness and silences in our meetings. While I have not focused on these issues in this thesis, I have pointed to some of our difficulties in places throughout the chapters (see particularly the next chapter and my final discussion).

All of us were used to working in anarchist collectives that were dominated by Pākehā and members of Black Rainbow often commented that being in this Māori majority group 'felt different'. This collective allowed a space to describe how Māori and Pākehā work together in the anarchist scene, while also providing an opportunity to experience another way of working. Thus, the whole group from the first meeting can be understood as the 'action' and the 'research'. This question of 
what working in a Māori-centred anarchist collective 'does' is one that I have been particularly interested in throughout this thesis and reflect on in depth in my final discussion, 'Processes of Pākehā Change: 'learning to be affected' while working across difference'. This of course relates to questions of 'learning to be affected' by co-existence (to borrow Gibson-Grahams term again) and I found autoethnographic methods especially useful in my attempt to articulate that embodied learning.

\section{Autoethnography}

Brigitte Bönisch-Brednich pointed out early on that if I was going to be working with my own anarchist community I would also be carrying out autoethnography, and the writing of auto-ethnographers came to have a large impact on my work. Leading proponent of autoethnography, Carolyn Ellis writes:

As an autoethnographer, I am both the author and focus of the story, the one who tells and the one who experiences, the observer and the observed, the creator and the created. I am the person at the intersection of the personal and the cultural... As an autoethnographer, I tell a situated story, constructed from my own current position, one that is always partial, incomplete, and full of silences, and told at a particular time, for a particular purpose, to a particular audience (2009: 13).

What I find most useful about the work of auto-ethnographers is their willingness to turn towards their own emotional responses as a source of information about society. Laurel Richardson says that this kind of writing is 'a way of making sense of and changing our lives' (quoted in Ellis 2009: 13) and encourages her students to name their most disturbing feelings, as a way of taking the power out of them (Richardson 2007). This approach liberated me to explore my more unpleasant thoughts and feelings, a helpful antidote to reactive denial and defensiveness so common when people from dominant cultures work with people who experience oppression. It is this approach that helped me to examine the tensions between Kaupapa Māori and anthropology through my own fears in this chapter. Exploring 
my inner world also allowed me to empathise with and understand the reaction of other Pākehā to challenges presented by Māori. Once it became clear that Black Rainbow was going to be a Māori majority group, this element of autoethnography became more important, as I became one of the major sources of information about the Pākehā side of this cross-cultural experience (see the next chapter, 'A Black Rainbow Story: How I have written this thesis', for more on my use of autoethnography).

Aside from my reflections on my experiences in Black Rainbow, I also undertook a mixture of autoethnography and participant observation within the wider anarchist/activist community I am a part of. This helped to contextualise the insights of the Black Rainbow collective, as well as providing rich material on this community. One significant opportunity for this wider observation was my membership in a collective which set up an animal rescue sanctuary in Ōtaki. One of the intentions of this collective was building relationships with the local people of the area-Ngāti Raukawa-with eventual partnership as a goal. This project involved working on decolonisation issues and complex relationship negotiations within a Pākehā dominated collective and therefore acted as an interesting counterpoint to Black Rainbow. Also, the two Māori members of this animal sanctuary collective, Te Awanui and Kura, ${ }^{3}$ were also members of Black Rainbow and Kura is Ngāti Raukawa. The difficulties Te Awanui and Kura had with this sanctuary project are reflected in Black Rainbow's discussions. To get another perspective, I interviewed the Pākehā founder of this sanctuary project. Similarly, I also interviewed a Māori woman who used to be very active in the anarchist scene who staunchly supports some of the non-Māori people criticised by Black Rainbow. Originally I thought to include excerpts from these interviews in this thesis, as complications to the story created by members of Black Rainbow. However, after experimenting with this, I came to realise that this would only put these people 'out on a limb'-unsupported by the surrounding discussion and literature, compared to

\footnotetext{
${ }^{3}$ These are pseudonyms.
} 
the stories shared by members of Black Rainbow, and would make these two women's arguments seem comparatively weak. I decided to simply tell the story of the Black Rainbow collective and the meaning we made together, rather than claiming to represent the 'reality' of the entire anarchist scene.

\section{Interviews and participant observation}

Similarly, I collected life-history interviews with the members of Black Rainbow that I have not included in this thesis. As it became clear from early meetings that identity and life long experience informed Black Rainbow members' perspectives on the anarchist scene, Brigitte Bönisch-Brednich suggested that I carry out life-history interviews with participants. In the interest of further democratising the research and of extending the involvement of participant-researchers, I asked if other members of Black Rainbow would like to act as interviewers. We discussed possible questions together and carried out semi-structured interviews, with people nominating the person they wanted to be interviewed by. This resulted in interviews of various length and depth. As one of the participant-researchers, I was also interviewed. This was helpful for my engagement with autoethnography. These interviews, have not been quoted in this thesis, but have informed my understanding of what was spoken about in our collective discussions.

The same is true for the extensive field notes and journal reflections I have from my observations of the anarchist scene, as well as other informal research, including attending important events as they arose, such as Aotearoa Anarcha-Feminist Hui (April 2-5, 2010), a conference which focused on decolonisation and racism within the movement and a critical-whiteness conference for activists and artists entitled 'Whiteness/Whitemess' (May 15-16, 2010). Conversations and observations with members of the anarchist community, as well as Treaty educators, academics and general members of the public also continually added my understanding of colonisation and working across difference. 


\section{Issues of accountability}

Observing my own community, while working with a group that is critical of that community, raised complex issues for me around accountability. Who researchers are accountable to is a key question raised by both Kaupapa Māori and antioppressive researchers and I was aware of the need to remain actively engaged in feeding back to participants and members of the anarchist community about my research and developing analysis. This was possible within Black Rainbow because our collective accountability to each other was clear and we were committed to working through disagreements together. However, it was more difficult with the wider anarchist community which is thinly spread and amorphous. Tolich has raised ethical concerns about autoethographers writing stories about others without following rigorous consent processes. Following his recommendations, I attempted to practice 'process consent'-continually checking whether participants want to continue to be part of the thesis (Ellis 2007; Tolich 2010). This checking brought to light difficulties within Black Rainbow, some of which we were able to discuss as a group. I have used pseudonyms for the third parties mentioned by the members of Black Rainbow in our discussions and taken pains to protect the identities of those third parties; nonetheless it is likely they will recognise themselves in these stories and they may not like what they read.

Openness about my emerging analysis and observations is crucial if this research is to act as an intervention within my community, rather than merely a critique. Potts and Brown have emphasised the importance of including key stakeholders in the process of data analysis, as these are the people who will be responsible for acting on the findings (2005). Given the nature of the anarchist scene (as well as the time restraints of my PhD project), I have not been able to do this in a formal way, although Black Rainbow did present some of our reflections during a day of talks held in celebration of the tenth birthday of the 128 community centre (July 2012). Informally, I have attempted to engage in discussions with people in the wider 
anarchist scene about my research. Unfortunately, I have found that my association with Black Rainbow has led to a break down in relationships with some of the people who members of Black Rainbow are most critical of, and at least one of those women has told me that she is not interested in talking with me about those issues at this time. This experience highlights the difficulties with obtaining engagement and consent from all community stakeholders when there are major conflicts. Regardless, I write with my accountability to that community in mind.

\section{Reflections on positioning in collaborative research}

In this chapter I have discussed some of the impacts of Kaupapa Māori research on contemporary anthropology here in Aotearoa New Zealand and have suggested that by 'learning to be affected' by Kaupapa Māori, we can begin to create an anthropology more of this place. The collaborative methods I have employed in this thesis offer an experiment in this kind of responsiveness. However, I would like to end by exploring the issue of 'positioning' further, as this is a key question for nonMāori researchers attempting to work with Māori. Again, I draw on the concept of 'learning to be affected' as a way out of 'Pākehā paralysis'.

Gibson-Graham and Roelvink write about 'learning to be affected' as 'an ethical practice', involving turning towards co-existence, in order to allow oneself to be transformed by difference (2009: 325). I came to wonder if, viewed specifically as a research ethic, this same call for 'learning to be affected' can also be found in Russell Bishop's assertion that:

The researcher cannot 'position' herself or 'empower' the other. Instead, through entering a participatory mode of consciousness the individual agent of the ' $I$ ' of the researcher is released in order to enter a consciousness larger than the self (Bishop 1998: 205. My emphasis).

While I am attracted to this notion of 'a participatory mode of consciousness', I am also wary that it could be used to obscure difference. Alison Jones has 
demonstrated how a Pākehā desire to 'share' experiences with Māori in the classroom, to be unified through mutual understanding, is a form of re-colonisation. She recommends instead, greater introspection and the developing of a 'politics of disappointment' among Pākehā (Jones, 2001: 315). Leading on from Jones, Avril Bell (2008) has suggested the 'notion of the productivity of ignorance' as a necessary part of the de-centring of Pākehā. This seems an appropriate response to acknowledging what Narayan (1988) has identified as the 'epistemic privilege' of insiders to oppression and is in keeping with the central tenet of anti-oppressive praxis that 'not everything is knowable' (Moosa-Mitha 2005: 66). Bell advocates for 'a processual and self-reflexive relation to knowledge, a relation in which the status of existing knowledge is always provisional. This is ignorance as an act of responsibility for the other, rather than ignorance (or knowledge) as domination' (Bell 2008: 864).

Coupled with a commitment to 'learning to be affected', I believe that this productive ignorance allows me to enter the 'participatory mode of consciousness' described by Bishop. This is precisely because it de-centres me. Danny Butt expresses a similar experience beautifully in his paper 'the Opposite of Whiteness':

I think about the relationship I have with my girlfriend - around her difference my boundaries soften. I am taken out of myself by her and returned to a refracted version of myself at the same time... Even though I can talk about this feeling I can't actually explain it, and increasingly I believe that any attempts to explain it are counterproductive. The attempts at explanation are also attempts to gain possession of my own dispossession. I want to find the feeling rather than diagnose it, and this occurs through maintaining curiosity and lack of knowledge about what is happening (Butt 2010).

It is this kind of dispossession I am seeking to explore through this research project.

This has practical implications for how I carried out and understand my research. Through turning toward this kind of 'participatory mode of consciousness', this 'learning to be affected', I began to understand how I came to the research plan 
presented here through a series of collaborations (including conversations over dinner, in meetings, on buses, in academic offices and cafés) that have pushed me in certain directions every step of the way. I was aided in this understanding by reading Michael Farrell's Collaborative Circles which demonstrates that 'Creative work is rarely done by a lone genius. Artists, writers, scientists and other professionals often do their most creative work when collaborating within a circle of likeminded friends' (Farrell 2001: book jacket). However, the moment of clarity truly came when a friend asked: 'So how did you come up with this research plan?'

I have tried to write this methodology chapter in a way that illustrates the collaborative process through which this project has evolved, by pointing to key suggestions from academics and friends. I would like now to illustrate this collaborative shaping of my research design with a story from the establishment of the Black Rainbow collective:

In July 2010, once I thought I had a fairly solid plan for collaborative research, I sent out invites to an initial discussion about setting up a collective. At that time I was hoping for a final group of about five or six, and so I sent invites for a pot luck dinner to ten people I thought would be interested. Imagining a fairly evenly mixed group, I invited five Māori, four Pākehā and an Indian woman. I got many enthusiastic replies. However, two things pushed me quickly in a new direction. Firstly, I received an email from a white women (who is very active within the anarchist scene) expressing her disappointment that she was not invited to join the project. In my reply I had to delicately explain that one of the aims was to centre Māori-most especially those who have become marginalised from the anarchist communityand that since she has unresolved issues with some of these people, I wanted to prioritise their involvement over hers. Secondly, Mara (who was one of those particularly 'burnt out' Māori women) didn't reply to my invite and I started to worry that there were people in that initial set of invites that she would rather not work with. I ran into her at the university library and muttered embarrassedly that 
maybe if my aim was to centre Māori, I shouldn't have invited the people I thought would work well together. I should've found out who Māori were excited about working with. Mara just said, 'Yep'. I went home and sheepishly retracted my initial invitation. Then I started speaking one-on-one with the five Māori people and my image of the project group started to shift.

A couple of people named mostly other Māori as the folks they were most interested in working with. Kura said outright that what she wanted most was to work with more Māori. She was used to it being just her, or her and Te Awanui in collectives with a bunch of Pākehā and she was keen to be in a space where she wasn't expected to represent all of Māori opinion and where she could learn from other Māori activists. I came to wonder if a Māori majority group would be better for everyone involved-a supportive, refreshing and stimulating change for Māori members and a chance for non-Māori to practice 'learning to be affected' in a Māori-centred group. This shift in thinking also solved another problem, the fact that after talking with everyone, Hayley ${ }^{4}$ was the only non-Māori anarchist that everyone was really enthusiastic about working with. Since I wanted to keep the collective fairly small and intimate, and there were already five Māori people, it seemed as though the seven of us would make up a good group. After some discussion at our first meeting, it was decided to keep the group as it was and make it a closed collective.

You can call this approach Participatory Action Research, or interactive interviewing, with autoethnography. You might say it is in keeping with a Māori research kaupapa. However, I prefer to call it 'learning to be affected by coexistence' because it helps me to concentrate on a greater integration of my academic, activist and personal selves (see Ellis 2009: 18, 77). While it is one of the

\footnotetext{
${ }^{4}$ This is a pseudonym.
} 
overt aims of my project to weave the methodologies into the social justice concerns of this topic, how these two come together within my role as researcher, activist and friend has not always been obvious to me. The notion of 'learning to be affected' connects my role as anti-oppressive researcher to ideas of being an ally in a much deeper way (see Margaret 2010b). Increasingly, it seems to simply come down to relationships-whether I can sustain them and remain responsive within them (see Spectra 2013). This has involved listening and accepting criticism with humility, through a re-imagining of relationships that acknowledges the collaborative nature of everyday life.

This is where the pains and pleasures of engagement mix and blur into each other. It has been interesting to separate them for the purposes of this chapterespecially to move away from solely focusing on the negative emotions which can paralyse us-however in my experience they exist together as a complex mess. Embracing this mix of the pleasures and pain of engagement, 'learning to be affected' by it, helps me overcome Pākehā paralysis. In this chapter I have tried to position my research within the current academic climate and begun to imagine another anthropology of this place. I suggest a 'learning to be affected', a turning towards an anthropology already being transformed by Kaupapa Māori and a leaning into both the pleasures and the pain that that opportunity brings. I hope to assure emerging researchers that Pākehā paralysis can be overcome through engagement. However, I also want to warn against moving too quickly past the challenges presented by Kaupapa Māori. For me, this approach has created a research project employing various collaborative methods, which produced a wealth of material and a great deal of learning for me, as both an academic and an ally. 


\section{Chapter 2}

\section{A Black Rainbow Story}

\section{How I have written this thesis}

$20^{\text {th }}$ of April 2013

I wave goodbye to Hayley and Francis ${ }^{1}$ as they pull out of their driveway. It is a rainy weekend at the end of a long summer and I'm house-sitting while Hayley and Francis (two members of Black Rainbow) take their baby to visit Francis' parents. I have my slippers and track pants, a bag full of books and a plan to hunker down to write. After wandering around for a moment, unsure what to do with myself in someone else's home, I settle down on the couch next to their giant cat and begin rereading Ruth Behar's The Vulnerable Observer: Anthropology that Breaks Your Heart. True to the title, Behar's book always makes my heart swell and ache. I feel it like a weight on my chest-this horrible/wonderful possibility of writing in a way that feels meaningful and real. Soon I'm gazing out the window, thinking about all the stories that won't be told in this thesis. Stories about love and friendship, anger and hurt. The stories that make us most vulnerable. People say I am brave for writing this thesis, but I feel small in the shadow of all these untold stories. Turning my attention back to The Vulnerable Observer, Ruth Behar tells me this is alright:

Loss, mourning, the longing for memory, the desire to enter into the world around you and having no idea how to do it, the fear of observing too coldly or too distractedly or too raggedly, the rage of cowardice, the insight that is always arriving late, as defiant hindsight, a sense of the utter uselessness of writing anything and yet the burning desire to write something, are the stopping places

\footnotetext{
${ }^{1}$ This is a pseudonym.
} 
along the way. At the end of the voyage, if you are lucky, you

catch a glimpse of a lighthouse, and you are grateful (Behar 1996:

3).

While I have outlined the collaborative methodology I have employed, the writing of this thesis is something I had to do mostly alone (see Jones and Jenkins 2008). Therefore, I will spend some time here charting the ways I continued this labour of writing stories, including literature and making meaning, as well as some of the issues of negotiating authorship in collaborative research.

\section{Why write stories?}

When it came to writing about the ideas that came out of the Black Rainbow meetings, I found that I wanted to tell stories, rather than organise what I learnt into thematic categories. Following Carolyn Ellis' work on 'interactive interviews', this seemed the most appropriate way to represent what were moments of shared meaning making within our discussions.

In their article 'Their story/my story/our story: Including the researcher's experience in interview research', Carolyn Ellis and Leigh Berger show that interviews have come to be understood, not as the transmission of information from participants to researchers, but rather as 'collaborative, communicative events' (2003: 469). During these events, participants do not simply tell the readymade stories they brought with them to the interview, but rather narrate 'improvised stories in response to the questions, probes, and personal stories of the interviewers' (ibid.). Therefore, Ellis and Berger encourage the use of interviewing techniques, such as interactive interviewing, which not only acknowledges but celebrates this dialogical nature of interviews: 
[P]articipants can be given an important role in determining the research process and its content, as well as in interpreting the meanings of the interviews. Likewise, the feelings, insights, and stories that the primary researcher brings to the interactive session are as important as those of other participants; the understandings that emerge among all parties during interaction-what they learn together-are as compelling as the stories each brings to the session (2003: 475).

This understanding of the interview process as dialogue also demands a different way of writing about what comes out of these discussions - it demands stories about these events. Stories which show how meaning was made together by all the participants.

The collaborative research method I used suits a way of representing data that is contextualised. I did not ask participants a set of questions that could then be placed thematically into chapters; rather, the statements they made arose from the conversations we were having. Points of analysis came out in these discussions in response to stories of personal experience. I am interested in showing how we made meaning together in these discussions. This process cannot be reduced to brief summaries; instead, it comes out through our lengthy discussions. During these events, the meaning we made was never totally fixed. It was embedded in particular stories and moved in response to new stories being told.

The power of stories to open space for various understandings is beautifully described by Trinh T. Minh-ha in Woman, Native, Other: 'The story circulates like a gift; an empty gift which anybody can lay claim to by filling it to taste, yet can never truly possess. A gift built on multiplicity. One that stays inexhaustible within its own limits' (1989: 2). This also speaks to the politics of representation. When I was looking for a way to present my work ethically, Lorena Gibson suggested I follow the example of Lila Abu-Lughod (see Gibson's use of narrative in her ethnography of hope in grassroots women's organisations, 2011). In her book Writing Women's Worlds: Bedouin Stories, Abu-Lughod comments on how telling tales offers an 
alternative to what she see as 'the most troubling aspect of ethnographic description' - the way it 'trafficked in generalizations' (1993: 7). Abu-Lughod argues that anthropologists should be especially concerned about generalisation, firstly because it is part of the language of power (held by the distant, objective expert and all the colonising implications of that position) and secondly because generalisation contributes to the creation of 'other', bounded, timeless, 'cultures'. Abu-Lughod calls this entrenched understanding of bounded cultures 'dangerous fictions' and argues for 'writing against culture' (ibid: 9). While there are many ways we could 'write against culture', Abu-Lughod says: 'Telling stories, it has seemed to me, could be a powerful tool for unsettling the culture concept and subverting the process of 'othering' it entails' (ibid: 12). This choice of writing stories over generalisation, therefore, resonates with the difference-centred philosophy at the heart of my anti-oppressive methodology.

Abu-Lughod gives a powerful argument for this style of representation:

First, the refusal to generalize would highlight the constructed quality of that "typicality" so regularly produced in conventional social scientific accounts. Second, description of the actual circumstances and histories of individuals and their relationships would suggest that such particulars, which are always present (as we know from our own lives), are also crucial to the constitution of experience. Third, reconstruction of people's arguments about, justifications for, and interpretations of what they and others are doing would show that, within limited discourses (that may be contradictory and certainty are historically changing), people strategize, feel pain, contest interpretations of what is happening - in short, live their lives. In one sense this is not new. Bourdieu (1977), for example, theorizes about social practice in a similar way. The difference there is that one would represent through textual means how this happens rather than simply assert that it does so (1993: 14).

This became a useful guide for which stories to include, as I attempted to show how we make sense of this contested reality-where the members of Black Rainbow contradicted each other or backed down to allow consensus, as well as the moments where we created shared meaning. 
By showing how we tell our stories and share our interpretations, these Black Rainbow discussions also show, as Abu-Lughod points out, that storytelling makes plain the feminist 'inevitability of positionality': 'A story is always situated; it has both a teller and an audience. Its perspective is partial (in both senses of the word), and its telling is motivated' (1993: 15). When sharing their stories, the members of Black Rainbow were aware of the academic audience, as well as the activists who would read this thesis. Yet, we also told our tales for each other as much as for these future readers. Likewise, I have used the participants' stories in ways in this thesis that they would not have foreseen. Still, I write this for them, and the anarchist scene, as well as my examiners.

\section{How I wrote the stories}

When I came to write each of the three main body chapters, therefore, I began by writing stories about our meetings. My aim was to create a larger 'story of Black Rainbow', which traces the development of the group chronologically. For the most part, this was based on the transcripts of our audio recordings, although I also relied on my field notes and memory. I was influenced by Abu-Lughod's emphasis on letting people's stories speak for themselves, with little interruption from the author, I 'tried not to be intrusive' (1993: 29). I also followed Carolyn Ellis' (2004) use of extended pieces of dialogue, to tell stories. Therefore, for each meeting I wrote a story centred on a section of our conversation. These selected conversations were largely based on the transcripts, which I edited in minor ways to make them more readable-taking out false starts and repetitions, as well as summarising over details that I believed to be of less interest to general readers. To this dialogue I also added a small amount of scene setting. I chose to write these stories in present tense, not to convey a sense of timelessness, but rather the opposite-so you (the reader) may have a sense of being in that particular moment. Of course, as Behar notes, what we write can never fully capture these 
conversations, which are 'unique, irrecoverable, gone before they happen, always in the past, even when written up in the present tense' (1996: 7).

As Behar's comment suggests, the stories I have presented here are not these conversations 'just as they happened'. Rather, they are crafted narratives and I have chosen to tell them for specific purposes. I was concerned to prioritise the voices of the members of Black Rainbow and show these meetings as events where meaning was collaboratively made, however, I also selected which conversations to include based on particular themes I decided were central to each chapter. This is the paradox of writing 'Their story/my story/our story' (Ellis and Berger 2003). Put simply, faced with the large amount of dialogue I had to choose from, I had to pick and choose what to include and the easiest way to do that was thematically. Therefore, the first Black Rainbow chapter focuses on 'Identity', the second on 'Relationships' and the third on 'Power-sharing'. In part, these chapter headings were influenced by my reading of anti-oppressive theory-which continually stresses the importance of identity, relationships and power-and in many ways dividing these into separate chapters is arbitrary because all three themes run throughout every one of our conversations.

Yet, these themes also seem to have special resonance with different moments for the group. At our first recorded meeting, we took turns talking about 'where we come from', which naturally led into discussions about the importance of identity and became the centre of chapter 3.1 also included this full conversation as a way of allowing the members of Black Rainbow to 'introduce' themselves to you (the reader), so that you can see their distinct personalities and life histories. Following Abu-Lughod, I hope that this will allow some familiarity for the reader with these individuals, creating less distance and therefore will be less 'othering'. I chose to focus on relationships in the chapter 4 , because we had a lengthy discussion about intimate cross-cultural relationships and because this was a time of deliberate relationship building for the group. I therefore tried to include stories that both 
'tell' about relationships as well as 'show' relationships. Chapter 5 centres on a lengthy discussion where members of Black Rainbow sharing stories from the anarchist scene. I was particularly interested when writing the stories for this chapter to show how we made sense of our experiences together as a group-how personal stories were connected to points of analysis-particularly around obstacles to power-sharing.

While I set out to let participants speak for themselves, I quickly realised that I had to be the author of this thesis and that means asserting a degree of control over other people's stories. Vivian Gornick's excellent book, The Situation and the Story: The Art of Personal Narrative helped me come to terms with this. Gornick argues that 'without detachment there can be no story; description and response, yes, but no story' (Gornick 2002: 12). This was really useful for me, for both writing the stories and thinking about the meaning I have made through them. Because I have followed a methodology that emphasises engagement and productive ignorance, I have at times been guilty of romanticising mystification- of wallowing in the 'bigness' and 'messiness' of the situation, the flux of lived experience within colonisation-rather than finding the 'story'. This lack of distance is not a bad thing, as I have discussed in the previous chapter, entering into a 'participatory mode of consciousness' has been crucial while carrying out collaborative research (Bishop 1998: 205). Nevertheless, I find Gornick's argument that empathetic detachment is necessary for writing very convincing: 'Every work of literature has both a situation and a story. The situation is the context or circumstance, sometimes the plot; the story is the emotional experience that preoccupies the writer: the insight, the wisdom, the thing one has come to say' (2002: 13).

I have tried to write in a way that allows collective meaning making to be seen. Yet, while these stories capture the moment of various conversations we had as a group, for me the process of meaning making also continued while listening to, transcribing, editing, reflecting on and writing about these conversations in the 
construction of this thesis. In the words of Laurel Richardson and Elizabeth Adams St. Pierre, this is 'writing as a method of inquiry' (2005), rather than reporting and it has been through this process that I have discovered 'the thing I have come to say'.

Likewise, I know other members of the group have continued to reflect on our discussions, in further conversations, introspection and their own writing. Yet their later reflections are not recorded here. This thesis is ultimately my story, prioritising my learning, and I have tried to make that clear throughout. Trying to face this honestly, I found this comment from Abu-Lughod very helpful:

Until we decide - or are forced - to move anthropology to new "shop floors" (in Fox's phrase), or to abandon it altogether, we should perhaps be more modest in our claims to radicalism. At best we are talking about reform - undertaken with as good a sense as we can develop of the world context in which we work. As long as anthropologists are in the business of representing others, the ethnographies through which they do so will likely remain a primary mode of anthropological production (1993: 267. My emphasis).

\section{Writing about myself: autoethnography}

This recognition that we are 'in the business of representing others' is also beautifully captured by Behar's observation that 'Nothing is stranger than this business of humans observing other humans in order to write about them' (1996: 5). Behar encourages us to write in a way that makes it clear that it is another human observing the people represented in our texts, rather than the distant omniscient eye of objective universal writing. In following this advice, my writing style has also been influenced by the work of Carolyn Ellis (1996, 2004, 2009), Laurel Richardson (2007) and Kimberly Nettles (2008). These authors share a resistance to a conclusive authority over the work they produce and this remains the central argument for using autoethnographic writing. In Donna Haraway's words, 'Location is about vulnerability; location resists the politics of closure, finality...' (1988: 590). 
Behar takes up this notion of making oneself vulnerable and writes, 'When you write vulnerably, others respond vulnerably' (1996: 16). To me, this is the most powerful statement she makes, as it resonates with my desire to invoke an openness to 'learning to be affected', especially in other Pākehā readers. It is certainly true; nonetheless, that when we write vulnerably people will not always respond vulnerably. Many people find it deeply uncomfortable and there has been significant criticism of inclusion of the author in the text. Behar herself notes that not all attempts at vulnerable writing are successful-some are in fact tedious or humiliating-and she stresses that biographical details are only interesting if they serve an argument, if they allow us to thinking more deeply about the topic of study. Behar goes on to assert that:

The charge that all the variants of vulnerable writing that have blossomed in the last two decades are self-serving and superficial, full of unnecessary guilt or excessive bravado, stems from an unwillingness to even consider the possibility that a personal voice, if creatively used, can lead the reader, not into miniature bubbles of navel-gazing, but into the enormous sea of serious social issues (1996: 14).

Likewise, I have included myself in this thesis in ways that I believe advance my arguments. There are two elements to this. The first is methodological-in response to critiques of Kaupapa Māori researchers about the way that non-Māori have tended to produce essentialising texts 'on' Māori written from a distance, I am attempting to write a deeply located and self-reflexive text. Minh-ha writes:

Remember, the minority's voice is always personal; that of the majority, always impersonal. Logic dictates. Man thinks, woman feels. The white man knows through reason and logic-the intelligible. The black man understands through intuition and sympathy-the sensible (1989: 28. Emphasis in the original).

I am interested in subverting these tired stereotypes, showing the dominant Pākehā culture as personal, by making myself visible in my subjectivity (see Frankenberg 1993, Ellis 1996, Shamblin 1996, Denzin and Lincoln 2008). This also points to the 
second reason that I am including myself in this text-for that which can be learnt about how Māori and Pākehā work together across difference. I do not want this to be a study only of Māori peoples' experiences; it is just as much about the beliefs and behaviours of white people. Therefore, I am interested in interrogating my thoughts, feelings and experiences around this.

Part of the reason I am interested in examining my own experience as Pākehā is also because many of the discussions we had in Black Rainbow involved complaints about the behaviour of Pākehā people (both in general and also that of specific people). Because I focused in this research on the collective meanings made between us as a group, rather than attempting to survey the entire anarchist scene, the people we speak about in the group do not get a chance to share their motivations and experiences. Yet I still wanted to find ways to write compassionately about their behaviour. Trying to demonstrate and understand related tendencies within myself is my way of doing this.

\section{How I related the literature to these stories}

Once I had written the stories, I set about working in the supporting literature. Aside from letting myself be visible in the stories, another way that I attempted to democratise the text is by my placement of this academic literature. The importance of this became especially apparent to me after I received critical feedback on an early draft of chapter 3 'Black Rainbow (August to October): Identity' from one of the members of Black Rainbow, Francis.

Following the tendency of those working in participatory action research to show concern for participants' feelings about how they are represented (see Ellis and Berger 2003; Kemmis and McTaggart 2005), I have shown drafts to the members of Black Rainbow throughout the writing process. Within the limited timeframe of the Ph.D. program (and the busy lives of the participants) I have tried to follow this 
practice, by showing participants both the stories of theirs I hoped to use and the drafts of chapters within which those stories appear. While this practice certainly slowed down my writing progress, the value of this kind of checking became plain when I received Francis' critique. I will give an account of this in some detail, both because it has influenced the way I wrote this thesis and because it highlights some of the politics of representation.

In the first draft, chapter 3 included the three stories that appear in this final text (a total of around 10,000 words) followed by 5,000 -odd words of my academic reflection on these stories. While I organised my reflections around statements that people had made in our discussions, I drew heavily on the academic literature here, and this is the section Francis took exception to. Here is an excerpt from Francis'email:

I didn't like the transition from our stories into academic analysis/context in the second part of the chapter-I think it's an example of what's wrong with a research framework-at this point I felt as if any power to explain myself was taken away. The way it is written at the moment often implied to me that the people you cite understand the real meaning behind our stories better than we do. I guess I felt silenced and not respected. Given that we weren't asked to contextualise our stories, and you said you chose to exclude our analysis and instead focus on the narrative, we lost all power as participants, and you stopped being a participant and became the researcher with the power to define and explain.

You chose the frameworks to contextualise our stories based on your learning, experience, and understanding. I don't think you acknowledge clearly enough that you are taking that power, and that this part of the chapter is completely centred on your understanding (September 27, 2012).

Naturally, this was painful to read. Francis was essentially telling me I had done the opposite of what I set out to do. Her comments actually confirmed some of my own gut reactions while writing that chapter. Still, I was shocked and disappointed that I had performed this kind of silencing. Moreover, as I saw it, if participants felt like 
this once the thesis was completed, my project would have failed. The tenets of anti-oppressive research (laid out in Chapter 1, 'Methodology: 'Learning to be affected' by Kaupapa Māori') demand that 'care is taken to shift power from those removed from what is trying to be "known" to those closest to it-that is, those people with epistemic privilege or lived experience of the issue under study' (Potts and Brown 2005: 263). A commitment to anti-oppressive methodology (and my friendship with Francis) meant listening carefully to her concerns.

Through this careful listening and reflecting I learnt a lot about the unconscious ways that we can continue to behave oppressively, despite all the good intentions and critical awareness we may have. Ironically, this was one of the themes of the chapter in question. I could see that some of the difficulties she raised could be corrected simply with better framing. Because this was a draft and I was concentrating on clarifying my ideas, I had not made it explicit that the analysis section was centred on my understanding or that the stories I chose to tell reflected my experiences of the group, not a simple reality. I could have 'fixed' this by adding comments to that effect and changing some of the wording, which is distancing and objectifying in places.

What I found far more disturbing was how, as Francis rightly pointed out, I had neglected the analysis of the participants and instead let myself and the academic literature contextualise their experiences. For example, I unpacked a comment Francis made about not being treated as a 'real Māori' using Avril Bell's (2004) discussion of 'authenticity'. As I reread what I had written, I remembered Francis speaking in a life history interview about the way that Māori are 'Othered', in terms that closely paralleled Bell's argument. I was struck by the question: 'Why did I use Bell's analysis instead of Francis'?' 
One reason is certainly, as Francis says, that I am used to the academic convention of participants as the people with experiences and the academics as the ones with answers. It is surprisingly easy to slide into this, despite subscribing to an antioppressive theory that demands the question: 'whose knowledge is constructed through our research projects?' and expects that ownership of knowledge is maintained by 'those who experience it, who need it' (Potts and Brown 2005: 261).

Yet once I began writing, I found that I could not simply present the knowledge of 'those who experience it'. As I have already mentioned, I realised while writing that I had to tell a story. I had to be the author with their words, to say what I have come to say. This being the case, I realised I would have to be clear and honest about my emerging analysis, as this influenced which stories I chose to tell. Meanwhile, I knew that I needed to put the supporting literature somewhere, and though I had been toying with alternative ways of doing this, I decided to write it up as a traditional essay first as a way of getting my head around it. But, we cannot simply write about the literature innocently, either-I had quickly fallen back on my training and began weaving my own analysis and observations through it. Seduced by an elegant argument, I had unintentionally let myself and the academic voices have the final say over the chapter.

When people critique vulnerable, auto-ethnographic writing, we often hear words like 'self-indulgent', but what struck me during this time was how this language obscures the pleasures of an elegant argument. Despite my concerns about 'closing' and 'fixing' meaning, I had enjoyed stepping back from all the messiness of being embedded in our shared stories and simply creating an argument. It meant I was able to put down the sadness, the confusion for a little while and feel like I had some control. This is also satisfying, self-indulgent work. 
I had to admit, too, that part of the reason I had not grasped onto Francis' analysis in the same way I had her experiences of growing up, is that as a social scientist I am saturated with talk of 'Othering'. It has become part of the ground we walk on as academics-important, but honestly, a little boring. By contrast, the way participants spoke about their lives seemed fresh and complicated, vital. So, I let the academic literature talk about the 'boring stuff', to make more space for participants to talk about the stuff of life. In my mind, I was valuing that 'life stuff' over academic analysis and using it to demonstrate the foundations of what Uma Narayan identifies as 'insider's epistemic privilege' (1988). There are, of course, important power issues here, where academic analysis is generally privileged as a higher way of knowing, while habits of reading assume that the concluding comments are the most important. Ironically, I was making an argument for taking insider's epistemic privilege seriously, while at the same time undermining that message by writing the chapter in a way that actually privileges outsider knowledge, unconsciously reproducing the hierarchy I had intended to resist.

This led me back to trying to find alternative ways of incorporating the academic literature. Much of the literature I had chosen I saw as backing up what the participants were saying-merely elaborating on the references they made. My intention in including it was to highlight the meaning that was being made among the group, not to say that these academics knew more about their the participants' identities than they do themselves. It is hard to overstate how much I have learnt from the people in Black Rainbow (see my final discussion, 'Processes of Pākehā Change: 'learning to be affected' while working across difference', for more on this), academic reading only helps me to understand some of that learning. Often I would talk with participants about what I had been reading and they would test and extend those theories (this can be especially seen in chapter 4, 'Black Rainbow (November to March): Relationships'). The two knowledge sources fed into each other, though the academic literature was easier to cite. It is simple to say that my analysis grew out of relationships with people as well as literature. It is more 
difficult to show it. Therefore, I was interested in finding ways to represent that within the text.

I chose to do this through extended footnotes, which hang directly from the comments members of Black Rainbow made in our discussions. This allows the academic literature to run alongside the stories on the page, rather than speaking over them at the end of the chapter. My inspiration for this approach came from Kimberly Nettles' Guyana Diaries: women's lives across difference (2008). This book is an auto-ethnographic account of research with a group of Caribbean activist women; however what I found particularly useful was how Nettles attached academic references as endnotes to statements she made about her personal life and experiences. As a reader, I felt this made the connections between personal and structural realities very clear. Yet, the use of endnotes places the literature as 'asides', while for the purposes of my research thesis I want this literature to be read as an important part of the discussion. For this reason, I have used a different font for my few asides that do appear in the footnotes, to differentiate the two strands. I found that by hanging these footnotes from comments within the stories created a similar effect to Annemarie Mol's use of the divided page in The Body Multiple: Ontology in medical practice (2002). While my use of footnotes is less sophisticated than Mol's subtext, I find them more straight forward and easier to read.

\section{Clarifying the meaning I have made}

After writing the stories and connecting the supporting literature with them, the final work to be done has been clarifying the meaning I am making from these stories. In many ways this seems like it should be a simple task-the most basic academic task of creating an argument and sign posting throughout so that the reader may follow that argument. But responding to Francis' criticism, that at a certain point I 'stopped being a participant and became the researcher with the 
power to define and explain', has complicated that task. Moreover, I have been trying to hold simultaneously, Minh-Ha and Abu-Lughod's use of story to resist generalisation and Behar and Gornick's insistence that a personal story must make an argument. So, how to say what I have come to say, without writing in a way that speaks past the other participants? What is the difference between elaborating the wisdom gained through these experiences and creating an elegant argument that 'closes' these stories from being read in different ways?

I have not completely resolved these tensions; rather, I hope that highlighting them is useful. I draw some comfort from Minh-Ha's emphasis on 'raising consciousness regarding the process by which language works or regarding the nature, activity, and status of writing itself' (1989: 21). Minh-Ha's discussion of writing as 'a sketched window on the world' is far more poetic and nuanced than anything I am attempting here; however, I find the basic concept that talking about the processes of writing goes some way to demystifying writing and breaking down the image that writing is simply 'a means of expressing a reality or emitting a message' (ibid.). I hope that through having this discussion about how I have written this thesis I can make some of the activity of writing visible.

Simply, I follow Minh-Ha's observation that 'I write to show myself showing people who show me my own showing' (1989: 22). In practical terms, I have tried to be clear about the meaning I have made throughout the thesis, by outlining why I have chosen to tell each story and what I learnt from it. Following J.K. Gibson-Graham, I try to maintain a 'beginner's mind" through 'practicing a "weak" form of theory that cannot encompass the present and shut down the future' (2006: 7-8). I have tried to distinguish this clearly from the academic literature I cite, so as not to simply rest on their academic authority and place myself with them as the 'knowers' opposed to the members of Black Rainbow as the 'doers'. 
Francis' criticism made me more attentive to the arguments that the other members of the group were making together through our discussions. To help make this shared meaning-making apparent, I highlighted certain phrases I saw as key arguments, such as 'the problem is the power dynamics', by presenting them in bold font and changing them to a larger font size. These also act as informal subheadings to help guide the reader through long, meandering discussions. For the same reason, I have also created little breaks throughout the some of the longer stories, as moments to 'take a breath' and think about what is being said. In these breaks I have pulled out what I think are some of the main points of meaning being made at that moment in the discussion. Many of these ideas actually run throughout the discussions; nonetheless, I have chosen to emphasise them at particular moments, for the sake of clarity. I am aware that you (the reader) may be able to notice a gradual shift over the three Black Rainbow chapters, moving from a greater emphasis on my own arguments (in chapter 3 ) towards more attention to those of the other participants (in chapter 5), as I slowly learnt to listen closely and track the arguments made in the group. Despite re-writing for consistency, these differences remain and demonstrate my learning through 'doing the work' of writing.

My own reflections have been placed around the stories. I resisted following the lead of Richardson (2007) and Ellis (2004, 2009), who write their academic insights into the stories themselves, as if they arose in the moment as an internal monologue. For my project this feels disingenuous, as the understandings I record here are those I hold at the time of writing, after months of listening to recordings, transcribing, coding, reading and writing. I could have included writing stories throughout the thesis to show this-academic autoethnography depicting my embodied self, labouring in my little office-yet I could not find the inspiration to write these stories, so I have limited this to the brief story about writing at the beginning of this chapter. Instead, I allow myself to be seen, flawed and vulnerable, as a participant in the Black Rainbow meetings. I have resisted the temptation to 
rewrite or remove things I said that I now find embarrassing and have instead highlighted these and reflected on them from my current, changing perspective.

\section{How I would like the thesis to be read}

Bearing in mind the way I have written this thesis, I would like the reader to notice the separation of the three strands-the participants' stories, the academic literature, and my own analysis-as running alongside each other, agreeing and disagreeing, but none having the final say on the matter. The stories I tell point to a much broader range of issues than I spell out in my argument and it is left up to you to make sense of this richness. By writing stories about selected discussions, I am hoping you (the reader) will have the chance to 'fill them to taste', to borrow MinhHa's phrase (1989: 2).

One of my concerns is that by presenting the meaning we made together, I am holding the understandings of my participants up to academic scrutiny. ${ }^{2}$ I hope that by including my own embarrassing statements, I can highlight the difference between the way we talk about things in conversations with friends (which are not as precise or fully worked through as we might like them to be) and the luxury of carefully choosing our words as we compose academic literature. As I wrote the first story in chapter 3, it dawned on me that my own 'where I come from' story would act as my main statement of positionality for this thesis. If I had authored something especially for that purpose, I would have liked it to be a bit bettermore concise and clear, more respectful. The fact that I feel uncomfortable with what I said made me think more deeply about how other participants may feel about their statements. This reminded me that our words are not a direct line to hearts or minds. Colleen Larson makes a similar point about her experience as a participant in a personal narrative project: 'By sitting on the other side of the microphone, I was able to see all that the researcher does not see. I saw the rest of

\footnotetext{
${ }^{2}$ This was pointed out to me by Jamie Burford.
} 
the story. The iceberg, not the tip' (1997: 468). Or, drawing on Minh-Ha's image, these spoken stories represent 'sketched windows' to personal worlds, within the larger 'sketched window of the world' that is this thesis. Even though I hope this is apparent in the stories, the written word has a power and finality about it, which seems to lock peoples' ideas down to what they expressed in a particular moment in time. Given the fluidity of meaning making in everyday life, I would ask you (the reader) to read the words of the participants generously and with full acknowledgement of this.

Coming back to Francis' criticisms and my concern for participants' feelings about how they are represented, Larson (1997) argues that 'story-givers' must be given a great deal of time to reflect on, edit, add to and make sense of the stories they have shared, within an 'ongoing conversation about life experience' with the researcher (ibid: 467). This longitudinal approach helped me to see this thesis as part of a longer timeframe of work with Black Rainbow, a step towards articulating some of the issues raised, rather than the 'final word' on these topics, from any of us. This is how I would like it to be read. 


\title{
Chapter 3
}

\section{Black Rainbow}

\author{
August to October
}

\section{Identity}

Addressing how Māori and Pākehā work together inevitability brings up issues of identity. In this chapter I tell the story of Black Rainbow's first three meetings through three major bodies of conversation from those meetings, selected to explore identity issues. These stories highlight the complexity of identity for both Māori and Pākehā living within colonisation. Through telling each other 'Where we come from' stories, members of Black Rainbow show some of the processes of identity formation and negotiation, within various relationships and structural realities. A major aim of this chapter is to allow the members of Black Rainbow to 'introduce themselves' and let you (the reader) see the meaning they make of their own identities. These background stories lay the foundations for the other stories I tell and offer a sense of the personalities you will become more familiar with over the course of the thesis. The experiences and analysis of members of Black Rainbow also offer an important contribution to literature on Māori and Pākehā identity. Following the critical, difference-centred approach of anti-oppressive theory, we can see how identity is particular to individuals in these stories, depending of life histories and personalities; however, we can also see the places where these stories overlap. These personal stories are followed by a discussion showing how issues of identity play out in the anarchist 'scene', where Pākehā usurp Māori roles and are able to dismiss Māori concerns, by prioritising relationships with 'real Māori', over those in their own community. 


\section{Insider's Epistemic Privilege}

Another aim of this chapter is to show my growing awareness of how these life histories lay the foundations for what Uma Narayan (1988) calls 'insiders' epistemic privilege' for the Māori participants, and a lack of that understanding in Pākehā (as 'outsiders' to colonial oppression). Narayan's article, 'Working together across difference: Some considerations on emotions and political practice', argues that 'members of an oppressed group have a more immediate, subtle and critical knowledge about the nature of their oppression than people who are non-members of the oppressed group' (1988: 35). This epistemic privilege is gained through 'knowledge of everyday life under oppression-all the details of the ways in which their oppression is experienced, seen to be inflicted, and of the ways in which oppression affects the major and minor details of their social and psychic lives' (ibid: 36). The stories in this chapter tell of 'everyday life under oppression' and show how Māori members of Black Rainbow have a heightened understanding of racism and the effects of colonisation, while Pākehā tend to find subtle forms of racism and white dominance more difficult to 'see'. This difference between 'insider' and 'outsider' knowledge can also be seen in the use of humour-with 'who is laughing' as an indicator of who 'gets it'. Following Narayan's suggestions that 'problems of communicating across difference will be easier to handle if both insiders and outsiders take the idea of epistemic privilege of the oppressed seriously' (ibid: 46), I have told extended stories of the Black Rainbow discussions in this thesis, demonstrating Māori epistemic privilege, in the hope that it will be taken seriously.

While it is my intention to honour this insiders' epistemic privilege and prioritise the meaning made by the group themselves, the selection of the stories I tell and the supporting literature I draw on is also based on my own interpretations. The stories told here contain a much richer and broader insight into identity than the few points I am highlighting. This has been left for you (the reader) to see for yourself. I 
will briefly outline the key points I wish to make here, to connect the various threads of this chapter.

In the 'Where we come from' stories, I was struck by expressions of struggle with 'insecure' identities among Māori members of Black Rainbow. Members explained this as the result of either being 'raised Pākehā' or having experienced Māori culture as defined by social inequality (poverty, substance abuse, violence and prison). Finding themselves lacking in terms of positive Māori identity markers, they shared ideas about what it means to have a fully grounded Māori identity, including growing up in one's ancestral homeland with Māori parents who spoke the Māori language at home, encouraged Māori cultural competency and were active in the surrounding Māori community. Members of the group show an understanding that a lack of access to this 'traditional' Māori identity is one of the effects of colonisation. I believe that living with complex identities, while holding a full awareness of the preferred 'traditional' Māori identity, has not only created a lifetime of identity negotiation and development for the Māori members of Black Rainbow, but has also given them the insiders' epistemic privilege to recognise incidents where their Māori identity is subtly undermined.

By contrast, in the 'where we come from' stories, the Pākehā members of Black Rainbow (including myself) both expressed a difficulty with recognising our cultural specificity and conferred dominance we had while growing up, which can be seen as the life history origins of our lack of epistemic privilege, as outsiders to oppression. Narayan shows how a lack of sensitivity among 'outsiders to oppression' means they often casually hurt insiders by not only offending them, but also dismissing their expressions of offense. I see this outsiders' lack of sensitivity as the source of the casual undermining of Māori identity that Black Rainbow talk about in the final story of this chapter. Pākehā identity tends to be defined by what it is not, namely, Māori. This settler identity project creates a 'repressive authenticity' that Māori individuals are expected to live up to if they are to be 
recognised as 'real Māori'. The image of 'authentic' identity includes similar 'traditional' Māori identity markers named by members of Black Rainbow, but with the added expectation that 'real Māori' will be completely 'Other'. This leads to a failure by many Pākehā to acknowledge difference in people who hold identities that also have elements of 'sameness'.

Narayan shows that working across difference represents a threat to insiders' identity generally:

What all these failures I will list have in common is the inability of the outsider to fully understand and respect the emotional responses of the insider. In some cases, the response of the outsider violates the insider's sense of self-identity, self-worth or self-respect. In other cases, the response of the outsider violates the insider's sense of identity and solidarity with and respect for her group (ibid: 41).

I suggest that 'repressive authenticity' adds to this threat. Undermining members' Māori identity effectively denies their belonging as insiders to their own oppression. This negates their insiders' epistemic privilege and can be seen leading to problems in communication across difference. Moreover, I came to see nonMāori dismissals of Māori in the anarchist scene, in favour of 'real Māori' elsewhere, as aggravating hurt and frustration over identity that Māori members have had to negotiate throughout their lives. I have selected the stories in this chapter to both demonstrate the insiders' epistemic privilege of Māori members of Black Rainbow and to show the emotional cost of having that insider status denied. 


\section{'Where we come from'}

$22^{\text {nd }}$ of August 2010

'So shall we move onto the round?' I ask hesitantly, uncomfortable in my role as researcher/instigator. Gathered in my small lounge on a dreary winter's day is the newly formed Black Rainbow collective, minus Mara, who has an injured foot. We've eaten and had a few fairly stilted conversations about research methods and group process so it seems time to move on to the main focus of the meeting. While others are nodding and quietly agreeing, no one appears about to speak.

'Who's gonna start?' I whisper and get a few giggles.

'What's the discussion question?' Francis asks, 'I kind of vaguely know and it keeps changing in my head.'

'Where we're coming from,' says Amiria. ${ }^{1}$

'What does that mean?' Francis asks and sets everyone laughing.

'Like what level are we talking?' Hayley says.

'Yeah, I think Kura explained it really well last time,' I say, reiterating that this was her suggestion. 'Can you remember what you said?' Kura shrinks a bit and others laugh sympathetically as she's put on the spot.

'Not particularly,' she says in a small voice.

'Yeah, I wish I'd written it down, sorry.' I say, feeling like I should be more responsible as I watch Kura struggle.

'Maybe it was like pyshically where we come from,' Kura says. 'What has lead to a group like this, I guess. Or in my mind where I was coming from is kind of like a mihi. ${ }^{2}$ Or maybe I was thinking experiences with cultural identity and stuff like that.' The room hums with recognition. 'It's open to interpretation.'

\footnotetext{
${ }^{1}$ This is a pseudonym.

${ }^{2}$ Speech of greeting, often involving a formulaic naming of one's place of origin and tribal affiliations.
} 
'I think that gives us lots of things - to decide what we want to engage with,' Francis says.

'Yeah, totally,' I agree. Then after a silence, 'I really want it to not be me that starts.' 'If only we had some straws to draw,' Francis jokes, but after another moment she says, 'Ah, I can start.'

'Yay you,' Hayley says.

'Having said that, I'm not really sure where I want to start,' Francis says. 'So, I'm adopted and my family's Pākehā. I've possibly told each of you this individually but, on my social worker's report about my birth mother it has all this stuff about how she's got dark hair and tans really well, but is European. And my father's got dark hair and dark skin but is completely European. And it's like, yeah.' Francis' wry tone makes everyone laugh. 'So reading it felt like a story that people had made up to explain away any darkness that might come out in me later. And they, the state, guaranteed to my parents that I was Päkehā. And I don't think they would have adopted me if they'd known my father's Māori. Yeah, and I grew up kind of with this question about my ethnicity, that I turned into a joke, because people were always asking me. I had all these different answers for it.

'I grew up mostly in Whangarei. Which when I was growing up was a really racist, poor town. My family didn't really like me having Māori friends and some of my Pākehā friends, I don't think their parents particularly liked that I might be a bit brown. And I definitely wasn't Māori enough to hang out in the Māori groups and it was a really weird space. When I went to university at some point I had dreads. With dreads everyone just assumed I was Māori. Before there had been speculation, whereas now it was like: "she's definitely Māori".' Everyone laughs. 'And it became really difficult to negotiate. The Māori student network and the Māori staff network were both like: "You should be involved". And having to go through this explanation about not knowing what my ethnicity is and: "Well that's ok, a lot of 
people don't know what their iwi is". And yeah.' Francis smirks and everyone laughs. '-"I actually don't know what my ethnicity is!" And being really drawn to that but not knowing for certain. And having my parents reassure me like: "No no no, you're obviously not Māori, lots of people have your colouring," like my mum has really similar colouring to me.

'Then when I was about thirty-two I finally tracked down my father. He's from Ngāi Tahu. Which is an iwi I know absolutely nothing about. Or knew nothing about. I found it really hard. I'd sort of been engaging with questions about tino rangatiratanga and how I could be involved with education work around that stuff as a Pākehā. And trying to work out in my head where I could fit in. And then trying to rethink all of that. Like, ok, well now I don't even know what I consider my identity to be. I felt as a Pākehā I sort of had the luxury of not having to completely engage with the questions of what tino rangatiratanga is, because it wasn't mine to define. I didn't really have to have an answer to any of those questions. Then, ok now, should I have an opinion on stuff? I don't know. And not knowing anything at all about my iwi. And not knowing, I don't know-whether that stuff's important. Whether it is even important enough to me to look at. And, why do I feel like it is?

'So now a few years on, I still feel really torn about my identity. I identify as Māori and I also identify as Pākehā, and I think that's probably where I'm going to end up. Kind of identifying as both. I've gotten into arguments with people about whether I can have that identity-a dual identity. Which seems straightforward to me, but... I feel unsure about my identity as Māori, given that I spent thirty-three years not identifying as Māori. ${ }^{3}$

\footnotetext{
${ }^{3}$ In her thesis Manu is my Homegirl: Navigating the Ethnic Identity of the Māori Adoptee, Emma West makes a similar observation, arguing that Māori adoptees face complex identity negotiations as they are 'faced with making decisions between two identifiably different social groups, in an era where the distinctions between being
} 
'I had this really cool talk with this woman, who was saying that both of her parents are Māori, both of them grew up in their papa kāinga ${ }^{4}$, for both of them, te reo ${ }^{5}$ is their first language. But they raised their kids totally in te ao Pākehā. And encouraged them to follow that path. And so she's really uncertain and insecure in her identity as a Māori. ${ }^{6}$ But at the same time she's really accepting of that insecurity. Like: "I'm going to feel comfortable feeling insecure about it". Which I want to be able to get my head around better. Talking to someone who, I feel, has so many more anchoring points, who still feels really insecure in her identity as a Māori woman, just made me think, how many people feel-? Yeah. That's all I'm going to say.'

Māori and Pākehā has [sic] become prevalent' (2012: 64). Within this politically charged environment, West argues that contradictory subtypes of Māori identity, such as those expressed by Māori adoptees, are often seen as 'irrelevant' to contemporary Māori identity politics. Similarly, Avril Bell notes that 'doubled or hyphenated' Māori-Pākehā identities are uncommon in Aotearoa New Zealand, as this hybridity is seen to carry the threat of assimilation (2004: 78). Paul Meredith, however, asserts a Māori-and-Pākehā identity by using a postcolonal reclaiming of 'hybridity' in the 'third space' to challenge essentialism (1999).

${ }^{4}$ Original home, often in the sense of tribal homeland.

${ }^{5}$ The Māori language.

${ }^{6}$ Belinda Borell writes:

'Establishing a 'secure' Māori identity based solely on particular criteria of Māori culture (i.e. te reo Māori, tikanga, knowledge of marae and whakapapa [genealogy]) continues to be problematic for some Māori. Those who are not connected in this way are often defined by what they are seen as lacking; hence terms such as disconnected, distanced, detached and dissociated' (2005: 190).

In her article 'Defining Māori', Kim McBreen connects this uncertainty about her identity to internalised notions of the fixed and knowable Māori as the 'Other' invented by colonial Orientalism (2011a. See Said 2003). 
'Awesome, thank you,' I say a little weakly. Do I sound too much like a cold 'researcher'? I knew that Francis was adopted by Pākehā parents, but I am feeling the full weight of that for the first time.

'Thanks,' says Kura.

After a moment of recovery, I tentatively ask, 'Do you wanna-' and Te Awanui completes my thought, 'Are we going around?'

We are both looking at Hayley, who is sitting to the right of Francis.

'Mh... I don't feel ready to speak,' Hayley says. 'I don't know what I have to say, so I can either be rambly or pass and come back.' Everyone laughs. 'Does anyone feel ready to talk or know what they wanna talk about?'

'I'll give it a go,' Amiria offers. 'I grew up in Gisborne, which is quite, well, "bicultural", but it's got two main cultures there, it pretty much 50/50 Pākehā/Māori. But I was raised quite Pākehā. I was above average at school and stuff, so got by on that for a while. Then, it's weird because even though I don't have that much connection to being Māori or whatever, you're always gonna be seen as Māori, just because of how I look and stuff. So, even though I know about Pākehā culture and have been raised through it, I'm always going to be Māori. I'm still very confused about my identity, I guess.

'It's only been recently, in the last few years, that I've started really trying to discover my Māoriness, I guess. I mean I've always had contact with my grandparents, we'd talk about the old days and stuff. But they were of the generation that got hit for speaking Māori. So, my grandpop hasn't spoken Māori until-'Amiria interrupts herself to exclaim with delight, "I heard him speak Māori actually last weekend. They seem to be reconnecting with that a lot more, with a lot of their mokopuna ${ }^{7}$ going through Māori schools and kōhanga. ${ }^{8}$

\footnotetext{
${ }^{7}$ Grandchildren.

${ }^{8}$ Māori language immersion preschool centres.
} 
'So yeah, still kind of struggling with my identity. But I'm very proud to be Māori. It feels like I'm working in quite a Pākehā way to find out my Māoriness. Like going to school, learning te reo through Pākehā academic means. Because they're the most available and easier means to get to, rather than sourcing it through my whānau, who l'd say a lot of them don't really have that sort of knowledge anymore. So yeah, doing the radio show with Mara. It's another grasping at culture, and us together trying to work through it. But also that's kind of on a Pākehā level as well. I'm still very much floundering with that. I think that's all I've got to say for now. There'll probably be another rant another time.'

As everyone laughs, I tease 'No, this is your last chance.

'That's it!' says Amiria.

'I don't feel like-' Te Awanui begins as we look to them for their turn in the round. ${ }^{9}$ 'I feel really really emotional when I try and talk about this stuff.' They laugh and say, 'I don't feel like I can deal with it. So I'm just gonna not say anything right now.'

'That's cool,' I say.

'Sorry,' Te Awanui says softly.

'It's ok,' Hayley whispers back.

So Kura continues the round, the strain of speaking to the group audible in her voice, 'My dad's Māori, but I was raised by my mum who's Pākehāa. And she's quite condesending about anything to do with me and my brother being Māori. I guess because she associates that with my dad and he was a real arsehole to her when they broke up. I guess I didn't really know I was Māori until I started having contact with my dad, which would have been when I was about seven and I start going and

\footnotetext{
${ }^{9}$ Te Awanui is a trans-masculine person, assigned female at birth, who prefers the gender neutral pronouns 'they' and 'their' (instead of she/he and hers/his).
} 
staying with him. He had a son a few weeks before I was born with another woman and she's Ngāti Raukawa-and he's Ngāti Raukawa too-and she's been raised Māori and is really involved in that community. So when I'd go and stay with my dad it was like full immersion, they spoke te reo at home. And they wouldn't really speak English so I could understand, which was quite weird. So for a really long time my association with being Māori was feeling really left out and weird about it because we weren't really allowed to spend much time with my dad and I was just really, kind of jealous that my other siblings were very fluent and really into their culture and really immersed in it. ${ }^{10}$

I've always kind of associated being Māori with my dad as well and he's been quite... we've had a real turbulent and weird relationship. And sometimes I think he uses the Māori values and whānau and all this stuff to be kind of manipulative. I was into being Māori when I was younger but as I got older and started noticing his shit, I would just associate me being Māori with me being related to my dad, who was a real dickhead most of the time. I guess when I'd get interested in that kind of stuff, it would make him really happy and he'd be like: "Yeah, you are Māori. And you can be part of this... my family". And I still have problems with that kind of stuff because I do feel like I'm satisfying him by being Māori. Or being interested in that.

${ }^{10}$ In her article 'Māori identities: Fixed, fluid, forced', Tracey McIntosh categorises this as 'traditional Māori' identity: 'a contemporary identity that is articulated by Māori and can be characterised as presenting particular identity hooks as markers of identity. Whakapapa, mātauranga Māori [Māori knowledge], proficiency in te reo and tikanga are all seen as important' (2005: 43). This is an identity based on a particular type of cultural competence, which 'comes with a set of expectations that someone will not only "be" Māori, as indicated by knowledge of one's whakapapa lines, but will also "know” what being Māori is and will "act” Māori' (ibid: 44). McIntosh argues the activists and academics that hold and promote this identity offer inclusion in Māori revitalisation, yet can also 'exclude some Māori by having relatively unyielding criteria in place to prove one's "Māoriness"” (ibid: 45). 
But I guess lately our relationship's gotten heaps better. I've been really interested in trying to learn stuff from him without pandering to his desire for me to be Māori. But it just feels way safer now. Yeah, so my relationship to being Māori has always been so connected with him and what our relationship is like at any point. And I guess that's all I'm going to say at the moment.'

As it comes to my turn to speak, I ask if we can take a quick break while I go to the bathroom. While I am gone, the audio recorder continues to listen. ${ }^{11}$ After a moment of silence, Te Awanui says, 'It's kind of funny, how it feels awkward. You know, if I was having individual discussions with any one of you I think I could real easily talk about stuff. But for some reason it feels sort of awkward sitting in this group.' Everyone laughs as Te Awanui makes a little 'Arh!' sound, mocking their own sense of alarm.

'It's hard to condense down something so complex,' says Hayley.

'That's so true,' says Kura.

'Yeah and I guess it is harder to say something really personal to a group of people,' says Te Awanui.

'Instead of one on one,' says Amiria.

'It feels weird as a round as well,' Francis adds. 'If it was one on one we would be having conversation, not: "Here's my story".' Everyone laughs.

'Yeah it feels like when you're having a round, I don't want to interrupt when someone's speaking. Like: "Aw, Really?!"' Te Awanui laughs. After a moment of quiet they yawn and say, 'Maybe we could have our next meeting in the sun, with beer.'

I return from the bathroom to a conversation over whether the beach will be sunny in winter.

\footnotetext{
${ }^{11}$ Participants know that the recorder was on during this time and have approved this story.
} 
'What's this,' I ask, 'we're having our next meeting at the beach? Sweet.'

Not realising that there has also been talk about concern with the format of this discussion, I charge on with my story. 'I guess I feel uncertain like everyone does. I'm Pākehā. I grew up mostly in Taranaki, but partly in Auckland. Then I went to Dunedin for university, which is almost entirely white. While I was in Auckland I went to a school where I think there was usually about five white kids in my class. So I guess that was my first understanding of cultural and racial difference. It was quite a cultural sort of school as well; we had lots of culture days and food sharing. So the whole Māori issue when it first came up for me was like: "Aw, stink, I'm not Māori"' I'm nervous and trying to make people laugh; they do a little.

'This is probably just a little stupid story, but I remember being at the pools on an outing and all these Māori kids-who were all the cool tough kids-had declared that this little island in the middle of the pool was for Māori only. And one of my best friends - who was quite fair but had a Māori mother-was up there and I was like: "But my friend's there" and they were like: "Well she's Māori".' This gets a real laugh and I say, 'The only reason I'm telling this story is not because I have a grudge against Māori, but because it's when I first started thinking about that stuff. ${ }^{12}$

\footnotetext{
${ }^{12}$ My story here reflects Ruth Frankenberg's observations in 'Growing up white: Feminism, racism and the social geography of childhood' (1993), where the women she interviewed tended to talk more about their encounters with 'other' cultures and, by doing so, demonstrate childhoods marked by an absence of clear notions of their own cultural identity. While I felt self-consciously 'white' at this school, I also subscribed to the often heard Pākehā complaint: 'We don't have a culture'. This complaint is often in direct response to Māori grievances and is based on an assumption that Māori have access to cultural belonging and richness that Pākehā do not. Similarly, Avril Bell (2004) notes that Pākehā culture is often defined by a 'lack' (compared to Māori, who are seen as having a primitive 'essence').
} 
Next I speak about Hayden ${ }^{13}$, a Māori man I was in a relationship with from when I was sixteen until I was twenty-two years old. I share too much about his private struggle, his complicated family situation and his rejection of Māori culture and I later feel uncomfortable about this. ${ }^{14}$ Perhaps I am trying to show the group that I had some personal experience with the difficulties of urban Māori identities. Finally I get to my main point, 'We had quite a lot to do with his older sisters, because he was really into kids and we'd do a lot of babysitting and stuff, so I guess that was my main contact with Māori culture throughout my early years. But I don't think I

\section{really examined what it means to be Pākehā. ${ }^{15}$}

'Then, I went to university and my whole thing was to study different cultures. I thought that New Zealand was boring and that Pākehā culture was dumb and I wanted to live anywhere else and learn from other perspectives. I studied Hinduism mostly. And I was involved in some anarchist organising. Then I came here and was involved in the October 15th group. I thought that the way things were being handled in that group was really weird. I started talking to Hayley and Francis and Mara about it (mostly) at that time. I was feeling really angry at the way things

\footnotetext{
${ }^{13}$ Hayden preferred that I use his real name.

${ }^{14}$ As the author I have the opportunity to edit my story in a way that others in the group do not. However to balance this, I also offered the other participants the option of cutting out or editing any of their material when they were given this story to check.

${ }^{15}$ Pākehā identity is often marked by its invisibility, at least to the people holding that identity. In 'The silent centre: Where are Pākehā in biculturalism?' Malcolm MacLean notes: 'Pākehā have already identified our boundaries, we know what we are not: we are not Māori. But how many Pākehā can clearly identify what we are?' (1996: 110). Tim McCreanor's article “"Stick and stones may break my bones...”: Talking Pākehā identities' (2005) illustrates this by focusing on the 'standard story' Pākehā use to talk about Māori, rather than what they say about being Pākehā. Here Pākehā is 'the invisible marker that depends on the racial other for its own identity' (Leonardo 2004: 137).
} 
were being done but also comepletely didn't know how they should be done instead. And that's what made me go: "Jesus! I really know nothing about how Pākehā should be relating to issues around Māori".

'Because I'd always felt shy of issues to do with Māori. I think if I'd realised Operation 8 was such a Māori issue I maybe wouldn't have got involved! But it was just because I knew some of the arrestees and I thought these seem like really nice people and they might be going to jail, so I better help out. When the Foreshore and Seabed Bill happened some friends of mine were going up to the hīkoi ${ }^{16}-$ I was living in Dunedin. I was actually really pissed off at them because I thought here were these white middle class people who, as far as I know, had never done anything around Māori issues-I think some of them had learnt a little te reo-but it just felt like jumping on a bandwagon. Their heart was in the right place but, I just felt really like: "Ew, this is some kind of political voyeurism".' I know that I'm not doing a very good job of explaining my past discomfort, so I throw in a weak 'I don't know. I just felt too dumb. Too self-conscious to get involved in anything to do with Māori.' I address Francis, 'Kind of what you were saying about not defining tino rangatiratanga or whatever as Pākehā,' but her confused look makes me realise I haven't thought this through and I trail off with an uncertain 'and la la la?' 'But then during that October 15th stuff, and realising my own ignorance, I sort of woke up and went: "Māori issues are Pākehā issues". I mean, there's different sides of it, but: "I am colonisation". I'm the living, breathing continuation of settler culture and as long as I don't engage with this stuff, and know nothing really in depth about Māori ways of being, then, I'm just, yeah... A lot of people go: "Oh, I try not to get into that guilt thing about what happened in the past". But I'm not talking about the past. I feel really uncertain about my identity. Not because I don't feel in touch with it-because I think it's all I've ever lived-but just because I don't know how to live it in a way that I think is actually ok.' I laugh weakly, Francis looks at me with recognition and I give a little shrug.

\footnotetext{
${ }^{16}$ March.
} 
I catch Hayley's eye and ask, 'Do you wanna?'

'I grew up on the Kapiti coast and in Palmerston North,' Hayley says, 'with my sister and my parents. Both my parents are Pākehā and, I think, three of my four grandparents were born here and their families migrated from Great Britian. It was never something that was talked about very much-where my grandparents came from or where they settled. That wasn't something that got talked about. And I think my mum-who was the one I talk to about it-never knew very much either. It was like your culture isn't constantly challenged so you don't need to think about it too much. ${ }^{17}$

So I grew up in an environment where things just were what they were and it wasn't cultural, it was just what it is. And I think it was quite late before I started to see things in a cultural framework. And realised that as I grew up I actually got heaps of strong messages about culture. And heaps of racist messages, that I didn't really understand. I remember talking a lot at high school with my best friend and we would argue and were both sort of mouth pieces for our parents. My parents were very much coming from the position of working-class, pulling-themselves-up-by-theboot-straps and succeeding through owning their own business-meritocracy. Her parents were real Green-voting, liberal, middle-class, educated. So I think I learnt

\footnotetext{
${ }^{17}$ Joan Metge notes this common experience for Pākehā in her book Tuamaka: The Challenge of Difference in Aotearoa New Zealand:
}

Those of us who are Pākehā often miss the important dimensions of ancestry and culture, partly because we are members of the majority, so surrounded by people like ourselves that we are not conscious of having a culture of our own; and partly because the culture that influences us more powerfully than we recognise stresses individual achievement and places little value on the study of the past (2010: 2). 
heaps through arguing: "Let's not have race based scholarships, because everyone's equal now".' Hayley laughs at herself, 'That sort of thing., ${ }^{18}$

'So yeah, that's the environment and the values I grew up with. And then it was in my teens that I sort of started waking up and I moved to France, got politicised in a hurry and went to the $G 8^{19}$ - before I really knew what the G8 was. I think that put me onto a new path when I came back. I think what lead me from that upbringing to being here was just starting to come to understand that once you're out from under your parents' thumb there are actually other opinions about the way the world works that are really interesting and valid and that you can learn from.

'Starting to learn te reo-about three or four years ago now-being in that environment was when I really started looking at the complexities of what it meant for me to be a Pākehā on colonised land. And to be a Pākehā taking up space in a class. And really getting confused about those things and trying to find a place that

\footnotetext{
${ }^{18}$ This reference to scholarships points to an element of what McCreanor calls the 'standard story' Pākehā tell about Māori: 'Māori privilege'. Not to be confused with Narayan's notions of 'insiders' epistemic privilege', this is the myth that:

Māori have unfair and privileged access to rights and resources unavailable to the rest of society. The Māori Affairs Department, the Waitangi Tribunal, the seats in Parliament, cheap housing loans, their own rugby team, educational supports and quotas, and fishing rights all add up to special treatment which is racist and akin to apartheid (McCreanor 2005: 57).
}

As Hayley also notes, this idea of 'special privileges' violates another myth: that of equal rights in New Zealand. Naturally, this discourse obscures the existence of Pākehā structural dominance. Cultural boundary setting through talk about Māori, combined with the insistence that 'we are all equal now' works to make Pākehā identity normal and neutral—invisible.

\footnotetext{
${ }^{19}$ The G8 refers here to the annual summit meeting of The Group of Eight, heads of government of the eight largest national economies, which attracts large-scale protest.
} 
had some integrity. And that wasn't about essentialising difference, but was about aknowledging that it doesn't matter who I am, I'm still white and I still have white privilege. ${ }^{20}$ And you can't overcome that. You just have to own it,' she laughs. 'And try and understand it. That's pretty much me for now.'

After a period of silence, I ask, 'Do you feel like saying anything Te Awanui? Or do you wanna just leave it at that?'

'Um...' they laugh nervously, 'I can tell yous where I come from. I was born in South Auckland, in Mirimiri, in a house bus and my parents travelled round lots. And I've got two older half sisters and two older full sisters and two younger sisters and a little brother. And I don't know any of my extended family. Because both my parents disowned their families. Or were disowned by their families. And, yep, we travelled around lots and then I grew up mostly on the west coast of the South Island. In an old mining town where no one else lived, except two other houses.

'And when I was maybe five or six, we had neo-Nazis move in across the road from us. I guess that was the first time that I ever thought about being Māori,' they laugh. 'Before that, my parents were druggies and alcoholics and lots

${ }^{20}$ In 'White privilege: Unpacking the invisible knapsack' (1990), Peggy McIntosh attempts to break down the invisibility of whiteness by naming all the privileges she can think of that she has because she is white, such as number 10: 'I can be pretty sure of having my voice heard in a group in which I am the only member of my race’. Like Metge and McCreanor, McIntosh argues that white people are taught to see themselves as individuals, rather than products of a specific culture. This individualism and invisibility of cultural identity also relates to white insensitivity about racism, McIntosh writes: 'I did not see myself as a racist because I was taught to recognize racism only in individual acts of meanness by members of my group, never in invisible systems conferring unsought racial dominance on my group from birth’ (1990: para.18). 
of their friends were in the Mongrel Mob, ${ }^{21}$ and I think that's part of the reason we left the city. Because I don't think they thought it was a good idea to have six daughters in the Mongrel Mob,' Te Awanui laughs. 'And so, there was always lots of Māori people around. But when I was a kid everyone just partied lots and it was pretty crazy. But then we lived across the road from skinheads. When they moved in they were really nice. They were like: "No, we're running away from our old gang".' '"We're nice skinheads",' Francis throws in.

'Yeah! Yeah, yeah: "We're nice skinheads!"' Te Awanui laughs and everyone joins them.

'And then at some point they built about a four metre high fence all round their house and put up the swastika flag,' Te Awanui's words still ring with humour. 'Gosh' Hayley says, as I say 'Oh Jesus.'

'And started blowing stuff up and pointed a big spotlight-from the mines-on our house and that kind of thing.'

'Wow' I say, as Hayley says 'Shit'.

'"But it's just light so there's nothing wrong with it, you can't do anything about it",' Te Awanui quotes their tormentors, laughing and excited, "It's just light!"' I am not laughing. I'm looking at Te Awanui with concern and when our eyes meet I can feel what different places we are in. I see it register in their eyes, the rapport broken. Te Awanui continues in a more serious tone, 'And so they harrased us a lot when I was a kid. But I guess when I was younger-I think they stopped harrasing us so much after a couple of years'.

\footnotetext{
${ }^{21}$ The Mongrel Mob is an organised street gang in New Zealand, with a predominantly Māori membership. See Pip Desmond's Trust: A True Story of Women and Gangs (2009) for an intimate account of street gang culture in Wellington in the 1970s.
} 
'But where I grew up there were the Huntleys, the MacIntires and us and one other Māori family. There were like four of us so we were all kind of cuzzies. ${ }^{22}$ But we weren't actually related. Except we were related to the Huntleys, but I didn't know that until it was too late. Nah!' Te Awanui breaks into laughter and takes the whole room with them, then adds, 'There were no babies so it's alright' to more laughing. 'But yeah, it was a really racist town. And being Māori meant being from a ridiculously big family and half your uncles are in jail. I guess my ideas around being Māori weren't very positive. ${ }^{23}$ They were just that we weren't normal. I mean, normal people were like Pākehā people. And Māori people were with lots of dogs and kids and stuff like that. Yeah, so the ideas about Māori culture that I grew up with were totally like the mainstream sterotypical ideas about what it is to be Māori. And I remember when 'Once Were Warriors" ${ }^{24}$ came out being like: "Oh! Yeah, that is Māori culture!'” Te Awanui laughs, 'that's what I'm used to.'

'Then when I was fifteen I moved to Nelson and all my friends were white-I had lots of Asian friends-and I just didn't ever think about my own culture. Ever. For ages. And then when I was nineteen and I got pregnant, I was like: "Hah! Ok! I want my daughter to grow up-' Te Awanui interrupts themself to laugh at the irony of this and I think about their son, Tim. ${ }^{25}$ "II want my daughter to grown up with her culture". And I started to want to find out about stuff. Yeah... but it's quite scary. And I guess what you were saying, it's quite hard. It's quite hard for me to go through my whānau and find out stuff and... I guess I feel a little bit lost. The end.'

\footnotetext{
${ }^{22}$ Cousins.

${ }^{23}$ Tracey McIntosh writes that: 'For too many people, unemployment, illness, psychiatric conditions, poverty and prison life are marks of being Māori' (2005: 49). McIntosh labels these as 'forced identities', negative constructions, characterised by marginality (from both mainstream and Māori society), which stem from social inequality that creates negative perceptions that may become internalised and normalised.

${ }^{24}$ See Tamahori (1994).

${ }^{25}$ This is a pseudonym.
} 
'Thanks Te Awanui,' Hayley says.

'Wait,' Te Awanui adds after a moment, 'that story finishes six years ago! Maybe I'll tell yous the rest another day.' We laugh and then fall into a heavy silence.

'It's kind of interesting that we're all-l'm trying to think of a word that's not "fucked up",' Francis laughs, 'but we've all got stuff about identity as a result of growing up in this country. Whether we're Pākehā or Māori. You know, colonisation kind of fucks everyone up.'

We all respond with agreement.

'Unless you're "just from the earth",' Te Awanui jokes and we laugh.

'You mean a "gypsy"?' I ask cheerfully, remembering the woman Te Awanui is impersonating.

'You're just "part of the universe", Te Awanui adds.

'Ah, bless those people' Francis says, as we continue to laugh.

The conversation continued for another hour or so, as we explored different elements of identity together.

There was a great deal of sadness in the room that day. Francis wondered aloud if someone with so many 'anchoring points' in Māori culture can still feel 'really insecure in her identity as a Māori woman', how many others must feel the same, and this lead to a series of admissions about 'grasping at culture' from various stand points. As we continued around the group, story after story piled up to create an overwhelming sense of the mess colonisation has left us in.

In some ways, this seemed as true for Pākehā identity as it did Māori. This discussion helped me see how both Māori and Pākehā in Black Rainbow shared an experience of Pākehā culture as 'normal' in childhood and struggled with 
developing new cultural competencies in adulthood. I was struck by how competent in Pākehā culture all the Māori members of the group are, and how familiar with me, as Pākehā, that makes them. Yet, while recognising this 'sameness', the lifelong identity negotiations Māori spoke of seem to represent a major point of difference. While Hayley and I both struggle with the 'invisibility' of Pākehā culture, we do not have to 'discover' our culture in the same way that Amiria speaks of developing competency in Māori culture, because that competency was never denied us. While I am confused about what it means to be Pākehā, I felt there was a greater 'heaviness' around identity expressed by Māori in the group. I gained a passionate respect for the complexity of modern Māori identity through these discussions and this drove me to emphasise the insiders' epistemic privilege possessed by the holders of these identities. Likewise, these 'where we come from' stories allowed me to see how protected I had been from identity struggle and how this contributed to my obliviousness as an outsider to colonial oppression.

\section{Humour and insider's epistemic privilege}

This gap in understanding can be seen through the use of humour in Black Rainbow. I experienced the difference between insiders to oppression and outsiders most powerfully as Te Awanui laughed throughout their account of childhood experiences with skinheads. The contrast between their laughter and the obvious shock and pity expressed by Hayley and I, is telling. I found listening to Te Awanui's story upsetting, partly because I was unnerved by their laughter and I did not know how to relate to them around it. That there was a moment when I felt like Te Awanui saw me struggling to connect and switched from this animated story telling to a more 'seemly' display of emotions-one of passive, quiet sharing-was equally troubling, as this reminds me of Narayan's point that outsiders to oppression often make 'inappropriate judgements about what insiders ought to do or feel' (1988: 45). 
Attempting to reconcile this experience lead me to read Michael Jackson's chapter 'From the tragic to the comic' in The Politics of Storytelling: Violence, Transgression, and Intersubjectivity (2002). Jackson observes that: 'we laugh because we are caught between empathy and neutrality ... we are really laughing at something that might happen to ourselves' (2002: 188. Italics in the original). Te Awanui's experience of racist harassment is not something that 'might have happened to me', nor Hayley, and clearly this lack of recognition prevented us from finding Te Awanui's story funny. Our expressions of horror reflected the tragic nature of the story, without being able to empathise with the gleeful nature of Te Awanui's telling. Jackson helped me to understand how humour transforms tragic experience:

The comic is not the opposite of the tragic so much as a strategy for countermandering the tragic with distance and indirection ... traumatic events overwhelm and diminish us, and we withdraw into ourselves, feeling singled out, silenced and powerless in the face of forces we can neither comprehend nor control. Though tragedy is suffered in solitude and silence, comedy opens up the possibility of subverting the original event by replaying it in such dramatically altered and exaggerated form that it is experienced as 'other'. It is often said, of tragedy, that healing takes time. With distance comes release. The comedic is the ultimate expression of this kind of distancing and release, and entails three critical transformations in our experience. First, the comedic restores a sense of agency. Second, it fosters a sense of emotional detachment. Third, it entails shared laughter, and thus returns us to a community of others ... In this sense we are able to review the human condition from a general rather than exclusively personal standpoint (ibid: 182).

Te Awanui said earlier in the discussion that they find it hard to talk about where they come from without weeping; instead, they laughed.

This points to the important liberating role that comedy plays, and it allowed me to see the Black Rainbow story I am telling as a comedy of sorts. In conversations with Te Awanui since then, they have often commented how great it is to be around the few people they can really laugh with about their lower-class childhood, since most of the people in the anarchist and queer scenes are white, middle-class and just get 
shocked when they talk about some of the things they have lived through. Similarly, the members of Black Rainbow came together not only to share our grief over marginalisation of Māori within the anarchist scene, but to laugh about it, and you can see the use of humour throughout our discussions. We moved quickly between serious discussion and joking around. Jokes that pointed towards larger shared understandings were common, and I found myself sometimes 'getting' these jokes and at other times not at all. Who is laughing tells us a lot about who can relate to particular experiences. Not always being in on the joke was part of the decentring Hayley and I experienced in Black Rainbow. Insiders to oppression clearly have in jokes'. Turning towards this use of humour helped me recognise how shared laughter communicates insiders' epistemic privilege, as well as resisting isolation and building solidarity (this discussion of humour is continued in chapter 5).

\section{'To be Māori is to be colonised'}

Throughout our discussions, it was clear that insiders' epistemic privilege around racism was strong within this group. I was humbled by the Māori members' subtle and complex understandings of racism and how the structural results of colonisation relate to personal experiences. In this next story, Mara explains the various ways her Māori identity has been shaped by oppressive conditions over which she has no control, as well as encounters with people's attitudes about what it means to 'be Māori'.

$5^{\text {th }}$ of September 2010

'I would quite like to, if I'm gonna do my little spiel thing,' Mara hesitantly suggests, 'because everyone else has done it, I would quite like to get it over and done with, rather than just have it sit there like-'

'Yeah, totally,' I agree. 'Well, should we leave this stuff for a bit and do that now? Or do you wanna have a break first?' 
'Maybe after,' says Mara.

We are about forty minutes into our second recorded meeting and I feel bad that Mara had to bring this up herself. We have been talking about group process, some of the questions and actions we are most interested in exploring, as well as what we know about groups that have gone before us, like ARC (Anti-Racist Crew) and Takutai Moana Poneke. Once we have all gathered in my lounge again, now with fresh cups of tea, Mara tells us her story.

'Speaking about Christchurch, it's where I'm from; it's where I grew up. And it's quite a strange place. Really, I mean, it's pretty white. Where I grew up it was pretty brown, with quite a few Māori around. A few Samoan and Tongan communities as well. It was also quite low income. On the whole idea of 'when you first knew your ethnicity', I don't think I've ever not known that I was Māori. I grew up with my mum, but if I would hang out with my dad it would be like: "Aw, this is your cousin. And this is your cousin... And this is your cousin".' Mara makes everyone laugh. 'And I'd go to a party and eat pūhā ${ }^{-26}$ and pork bones and there'd be people from Black Power $^{27}$ there. They were all my friends' parents. Lots of my dad's friends were exBlack Power and ex-Mongrel Mob and that sort of stuff. But also, he was always in and out of prison when I was a kid-I think his longest stint was about three yearsand I would be going out to prison, visiting him sometimes. So it was always, always present. But there was always a real negativity around it. For a really long time that's what it meant for me-to be Māori was to be poor, was to be surrounded by drugs and alcohol and, yeah, prison. I remember being at a school camp and someone being like: "What does your dad do?" I said: "Aw, he's in prison". And someone being like: "Oh my god, I can't believe you're dad's in prison!" And I was just like-,' Mara hums "I don't know" and shrugs. Everyone laughs as she further explains her childhood reaction, "Ah, whatever", "What's the drama?" Like: "Why is that so abnormal?" So for a long time I was like: "Well I'm Māori, but I'm not

\footnotetext{
${ }^{26}$ Perennial sowthistle, often cooked in a stew with pork bones.

${ }^{27}$ Black Power is another Māori-majority street gang, the primary rivals of the Mongrel Mob.
} 
that kind of Māori". "I'm not really Māori". But I always knew that I was. So I was always "Pākehā-Māori", "part Māori", never just Māori. It took quite a while for me to purge that from myself.

'There was one incident I remember, I had a bone carving that my dad had made me and I was wearing it at school and there had been some meeting about Māori scholarships or something. My sister had gone and I thought: "It's going to be really boring. I'm not gonna go", so I didn't. And then where I was hanging out at lunch, the head of the Māori department came up to me and looked at my bone carving and said: "You should be ashamed". Because I didn't go to the meeting.'

'What?!' Amiria says.

'So that was a real: "What the fuck?" kind of moment,' Mara continues. 'I told my sister about it and she was really pissed off. But that fed into all those other insecurities as well. Because I grew up in a Pākehā world, I mean with Mum. Even though I am Māori, I think I grew up in a distinctly Pākehā environment, because I didn't grow up with my dad. And there's obviously really good reasons for that. But yeah, that also fed into the not wanting to really be Māori.'

'But then working through some shit-activism really helped that-realising that there are reasons. I do believe that we are largely products of our environment. Of our economic system, of our society and colonialism and all that. And I came to think: "Well, to me, to be Māori is to be colonised". On a daily, hourly, minutely basis. Too many people will ask you: "But are you in denial of your other heritage?"'

'Your Pākehā heritage?' l ask.

'Yeah. It's like: "Well you're assuming I have Pākehā heritage because of the colour of my skin!-but you're right",' Mara laughs and continues. 'It's like: "No, why would I? I know the village that my great great grandfather's from" and then 
they're like: "Oh, ok".' Mara laughs again and asks the group 'You know, you know $?^{28}$

'Yeah, so being involved in activism is really challenging. For ages I didn't deal with the Foreshore and Seabed, I just ignored the whole issue. Because I knew that once I started looking into it, it was going to push forward a whole other set of issues I wasn't quite ready to grapple with. And in some ways it was really difficult to deal with relationships that I had in the past-where I could put those things on the back burner-and relationships I have now. Because the people that I was friends with

${ }^{28}$ Mara's claim to a Māori identity shaped by colonisation suggests the development of what McIntosh describes 'fluid' identity, which 'plays with cultural markers such as language, custom and place and reconfigures them in a way that gives both voice and currency to their social environment' (2005: 46). These are positive Māori identity constructions that vary from the 'traditional' identity mould. The politicised nature of Mara's identity claim also calls to mind McIntosh's point that 'fluid' and 'forced' identities are intimately related to the formation of the 'traditional'. McIntosh writes:

It needs to be noted that the 'traditional' identity today is itself a fusion of classical Māori identity and the politics of the 'radical Māori' of the Māori renaissance. Ethnic identity formation is a 'process rather than a result'... Since the 1960s, and particularly the 1970s, the most common face of Māori presented to the nonMāori audience has been the 'radical' one. For the most part, it was a very specific face: young, urban and angry... radicals were typically criticised as 'false Māori who adopted Pākehā techniques to protest Māori take (causes)' (2005:47).

This history behind the development of the 'traditional Māori' identity shows that it overlaps with 'forced' and 'fluid identity in complex ways and cannot be seen as strictly separate. Further, people may move between these different identities-both in different phases of their lives and in the way that they are identified by other people. 
are a little bit more 'Kiwi' than 'iwi' I guess.' Mara's reference to the Kiwi/iwi dichotomy makes everyone laugh. ${ }^{29}$

'I got into this one argument with a friend once,' Mara explains, 'well I wouldn't call her a friend anymore. It was around the Foreshore and Seabed protest, we were at $U_{n i}{ }^{30}$ and I handed her a flier-I'd been putting fliers around, leaving them on bus stops. I had this instinctual, gut feeling that she didn't want to take it. Then she said that she didn't want it and I was: "Why's that?" kind of going: "Oh no, please don't answer",' everyone laughs along with Mara as she continues, 'she was involved in ecology research and was like: "Oh, I'm so sick of Māori! I had to go into all these ethics approval meetings and-blah blah blah-I'm so sick of Māori going on about 'taonga ${ }^{31}$, taonga, taonga' and then completely killing the environment". I was like: "Actually mostly it's Pākehā that, as a society"-well I didn't say that, but it's not really Māori that put all those things in place that have fucked up the environment. And I said: "I'm Māori and I don't do that". And her response was: "Well, I don't think of you as being Māori." Mara's voice cracks at the end of this phrase and others in the room gasp.

'Oh-no-she-didn't!' Amiria quips, making everyone laugh.

'She did,' Mara replies.

'Holy shit,' Amiria says.

"I just looked at her and burst into tears, and left. I was like: "I hate her so much." And so I'm not friends with her anymore.'

\footnotetext{
${ }^{29}$ This is a reference to the National Party's 2006 election billboards which labelled the Labour-led government 'Iwi' and the National opposition 'Kiwi' (see it here:

http://www.teara.govt.nz/en/national-party/4/3, accessed 13 February 2014). These billboards tapped into a popular discourse surrounding the Foreshore and Seabed Act (2004) that Mãori were attempting to prevent 'regular Kiwis' (New Zealanders) from accessing the nation's beaches, pointing to wider Pākehā anxieties about Māori receiving 'special privileges' (McCreanor 2005).

${ }^{30}$ University.

${ }^{31}$ Treasure, in this case a reference to the value of local natural resources to Māori communities.
} 
'Did she ever talk to you about it afterwards?' I ask. 'Apologise or anything?

Because that's pretty full on, making someone cry, because you say you don't think of them as Māori!'

'Yeah yeah,' Mara says. 'No. I wouldn't, it's not worth-'

'Oh, I'm not saying you should put it right with her,' I say.

'I know, I know,' Mara says.

'I'm just wondering if she ever thought-'

'No, it would only be if I put that forward. But she wouldn't think that she was wrong, that's the thing.'

'I had another incident at university as well,' Mara says, 'where I was in this geography class and we were talking about why some ethnic groups have a shorter life expectancy than others, like Māori for example and I thought: "Oh no. Noooooo!'” Mara elicits a mix of groans and laughter from the group. 'So the lecturer asked for reasons why, and some people said: "Language barriers?" and I thought: "That's not too bad, that's ok". Someone else was like: "Because they eat lots of McDonalds"'.

'Fuck,' says Hayley, as the rest of us gasp or giggle.

'And the lecturer said: "Well that's true". I said: 'Um-Colonisation!"' Mara's sassy tone makes everyone laugh. 'The lecturer said: "What 250 years ago? I'm so sick of people going on about colonisation and blaming this stuff on colonisation".'

'Fuckin' hell!' I say.

'"Why don't people take personal responsibility?"' Mara quotes.

'Woah,' says Hayley.

'This other woman in the class said: "But if you look at the structural...", she was just trying to talk about it on an academic level and he was like: "Nope, nope".' 
Kura and Hayley exclaim 'Wow' and 'Woah'.

'Turns out he was a Republican,' Mara notes and others laugh. After a moment she concludes, 'So that was just really fucked up. And it's quite strange still working in that environment. Well, not really feeling part of the Māori community but still having to, I don't know-'

'Put up with that sort of shit,' Amiria finishes.

'Yeah,' says Mara, 'but it's just a lens into the way people think about colonisation and what it is to be Māori and all that sort of stuff. ${ }^{32}$

'One of my friends was saying to me', Te Awanui says 'that someone asked her: "Why are so many Māori really poor and don't have this-" I don't know, all this shit that's obviously from colonisation and she was like: "Well it's either that extreme colonisation does have an effect on Māori, or they're just an inferior race and can't sort their shit out, or else they just love it!"' We all laugh. "They just love being poor

${ }^{32}$ In their article, “'It's hard at the top but it's a whole lot easier than being at the bottom": The role of privilege in understanding disparities in Aotearoa/New Zealand', Belinda Borell, Amanda Gregory, Tim McCreanor and Victoria Jensen note a rise in victim-blaming:

Popular contemporary explanations of current disparities draw upon an egalitarian ideology of equitable social relations to emphasize the responsibility of individuals for their life choices and experiences in ways that match the neo-liberal political climate that has been established over the last 20 years. These explanations often negate both wider societal influences and the possibility of acknowledging advantaged groups' position in society (2009: 34-35).

Mara alludes to the way that this emphasis on individual responsibility also suggests what people think 'it is to be Māori', as Borell et al. note, exclusion from privileged groups is often seen as the result of some personal deficit, such as a 'lack of effort' (ibid: 35). 
and in prison!" That's a good one, because obviously people do think it's one of those things, eh?'

'Yep,' Mara says.

'The idea of personal responsibility is just so weird, isn't it,' I say. 'You know, taking personal responsibility is something that people can decide to do for themselves, but if you look at a whole group of people who are afflicted by certain ill effects of colonisation and then say to them: "Oh, you've all just got to sort your shit out", it's just so stupid.'

'"You're just all eating too much McDonalds",' Te Awanui says and Mara cracks up, 'Yeah, yeah yeah.'

'Surely the people who say that believe in cause and effect in other areas of life!' I say.

'Like: eat McDonalds-die overweight,' Te Awanui laughs.

'But it seems there is a real concerted effort to not know,' Francis says, 'and to not think deeply. Because it's really confronting, it's really shit. Like, our reo ${ }^{33}$ teacher died of a heart attack when he was forty-four. My dad has heart problems and he's in his seventies. And my parents, when I said: "I'm going to a tangi ${ }^{34}$ because blah blah", my parents totally ignored what I said and started talking about dad's heart. It was really really weird. I'm really intellectually interested in my reo teacher, how he was forty-four. He had a swollen heart, they knew he had a problem, but he was told that he didn't need to be on medication and didn't need to have his heart checked out and my dad's in his seventies and gets loads of medical attention. And yeah: "It's all personal responsibility"., 35

\footnotetext{
${ }^{33}$ Language, ie. Māori language.

${ }^{34}$ Funeral.

${ }^{35}$ McIntosh (1990) and Frankenberg (1993) also point to this 'concerted effort to not know', as supporting conferred dominance and preventing us from thinking clearly
} 
These comments get a lot of support from the rest of the group.

'Mhm,' Mara says. 'I mean, yeah, my dad died when he was forty-four as well, from a heart attack. And ah well, people will probably be like: "It's because he drank a lot, and also because he was a smoker and smoked shitloads of weed" and all that sort of stuff. But, it's also because he lived in poverty when he was growing up.'

'And all that drinking and weed and stuff is ill effects of colonisation as well, eh?' I butt in. 'It's not like he was just: "Hey, I wanna drink my life away".'

'No no,' Mara says. 'But, some of the floors in their houses were just dirt and he had rheumatic fever, which is a poverty induced thing. And you could follow that back further a generation, how they lost control of the land and language, and all that sort of stuff. You can follow that back another generation and it's actually really easy to track these things. ${ }^{36}$ But when, as a society, we're seeing such denial of those things-'

about equity: 'The silences and denials surrounding privilege are the key political tool here' (McIntosh 1990: para.20). However, it is important to recognise, as Zeus Leonardo points out, that these white privilege texts also 'reinforce the innocence of whiteness' by presenting 'an image of domination without agents' (2004: 138), where racist teachings are 'depicted as actions done or passed on to a white subject, almost unbeknownst to him, rather than something in which he invests' (ibid: 143. Emphasis added). Leonardo, therefore, does not offer white people the same freedom from shame and guilt that McIntosh encourages, because: 'despite the fact that white racial domination precedes us, whites daily recreate it on both the individual and institutional level' (2004: 139).

${ }^{36}$ Borell et al. make a similar point, noting that the disparities between Māori and non-Māori, in terms of health, wealth and education, remain entrenched in our society are well understood as:

[T]he result, at least in part, of the imposition of monocultural political and bureaucratic policies and practices established in the colonization of the country by Britain. Key early examples include 
'Well, we're all equal now,' Te Awanui says ironically, 'people just need to sort their shit out. Everyone's in the same boat.'

Mara agrees and we fall into silence.

This discussion shows how within a white supremist environment, Pākehā people are able to wilfully 'not know' the conditions colonisation places on Māori people and Mara speaks about how some blatantly racist comments about what it means to be Māori have impacted on her identity. Among these stories, Mara mentions the challenge of being involved in activism, suggesting that her experiences in the anarchist scene are part of a lifetime of identity negotiation. In the next story, Mara, Francis and Hayley speak in more detail about how ideas about what it means to be Māori impact on Māori participation in the anarchist scene. I found Narayan's ideas about outsiders' failings useful when trying to understand how a community committed to social justice could reproduce the racism of wider society and continue to undermine Māori identity. Narayan writes:

Sometimes, even the best intentioned outsiders cannot seem to get away from clichés and stereotypic generalizations about insiders. I am not talking about clichés at the level of 'All blacks are lazy' or 'All women are irrational' which are evidently offensive, but much more insidious and difficult to see clichés and generalizations (Narayan 1988: 44).

In the discussion below, Mara, Francis and Hayley speak about their experiences of working with the October $15^{\text {th }}$ Solidarity crew, showing how 'insidious and difficult to see clichés' about who 'real Māori' are have led to Māori within the anarchist scene being dismissed, while Māori outside the scene are romanticised. This final story gives a sense of how the events around the Operation 8 raids represent a

the limiting of Māori democratic representation by means of a qualifying standard of land ownership in individual title (where Māori ownership was characteristically communal) and the withdrawal of state funding for schools whose language of instruction was not English (2009: 32-33). 
crisis point for this activist community. Amongst the heightened emotions and stress in the aftermath of police violence, and with a group of people trying to cope with complexity of prisoner support and colonisation, Mara and Francis faced threats to their Māori identities.

By behaving as though some Māori are more authentic than others, members of the anarchist scene offer an example of Narayan's point about the 'failure by outsiders to avoid crude and "stereotypic" generalizations about insiders' (1988: 44). These issues of authenticity came to the fore when Francis and Mara expressed concerns to members of the October $15^{\text {th }}$ Solidarity group about some non-Māori speaking on behalf of Māori, flaunting their knowledge of Māori language and usurping Māori roles. These issues are discussed in terms of 'claiming indigeneity' in chapter 5, 'Black Rainbow (April to June): Power-sharing', however I also came to see these incidents of entitlement as an example of what Narayan identifies as the outsiders' 'failure to see why something that is not explicitly insulting to a person or group may be implicitly so' (ibid.). Mara, Francis and Hayley speak about how these concerns were dismissed and the corrosive effect that had on their participation in the anarchist scene. This offers an example of what Narayan names as the outsider's 'overt denial of the validity of the insider's understanding and/or response' (ibid: 41). Reading Narayan I came to see these various elements of outsiders usurping Māori roles, dismissing their concerns and prioritising relationships with 'real' Māori, combining to represent both, a failure to recognise the insiders' epistemic privilege of Māori within the anarchist scene, as well as an undermining of Māori anarchists' claim to belonging as insiders to their own oppression. 


\section{'Cool, a "real" Māori told you'}

$16^{\text {th }}$ of October 2010

'I wonder if it's worth us talking about... the October 15th stuff,' Mara says.

'Yeah, I was just thinking - when you guys said you don't know that much about itonly if you actually were interested,' Hayley says to Kura and Te Awanui.

'Yeah,' Mara agrees.

The group sits around the large table in Te Awanui's small kitchen. I am laid up with cryptosporidium, caught from sick calves at the animal sanctuary, and cannot make it to this meeting. But while I languish at home, the little audio recorder listens to the group's conversation. ${ }^{37}$ This is a hard day, the day after the anniversary of the October $15^{\text {th }} 2007$ raids that imprisoned three members of the Wellington anarchist community, as well as fifteen others around the country. To mark the anniversary, Valerie Morse-one of the arrestees-held a book launch for her edited collection, The Day the Raids Came: Stories of Survival and Resistance to the State Terror Raids (2010a). Some of the members of Black Rainbow had been at the launch and this came up as being 'on top' for them in the opening round of the meeting.

'I don't know how much value there is in rehashing it,' Hayley continues, 'unless it would be helpful somehow to you understanding the scene.'

Kura makes a thoughtful sound.

'I think it would be really helpful for me,' Te Awanui says, 'I have talked to lots of people a little bit about stuff, but there's just so much to it. Also, there's so many real different perspectives. It seems like the story's real fucking different depending on who you hear it from,' Te Awanui laughs and others agree. 'But I don't usually

\footnotetext{
${ }^{37}$ The group used the recorder to record this session themselves. This allowed members of Black Rainbow to more fully take on the roles of participant-researchers. It also created an interesting dynamic for me, doing research while absent.
} 
question people too much about it because it seems like everyone's traumatised by it.' Their laughter infects the group, 'So I don't want anyone to feel like they need to tell me about it. But I would like to hear about it if people would like to talk about it,' they add gently.

'I feel the same,' Kura says. 'I always feel rude for asking, because I don't wanna be like: "Just gossip to me".'

'"Oh, l'll just bring up all this emotional shit for you",' Te Awanui jokes and everyone laughs. 'That's the thing.'

'"Oh cool, that's really interesting. Now I know",' says Francis, which increases the laughter.

'Yeah,' Francis says, 'I've always been really interested in your perspective, Mara, because I feel like you've had the sort of issues that I ended up growing over that period, for longer than me.'

'Right, yeah,' Mara says. 'I was getting burnt, more and more burnt, as you were coming in. And then when I was out, you were getting burnt.'

Francis laughs, 'Yeah, I think you were pretty much done with the scene by the time I turned up.'

'Oh yeah, it was severely doing my head in,' Mara says. 'It was horrible... because you haven't had the chance to confront people about stuff. Or challenge it. You just end up-well, I end up feeling really uncertain about where I stand. And also a bit fucked off, because all of these issues are really important to me. But because of the way things have worked out I can't engage with them, can't organise around them, like completely powerless. And that's not the thing that should have come out of October 15th. It should have empowered people, especially the few Māori people within the community.' 
'Some of the key lingering issues for me about that whole time,' Hayley says, 'were that heaps of people did a fuck-load of support work while they were in prison and were feeling unacknowledged for that. And we were also being told that we didn't do enough or that we abandoned them. When they came out, everyone had different pieces of information about what happened or didn't happen. And no one was allowed to talk about anything. So there was a lot of secrecy. There still is. And so we were sort of expected to defend them, publicly and personally, without knowing what they did. Or disagreeing with the bits we thought we knew, but not allowed to talk to them, or anyone else, about it. So there was that huge thing. And-'

'And then there was,' Mara interrupts, 'sorry-just on that-then there was the stuff about people not being able to be in the same space so trying to negotiate between the different people and people getting pissed off with us because we weren't doing that properly for them.'

'Because they had non-association orders,' Hayley explains.

'But then also not being able to do stuff and there was a whole lot of stuff that was really emotionally draining,' Mara says. Francis and Hayley agree.

'And I think the other big one was,' says Hayley, 'it seemed like there was this blindness to the Māori activists in the Wellington scene and a real exoticisation of Tūhoe and "real Māoris". ${ }^{38}$ A few people laugh and agree, 'that was really bizarre.'

'Can I give a solid example of things like that?' Mara asks. 'Josh ${ }^{39}$ from Tūhoe and another younger dude-who already lives here-came to visit $128 .{ }^{40}$ So some of us

\footnotetext{
${ }^{38}$ When satirising others' attitudes, Hayley tends to say 'Māoris' - with the inappropriate English plural ('s') added and a thick New Zealand accent. This seems to express ignorance or naiveté, because she would never refer to a group of Māori as 'Māoris'; though this is a language feature of many Pākehā.

${ }^{39}$ This is a pseudonym.

${ }^{40}$ The 128 radical community centre, 128 Abel-Smith Street, Wellington.
} 
stopped 'round to meet him, because obviously it was our first engagement with people from Tühoe. And because we were all really nervous about where we should be standing and what some of their perspectives were on things. So we came into the kitchen and were hanging around having cups of tea, and it just turned into Chris and Tony ${ }^{41}$ using as many Māori words as they could, with other people just like standing by like: "Mmmmh"'-she takes a big breath in and breaths out a mockingly self-satisfied_'“Aaaaaaawh". Real romanticism.' ${ }^{42}$

\footnotetext{
${ }^{41}$ These are pseudonyms.

${ }^{42}$ Avril Bell discusses this tendency to romanticise and exoticise 'real Māori', by tracking the notion of 'authenticity' back to the Romantic tradition. During the period of rapid social change that marked the beginning of European modernity, concerns over loss of tradition became associated with a loss of human authenticity. With the 'discovery' of the 'New World', the Noble Savage was constructed as a way to critique modern 'civilisation' and 'as a source for replenishment of the “losses” of modernity' (2004: 35). Present day anarchists (whose primary point of unity is a critique of capitalist society) response to Tūhoe as 'real' Māori-an original survival of Māori culture—and 'real' freedom fighters—willing to take up arms to maintain their traditional nation—could be seen as continuing the European Romantic tradition. Kim McBreen notes: ‘Tame Iti’s facial moko [Māori tattooing design] has become an emblem of Māori resistance, turning up on t-shirts and stencilled graffiti. It sometimes feels as if masculine images are the symbols of real protest' (2011a: paragraph 41). These images of Tame Iti as 'warrior', which he artfully employs in his performance of political activism, have strong echoes of the Noble Savage. Iti’s 'warrior' image is a powerful anti-colonial tool, particularly because it taps into the historical myths of Māori as 'a savage, bloody warrior race', which Moana Jackson explored in his keynote address at 2009 Cutting Edge conference, 'Once Were Gardeners':
}

Where did that image come from? Where did the novelist Allen Duff get the idea of naming his novel "Once Were Warriors?", when a clear and actually objective analysis of our society could have been more properly called, "once were gardeners", "once were poets”, "once were singers”, and (if you're from Kahungunu) "once, and always, were lovers" (2009). 
'True,' Kura says, sounding somewhere between surprised and embarrassed.

'Me and Jeremy ${ }^{43}$ were both there,' Mara says 'and when I left I was like: "Oh my god! What the fuck was that about?!" And he was just like: "That was quite sickening". Because he's from Gisborne and grew up with lots of Māori and he was just like: "That was gross". And yeah, then I was like: "Oh my god, I never want to do that again". And being in a room with mostly Pākehā and using Māori words that other Pākehā didn't even know! You know?! How is that being inclusive and trying to create conversations?'

Te Awanui's son Tim comes into the room crying 'Finished! Finished!'

'Is it finished?' Te Awanui asks. 'Do you want me to put it on again? I'll fix it for you eh?' and leaves the room to put Tim's film on, while Mara asks Hayley and Francis if they were there that day.

'Yeah I was there,' Francis says, 'I thought you were too.'

'Maybe I was and I've forgotten,' Hayley replies.

'What was your perspective on it?' Mara asks.

'Well, yeah,' says Francis, 'I think at the time I wanted to kill Chris for many reasons around that sort of thing.'

Jackson explains that this 'warrior race' image derives from an early Spanish conquistador story of a warrior race that guarded the supposed "Lost City of Gold" El Dorado. This image of the 'warrior race' was overlaid onto all indigenous people. While Māori in the anarchist scene are mostly women, who could easily fit Jackson's version of 'authentic' Māori as gardeners, poets, singers and lovers, it is perhaps not surprising that the Tūhoe 'warrior' performance has captured the imagination of many anarchist activists, given that people within that scene also come from a tradition of romanticised violent resistance (see Chamsy el-Ojeili 2012).

${ }^{43}$ This is a pseudonym. 
'Bless him, but-' Mara says and everyone laughs.

'Yeah, I mean we've totally fixed our relationship,' Francis says.

'Cool,' Mara says.

'But yeah. And bloody Tony. Yes.'

'It's so horrible,' Amiria says, 'that kind of showing-off. You know: "I know this much te reo, yeah check me out" sort of thing.'

'Do you want something to eat?' Hayley asks Tim. 'Do you want the rice?'

'Woah! Are you still hungry?!' Te Awanui asks Tim and clatters in the kitchen. 'Let's make sure things stay tidy, ok?'

Meanwhile, Francis carries on the conversation, 'Yeah, definitely at the time I felt like there were Pākehā activists that would do anything to connect with Māori outside our scene. Which meant that it was really hard for Māori within the scene to also have relationships with those involved. There was just not space to talk to anyone because there was just a few of the Pākehà activists who were all like: "This is all about me and my chance to be a-super star".'

'I remember we were at 128,' says Mara, 'me and Francis were having a conversation and we were actually starting to talk about all these issues. Faith ${ }^{44}$ came in and started trying to join the conversation and I said: "Uh, we're just having a conversation about Māori stuff". Just to say: "You're not welcome". She's like: "Well I've got some Māori, like back five generations ago" and then just sat there and tried to join in on our conversation.'

'I think it might have been ok if she had just sat there,' Francis says. 'She was trying to have the conversation for us.

\footnotetext{
${ }^{44}$ This is a pseudonym.
} 
'Yeah,' Mara agrees. 'She was trying to have the conversation for us. Yeah yeah.' 'Oh god,' Kura laughs.

'That's the way it ends up being,' Mara says. 'Certain people trying to involve themselves or trying to own that. And when that stuff kind of happens, it's really dehumanising.'

'It seemed to me,' Hayley says, 'that after some time, you two-and other peoplestarted talking about how they were feeling about stuff and particularly about the way that people were engaging in these weird ways with Māori that were involved, or the racism that was involved in the state response. And then actually challenged them on it. Like I know Francis challenged them on it directly. And-whoops, I'm speaking on your behalf sorry,' Hayley laughs before continuing, 'I just remember how awful it was when you put forward your perspective about how it was about those Māori and not these in the community and they were like: "Ok, thanks for your opinion! I probably would have done the same thing anyway, but thanks!"' 'Mh, true,' says Kura, sounding like she knows how hard that must have been. 'Like: "You're so relevant"-is how we were feeling,' Hayley says. 'Yeah!' Mara agrees.

'Yeah,' says Francis, 'I said, for example, that I didn't think it was a good idea to have Helge ${ }^{45}$ mihi at public meetings, especially when there were Mãori on the stage behind him. And there were Māori involved in the group already. Vicky ${ }^{46}$ was on the stage behind him, Vicky could mihi to people. And I got this blank: "Oh yeah'-like everyone knows I have this problem with Helge mihi'ing. And then, what's his name?' Mara and Hayley try to help Francis find the name, but then she continues, 'so some Māori activist-that wasn't involved in the Wellington scene particularly-said the same thing at a later meeting and the group really took it on

\footnotetext{
${ }^{45}$ This is a pseudonym.

${ }^{46}$ This is a pseudonym.
} 
board, like: "Oh yeah, this is something we really need to be aware of". And it was just like: "Cool, a 'real' Māori told you, I'm really pleased".' Francis' sarcastic frustration makes everyone laugh. ${ }^{47}$

I brought up exactly the same thing!' Mara exclaims. 'And people's response was: "Oh well, someone invited him to speak" and I was like: "But he should know better".'

${ }^{47}$ Following Said, Kim McBreen explains this idea of 'real Māori' as being based in notions of the 'Oriental' as 'representing the opposite of how Europeans see themselves', where the 'exotic and inferior' contrasts and 'confirms Europeans as normal and superior' (2011a: paragraph 17). While McBreen shows how stereotypes of 'real Māori' were created to affirm the superiority of European civilisation, Avril Bell argues that these notions grew out of critiques of modern civilisation and a desire for the 'replenishment' of lost humanity. Ironically, whether affirming or critiquing civilisation, these competing European traditions insist on Māori remaining the unchanging and distant Other, creating what Bell terms 'repressive authenticity’:

[T]he authentic indigene is spatially separated - in the New Zealand case on the marae, for instance, rather than in the courtroom. Their authenticity depends on this spatial separation. As soon as they become suburban neighbours they become 'lovely people' 'just like us', or problematic deviants and recipients of welfare. Difference either disappears or becomes demonised. Indigenous difference continues to be positively evaluated only as long as it is 'somewhere else' in a direct continuation of the logics of the Noble Savage (2004: 65).

Simply replace the 'courtroom' from Bell's example with 'vegan potluck' in the anarchist scene and the logic is the same. In contrast to Māori anarchists sharing these potlucks or sitting through hours of meetings here in Wellington, the members of Tūhoe who live in their traditional lands in the Urewera, are clearly spatially separated and may therefore be more easily seen as 'authentic'. On a more subtle level, this logic explains how other urban Māori activists can also be seen as more authentic than Māori within the anarchist scene-proximity breeds inauthenticity. 
'Yeah: "Say 'No'",' Francis agrees.

'It's like: "You don't have to do what Paula 48 tells you to do all the time, say 'No'",' Mara continues. 'Because I remember someone saying he was a bit hesitant but he felt like he was being pushed forward a bit. But he did it anyway. Another Māori had said it was ok then.'

'I remember at some point,' Hayley says, 'he did a mihi somewhere because the people in that space found it more appropriate for him to do that than for a woman to stand up and do her mihi in Māori. It's not my place to make a judgement on that, but there were people like Francis-and people down here-that had opinions about that. And that wasn't important because the opinions of the 'real Māoris' were the way it was. There was this unwillingness to engage in some of the complexities because they really wanted to be on side, and down with the Tühoe crew, and it was just bizarre.'

'There was another really awkward thing,' Mara says, 'that I feel really awful about that whole thing. When they were in prison-because l'd been working with Wiremu $u^{49}$-I said that I would be the person to go between the scene and his family. ${ }^{50}$ So I ended up taking abuse from both sides. And there was this thing where we were trying to organise food and stuff for them but-because some of the people who were doing that stuff didn't want anything to do with him-I had to do everything alone.' Mara's voice breaks with tears. 'It was so bad.'

'That's so awful,' Amiria says.

'I can't believe it's three years on and it's still so raw, eh? And so unresolved,' says Hayley tenderly.

'I feel like anytime anyone has tried to talk about it, you kind of get yelled at,' Francis says. 'I know people who have been. Vicky has told me how fucked off she

\footnotetext{
${ }^{48}$ This is a pseudonym.

49 This is a pseudonym.

${ }^{50}$ Wiremu had been excluded from the Wellington anarchist scene prior to his arrest, during the period of upheaval in the scene around sexual and domestic abuse.
} 
was with me that I'd talked to Paula and Helge about them making the decisions they made. It's like you're not allowed to have an opinion even.'

'No,' Mara agrees weakly. After a silence she gives a big sigh. 'Yeah, so you end up sitting in coffee shops or around kitchen tables talking about all the fucked up stuff. It doesn't go anywhere. And I mean what do you do? Even if you sit down and talk to someone, they're not going to listen to you. They're not going to take things on board. They just don't get it. You know, it's one thing to be in the fucked up scene anyway, but to have to carry around all that additional stuff. It's just like, phew.'

'The scene was so fractured beforehand,' Francis says, 'it was really hard. I mean it was impossible for us to support each other before shit was happening. And then shit was happening and we weren't allowed to talk about stuff.'

'It was the worst,' Hayley says.

'It was just so horrible,' says Francis.

In this chapter, I have shared stories from the first period that Black Rainbow spent together, when issues of identity came to the fore through our decision to share our 'where we come from' stories. The discussions we had during this period were the most emotionally charged we had and their impact on me has been deeper and more subtle than I fear I have expressed here. Through these discussions I developed a much greater appreciation for what Uma Narayan calls insiders' epistemic privilege and the origins of outsiders' failure to recognise this privilege. Reflecting on this I came to see the unequal degree of threat to identity that working across difference represents for Māori and how undermining Māori identity can be used to dismiss the concerns of Māori people, by denying them as full holders of insiders' epistemic privilege. This has sobering implications for our relationships and hopes of power-sharing, which will be discussed in the following chapters. 
As I was re-working this chapter, Mara sent out an email (December 9, 2013) to the members of Black Rainbow with a bell hooks quote, which she saw as particularly relevant to our discussions about the October $15^{\text {th }}$ Solidarity group. I end with this quote because it sums up neatly the way that notions of 'authenticity' support the conferred dominance of white activists, allowing them to be the arbiters of whose knowledge counts as insiders' epistemic privilege:

When I participated in feminist groups, I found that white women adopted a condescending attitude towards me and other nonwhite participants. The condescension they directed at black women was one of the means they employed to remind us that the women's movement was "theirs"- that we were able to participate because they allowed it, even encouraged it; after all, we were needed to legitimate the process. They did not see us as equals. They did not treat us as equals. And though they expected us to provide first-hand accounts of black experience, they felt it was their role to decide if these experiences were authentic. Frequently, college-educated black women (even from poor working class backgrounds) were dismissed as imitators. Our presense in movement activities did not count, as white women were convinced that "real" blackness meant speaking the patois of poor black people, being uneducated, streetwise, and a variety of other stereotypes. If we dared to criticise the movement or the assume responsibility for re-shaping feminist ideas and introducing new ideas, our voices were tuned out, dismissed, silenced. We could be heard only if our statements echoed the sentiments of the dominant discourse (2000: 12-13). 


\title{
Chapter 4
}

\section{Black Rainbow}

\author{
November to March
}

\section{Relationships}

$20^{\text {th }}$ of November 2010

At Mara's suggestion, the next time we meet we go to Pataka Museum, Porirua, to see Nga Kakahu: Change and Exchange by Roka Ngarimu-Cameron and Jo Torr. Hayley and Francis are sick and can't make it, but the rest of us have a lovely day wandering around Porirua, buying bright nail polish and fake flowers and eating hot chips at a picnic table in the sun. It is a classic kiwi bonding scene, one which makes me nostalgic for my teens. And it feels relaxed. This feels like friends hanging out together, not research participants. That is important.

On the car ride back to Wellington, I mention the high turnover of Māori in the anarchist scene:

I really noticed that listening to you talk about October $15^{\text {th }}-$ Mara got burnt out and left as Francis was coming in, then Francis left as you guys came in. It's like there are three generations in this group.'

'It's just hard being in the world as Māori,' Mara says. 'Let alone dealing with scene stuff.'

'Like getting disappointed all the time? I imagine that wears you down,' I say. 'Being in the scene in general is exhausting, but I think it gets harder and harder if you're 
marginalised as well. It's hard for women to stay in the scene, even harder for Māori.'

'There are more women,' Te Awanui says, 'so people have your back. Women actually run the scene. But there are so few Màori. Most of my friends are women now, there are only a few onto-it men I consider friends. If a man is a jerk about gender and doesn't treat me with respect 'cause I'm a woman, ${ }^{1}$ I just write him off. But I'm not so willing to do that with race. If there are already so few people you feel safe with, it feels really scary to challenge them about race stuff.'

'And you're just around it all the time,' Mara says.

'So you get used to not challenging it,' Amiria adds.

Te Awanui's comment about it being scary to challenge your friends about racism, when there are so few people you can trust, really stayed with me. It brought home for me the personal in the political (to re-work Hamisch's iconic phrase, 1969) - the way that the anarchist scene is made up of friendship circles and how important those relationships are for support and well-being. It is painful to think of Māori activists tolerating hurtful racism from their friends, rather than risk those friendships. For me, this moment captures the focus of this chapter, which is relationships.

In this chapter I tell the story of the next period that Black Rainbow worked together. As with the previous chapter, I want to prioritise the voices of the participants and the context their comments arose within, yet I have also selected pieces that reflect the particular theme of relationships. This was a deliberate relationship-building period for Black Rainbow, where slowly over time, through a mixture of just hanging out together, inviting each other to talks, art gallery and

\footnotetext{
${ }^{1}$ Te Awanui was still presenting as a woman at this time.
} 
museum exhibitions and political demonstrations, as well having more focused conversations in meetings, we developed stronger relationships and trust as a group. One of the aims of this chapter is to show this relationship development. To give a sense of the kinds of things we did together, this chapter begins and ends with snapshots of group outings - one to an art gallery and the other at a hīkoi/demonstration. In between these snapshots are two longer chunks of conversations from meetings. The first remains with the theme of relationshipbuilding, although it looks more closely at a time when I felt those relationships were threatened. Theory of 'racial microaggressions' (Sue et al. 2007) helps me reflect on the paralysing confusion I experienced during that time.

My third story centres on a discussion we had about cross-cultural intimate relationships. This discussion is the heart of the chapter, where the bulk of the analysis comes through the meanings we make as a group. Showing this shared meaning making is another major aim of this chapter. While this was a discussion of romantic relationships, the themes we talk about-including power, how emotions are valued and the link between identity and relationships-have wider implications for how we work together across difference. To understand this connection, I am drawing again on Uma Narayan's article: 'Working together across difference: Some considerations on emotions and political practice' (1988). I will briefly outline my thinking here, to connect the various threads of this chapter.

\section{Emotional sources of epistemic privilege}

Mara comments in the snapshot above: 'It's just hard being in the world as Māori.' This called to my mind Narayan's point that while insiders to oppression hold epistemic privilege (discussed in the previous chapter); this knowledge comes with a burden of emotional labour. Narayan argues that 'a very important component of what constitutes the epistemic privilege of the oppressed has to do with knowledge that is at least partly constituted by and conferred by the emotional responses of 
the oppressed to their oppression' (1988: 38). This sensitivity to oppression, of course, comes with a high emotional cost, as Narayan makes clear:

Although being an insider to a form of oppression may confer epistemic privilege, it certainly constitutes a burden. The insider lives with all the forms the oppression takes, from everyday and trivial manifestations to violent and life-threatening ones... It is the insider who pays the price of oppression and even sympathetic outsiders, since they are prone to blind-spots and clumsiness, can offend and hurt the insider more than they imagine. The insider can neither simply walk away from the issues, as the outsider always can, nor can she ever inadvertently hurt the outsider in quite the same way. Thus, since the brunt of possible hurt is most often on the insider, the burden of taking care not to cause offense can fairly be laid on the outsider (1988: 40-41).

While emotional reactions may be a key source of insiders' epistemic privilege, I learnt through conversations in Black Rainbow that the emotions of Māori people are often read as overreactions, because Pākehā culture powerfully asserts that getting upset prevents reasonable arguments. I came to see these sanctions on emotional expression as allowing the dismissal of insiders' epistemic privilege. This is exacerbated by the subtlety of modern racism, where the slights ('microaggressions') insiders react to may not be apparent to well-meaning outsiders. The resulting confusion can cause outsiders to shut down or become angry and defensive when insiders express hurt over their behaviour. These emotional reactions from outsiders add to the initial hurt caused to insiders, inhibit communication and damage relationships. This has clear implications for working together across difference (I will extend this argument further in my final discussion, 'Processes of Pākehā Change: 'learning to be affected' while working across difference').

Moreover, the prevalence of the Pākehā cultural value of emotional repression can also impact on the sense of self, with some Māori people made to feel 'crazy' for being 'overemotional' in relationships with Pākehā. This connects to another major 
insight that I developed listening to the Black Rainbow discussions, namely the relational nature of identity. This chapter therefore builds on the previous chapter, by exploring how identity is experienced in relationships. Moosa-Mitha notes that: 'the self is also deeply dialogical or relational where it affects and is also affected by the multitude of relationships and experiences of oppression that it faces in society' (2005: 66. See also Rata 2012). In our discussion, some Māori members talk about how they have chosen Pākehā partners because they were 'raised Pākehā' or because cultural stereotypes and internalised racism about Māori affect who they are attracted to. Within cross-cultural relationships, Pākehā partners can represent the assimilative powers of wider society for Māori who are attempting to develop their Māori identity, while cultural stereotypes also affect what we expect of each other and may obscure the more subtle differences each person brings to their relationships. During this period, I also became aware of the subtle ways that my own identity was shifting through association with Black Rainbow.

\section{Threatened relationships:}

\section{Microaggressions and failure to relate}

$11^{\text {th }}$ of December 2010 'Is anyone (other than Rachael),' Francis laughs 'going to the meeting on Tuesday?' 'Yeah,' Kura says.

It's a hot day and we are sitting around the comfy lounge of Te Awanui's new place. Everyone is a little lacklustre-it's been a long year and we are just trying to squeeze in a little time together before people go away for the summer. The meeting Francis is referring to is one planned by another collective that Kura, Te Awanui and I belong to. The decolonisation workshop we organised with Clara ${ }^{2}$ (a Treaty educator) for the animal sanctuary group, was something of a disaster, so the Tuesday meeting is a follow-up.

\footnotetext{
${ }^{2}$ This is a pseudonym.
} 
'Yeah, I think I'll go,' says Te Awanui.

'Yeah?' l ask with a sigh.

'But I don't know if I wanna,' Te Awanui adds.

'Yeah,' Kura agrees.

'I would like to go to another meeting with Clara,' Te Awanui says, making Kura laugh loudly, 'and just go, "What the fuck!?"'

'It sounds shocking,' Francis says.

'It was so offensive!' Te Awanui says. 'Not only was it just not useful-I mean maybe if it had been a Pākehā-only group, who hadn't heard about any of it before, it would maybe have been a bit useful? But considering the context that she knew that all of us had some idea around this and had done something. Like the whole Treaty thing-half of it was like: "Here's this Treaty thing", "Here's this timeline of dates".'

'And something about how "Māori were implicit in their own colonisation",' Kura adds, "They have been part of the process all the way along, they're not just passive bystanders". And it was like, "what are you trying to say?"”

'Does she know what colonisation is?' Mara asks. 'Apparently everyone hated it.' 'Yeah,' Kura agrees and I cringe, feeling responsible for the whole mess, because I was the one who asked Clara to do the workshop.

'It seems like it would be really good for her to get feedback on it,' Francis says. 'Yeah,' I say. 'I sent her an email about it and we had already arranged, before the workshop, that me and her will meet up next Tuesday. But I'm not sure if that is going to happen now, because her only response was that she is feeling disturbed by the whole thing and that she would get back to me later.'

'I think that: "Disturbed by the whole thing" sounds like: "I'm upset that people are upset with me",' Te Awanui says.

'Yeah, I'm trying to be generous and think that she could be disturbed that she'd fucked up and is thinking about it and that's why she didn't say a whole lot,' I say. 
'But any time you pulled her up on anything, she was pretty much like,' Te Awanui gives a big theatrical sigh of frustration and quotes Clara: "'Well, actually, Māori people believe that you need a man and a woman for ra ra ra" and we're like: "Well, actually, we are Māori people and we're dykes! And we don't think you need a man and woman for anything! And so you can't just say that".'

'Yeah, totally,' I say. 'I'm not very confident that she's taking it on board.'

Te Awanui continues, 'I felt like in the beginning when we were really nicely saying: "Oh, can you maybe not say 'our country' or 'our history' because it's not (we don't all have the same histories, we certainly wouldn't all say this is 'our' country)," she was real defensive even at that point. And then by the end where I was just like: "you're being a fuckwit" (except I didn't actually say that, but you know, when patience was a lot more run out).' We all laugh with Te Awanui.

'But I heard that she made herself "accountable to the Māori in the room",' Francis says with heavy sarcasm. 'So at least she was doing that.'

Te Awanui laughs loudly. 'Oh yeah? I must have missed that!'

'Maybe two or three times she asked: "what do Māori think?", but she was just talking to you,' Kura says to Te Awanui, 'totally ignoring me.'

'Cool.' Mara says flatly.

'Plus, I don't want to be asked: "So you, what do Māori think?"' Te Awanui says. 'I just want her to listen when I'm talking.'

'Yep,' Mara agrees.

'Yeah,' I say. 'And it did seem like when she was asking you things it was sort of to enrich what we were learning, like to be educators of the Pākehā in the room, rather than for you to be getting something out of that workshop. I don't know.'

'It was just incredibly unsuitable for a mixed group, eh?' says Te Awanui. 
'I feel really unsure about the meeting that's planned,' Hayley brings us back to the Tuesday meeting.

'Same,' I say.

'And I don't know if I'm just being a bitch,' she continues, 'but the wording of the email seemed a bit weird. Like: "Anarchists engaging with Māori". It kind of implied that there were no Māori anarchists.'

'Yeah, totally!' I say and Kura agrees.

'Oh,' Te Awanui says. 'I haven't read it.'

'Yeah, that was the thing,' I say. 'I mean, us three are in that group and I think we hadn't really talked about-there was no planning of that wording, is what I'm trying to say. And maybe we all thought that that discussion was going to be something different, I'm not sure. What I was imagining was some kind of follow-up to Clara, where we could talk about stuff and whatever came out of it. The main thing that we had talked about (or what I got out of it) was that it was a chance to get the people that were at the decol ${ }^{3}$ workshop back in the room and see if there were more people who were interested in working together. And what people wanted to do, stuff like that. We asked Paula to send out an invite because she'd been the person that everyone had got in contact with for the decol workshop so she had all the addresses. And I can't remember if she had talked about phrasing the question in those terms or not, but it surprised me a little bit as well. I think partly she posed it as a question so that it could be broadened out more to people who hadn't been at the decol workshop and so there would be some focus to it. I don't know.' I laugh, 'Partly I want to say, "Oh it's all Paula's fault!" but actually I feel really responsible for us not planning it more and not talking about it more. And it wasn't until Paula sent out that email and asked me to forward it on to this group that I thought: "Fuck!" Because I thought: "They won't want to be there at all, that sounds awful".' Everyone laughs and I continue, 'then I suddenly thought: "We haven't organised any facilitators or anything". And thinking about how shit it

\footnotetext{
${ }^{3}$ Decolonisation.
} 
would be for you guys, who would already know it would be shit, made me realise that we hadn't put anything in place for Kura and Te Awanui-making sure it isn't shit this time around.'

'Look, I just gave up after the Clara workshop, actually,' Te Awanui says. 'I was just like: "Meh, whatev's." "Well, I kind of said, but I didn't say real clearly, I would come along to a discussion, but I don't want to organise it, because I don't want a repeat performance.'

'Yeah, yeah,' I say, as Te Awanui laughs.

'So it makes me feel like that,' Te Awanui says. 'And I don't want all the other Māori people to be like: "Fuck this!" and not dealing with it.'

'Yeah, it just seems like there is no structure to it,' Mara says. 'No aims. And two hours? I think there are different things that need to be addressed. One is just pure history, like: "What is colonialism?", "How does it work?", "How has it fucked over this country?" You know and maybe even a history of the Treaty, because lots of people don't even know that stuff. And then the analysis as well. But it's really hard to do the analysis when people don't even know the history or terms.'

'True,' Kura says.

'We did a lot, in Clara's workshop,' Te Awanui says, 'going through the Treaty: "So in this first paragraph, what's it saying? What's being promised? la la la." Which I felt was a real waste of time.'

'Yeah!' Mara says.

'Because we all sort of know what the Treaty says,' Te Awanui continues, 'and most of us don't actually know what the Treaty in Māori says. Except that on the main points it's real different.'

'So they didn't go through the Māori version?' Amiria asks.

\footnotetext{
${ }^{4}$ Whatever.
} 
'Nup,' Te Awanui says. 'There was some: "It says something different". Something, eh?'

'There was a translation of the Māori version that we looked at as well,' I say.

'Yeah, but it didn't-' Te Awanui begins.

'It wasn't usefully organised at all,' I say.

'But I guess I don't think of colonialism as just being about the Treaty,' Mara says. 'That is one small component of it. Or you could look at all the breaches or all the things from that. Not just focus around the wording.'

'Yep,' says Amiria.

Francis says, "I guess when Clara first got involved in doing Treaty work in the "70s and '80s, educating people about the Treaty was-'

'Just that,' says Amiria.

'-really radical,' Francis says and others agree.

'But now, we all know basically what it says,' Te Awanui adds. 'We all know that there are huge fucking discrepancies, that the English version says the opposite of what the Māori version says and neither of them are being upheld anyway. And the purpose of the Treaty is colonisation-getting more land and more power. We don't need to keep going over that for an hour.'

Mara says, 'It's almost like a diversion from actually-'

'From actually talking about the things we need to talk about,' says Te Awanui and there are noises of agreement among the group.

We complain a little more about Clara's workshop, then Kura changes tack. 'I thought that the meeting on Tuesday was more of a debrief type thing.'

'Yeah, that's what I was expecting as well,' I say.

'Actually,' Kura continues, 'I feel a bit weird about being accountable for that.' 
'That email?' l ask.

'Yeah,' says Kura.

'Yeah, same.' I say.

In the end, Kura and Te Awanui decided not to come to the follow up discussion and I still feel a sense of shame and sadness that they were marginalised all over again by that event. I find this difficult to write about, but it also seems very important to include in this chapter because I have strong feelings around it. It was a frustrating time and I want to push it away rather than think about it again. Yet, I am taking this desire for avoidance as evidence that I need to look at it closely. This was a time when I felt I was compromised by my actions within the sanctuary decolonisation group and I was concerned about the threat this posed to relationships within Black Rainbow.

I see this as a story about letting people down and failing to relate. Clara spoke at length about new theories of relating - a deep responsiveness - similar to what is found in Charles Te Ahukaramū Royal and Betsan Martin's chapter, 'Indigenous ethics of responsibility in Aotearoa/New Zealand: Harmony with the Earth and relational ethics', which employs the musical metaphor of 'sympathetic resonance' to reflect on responsiveness:

A key feature of sympathetic resonance is its spontaneous aspect. One voice inspires and elicits a spontaneous and sympathetic response from another. In human relationships, this idea suggests a subtle and sympathetic level of relationship. If we imagine two humans as musical instruments, the idea is that one individual resonates with another in spontaneous and sympathetic ways - not only in the quality of articulated and conscious communication between them but also in the bodily and unplanned way they relate with one another. Here we can see that listening involves more [than] the use of the ears and a 
focused concentration of the mind - it is 'listening' with all the senses, the body, the emotions, spirit and so on (2010: 48-49).

Sitting listening to this beautiful philosophy about relationships in a room full of people Clara had already alienated was unnerving. Her passionate beliefs and a strong commitment to Māori and Pākehā partnership did not prevent Clara from insulting Kura, Te Awanui and Pravina ${ }^{5}$ (an Indian woman who is a close friend to both). As they became increasingly irritated and challenged her on several comments, her response seemed, as Te Awanui says, 'real defensive' and 'upset that people are upset with me'. Again, I find Narayan useful for articulating this particular dynamic:

Outsiders often assume, wrongly, that good will on their part is a guarantee against causing offense to insiders, and when insiders are offended and express their anger, the outsiders often react with honest bafflement and anger since they cannot understand how someone sympathetic to a form of oppression could conceivably be seen as having offensive views or attitudes (1988: 41).

I do not presume to know whether or not Clara's thinking is quite so naive. Narayan's words; however, help me to think about the confusion and the threat to one's self image that occurs at the moment when we are confronted with another person's response to our behaviour. This disconnection between Clara's intentions about relating and her inability to be deeply responsive to Kura, Te Awanui and Pravina's distress was paralleled by the disconnection I was feeling at the time between my ideals and my behaviour. While we were building ideals in Black Rainbow, talking about how things could be done better, I was feeling helpless and clumsy in animal sanctuary decolonisation group. I wrote this in my journal at the time:

The only major reflection that I have about Clara's workshop is that I can think about ethical relating to Māori but I find in person I fuck up all the time

\footnotetext{
${ }^{5}$ This is a pseudonym.
} 
- it is hard to change actual behaviour - the body and the brain respond in ways I don't intend. It seems the same with Clara-her relational theory didn't seem to match her behaviour towards Kura, Te Awanui and Pravina. So I feel understanding towards her (and myself by extension) but also disappointment - since I was hoping for guidance, a role model (December $2,2010)$.

Both, during Clara's workshop and in discussions with the decol group about the follow up meeting, instead of speaking up as an ally, I found myself responding to my anger and confusion by withdrawing, shutting down. The fact that I had a dual identity as 'researcher' at this time made it even easier to fall into a position of 'observing' rather than acting. I failed to support Kura and Te Awanui, repeatedly, and my guilt comes through in the story above, where I struggle to both separate myself from Clara and Paula, as well as take responsibility for my own shortcomings.

I am sharing my feelings about 'failing' not only for academic reflexivity, or personal therapy, or merely to point to the anxiety Pākehā carry as colonisers, but rather because I am interested in these feelings as evidence of social norms. I am interested in what stops us from being better allies. Here I am influenced by Sianne Ngai's Ugly Feelings (2005), which turns towards the 'minor', 'weak' feelings (envy, irritation, paranoia, anxiety) that are usually ignored in discussions of emotional motivations of politics, 'being prolonged and distracting in ways that seem to block action' (Ngai 2005: 13). It is all too easy to focus on a few personalities who cause more blatant offense, but I am also interested in all the other people in the room who allow that behaviour to continue by remaining silent. Throughout our discussion above, neither Te Awanui nor Kura say outright that it was disappointing that other people at the workshop did not say more to support them, although Te Awanui articulated this clearly in a later discussion, which appears in the next chapter. During our discussion, I was still too ashamed to address it directly. 
On reflection, I can see that one of the things that prevented me from speaking up was the confusion that came from wanting to be 'nice' and 'fair' to Clara-to take a generous interpretation of her meaning. At the time, while I was responding to Te Awanui and Kura's expressions of anger and distress, I was also fretting that they were taking offense at Clara's words instead of listening for her intentions. I was unsure how to mediate in a way that allowed everyone their dignity. This confusion can still be seen coming through in the story above, where I defend Clara-Yeah, I'm trying to be generous and think that she could be disturbed that she'd fucked up'-but then I back down quickly and support Te Awanui again. I can also be seen lightly contradicting Te Awanui's telling of events, as if to 'correct' them, but then rushing to agree again:

Te Awanui: 'Because we all sort of know what the Treaty says, and most of us don't actually know what the Treaty in Māori says. Except that on the main points it's real different.'

Amiria: 'So they didn't go through the Māori version?'

Te Awanui: 'Nup. There was some: "It says something different". Something, eh?'

Rachael: 'There was a translation of the Māori version that we looked at as well'

Te Awanui: 'Yeah but it didn't-'

Rachael: 'It wasn't usefully organised at all.'

Looking back, it is embarrassing to see myself doing that. The work of Derald Wing Sue and his psychologist colleagues helped me think about this, with their discussion of 'racial microaggressions' (Sue, et al. 2007). These subtle everyday indignities include 'microassults', 'microinsults' and 'microinvalidations'. Sue and his colleagues note that: 
The power of racial microaggressions lies in their invisibility to the perpetrator and, oftentimes, the recipient... For the recipient of the microaggression, however, there is always the nagging question of whether it really happened...Many people of colour describe a vague feeling that they have been attacked, that they have been disrespected, or that something is not right (ibid: 275277).

This idea of 'invisibility' clearly relates to the insensitivity brought about by white privilege (discussed in the previous chapter) and the 'vague feeling' tells us something about the way that emotional responses underlie insiders' epistemic privilege, as Narayan argues. What I find most useful about this is the subtlety of the forms modern racism takes and that is conveyed by the term microaggressions. And specifically for my current discussion, I am interested in the way that this encourages us to minimise these little slurs:

In most cases, when individuals are confronted with their microaggressive acts..., the perpetrator usually believes that the victim has overreacted and is being overly sensitive and/or petty. After all, even if it was an innocent racial blunder, microaggressions are believed to have minimal negative impact. People of color are told not to overreact and to simply "let it go" (ibid: 278).

What was clear during Clara's workshop was that, regardless of her intentions, her dismissive gestures, awkward comments and defensive tones were having a negative impact on Kura and Te Awanui, who were becoming visibly outraged. My desire to be 'fair' to Clara was, in fact, dishonouring their emotional responses and the epistemic privilege gained from these feelings. The idea that people of colour 'overreact' to microaggressions also reflects the sanctions that dominant Pākehā culture place on overt expressions of emotion, which I came to understand much more deeply through a conversation Black Rainbow had about intimate relationships between Māori and non-Māori/Pākehā, presented in my next story. 


\section{Talking relationships: Identity, emotions, power}

Here I have included a large segment of the conversation we had about intimate relationships. We talk about cross-cultural communication, power, emotional expression, the connection between identity and our relationships and how larger structures relate to the specificity of individual experience. I have left the various arguments about these issues as they were discussed by the group, rather than laying another coat of analysis on top of them. For this reason, I have given supporting literature in extended footnotes, which hang off the points that members of Black Rainbow make. This discussion springs from two articles that we had read, so the theory is heavier at the beginning of the discussion and, therefore, so are the footnotes. In the later part of the discussion we expand on that theory and test it with stories about our own experiences. I have also taken short 'breaks' from the story to reiterate what is being said. These are only a fraction of the meaning that can be taken from the experiences and arguments participants share here and it is not my intention that they should be read as universals. I am interested in highlighting the meaning(s) that we created together, the points that remained contested and confused and how we connected theory to our personal lives. Indeed, one of the things I find especially interesting about this discussion is the way the group moves backwards and forwards between generalising statements about cultural difference, and complicating statements that resist generalisation. This shows some of the tensions between attempting to name cultural difference in relationships, while also trying not to flatten the complex identities of the people in those relationships into cultural stereotypes. 
'I didn't re-read the chapter from the sexuality book, but I read the paper that you sent,' Francis says turning to me. 'Which was academic.'

I laugh along with her and agree. Together again after the summer, we are sitting in Te Awanui's lounge on Waitangi weekend (a holiday that marks the signing of the Treaty of Waitangi between iwi Māori and the Crown in 1840), discussing two readings. The first is Marewa Glover's, 'Eroticising equality, coming to power', from Jessica Hutchings' edited book, Sexuality and the Stories of Indigenous People (2007). The one Francis is referring to as 'academic' is Ken Waldman and Luis Rubalcava's, 'Psychotherapy with intercultural couples: A contemporary psychodynamic approach' (2005).

'It seemed, from memory,' Francis says 'that they were talking about quite a different thing-problems of cross-cultural communication in relationships, rather than power differences as a result of ethnic differences.' 'Yeah, true...' I say, 'I think the thing I found most interesting about that psych article-which instead of sending out, maybe I could have summed up in two sentences - was the way that it can be easy to pathologise someone else if you don't understand where they're coming from culturally and you're expecting them to fit within your values. So you assume that everything that differs is just them being a bit crazy or immoral. ${ }^{6}$ And you could relate that to power things in that

\footnotetext{
${ }^{6}$ The meaning I took from Waldman and Rubalcava’s article is perhaps stronger than they intended. Re-reading it I was not able to find reference to 'pathologising' cross-cultural partners. Waldman and Rubalcava point more gently instead to a lack of awareness about the socially constructed nature of individual values and behaviours:
}

One of the difficulties in working with intercultural couples... is that each partner views the other (and any difficulties that may exist between them) through his or her own cultural organizing principles, without being aware that the perceptions, and the 
when there's a dominant culture that is judging other cultures, through their values, then they subordinate the other one by treating them as if they're crazy. But just personally, when I read it I was really affected by it, because I think that happened a lot with Hayden, ${ }^{7}$ who I was with for many years. And because he was an orphan and had violence in the home and had suffered from a lot of depression, it was easy to think the things he was doing were from him being damaged, rather than a cultural difference.'

'Do you feel like you could give an example of that?' Hayley asks.

'Yeah,' I reply, 'because around the same time I read an article in Talking Past Each Other, and they talk about whakamā, the shame thing. ${ }^{8}$ And that section exactly explains Hayden, his behaviour and his way of shutting down. ${ }^{9}$ That was something I just thought was him not being able to cope with anything, rather than being a

feelings that arise from them, are individual, subjective and culturally influenced. Rather, individuals presume that his or her perception of the other is objective, true and factual. Each partner makes sense of the other's affect, behaviour and expression in terms of his or her own unconscious cultural organizing principles (2005: 236).

Though, they do note that a lack of awareness about different cultural values led to mutual frustration, which often results in 'further polarization and attempts to denigrate the other's perspective' (ibid. 238).

\footnotetext{
${ }^{7}$ I have read this to Hayden and discussed it with him.

${ }^{8}$ Metge and Kinloch write:
}

Whakamā is used by Maoris [sic] to describe both a 'state of mind' (more accurately a state of feeling) and the behaviour associated with it. This behaviour involves varying degrees of withdrawal, beginning with downcast eyes, monosyllabic answers and minimal response, passing through a form characterised by a shuttered look, stony silence and unresponsive immobility, to running away and 'hiding' (whakapeke) (Metge and Kinloch 1999: 22-23).

Joan Metge covers this in much more detail in In and Out of Touch: Whakamaa in Cross Cultural Context (1986).

\footnotetext{
${ }^{9}$ Perhaps rather than saying this 'exactly explains' his behaviour, a better way to put this is that it offered me a new interpretation of that behaviour.
} 
different way of coping. And it was quite sad, reading those two articles together, and in retrospect. It was sad. I think at the time I thought that I was more emotionally intelligent or competent. I thought I could teach, or encourage, him to deal with relationship stuff in a different way. Really I was just doing what they talk about in that article-a Pākehā tendency to try to talk people out of feeling that way, rather than letting them be and talking to them about it later. ${ }^{10}$ When I first read it, it was really painful because I wasn't in contact with him at the time so I couldn't talk to him about it. But more recently, we were able to talk. I read out that section to him and every line he was like: "Yep. Yep. Yep." He still has those same ways of relating and I guess I was trying to encourage him to feel like his way of doing things was ok. But unfortunately, his attitude was: "Oh well, just because it has been described, just because Māori people understand it, doesn't mean it's a good way to be".' Throughout my story, Kura makes a lot of sounds of recognition. I feel exposed, like I have shared too much too early and I pull back to academic language, where I feel more comfortable. ${ }^{11}$ 'I guess it made me think that ways of

${ }^{10}$ Metge and Kinloch write:

Maoris [sic] readily recognise whakama and decide how to handle it according to its likely cause. Usually they leave the victim alone for a while to recover, especially if his whakama $\bar{a}$ is caused by shame for wrongdoing. There is a saying: 'Let him alone: he is punished by whakamā'. For to Maoris, social isolation, whether inflicted by self or others, is a punishment... When those around him consider that the time is ripe, they take steps to bring the victim back into social circulation: by a loving touch, an offer of food or a cup of tea, an invitation to join in some activity, a word of praise or reassurance. The one treatment guaranteed not to succeed is the one Pakehas [sic] usually try in ignorance and frustration: trying to talk them out of it, whether jollying or scolding (Metge and Kinloch 1999: 24).

${ }^{11}$ I have to thank Laurel Richardson for helping me understand how I use academic distance as a coping mechanism. Richardson acknowledges this tendency in herself in her moving book (2007) Last Writes: A Daybook for a Dying Friend. 
reacting emotionally are relational, and it all depends on how the people around you react to the way that you are being emotional, whether it works well or not. ${ }^{12}$ After what feels like a long silence, I say, 'I was trying not to do the first big spiel and then I did one.' Everyone laughs.

Te Awanui says, 'Thanks for doing the first big spiel.'

Here I would like to take the first 'break' from the story to reflect on what is being said. Reading about whakamā made me question what I thought I knew about my relationship with Hayden. This allowed me to see how Pākehā culture influenced my expectations about healthy relating. It also illustrates how those expressing emotions in ways that differ from the dominant cultural norms may become framed in deficit terms, especially by those ignorant about this cultural difference. This obscures power dynamics and hinders communication across difference.

'I felt like, in that article that you sent,' Kura says to me, 'lots of the examples of the culturally specific stuff-I don't know how you determine what was culturally specific and what's just a vast generalisation. So, it was interesting, but I couldn't see how it could be applicable, because I don't know how you would decide those characteristics were culturally specific. Maybe it was just some of the examples they used, they were just really wide and generalised. Like: "these people are used to communal living and these people are capitalists", it just seemed like such wide assumptions.'

\footnotetext{
${ }^{12}$ Waldman and Rubalcava touch on this, referring to anthropological assertions of the 'relational nature of emotion' (2005: 235).
} 
'Yeah, that's true,' I say. 'I wondered that myself, how you actually put that into practice-it is obviously for people working with clients-without being just real stereotyping?'

Francis says, 'Irihapeti Ramsden, when she's talking about cultural safety, talks about how every relationship is a bicultural relationship, because everyone is coming from their own space. Then you don't have to make generalisations about why you think that way or behave that way. ${ }^{13}$

'I haven't quite thought this through,' Hayley says, 'but does that mean their social culture and their family culture?'

'There's always difference in power,' Francis replies, 'even if they shift. Even if it works out that there is equal power, in different conversations, it shifts.'

'It just seems that if the power is shifting,' Hayley says, 'then there is an acknowledgement that certain aspects of that culture gives them power. Which is a stereotype of that part of culture. Does that make sense? Not really?' There are a few murmurs of agreement.

${ }^{13}$ Irihapeti Ramsden's innovative view of 'biculturalism’ is that: ‘All interactions are by definition bi-cultural as they essentially occur between two people, the nurse/midwife and the client. However, bi-cultural in this instance again, is referring to culture in its broadest sense rather than being focused on ethnicity' (Ramsden 2002: 114. Italics in the original). This is a deliberate move away from the more common use of 'biculturalism' as 'a euphemism for Māori and non-Māori relationships' (ibid: SII, 7: 9). Rather, the two cultures in this bicultural interaction represent the two people involved, and the cultural difference between them may include 'socio-economic status, age, gender, sexual orientation, ethnic origin, migrant/refugee status, religious belief or disability’ (ibid: 114). Ramsden’s notion of 'all relationships as bicultural' therefore focuses our attention on how we negotiate difference in cross-cultural interactions. This reminds me also of Avril Bell's use of Lévinas’ philosophy of the unknowable other (2008). 
'I think this relates to something I was reading the other day,' I say, '-because I'm trying to get my head around theory at the moment. Anti-oppressive theorists see every experience of oppression as specific and fluid and multiple and everyone's got intersecting-sorry.' I interrupt myself and laugh, 'there's lots of different stupid words in there. But, no one individual can be stereotyped is what I'm saying, but at the same time there are stable and clear systems of oppression that you can talk about collectively. ${ }^{14}$ So if one individual isn't always the oppressor-they might be an oppressor in a moment, but that's not all they are- they are still tapping into those systems. Is that kind of what you are talking about?'

'I don't know,' Hayley admits, 'it wasn't a fully formed thought. I was just thinking, it doesn't necessarily mean you aren't creating stereotypes if you say that everyone comes from a unique situation.'

'But it doesn't mean that you have to be creating stereotypes,' Francis says. 'Like: "You are a woman, so you must think like that. And in a relationship with a man, there will be this cultural difference". You know you are dependent on stereotypes in that situation. ${ }^{15}$ My understanding of what she was saying is that everything is

\footnotetext{
${ }^{14}$ I am drawing here on Moosa-Mitha's (2005) summary of the ontological assumptions of anti-oppressive theory as grounded in the subjective, differential and specific nature of oppression (as discussed in chapter 1, 'Methodology: "Learning to be affected” by Kaupapa Māori’').

${ }^{15}$ Ramsden's distaste for cultural stereotypes can be most clearly seen in her critique of Transcultural Nursing education:
}

Nurses are taught to observe people according to their culture specific behaviour from a multicultural model. They therefore think that they require a sort of cultural check list. A cultural smorgasbord. Such a model does not allow for the diversity within cultures, for the differences between conservative and liberal, age and youth, urban and rural, rich and poor and gender interactions (Ramsden 2002: SII - 5).

This cultural stereotyping also supports the nurse's position of power, as the one who decides what is culturally appropriate, rather than being open to genuine expressions of difference from the other person. 
relationship specific as well. In some contexts it is more powerful to be, I don't know, an out lesbian than it is to be straight.'

'Sometimes it's more powerful to be Māori,' Kura adds, 'sometimes it's weird.'16 'Yeah,' Francis agrees. 'If only there were more contexts like that.' We laugh and then fall into silence.

'So, in that article that you suggested, Kura,' I say, 'the section about BDSM, ${ }^{17}$ was that her point there? That this is kind of a solution? A way of making power dynamics explicit and then working within them ${ }^{18}$ Is that what you guys took out of it? It was really interesting, but I didn't know exactly what the suggestion was there.'

'If it was the solution?' Kura asks.

'Damn, I wish I read things!' Te Awanui laughs.

'I can grab the book out of the car if you want?' Francis says.

\footnotetext{
${ }^{16}$ Moosa-Mitha notes that within the work of anti-oppressive theorists (notably hooks, 1989 and 1990), 'Concepts that treat the margin as being in a dichotomous relationship with the centre are also disrupted; the "margin” is also recognized for being a space of power' (2005: 63).

${ }^{17}$ Bondage and discipline, domination and submission, sadism and masochism.

${ }^{18}$ Marewa Glover writes:
}

One sexuality that overtly promotes healthy, non-abusive relating where individuals needs are honoured despite gender, sexual preference or race, is BDSM... I like the overt recognition of power and an institutionalised framework for its analysis, deconstruction, exchange and reconstruction as play that BDSM demands. There is an institutionalised code of ethics (tikanga) to govern relationships and BDSM practice to insure the physical and emotional safety of everyone involved (Glover 2007: 64-65).

Although, she goes on to add 'The potential I see in BDSM as a model for equitable relating is probably not played out in real life by very many people’ (ibid: 65). 
'I can't read!' Te Awanui replies. ${ }^{19}$

'We could read aloud,' Kura says. 'It would be fun.'

'Ok!' Te Awanui laughs.

'Hayley has a lovely reading voice,' Francis says, and sets off more laughing. 'But what I took from that-and it has been ages since I read it, so I might be wrongyeah, it was about making it explicit. There are awesome lessons we can learn from BDSM, like to negotiate.'

Complex identities require complex power negotiations in relationships. When trying to understand difference in cross-cultural relationships, there is a danger of generalisation, which obscures the variety of identities within cultures. The notion that every relationship is bicultural allows a greater recognition of the specific difference that each person brings to every relationship, and potentially offers an ability to negotiate more subtle differences in power.

'Is there a way we can make this conversation more inclusive?' Hayley asks, 'Like give a summary of the reading? Or choose a point out of the reading and then try to talk about that?'

'Or maybe just use the reading as a jumping off point to talk about personal relationships,' Francis suggests. 'If that's something people feel ok talking about.'

'So the reading was about Māori and non-Māori in intimate relationships, eh?' Hayley says. 'And what the dynamics are?'

\footnotetext{
${ }^{19}$ Te Awanui has problems with terrible migraines, making it difficult to read for great lengths of time.
} 
'Something I'm interested in is the way it seems Māori and Pākehā deal

with emotions,' Te Awanui says. 'I was reading this thing the other day-I can read some things a little bit-it was this thing I got from a relationship counsellor years ago. It was talking about how to have good arguments. And it was being very much like: "If you feel emotional, just push that down".'

'Oh my god,' Hayley sighs as everyone laughs.

'"And then talk about it nicely",' Te Awanui continues. '"Or talk about it later". And for me, the more I don't talk about something, the more upset I get. And I don't know if that is a cultural thing, but it seems like Pākehā people are really good at not dealing with it at the time. ${ }^{20}$ Or I wonder if it's a cultural thing, that it is seen as a good thing to not get upset. ${ }^{21}$ And if you get upset, to just be passive aggressive. Ha! No: "do something later when you're not upset".'

'Yeah, that is a really common description of a western cultural value,' Francis says, 'that's supposed to suit men more than women and yada yada.'

${ }^{20}$ Metge and Kinloch make a similar observation, writing that:

Pakehas generally dislike open displays of hostility, requiring that individuals should at least attempt to hide their feelings under surface politeness, and they are generally harder on physical than on verbal expressions of it. Maoris and Samoans, however, believe that the repression of hostility is unhealthy both psychologically and from the community point of view... Covering it up they see as folly and hypocrisy (1999: 28).

${ }^{21}$ In Watching the English Kate Fox supports this idea when she points to the 'strict prohibitions on earnestness, gushing, emoting and boasting' that underpins English culture: 'Rather than risk exhibiting any hint of forbidden solemnity, unseemly emotion or excessive zeal, we go to the opposite extreme and feign dry, deadpan indifference’ (2004: 66). Brigitte Bönisch-Brednich recognises this same tendency in New Zealand, noting that, '[f]or foreigners, it is very hard to learn this game and neither New Zealanders nor the English seem to make many allowances for misunderstandings here' (2008: 9). 
After a period of silence, Amiria says, 'Sometimes it's so hard to know what is attributed to your culture-being Māori or Pākehā-and what's attributed to all sorts of cultures that you're involved with, you know?'

'Yeah,' I agree, 'sometimes there's just differences between introverts and extroverts, stuff like that as well.'

'And I wonder,' Hayley says, 'when we talk about emotions or expressions of culture are we talking about how people grew up? Or ethnicity?'

'Or your history,' says Amiria. 'That's all interesting stuff.'

'Francis and I were talking about that a little bit in the car,' Hayley says. 'We have really similar backgrounds, in the way we were brought up. Really similar. But we are really different in the way we express ourselves.'

'That's just because I'm older and smarter,' Francis jokes and everyone laughs before settling back into silence. Sounds of laughter drift over from the Waitangi weekend party next door.

'I suppose I've only had relationships with Pākehā people,' Te Awanui says. 'I've never been in a relationship with another Māori. But with men and women, usually I feel like I'm crazy because I'm so overly emotional. And I think maybe I'm just real extreme, but I wonder...I think it's real valuable to deal with shit when it comes up. But it is really hard to say if it is a personal thing or a wider thing. But it is the same with boys or with girls; it's the same with people from lots of different backgrounds. So maybe I'm just crazy!... But, maybe not,' Te Awanui ends in a small voice. 'I wonder about that.'

'I guess there is the other part of it,' Hayley offers, 'that what's "crazy" or "not crazy" is being judged by Pākehā standards and what's the right way to show your 
emotions. So no matter where they come from, that is still part of culture affecting your intimate relationships.' 22

'Yeah, I think that's where power comes in,' Francis says. 'All the power is on one side. Most of us have been taught from a really young age not to get emotional, and that it gets in the way of good outcomes, and a reasonable discussion is not an emotional discussion.'

My phone rings, cutting Francis off. It's Mara, ringing to say she won't make it to the meeting. She has been at a protest about Egypt, which was led by a man known for his abusive behaviour. This made Mara grumpy and she just wants to go home and unwind. After I hang up, we talk briefly about this before getting back to the discussion topic.

'Can you remind me what you said?' Hayley asks Francis.

'You can say: "It's cool to be emotional" or "It's not cool to be emotional", but all the power of the culture we're in says: "It's not cool to be emotional". So when you're in a discussion with your partner about that, it's you against the world. ${ }^{23}$ Everyone laughs.

'It's already there that you shouldn't be,' Amiria says.

'Yeah,' Francis says, 'I can make someone else feel crazy because everyone's on my side, but they can't make me feel crazy.'

${ }^{22}$ In 'The socially constructed nature of psychology and the abnormalisation of Māori', Keri Lawson-Te Aho makes a similar point and comments on the large amount of Māori people receiving psychological services (in psychiatric hospitals, prisons and other state institutions) as an extension of colonisation:

The corruption in clinical psychology occurs when hundreds (perhaps even thousands) of Maori people are redefined as abnormal because they do not fit Pakeha defined notions of 'normality'. The corruption in clinical psychology occurs when Maori misery is created in order to make a buck (1993:31. See also Glover's essay in the same issue).

${ }^{23}$ Similarly, Lawson-Te Aho cites Moana Jackson as saying 'those who hold the power to define hold the power of reality construction' (1993: 26). 
'Yeah, that's dumb!' Te Awanui slaps their leg, laughing 'I hate that shit!'

'In some ways my experience has been different than that, though,' I say, 'because with Hayden, he would try to make me feel crazy, because he didn't want to talk about it. Then it would escalate, because, like you say, if someone is saying: "It's nothing, don't worry about it", I get more: "No, this is a problem and this is why!"' I laugh nervously and continue. 'But, like I said, it was because he didn't want to talk about it right then and he needed to go away and gather himself together. And back then I thought that was him not being able to deal with emotions and that kind of thing. But at the same time, I was trying to make him feel crazy I guess, because he couldn't deal with it. So, it was two things happening at once. And I have read the opposite as well where a Scottish woman who is used to talking about it right then and exploding (that was her family background) and her Māori partner would want to walk away. His family background was to just keep everything personable and, not necessarily positive, but you don't let things explode. ${ }^{24}$ So, I don't really feel like I know enough to understand what the big trends are. I can only talk about my own stuff.'

'Do you think there are big trends?' Francis asks. 'I just feel like we're a bunch of different pressures. As women and Pākehā or Māori and queer or not queer and middle-class or not middle-class. There is just heaps of different things pushing us in different directions and we just turn out the way we turn out. ${ }^{25}$

\footnotetext{
${ }^{24}$ See C. Archie's (2005) Skin to Skin: Intimate True Stories of Maori-Pakeha Relationships.

${ }^{25}$ Here, Francis' comments reflect theories of 'intersectionality', which highlight how individuals who differ from the norm in the more than one of the various cultural categories of gender, race, class, sexuality and ability experience multiple forms of discrimination simultaneously (see Crenshaw 1991).
} 
The dominant culture dictates a high level of control of emotional expression and this impacts of the self-perceptions of those raised to be more emotionally expressive, including many Māori, who may feel 'crazy' in relationships with those who conform more closely to Pākehā social norms. While power is shifting, those aligning themselves with the dominant culture can tap into the considerable power of that culture to define appropriate emotional expression.

'There are so many factors, eh?' Amiria says and others agree. 'Yeah, I've only been with Pākehā people as well, like non-Māori. So, I was thinking just before how it would be if I was with a Māori person. Being in a group like this with more Māori people is totally different from how I'm used to interacting with most other people. So it is kind of the same as intimate relationships. It would be quite different, I think.'

'I'm wishing that I had re-read it as well,' Hayley says, 'but I remember that there is some point in it about how Māori women could never reach their potential if they are in a relationship with a Pākehā person.'

'Yeah, it did say for her, she had decided that,' says Kura. 'That she didn't spend as much time being Māori. Or trying to be Māori or learning te reo or stuff like that. I thought that was quite extreme, though. ${ }^{26}$

${ }^{26}$ Glover writes:

In relationships with Pākehā women, it was their cultural ways, language, food and social culture that were practised. They were less likely to support me getting a moko, for instance. Single, or in a relationship with a Māori, I was more likely to learn and practise te reo, waiata [songs], karakia [incantations], tikanga, discuss Māori politics and watch Māori television programmes. Subsequently, I was more likely to experience and express creativity and express myself as a wahine Māori. On top of all this, I was tangata whenua and felt and expressed a level of manaakitanga [hospitality] towards my Pākehā 'manuhiri'. The 
'Was she saying it for her or was that what she thought generally?' Hayley asks. ${ }^{27}$ 'I think it was just for her,' says Kura.

'I thought that was interesting,' I say, 'because if you just said: "I could never be fully Māori or reach my full potential in a relationship with a Pākehā", that sounds quite confrontational or whatever. But because she broke it down and was like: "Because you find you do less of this kind of thing, you are less likely to pursue that kind of thing, you are less likely to have these conversations" I was like: "Oh yeah, of course". You are who your friends are and who you spend time with, you know?' 'Arh!' Te Awanui cries in joking, but perhaps real, alarm. Everyone laughs. 'Not totally,' I try to reassure them, 'but you know what I mean, you end up having the sort of conversations that the other people you hang out with want to have.' Te Awanui gives a 'Mhm' that sets off more laughing.

After we have quietened down for a while, I say, 'It's interesting too, she talks a little in that article about how her identity is reduced by being in a relationship with a Pākehā. I don't know if this summary is too extreme, but the Pākehā people she was dating, their identity or experience was enriched by dating a Māori person, because they had access to her whānau and different cultural things they could work into their art or poetry or philosophy. That was quite interesting.'

'And that it gave them some kind of status,' Hayley adds and others agree. ${ }^{28}$

relationships were not good for me in that my being, let alone my development as wahine Māori [a Māori woman], was undermined, if not actively discouraged (Glover 2007: 62-63).

${ }^{27}$ While Glover is speaking from her own experience, she also points to expectations of the wider lesbian-feminist community: 'The thinking back then was that "every Pākehā, no matter how liberal, well meaning, or politically sound, is racist, because white privilege which is part of the overall scheme of patriarchal oppression, operates regardless of gender”.' (Ngahuia Te Awekotuku, quoted in Glover 2007: 62. Italics in the original). 
'It's so sad,' Francis says. 'It reminds me of something I read about when the pill first came on the market-it just meant men had more sex. It's that same: whatever happens, the people in power always win.' She laughs and adds, 'I don't know why I found those things so analogous.'

'It's about power,' Kura says.

'I guess with Māori and Pākehā in relationships,' I say, 'Māori already have a really good intimate knowledge of Pākehā culture. So it's not like there is anything to learn for Māori people in a Pākehā relationship necessarily. Whereas, for a lot of Pākehā people, it's novel. ${ }^{29}$

'I don't know,' Te Awanui laughs, 'I'm always learning new things!' Everyone laughs with them.

'Maybe if it was truly a bicultural or cross cultural relationship,' Francis says, 'rather than once again, the Māori person is on that side.'

I'm definitely more exposed to Māori stuff, and do more Māori stuff, through going out with Francis,' Hayley says. 'Through no effort of my own.' She laughs. 'That's pretty much why I go out with you.'

${ }^{28}$ Glover writes:

I could see how Pākehā women got kudos for having a Māori partner. It meant they weren't racist. They gained entry to a Māori world, got to learn Māori beliefs, language, tikanga and symbols that they could use, appropriate was the derogatory term used, in their poetry and art. They got access and often acceptance into our whānau, a phenomenon that I found was not reciprocated by Pākehā families (Glover 2007: 62).

${ }^{29}$ I am drawing here on Ranginui Walker (2004) and Alison Jones’ (1999) observations that Māori tend to be 'bicultural', having a deep understanding of Pākehā culture, compared to monocultural Pākehā. 
Simultaneously Kura says, 'The props, ${ }^{, 30}$ and Te Awanui says, 'You get street cred. ${ }^{, 31}$ We all laugh.

'If only you did,' Francis laughs. 'I wish I could offer you that.' After a moment she continues, 'Yeah, it seems strange because, like Hayley was saying, I'm culturally completely Pākehā, having grown up in a Pākehā household and yet there is still stuff we struggle around. I guess, because of the stuff we're thinking about at the moment. Sometimes Hayley and I find that if I'm exploring ideas, I'm oversensitive if Hayley's critical, because she represents all of Pākehā culture.'

'Yeah, it's something that I don't think about enough,' Hayley says, 'that it's not just two people discussing ideas. If we are discussing ideas from te ao Māori, we're in really different positions in that conversation.'

'And it's hard to keep that sort of thing in your mind,' I say, 'because when you're just with somebody all the time and they're your buddy and you're used to debating stuff, it's easy to lose sight of those positions and just feel like you meld more into each other than you really do.'

'Yeah, if I'm arguing because I find Francis annoying,' Hayley says and everyone cracks up, especially Francis, 'but actually I'm arguing something that is a really commonly held worldview, then that's what I'm pushing onto her. Rather than just arguing because you're being annoying.'

'Because l've paused after speaking for half an hour,' Francis laughs, 'and you thought you'd take the opportunity.'

\footnotetext{
${ }^{30}$ Proper recognition.

${ }^{31}$ Credibility.
} 
This seems to get to the heart of the relational nature of identity, which is intimately shaped by the people we have relationships with. This can have different implications for Māori and Pākehā in cross-cultural relationships. Pākehā may find their identity expanded and their status increased through dating Māori, while for Māori who are actively trying to develop their Māori identity and cultural competency, Pākehā partners can represent the wider assimilative pressures of the dominant culture.

We sit for a while without speaking, and the sounds of the party next door fill the space.

Then Amiria says, 'I grew up quite Pākehā as well. I think a lot of Māori have the same experience if they're not in those really tight knit whānau settings. So it's kind of logical that I ended up with Pākehā partners.'

'There's lots of good reasons for it,' Te Awanui says. 'Like: "Pākehās can do anything and Māori just sit on the couch and drink beer and be violent to their partners".' 32 They laugh and we join them. 'I had some real interesting conversations at this workshop we went to about why you like who you like. I thought that was real interesting, how stereotyping affects who you're attracted to or what you think about people from different races and...'

'People from your own race even,' Amiria adds and there is a general hum of recognition around the group.

\footnotetext{
32 These stereotypes Te Awanui refers to seem to reflect the application of deficit theory to Māori, which Leonie Pihama and Mera Penehira note is common in everyday language in Aotearoa New Zealand and is used to explain Māori educational underachievement and crime rates as the result of family environments that are 'lacking' or 'culturally deprived' (2005).
} 
'When I was a kid,' Kura says, 'I was obsessed with the fact that I had to find the brownest boy possible to be my boyfriend. So I would have brown babies, so my children would be visibly Màori. But I was also obsessed with the thought that if I had a Māori partner, my life would be a lot more Māori. All my boyfriends were Māori,' Kura says, 'but everyone l've seen in the last five or so years have been white.'

'What do you think has changed in the last five years?' Francis asks.

'Probably my sexuality,' Kura says. 'But I don't know what else. I often think of lower-class as having a brown face. In the last five years, my mum got a well-paying job and all of a sudden we stopped being really poor. Maybe that had something to do with it, I started being able to fit in with the cool white kids.'

'I just recently read a book by an African American man,' Francis says. 'He's a geek and he talks about how being book smart and black means turning your back on being black. To be culturally black means to be a 'brother' and you can't be a 'brother' if you're all about the books. I'm still trying to get my head around how, but I think it is all really similar. When you head down a path you take on a language that definitely sets you apart from people of your own culture. In a way that other working-class people don't have to go through-leaving behind your own race. $^{\text {,33 }}$

${ }^{33}$ Francis is referring here to Vershawn Ashanti Young's book, Your Average Nigga: Performing Race, Literacy, and Masculinity. Young writes that:

Literacy is first and foremost a racial performance... When we ask black students to give up one set of codes in favor of another, their [Black English Vernacular] for something we call more standard, we're not asking them to make choices about language, we're asking them to choose different ways to perform their racial identities through language (2007: 142). 
'I remember seeing this bit on Oprah,' Amiria says, 'where she was talking to Will Smith. They were talking about how they change the way they speak in certain settings, like when they're with black people or rich white people. Or rich black people. It all kind of changes.'

'Have you found yourself doing that before?' Kura asks.

'I don't know,' Amiria says. 'I kind of revert back to speaking Māori-like with my family and my sister.'

'I think I make more of an effort to talk Pākehā when I want to sound smart,' Te Awanui says. 'When I want to get stuff, like when I'm at my doctor or at WINZ. ${ }^{34,}$ Everyone laughs with them on this. 'I want something and I know you're judging me, so...'

'It's funny,' Francis says, 'because l've started doing the opposite and it's really working for me.' This gets a big laugh. Te Awanui claps their hands together and roars with laughter. 'I speak like I completely don't know what's going on and then people take the time to explain stuff to me and I end up getting what I want instead of having an argument.'

'Oh, right!' Amiria says.

'Those games just suck, eh?' Francis laughs.

'Did anyone watch that thing on channel one a couple of weeks ago?' Amiria asks. 'Anatomy of Race? ${ }^{35}$ This woman was doing an experiment on race-she switches the tables. She divides the group into brown-eyed and blued-eyed people, and ostracises the blue-eyed people. It's this bullying tactic and it's kind of gross, but it is interesting to see how people reacted to it. She's done the experiment in different parts of the world and had different outcomes, but this time they just weren't having a bar of it. They were saying things like: "I'm not racist, I don't need to be put

\footnotetext{
${ }^{34}$ Work and Income New Zealand, social welfare service.

${ }^{35}$ See Curwin et. al. (2009).
} 
into this kind of setting, I know what it's all about". At the same time you could see they were doing the exact same thing-there were quite a few black people in the other group and they were just going silent. That spoke volumes, more so than turning the tables on the blue-eyed group. But yeah, there was this guy (he had big dread locks), a black guy, and he grew up pretty white-with white parents. He was saying when people speak to him on the phone they don't know he's black, but as soon as they see him it changes straight away. Yeah, he doesn't take his daughter to school because she looks quite white,' Amiria says.

'Oh God,' says Francis.

'And because it's quite a nice school, he doesn't want to spoil it for her.'

'Wow', Kura says, as I say, 'Stink'.

'That reminds me of something that Irihapeti Ramsden did,' Francis says. 'It wasn't a research study but when she was doing stuff with kids in the '80s, I think-she noticed that some kids seemed to be proud of their cultures and others didn't. So she started asking every kid she met if it's good to be whatever they were: "Is it good to be a Pacific Islander?" "Is it good to have Pacific Island parents?" or something like that. The Pacific Islanders and the Pākehā kids were like: "That's a really weird question". And the Māori kids generally said that it was not good to have Māori parents. It was really young kids, like five or six.'

I say, 'Yeah, getting back to that relationship thing, that's what I was thinking about before when we were talking about Pākehā getting cred for being with Māori. I think, what situation you're in and how you view things affects who gets the cred. Because when me and Hayden were together, for him being with me meant more access into a Pākehā world. All of his brothers had Pākehā girlfriends. Being Māori was something that, well, he still thinks is not a good thing to be. It means being on the dole or a truck driver and all those things that he grew up with that were negative to him. And not just those socio-economic things, but Māori culture in 
general just being something to get away from. ${ }^{36}$ Even at the time I thought that was sad, and I wasn't really comfortable with it, but at the same time I didn't understand enough about what it meant to be Pākehā to know how much pressure being with me put on him to be a certain way.'

While I speak, Te Awanui attends to their son, Tim, who is eating with us. Te Awanui apologises to me and after a moment says, 'I wonder if... I guess if he had more access to a Pākehā world through going out with you-that probably doesn't really translate to cred, as far as from his own culture goes: "sweet, you've got a Pākehā girlfriend".'

"Well, it did from his mates, you know?" I say. "But probably not from his aunties or whatever. Yeah, I have no idea. So it depends, what you're talking about."

'Yeah, I guess if you have internalised all those messages about how shit it is to be Māori,' Francis says, 'then of course you'd want a Pākehā partner.'

We sit in silence for a while and watch Tim eat and chat away to himself.

As this silence stretches out too long, I grasp for something to say, 'I remember when I was eighteen, my friend's dad-who is fairly racist-saying to her: "Don't ever marry someone from another culture, because since you're the woman you'll be the one that has to compromise and adapt to his culture". That was obviously just his thought, but it's always made me wonder, how much of that is true.'

'Well,' Te Awanui laughs, 'if you're Pākehā everyone else has already adapted to your culture!'

'Yeah, true!' I feel a little stupid for mentioning it as Te Awanui keeps laughing, but I really like their response. 'I guess that's what I was thinking-if you're already the dominant culture, is that the case?'

\footnotetext{
${ }^{36}$ When I read this to Hayden, he asked that I clarify that Māori is not a good thing for him to be. He does not mean that Māori is not a good thing to be in an absolute sense. There are aspects of Māori culture that he loves, for example polite manners and an emphasis on family. Nonetheless, there are certain parts of Māori culture he 'despises', such as 'staunchness', the warrior image, 'enforcing your views with your fists', misogynism and an embracing of the formula: 'to be Māori is to be criminal'.
} 
'If you have to adapt to someone else's culture at all,' Te Awanui laughs, 'it's only going to be a case of give and take.'

'Yeah, totally,' I say and we fall into silence again.

Generalisations about cultures have real world effects, including impacting on affective experiences of attraction. Internalised racism influences partner selection, with Pākehā partners representing an escape from negative stereotypes about Māori. On the flip side, attraction to Māori people can reflect a desire for a 'more Māori' life.

Te Awanui and Hayley fuss over Tim for a bit, then Hayley says to Kura, 'This is kind of a tangent, but what you were saying about wanting to go out with really Māori looking boys, so you could have Māori looking babies-that made me think about the messages around me when I was growing up. My grandmother was like: "Don't bring home a Māori boy", but then my friend's middle-class parents were like: "Aw, you should marry a black boy, because then you'll have really cute babies".'

Everyone laughs as Hayley explains, 'You know, real fetishised.'

'My mum was like that,' I say.

'Which was somehow deemed more acceptable,' Hayley says, 'than my grandmother saying: "Don't bring home Māori boys"-which is obviously not acceptable either - but is that really more respectful?' 'Well, it's more true!' Te Awanui says and gets a laugh from the group. 
'I keep thinking of this time I went out with a Fijian boy,' I say. 'My good friend met

him once, and she kept talking about him-how did she put it? Something like:

"primal sensuality"?'

'Woah,' Hayley says and the rest of the group laughs.

'Every time she said it,' I laugh, 'I'd just be like... "Um"...'-blank face.

'Ewhr!' Amiria says.

'Yeah, I guess those cultural stereotypes really affect what you expect

from someone in a relationship,' Hayley says.

'Oh yeah!' Te Awanui exclaims.

'What did that make you think of something?' Hayley asks.

'Um, no.' Te Awanui's quick response makes the group laugh. Te Awanui seems to want to hide, they shrink into themselves and say, 'Cake. It made me think about cake.'

'Man, there is so much awful stuff around sexuality,' Francis says.

'Yeah,' I agree, 'and as you say, being in a compliment doesn't actually make it ok.'

'Or particularly complimentary!' We all laugh and Francis adds, 'Jesus Christ.'

'I know!' I say. 'And she never said: "Because he's black, right," but it was just so obvious.' This sets off another round of laughter.

'Was he tall or...?' Hayley laughs.

'He wasn't tall,' I say, and Kura cracks up. 'He was black and he was a good dancer, that's all she knew about him.' The room explodes with laughter. ${ }^{37}$

\footnotetext{
${ }^{37}$ I was concerned about including this story about someone so close to me, especially because in the moment of joking around, I had brushed over much of the complexity of this situation, including that I had had little in common with this young man other than attraction. So, perhaps my perspective was not so different than hers, even though her choice of phrase made me uncomfortable. When I spoke with her about including this story, she agreed, provided I make it clear that it is me making the link between the word 'primal' and this young man being Fijian, not her. To me, a phrase like 'primal sensuality' has clear connotations of persistent colonial stereotypes about men of colour as being closer to nature, possessing an 'uncontrollable native sexuality',
} 
We talk for a while about whether or not things have improved since we were kids, in terms of racist comments being publicly acceptable. Amiria concludes, "I think it's at that stage where they know it's not right to say stuff. A lot of parents still are quite racist, but the kids are told they shouldn't say racist things.'

'It seems to me,' Te Awanui says, 'that people know it's not good to be racist now, whereas people thought it was ok to be racist. But it doesn't change what they think. ${ }^{38}$ They laugh. 'Or what they say! My mum's "not a racist" but my sister was seeing this guy-who I think was part Fijian-and mum was always referring to him as a "gorilla". I didn't know why. Then I met him and I was like: "Because he's Fijian. That is obviously why". But you know, she's "not racist". He looks like a gorilla to her, so it's perfectly ok to go around saying that. When my older sister first got together with her husband, about fifteen years ago-he's Tongan, mum was like: "Oh, those bloody Tongans, they're all in gangs, they all do this and that". I said: "That's stupid. Just because you know one Tongan person who's in a gang. That's like saying all Māori are in gangs". Now it's different, she doesn't say: "All Tongans are in gangs", but she still thinks the same things.' Te Awanui laughs, 'She probably still thinks they're all in gangs! She's like: "They bloody let one of the older sisters name the kids! 'Cause that's what those Tongans do". But then, my family context is probably not a very good indication of general society.' Amiria and Kura laugh along with Te Awanui.

'When I think about my sister's relationship,' Hayley says, 'she's engaged to a Māori woman, and yeah, my sister's become slightly less racist and my mum has become

against which white men can be defined as 'civilised' (Donna Matahaere 1999:114. See also Suaalii 2000, for how similar stereotypes are applied to Pacific Island women). For my friend, however, these words signal nothing more than an innate quality that she saw in him, which she may have chosen to use for any man who was particularly attractive, regardless of the colour of his skin.

${ }^{38}$ Māori political commentator Morgan Godfrey made a similar comment recently, when he wrote: 'We live in the age of racism without racists. Racism comes with its own stigma. People want to avoid that. But rather than change their behaviour, society has invented rhetorical parachutes. Suddenly racism can't exist without racial words' (2014). 
slightly less racist, from exposure to her and her family. But I really can't think that she has got anything out of knowing my family.' People laugh, but Hayley continues is a serious tone, 'I really don't think so. So it does seem like one way traffic in that respect.'

'I was thinking a bit before,' Te Awanui says, 'about expecting different things when going out with people from different cultures. I feel like I'm always the tough one in the relationship. I feel like I'm always the butch or, not that this is real stereotypy, but I'm always the one who fixes everything and is like: "Ok, let's deal with this big crazy situation. I'll fix everything. You can just be cute".' Te Awanui laughs cheekily and we all join in. 'I wonder if I would not feel like that-or like that was my role, or like I could be that person-if I was going out with a Māori woman. Or man. I wonder if that changes. If it's totally a cultural stereotyping, like Pākehās are just cute! But I don't know. I'm real practical. And I do practical emotional shit. And I wonder if that's something people I go out with expect from me based on cultural stuff-or not?-or if I would expect that if I was going out with someone who was Māori.'

There is a moment of quiet, serious reflection as we absorb what they have said. This is broken by dogs barking and Kura's laugh.

'That was half humour!' Te Awanui laughs apologetically.

'Yeah, yeah, yeah,' I say.

'Sorry,' Te Awanui says, 'I should stop saying those stupid things.'

'No, that's ok,' I say, trying to work out if they are apologising because they said Pākehā are "just cute".

Te Awanui sits and looks out the window next to them. There is quiet, except for Kura's puppy, Snoop, and Francis' dog, Mo, barking outside. 
'It's not working, Snoop,' Te Awanui says and then cracks up. To us they explain, 'He was trying to get her to play and then he picked up a bunch of flowers and dropped them on the ground, like giving them to her.' We all break into laughter.

'That's so cute!' Kura laughs. Then we settle back into saying nothing for a while, until Te Awanui speaks again, 'A few months ago, I was saying something to Charlie 39 about decolonisation and he was like: "Mh, I don't know, I've never thought about that kind of thing". I thought that is so weird, because if I was saying, "blah blah blah feminism" and my boyfriend was like: "Aw, I've never thought about what life's like for women", I'd be like: "You're such a dick!"' Everyone laughs along with Te Awanui. 'You know? But if my Pākehā boyfriend is like: "Aw, I've never really thought about what life's like for Māori people", I'm like,' Te Awanui shrugs, "Yeah, guess I was expecting that".' They laugh and correct, "I mean: "Hey, that's not ok!"' 'I think, how you experience things is so filtered through your politics, eh?' I say. 'Because when I was with Hayden, we were young and I hadn't given this stuff enough thought. But I was brought up quite feminist, so it always felt like our relationship was a gender struggle. That was there all the time. In retrospect, the cultural differences where there all the time as well, but they weren't in the forefront of my mind. And thinking about a friend-a few years ago she was really focused on decolonisation so she basically started only hanging out with Māori people. Now she's started thinking about gender issues and is thinking: "Do I cut my crowd in half again and only hang out with women?" And how-basically the opposite of what you said-if someone said something racist or just ignorant about Māori she would be like: "Fuck them, they're a jerk, I'm not going to be their friend". But she's got quite a few Māori male friends: "He's a nice guy, you know, he's a little bit sexist, but he's a nice guy" and now she's realising that's not acceptable to her anymore.'

'Yep,' Amiria says as others make similar sounds of recognition.

'But back to my own personal experience,' I say, 'I felt like those gender negotiations were there all the time with me and Hayden and then dating Sonny it's just totally

\footnotetext{
${ }^{39}$ This is a pseudonym.
} 
different. Maybe there are parallels there. It seems in Marewa's article that there was that similar sense of relief, or something, with all the shit she didn't have to deal with any more now that she's dating Māori.'

'Yeah,' Te Awanui says, 'I like that when I'm seeing women, there just one more aspect of shit that isn't there. There's still heaps of other power stuff, but there's that one thing that's not there anymore and it's good. I wonder what it's like to not have that cultural difference thing. But, it's stuff that I think can be worked on. I don't think it's things that can't be fixed.'

This conversation gave me a lot of reflect upon, in terms of how we relate to each other, as friends, lovers and members of various political groups. I learnt not only about how relationships are affected by differences across culture and identity, but how identity is also intimately shaped within relationships. Cultural stereotypes impact on attraction and the roles we expect of ourselves and others in relationships, and obscure the more subtle difference each person brings to the relationship. These points suggest that healthy relating across difference involves a careful negotiation of shifting power, which is attentive to and respectful of the complex identities that each individual presents.

I was particularly struck by the way that emotional expression was discussed among the group. While individual specificity was stressed-where personality, upbringing and personal history can all affect how we express ourselves-there was also a recognition of a Pākehā cultural sanction on what is a valid expression of emotion and whether or not this expression should come into 'reasonable' arguments. This led me back to Uma Narayan's notion that emotion plays an important role creating insider's epistemic privilege: 'Unlike concerned 'outsiders' whose knowledge of the experience of oppression is always more or less abstract and theoretical, the knowledge of 'insiders' is enriched by the emotional reactions/responses that the 
lived experience of oppression confers' (1988: 39). Sadly, Narayan also notes that one of the ways that outsiders demonstrate their lack of this emotional knowledge is by 'Minimizing the emotional costs of oppression' (Ibid: 39). I am left wondering, how can insiders knowledge be fully acknowledged, when the dominant culture maintains the power to define appropriate emotional expression? If we struggle with these things in our intimate relationships, how will we deal with them in the public spaces of collective meetings? These issues of relationship negotiation and emotions within collective organising are discussed in the following chapter.

I have one final story to tell from this time, another short snapshot to parallel the beginning of this chapter and show some of the kinds of relationship-building we did as a group. This story also captures some of the ways that our sense of belonging and identity is shaped by those we are close to. In this story I express the experience of feeling as though I was leaving my culture behind, through association with Māori. This seemed to happen organically, through relationships, rather than philosophical ideals. I will return to this in my final discussion, 'Processes of Pākehā Change: 'learning to be affected' while working across difference'; however, given the themes of this chapter it seems appropriate to end with a story about an event that I have a vivid emotional memory of, rather than an analytical one.

Cold. The rain falls heavy and cold. Black Rainbow has come together to support the hīkoi to parliament against the Takutai Moana (Marine and Coastal Area) Bill. We are minus Francis, who is sick and has to send her support from home. I wonder if I should have done the same as I struggle to follow conversations through a heavy head cold. Even though we have come together, we inevitably spread out, moved by the crowd. Amiria has her bike and has to walk at the back, so I try to stay with her. 
Clara passes me and says 'hello'. There are a few other Pākehā supporters-like Paula, and Jen Margaret ${ }^{40}$ with her baby-but most of the people on this demonstration are Māori. Some of the women up the front have kawakawa ${ }^{41}$ wreaths on their heads, reminiscent of tangi, and there is a heavy sense of grief. I feel that grief most strongly walking down Lambton Quay. Here with this a group of Māori, walking slowly and quietly in the rain. White faces stream past on the sidewalks, looking on awkwardly. I find it hard to look at these white faces.

A man in a suit with blue striped tie gets up on a bench and yells at us: 'It's the middle of the day! People are just trying to get on with it. You should be working, paying your taxes. The beaches are for us all! You should be paying your taxes. Getting on with it. You're haters and wreckers, all of you. Haters and wreckers.' This display is so over the top, I think I would believe someone who told me it was staged. As he rants and we slowly pass, I have a long moment to gaze at him and wonder. Is he Māori? He is a good looking man, confident in his world view and intelligent. He seems so baffled by us-l look at him with laughing eyes and he looks back with confusion. Or even desperation. He believes what he is saying so completely. There are a few angry and mocking retorts from the marchers and a cry of 'Mana Motuhake o Tūhoe!' from the back, but the wardens quietened it down with 'taihoa, taihoa'. ${ }^{42}$ This is a silent protest. Mara says that she doesn't like how controlling that is. But I like the effect-this silence is dignified, and we pass him by. But his words stay with me, like he voiced the silent lines of everyone walking past. ${ }^{43}$

Or maybe not. They don't look so certain. I know I'm an outsider among these Māori protestors, but by walking with them I feel the Pākehā on the sidewalks become

\footnotetext{
${ }^{40}$ See Margaret 2010a and 2010b.

${ }^{41}$ Pepper tree.

42 Wait.

${ }^{43}$ At the time of writing, long after the event, I heard this was actually staged for the sitcom, 'Halfcaste Broadcast' (Iti 2011), see it here: http://vimeo.com/30520002. This adds an extra interesting level of performance to the experience. I am choosing to include this story with all that messiness and subjective distortions.
} 
alien to me too. Vulnerable, with this heavy head in the rain, I let myself feel overwhelmed by an intimate commitment to the other people in Black Rainbow, who are lost to me, somewhere in this crowd. 


\title{
Chapter 5
}

\section{Black Rainbow}

\author{
April to June
}

\section{Power-sharing}

In this chapter, as with the previous two, I tell of the next phase of Black Rainbow through excerpts of discussions from our meetings. After all the relationship building work Black Rainbow had done, during this period we were finally able to really talk about what we wanted to get out of the group and the kind of actions we would like to do. The first story below shows the group discussing possible actions, including creating a 'zine telling stories of peoples' experiences of working in Pākehā dominated spaces. I have included this story because it shares Black Rainbow members' insights into important considerations around writing about these experiences, insights which have influenced the way I wrote the thesis. By explaining why storytelling is helpful for validating insiders' experience, both for members of the group and readers of the thesis, this discussion also places the following story in context. This second story is a lengthy discussion from the subsequent meeting, where we shared our stories with each other as the basis for writing the 'zine. In the previous two chapters I clearly selected which stories to tell based on the themes of 'identity' and 'relationships'; however, in this chapter I was most interested in closely tracking the arguments made in this final Black Rainbow discussion and it was only after doing this that I came to see this as the "powersharing' chapter. I will briefly outline my understanding of this theme here, to pull together the various aims and threads of this chapter. 
As with the previous chapter, one of the aims of this chapter is to show the meaning made between the members of the group. When tracking this meaning making, I was particularly interested in how fluidly storytelling shifts into analysis, which generates further stories. Building on my observations in the previous chapter about tensions in the group between making generalisations and resisting them, another aim of this chapter is to show how storytelling and humour are used to create a 'joking consensus'. This allowed the group to make meaning about the kind of things that they can expect to happen in anarchist organising, without allowing those observations to become 'fixed' generalisations.

This highlights one of the important things that this project does: it allows Māori in the group to affirm each other's insiders' epistemic privilege. In the previous two chapters I have drawn on Narayan's (1988) work to argue that insiders' epistemic privilege can be denied when those expressing concerns are seen as not 'real Māori' or framed as 'overemotional'. In this chapter, other reasons that Māori may not be listened to are also discussed, including the degree of power held by those who are challenged on their oppressive behaviour. A culture of conflict avoidance adds to this, in which people who are challenged may respond as though they are being 'abused' by the person 'calling them out' (naming their behaviour). This focus on the emotional reaction of the person challenged obscures the effect of their behaviour on others and the considerable emotional labour of speaking up against it. Throughout the final discussion in this chapter, Māori speak of times in Pākehā dominated spaces where they were 'uncomfortable'. I came to see Black Rainbow as a space where these members could use humour as well as analysis to resist power and celebrate their shared insiders' epistemic privilege, through roars of laughter.

The issue of Māori concerns not being listened to clearly has implications for power-sharing when working together across difference. In part, this seems a result of general power dynamics between insiders and outsiders to oppression; however, in this chapter the more culturally specific difficulties of Pākehā not understanding tino rangatiratanga and tikanga come to the fore. Given that tino rangatiratanga 
(glossed by Moana Jackson as 'political authority', quoted in Mikaere 2011: 255) and tikanga (seen as 'the first law of this land' by Ani Mikaere 2011: 254) are Māori principles which regulate power-sharing, responsibility and the management of relationships, it is not surprising that Pākehā dominated groups particularly struggle around these issues. In the discussions below, Māori members of Black Rainbow express a greater burden of responsibility when their collectives discuss tino rangatiratanga, the application of tikanga or Māori issues generally, and often find themselves in uncomfortable situations where they are either expected to speak for all Māori or are made to feel invisible by Pākehā who take it on themselves to speak for Māori. This raises issues about how Pākehā can take on some of this responsibility and support Māori in appropriate ways. This is a genuinely difficult task, which I am myself struggling with, so it is perhaps understandable that so many well-intentioned Pākehā make mistakes. Yet the Black Rainbow discussion also shows that while Māori may have greater responsibility placed on them, they are often constrained by Pākehā resistance to hearing criticism or complexity and to genuine power-sharing. This is the disappointing 'Black Rainbow story' told in this chapter.

$28^{\text {th }}$ of May 2011

'Do you wanna feed back?' Hayley asks as we settle into our seats in her and Francis' home. After spending the first half of the meeting discussing our frustrations with the group (especially lack of direction), and what we hoped to get out of Black Rainbow, we split into small groups to talk about potential projects. Now we have come back together to share our ideas.

'We thought we could make a list,' Te Awanui says. 'Like: "Here are some stupid things that people often say or do that are crappy for Māori people in an activist group". Maybe we could all share a story of a situation we've been in that was like: "Oh my god, I can't believe this shit happened", and make a little thing with those in it. Then we could be like: "If you're a Māori person who is in an activist group and this stuff is happening, that's not ok and it's alright to feel crap about it and want to change it". Or: "This has happened to all of us". And we could be like: "If you are in 
that position and you are thinking: "Ah! There are all these crazy Pākehās around me!" Email us and we can talk".'

'That's cool,' Amiria says.

'It would be good to put the challenge to Pākehā activists to step up when they notice stuff is happening as well,' Francis says. 'Because I think we've all been around those times when someone afterwards will say something, like: "I thought that was really stink". But instead of talking to whoever Māori person, why don't you talk to whoever Pākehā person? Work out what you are going to do?' 'Yeah,' Te Awanui says. 'In that decol workshop we organised, when Clara said things like: "When I say tangata whenua, I'm just talking about Māori who grew up with their hapū", it just kept feeling like we were the naughty kids in the class, who had to keep saying: "Um, actually, you can't say that Māori think this, or this is how it is for Māori or that urban Māori aren't tangata whenua". No one else was getting up and saying: "So maybe you do mean something else, but you need to be clear about that, because you're just making it sound-" 'Pretty racist,' says Kura.

'Yeah, totally,' Te Awanui says. '"You're offending Māori in this group".' 'Or: "I understand that we've paid you a lot of money, but you need to go now",' Francis says.

'Yeah,' Te Awanui laughs. 'Yep... It would have been really cool if it wasn't just people of colour in the room saying: "stop being so racist".'

Kura says, 'I just also thought it would be good on a personal level, to be able to share those experiences. Because I gather we've all had similar ones. And that will just keep perpetuating itself. There will be new people coming in, having the same experiences. So I think it would be a really good experience to be able to talk about that stuff and be able to take it and put it somewhere that makes it feel like we are doing something with it. Because it can be really hard to be like: "Well, they do all this shit stuff, but..." Yeah.

There is a lot of agreement with this. 
Hayley asks, 'Do one of you want to feed back from ours?'

'We were talking a little bit along those lines,' Amiria says, 'like maybe creating a resource for activist groups and looking at different ways of organising and meeting. And also, we talked a little bit about being radical Māori (not just Māori) and all those kind of things that come into it, like being vegan or queer or whatever. So exploring that a bit more would be quite cool.'

'Well,' says Mara, 'just to move things on a little bit, it looks like there is one clear common thing-the production of something surrounding groups and how they operate. In general and with a Māori thing to it.'

'Yeah, we can totally smash those two things together, and make a really awesome 'zine-y, pamphlet-y, paper-y thing,' Te Awanui says. 'Something on a paper!' 'Yeah!' Amiria laughs.

'Maybe at our next meeting we could use it as a chance to brainstorm that whole list of things of what to do and not do,' Hayley says. 'And people could think between then and now about a particular instance that stands out for them. We could share them and ask each other questions and then that might make it easier to go back and write about it.'

'Yeah, totally,' Kura says. But after a while she adds, 'Maybe if we are talking about "What not to do" we are focusing heaps on Pākehā, so we could also have something that re-affirms Māori in that group as well. Something that's actually positive to read. Because one thing about working with lots of Pākehā for me is that it makes me more insecure in being Māori, because I'm being asked what Māori think and I don't know. Are there ways of exploring...'

'The positive things that Māori bring to the group, or something?' I ask. 'As individuals, rather than being the token Māori?'

'Well, we were talking more about groups in general,' Mara says, 'how they operate, issues to look at when setting up groups. Lots of stuff that's already out there in the world, but maybe we could collate that and make it more applicable.' 'And there's probably stuff that is really healthy for a group, that is not specifically about being Māori or not being Māori, that would be good,' says Hayley. 'Like: "What are the various things that group members bring to the group?" It's about valuing people.' 
'Yeah,' Kura says.

'Cultural safety,' Francis adds.

Te Awanui says, 'I feel like I've had conversations where it's like: "When people are doing or saying this thing, it makes me feel really uncomfortable" and I'm real like: "Oh yeah! Me too! Oh, right". And I think it was quite a cool idea-maybe not so much: "This is what you shouldn't say if you're Pākeha" - but: "It's ok to be upset or angry when people are saying these kinds of things. And here are some things that you might say." It was awesome for me at the A-fem hui ${ }^{1}$, when it was ok to say: "Hey! I don't like the way everyone's talking, I don't know why, but I feel real like this isn't ok". And it gave me a little bit more room to feel, and to be like: "Maybe this is what is wrong with it?" Or for other people to say it. So I think the idea of: "These are some stupid things that might happen in groups" might be real validating and useful.'

'Can we make a note of what Kura said though,' Hayley says, 'so we can think about it more at the next meeting?'

Te Awanui writes down a few of Kura's points and I say, 'It sounded like you were saying something about affirming Māori in the group, eh? So it's not just like:

"Here's all the ways it's going to suck".' We laugh.

'Yeah, exactly,' says Kura.

"It's easier to have a whites-only group",' Francis jokes. After the laughter, she adds, "I really like the way you all first started talking about it-like experiences that we had, and how it made us feel. And then, potentially, this is how it could have been different. Not phrasing it like: "Necessarily, all Māori are going to feel this way" and: "This is necessarily a bad way of talking about stuff", but...' 'Yep,' Amiria says, and Kura also agrees.

After a thoughtful silence, Francis says, 'At the same time, it appears from reading the internet, that there will be Pākehā activists that will respond really badly to

\footnotetext{
${ }^{1}$ Aotearoa Anarcha-Feminist Hui, April 2-5, 2010.
} 
anything you say. No matter what you say about Pākehā needing to be a bit more mindful, it really offends some people.'

'Well, if you said it a bit nicer, maybe they'd listen!' Te Awanui laughs.

Hayley says, 'Yeah!' as the laughter in the room builds.

'If you weren't so irrationally emotional about it,' Kura adds, and we descend into more laughter and ironic joking.

\section{Telling stories, sharing jokes, making meaning}

I included this story because it shows some of the reasons why telling stories are important and what people hoped to get out of the group. Some members of the group also express a need here for something material to come out of our discussions. Because we have yet to produce the 'zine we planned to write, I have tried to model this $\mathrm{PhD}$ thesis on some of the intentions expressed in this discussion, including: validating Māori experience, challenging Pākehā to respond more actively as allies and sharing stories of things that happen-rather than essentialising those experiences.

As discussed in chapter 2, 'A Black Rainbow Story: How I have written this thesis', it has not been easy to honour the intention to simply share stories without generalising and still state clearly 'what I have come to say'. What I found especially interesting about the meeting in which we shared our stories for the 'zine (see the story below), is that people did not simply talk about the things that happen, they made meaning from those experiences. We moved backwards and forwards smoothly between people's direct experience and generalisations about the anarchist scene, other social justice groups, or wider society, showing how 'people strategize, feel pain, contest interpretations of what is happening-in short, live their lives' (Abu-Lughod 1993: 14). This seems a natural and important part of validating each other's experience. Here I would like to discuss how I see the validation of insider's epistemic privilege as being linked to shared meaning making, especially through humour. 
My thinking about this was partly sparked by Te Awanui's comment about being made to feel like 'naughty school children'. This reminds me of Neriko Musha Doerr's work in Meaningful Inconsistencies: Bicultural Nationhood, the Free Market, and Schooling Aotearoa/New Zealand (2009) with actual school children, which showed that bilingual Māori students who laughed at their mainstream teachers' mispronunciation of the Māori language were treated as though they were simply disruptive and disrespectful, when in fact they were expressing their awareness that Māori culture was being disrespected. The fact that people who challenge oppressive behaviour are often treated as disruptive, or even abusive, is discussed at some length in our discussion below. Staying with the laughter of the children, however, brings me back to the notion I discussed in chapter 3, 'Black Rainbow (August to October): Identity', that this thesis is a 'comedy' of sorts-where humour can be seen as a way of gaining agency over painful situations, expressing insiders' epistemic privilege and finding solidarity with others who have experienced similar things (Jackson 2002).

Thinking about the Black Rainbow Story as a 'comedy' helped me reconcile the way we spoke about resisting essentialisation and yet spent many happy hours caricaturing the Wellington anarchist scene (this can be seen especially in the story below). Black Rainbow was a group in which we could do just that, without worrying about the feelings of the people who represent some of the elements we found difficult. Humour is able to get at these tensions within a community. Michael Jackson quotes Henri Bergson's observation that: 'Comedy depicts characters we have already come across and shall meet again. It takes note of similarities. It aims at placing types before our eyes' (Jackson 2002: 169). Jackson notes that this is why these stereotyped characters 'have one-track minds rather than mixed emotions, why their personalities are unidimensional rather than complex' (ibid: 183). In this research I have not attempted to 'uncover' the full 'truth' of the events in the anarchist scene, by analysing the motivations or experiences of the third parties that appear in the stories told by Black Rainbow. They remain stereotyped to a certain degree and I hope that you (the reader) will 
not assume that they do not have complex realities that extend beyond the borders of the stories I tell. I was often struck by the messy bigger picture while undertaking my wider observations. As Te Awanui noted about the October $15^{\text {th }}$ Solidarity crew: 'there's so many real different perspectives. It seems like the story's real fucking different depending on who you hear it from' (see chapter 3, 'Black Rainbow (August to October): Identity'). Further, I am aware that by choosing to concentrate on the versions of events told by members of Black Rainbow, I risk alienating other members of the wider anarchist scene. As John Carty and Yasmine Musharbash note, 'Laughter is dangerous':

Laughter is a boundary thrown up around those laughing, those sharing the joke. Its role in demarcating difference, of collectively identifying against an Other, is as bound to processes of social exclusion as to inclusion. Indeed, the two are one. Laughing 'with' some people usually entails laughing 'at' others (2008: 214. Original emphasis).

Allowing the 'Black Rainbow Story' to be a 'comedy', however, lets us address important issues of injustice. Carty and Musharbash have also pointed towards the importance of humour in exposing social inequalities: 'Over and over, laughter and humour here erupt out of the fissures in colonial facades, and they are never far from the question of discrimination, domination and power imbalances' (2008: 213). I want to highlight here the role humour plays in resistance, both to power and to attempts to dismiss insiders' epistemic privilege. Narayan notes that insiders to oppression are often accused of 'paranoia', which undermines their ability to trust their insights, especially when responding to what can be seen as microaggressions (discussed in chapter 4, 'Black Rainbow (November to March): Relationships'):

Often, subtle instances of racism or sexism are such as to be open to interpretation, insiders are often aware of this and are often anxious and uncertain of their own perceptions ... But ... the insider is more often correct than mistaken in her suspicions. Sometimes less subtle manifestations follow that give the show away, or else, the insider meets other insiders who have the same feelings of unease and suspect similar prejudices on the part of the same person (Narayan 1988: 42-43). 
Black Rainbow created the space for Māori people to test and validate their perceptions of the anarchist scene, often in a light-hearted, humorous way that says 'this is not serious' (Fine and de Soucey 2005: 9). What we were talking about was, of course, often very serious. Yet, this element of humour also carries an important message that these statements are not 'fixed', our ideas remain fluid. Over time, these perceptions became part of a shared image, as we came to a 'joking consensus' (ibid: 8). Therefore, I am not only telling the 'Black Rainbow Story' in terms of a narrative of what we did and how things developed for us as a group. There is another 'Black Rainbow Story' here-the version of the way things are in the anarchist scene that we have constructed together as a group, meeting over the course of the year. It is this second 'Black Rainbow Story' that I wish to highlight here, by tracing the meaning we made together as a group, and I have paid special attention to this in the story below.

\section{Stories from the anarchist scene:}

\section{Tino rangatiratanga, power and responsibility}

When I edited our stories of the things that happen in the anarchist scene, I tried to do so in a way that allowed the relationship between the stories and the meaning making to be seen, while also tracking the analysis that arose in the discussion. From these points of analysis, I have hung related academic literature in footnotes. Because this is a long story-a lengthy, meandering discussion-I have highlighted phrases throughout the story, as informal subheadings to help guide the reader and make the meaning I am tracing more apparent. For the same reason, I have also created little breaks throughout the story, moments to 'take a breath' and think about what is being said. Many of these ideas actually run throughout the discussion, however, I have chosen to emphasise them at different moments in the discussion, for the sake of clarity. 
I have tried to simply reiterate what is being said rather than add interpretive analysis, however, I have cut parts of the conversation for brevity and flow, based on my interpretation of what was is more or less crucial. Therefore, I would like to briefly mention here that my thinking developed through the process of this editing, especially as I came to notice how running alongside issues of power were expressions of Māori bearing a greater responsibility, rather than that responsibility being shared among everyone in a collective. I also noticed the way that tino rangatiratanga and tikanga recurred in the discussion and, while I feel uncomfortable suggesting how these Māori concepts should be interpreted, I began to think of this discussion as mostly coming down to issues of power-sharing. Or, perhaps, a failure to share power and some of the things that prevent powersharing from happening, despite our best intentions. This emphasis on how tino rangatiratanga relates to power-sharing helped me to see the links between power and responsibility more clearly.

$25^{\text {th }}$ of June 2011 'So, did anyone think of an exciting particular instance that they want to share with the group?' Te Awanui laughs.

'I think "exciting" is not a good word,' Kura replies and gets a big laugh from the group.

We are sitting around Hayley and Francis' pretty living room again. After a quick conversation restating the kinds of stories these could be, Mara begins:

'Well, I remember one thing, from back in the day when I was in Wildcat. ${ }^{2}$ We were talking about Māori and gender politics and how you have all the differential equality and how that actually works within Kaupapa Māori. And looking at how sometimes Māori culture is used as an excuse to be sexist, or sexism is used through tikanga. Wiremu brought up the point that: "Well, there are actually Māori people in this scene. In this room right now! There are Māori people everywhere who deal

\footnotetext{
${ }^{2}$ Wildcat Anarchist Collective.
} 
with this in their communities. It's not like we just blindly accept it. Tikanga is challenged all over the place". ${ }^{3}$

'Was it silent for a bit?' Amiria asks.

'A little bit,' Mara replies and others laugh.

'So was it being talked about like there wasn't anybody there?' Hayley asks.

'Yeah,' Mara says. 'Talked about like everyone in the room was Pākehā. I think it was more that people were asking questions and they didn't know anything, which is fine, just discussing stuff. But it was a little bit weird.'

'So did the discussion continue after Wiremu said that?' Kura asks.

'Can't remember. But I'm thinking, you know, because we weren't 'real Māori' and stuff,' Mara ends with a shrug.

'I remember facilitating an October 15th strategic planning meeting,' Hayley says, 'and there was a moment where we were trying to decide whether the group supported tino rangatiratanga.' Te Awanui laughs loudly at this and Hayley continues, 'There were a couple of Pākehā in the room basically saying: "I've asked lots of people and no one can give me a definition. We can't possibly support this until someone can explain to me exactly what it means! Why are we putting it in at all?" And I mean there are some really important points in there about understanding, but it was in this real righteous way. ${ }^{4}$

\footnotetext{
${ }^{3}$ This can be seen reflected in academic work of Māori women such as Ani Mikaere (1994, 2011) and Leonie Pihama (2001). For example, Ani Mikaere argues that 'tikanga Māori is based on the imperative to maintain balance within whānau, hapū and iwi, including balance between women and men’ (2011: 193). Mikaere tracks 'the colonisation of tikanga' (ibid: 199), which undermined Māori women's power and leadership roles, and stresses that a 'crucial part of restoring Māori law must be the realisation that the oppression of Māori women cannot be justified on the basis that it is traditional' (ibid: 202).

${ }^{4}$ Mason Durie's (2005b), argues that there is 'no single definition' of 'tino rangatiratanga'. Durie gives instead a range of meanings that can be taken from the phrase-from individual wellbeing to self-determination to sovereignty. He does,
} 
'That was Glenda ${ }^{5}$, wasn't it?' Mara laughs. 'What I like about her is, she's actually open about it: "I don't know what this means. I don't think we should be supporting something just to make it look all nice". I disagree with her in some ways, but I really appreciate her honesty. And her thing of not just being all earnest ${ }^{6}$ about it, which is meaningless anyway.' 'Yep,' Hayley agrees. 'It was just the fact that the argument became between: "I don't know what it means, so someone explain it to me" (rather than I'm going to go and find out), versus kind of naively saying: "Yeah I support it (even though I don't understand it either), because it looks good". Those seemed to be the camps. And there wasn't anything very respectful. ${ }^{7}$ 'Yeah, if you care,' Te Awanui says, 'actually, you should go and find out.'

however, note that: 'It is possible to identify at least two facets of tino rangatiratanga: the way in which Māori and the Crown share power; and the way in which power-sharing occurs within Māori society... The common denominators are power, control, sharing, and authority’ (ibid: 6). We can see from this that the recognition of 'tino rangatiratanga' has implications for decision-making across different collectives.

${ }^{5}$ This is a pseudonym.

${ }^{6}$ Note the use of 'earnest' to mean a performance of earnestness, which is actually disingenuous.

${ }^{7}$ Despite this apparent ignorance in both 'camps', Jacob Otter’s thesis, 'Thinking through biopower: Māori, the Left and the Treaty Workers Movement' (2007), shows that these debates are not new to this activist community. Otter writes:

As I began to get involved in political activism just after the passing of the Foreshore and Seabed Bill in 2004 there was a lot of discussion within primarily Pākehā activist circles as to the place of tino rangatiratanga and Māori within the various perspectives of a 'just' future people adhered to. This created heated debate and often a strong sense of discomfort within these groups as to the level of support they could, or should, offer Māori (2007: 2).

Drawing on Foucault's notion of 'biopower', Otter traces the genealogy of the Left in Aotearoa New Zealand, concluding that 'today Māori are perceived as a threat to the values the Left is seeking to spread throughout the wider population' (ibid: 7). 
'Then it turned into a thing like: "Well someone should organise something, so we have something to talk about it",' Mara says. 'But then that never really happened. I think maybe that was left up to me to try and sort out. I can't remember. But people just jumping onto it-being: "I support tino rangatiratanga (even though I have absolutely no idea)". That made me really uncomfortable.'

Here I would like to take the first 'break' from the story to reflect on what is being said. These stories seem to share a problem of Pākehā ignorance around Māori culture, notably tikanga and tino rangatiratanga. This creates difficulties for working with Māori, both inside and outside of groups, because of an inability to engage with complex situations, especially when discussions about whether or not to support Māori overlap with other commitments, such as feminism or anti-capitalism. This also has the effect of making invisible the Māori people working within these groups, across these different issues.

'Have you told them about that English pōwhiri you went to?' Hayley asks Francis. 'So, I went to a permaculture design certificate course in Taranaki,' Francis says. 'We all gathered up at 'Environaki' (that's the name of the place) and then we all got sent down to the gate. A karanga ${ }^{8}$ started up at the building and the guy from Environaki with us replied: "Yep, we're coming. Yep, we're coming. We're coming up now". 9

There is a sense of shock in the room as Francis tells us this. Te Awanui laughs disbelievingly.

\footnotetext{
${ }^{8} \mathrm{~A}$ ceremonial call of welcome to visitors onto a marae at the beginning of a pōwhiri.

${ }^{9}$ During a pōwhiri, a woman representing the visiting party usually responds to the karanga with another ceremonial call, greeting the hosts and stating their purpose for coming. 'Yep, we're coming' is a poor substitute.
} 
'So, we got up to the top,' Francis continues, 'and the Pākehā guy that lived at Environaki did this whaikōrero ${ }^{10}$ in English, where he had a stick and he would:' Francis gives a little cough like elders often do during whaikōrero, 'he named the river and:' <cough> 'he named the mountain.'

The room explodes with laughter.

'It was this really painfully embarrassing copy of someone speaking,' Francis says. 'And then a Māori guy, who was doing the course, responded in te reo. It was just really bizarre! And I kind of wanted to leave. ${ }^{, 11}$

'Aw, that's so uncomfortable,' Amiria says.

I quote, 'We're coming up now,' and we fall into laughter again.

'Oh. My. God. You think they would have just not touched it, eh?' Te Awanui says. 'I don't know why people use stuff like pōwhiri,' Francis says, 'but it seemed to me like that was all about claiming indigeneity. Claiming the trappings and a connection to the land. ${ }^{12}$

\footnotetext{
${ }^{10} \mathrm{~A}$ formal speech, another important ceremonial element of pōwhiri.

${ }^{11}$ Joan Metge (2010) has written about the way pōwhiri has been altered through inclusion in public ceremonial, such as VIP visits and conference openings, taking on different purposes as well as different audiences, many of whom do not understand the Māori language or the meanings behind the various elements of this ritual of encounter.

${ }^{12}$ Mikaere writes about this 'claiming' in 'Are we all New Zealanders now? A Māori response to the Pākehā quest for indigeneity' (2004, also reworked in 2011), where she notes that Trevor Mallard, Michael King and Don Brash have all spoken about Pākehā as 'indigenous New Zealanders'. Mikaere also points to the way Pākehā travellers abroad 'leap forward to perform bastardised versions of the haka [posture dance] and "Pōkarekare Ana", and adorn themselves with Māori pendants in an attempts to identify themselves as New Zealanders...' (2004: 3). Avril Bell, like Mikaere, sees this as an attempt at 'resolving the dilemma of Pakeha ontological anxiety' (Bell 2004: 61) and finding belonging. These claims to indigeneity undermine Māori challenges to Pākehā domination.
} 
'Yep,' Mara says. 'On a slightly different thing about claiming indigeneity, and taking it back to the October 15th group, there were major issues there around figures within that group standing up and speaking for Māori. ${ }^{13}$ It's great that you've spent heaps of time in Māori communities, but that doesn't make you Māori. It doesn't mean you can stand up and do a talk about Māori in prisons.' She laughs. 'So somebody stood up and did a talk about Māori in prison?' Hayley asks.

'Yeah. We were at a demo and someone was talking about it. Afterwards I turned around and said to Amiria: "That was weird!"

We all laugh. After a thoughtful pause Te Awanui says quietly, 'Yeah, and it still happens.'

'I know,' Mara says. 'I think it's fine to say: "These are things we need to consider". But it's not up to that person to go into depths about how: "They've been traumatised!", when there are so many of us around that are able to do it. It may have been different if that speech was being given in Canada or something. I don't want it to sound like Pākehā can't say anything, it's just really important how you position yourself. And if you can't own your power and privilege, then maybe you shouldn't be saying anything at all.' She laughs. 'So that's one thing we could put in the book: "If you don't know any better, shut up! Stop talking".'

We all burst out laughing again.

'Yeah, there was this weird thing the other day,' Te Awanui says. 'Paula brought up that maybe we need to be talking again about supporting tino rangatiratanga,

${ }^{13}$ Narayan argues that:

[T]he right and power to speak for oneself is closely tied to the oppressed group's sense of autonomy, identity and self-respect. That it will foster and safeguard this sense of autonomy and selfrespect is a good enough reason to say that the oppressed should speak for themselves, questions of epistemic privilege apart (1988: 38).

The importance of Māori speaking for themselves is clearly articulated in Kaupapa Māori research literature. See for example, Russell Bishop’s (1998) argument that dominant research, written based on the interests of non-Māori, distorts Māori knowledge and prevents genuine power-sharing. 
especially for the people who are travellers and maybe have never heard of that or know even less than those of us who know something. And that was kind of good, in a way. But then it got into a discussion about what that means, both in practical terms around the house-with the way people eat and the things people say and do-and some weird stuff about following tikanga. And I was like: "Does anyone actually know about Te Atiawa tikanga? Because I'm pretty sure it's their land. Maybe if we are going to follow some tikanga, it should be theirs?" And then it was like: "But what does that mean?" It's one thing to have a list of things to do around the house, but it's different to understand why. It was quite a weird conversation. I don't know exactly why, actually, but I just felt real uncomfortable with it. Maybe it was just the fact of once again me being the only Māori person in the room! Sitting there listening to people talk about what it's like for Māori and what we should be doing. Then one of the people at the meeting was like: "Yeah, but why do you think you should do this, because obviously nobody in this group is Māori".'

'Oh no,' Kura says.

'She didn't!' exclaims Amiria.

'Phil" said: "Well, actually there are people in the collective who're Māori, like Te Awanui". And I was like: "Thanks for pointing that out".' We all laugh with Te Awanui and they continue, 'I mean cool. Good. But, it's just like: "Aww, It's always the same." You know?'

Ranging from more subtle incidents of speaking for Māori to blatant appropriation of ritual, Pākehā can be seen 'claiming indigeneity'. Naturally, this can be uncomfortable for Māori individuals and can, again, add to the invisibility of Māori in these groups.

'I find it really difficult,' Kura says, 'when groups start talking about tino rangatiratanga because quite often I don't want to be part of those discussions. Or I

\footnotetext{
${ }^{14}$ This is a pseudonym.
} 
feel really reluctant to. It is also really odd to be in a group talking about tino rangatiratanga and to be Māori, you automatically get that sense of responsibility. Like if they are doing something really stupid that is going to have an effect, it's going to fall on you. ${ }^{, 15}$

There is a lot of support for this statement from others in the group.

'Yeah, and you feel like you have to be the person who sorts it all out,' says Te Awanui.

'Yeah!' Kura says. 'And if someone says something really fucked or stupid, it's always uncomfortable. I haven't experienced it yet where I haven't felt either really tokenistic or really just not Māori enough, like just ignored a bit.'

'When we were at that A-fem hui,' Te Awanui says, 'that was the only time I have been in a group of activisty women where I've felt like: "Oh, actually people are listening to me". Not expecting me to come up with all the answers, but listening to me. I was like: "Oh this is how it feels!" Still a lot of stupid shit was happening, but I felt like: "I know that there are people here who've got my back". Yeah, people were getting each other. It was good. But it's really frustrating, eh?'

'I think one of the things that's really hard with tino rangatiratanga,' Mara says, 'which I didn't get for ages, is that it's connected to and it can't be separated from tikanga. ${ }^{16}$ But the problem with tikanga is how much of that is actually relevant?

\footnotetext{
${ }^{15}$ Narayan notes that one of the burdens that may fall on insiders to oppression is a responsibility to use their epistemic privilege to educate outsiders. While Narayan recognises that outsiders can only learn insider knowledge from listening to insiders, she argues that: 'concerned outsiders must recognize that their concern carries with it a responsibility to actively seek out and acquire such knowledge, rather than see it as the insider's responsibility to bring such knowledge to their attention because the oppression is "the insider's problem”" (1988: 37).

${ }^{16}$ Mikaere also stresses that tino rangatiratanga and tikanga are inseparable, arguing that when rangatiratanga — as 'a total political authority’ (Moana Jackson, quoted in Mikaere 2011: 255)—was reaffirmed in both He Whakaputanga o te Rangatiratanga
} 
And how much of it is just being held onto for ceremonial purposes? Or as resistance to losing knowledge? Because there are some weird situations when it's like: "Why are we doing this, when it's not relevant at all whatsoever?"'

'Are you talking about in Māori spaces?' I ask.

'Yeah, sorry. Māori spaces,' Mara says.

'Because I think that's really true in the anarchist scene as well,' I say. 'It seems so often when you're talking about tikanga, you're talking about stuff you do, eh? You're not talking about values and why you do them. ${ }^{17}$

'Yeah, we'll be talking about tea towels on the floor or something,' Kura says. 'Yeah,' Mara says. 'That's just dirty!'

We all crack up and Francis says, 'It's also not the reason more Māori aren't involved.'

'Yeah, totally. Not at all,' Kura says.

'If Māori said it was ok to have tea towels on the floor,' Mara says, 'would 128 be saying: "Let's have tea towels on the floor"?'

This sets us off laughing again. ${ }^{18}$

o Nu Tireni (the Māori text of the Declaration of Independence) and Te Tiriti o Waitangi (the Māori text of the Treaty of Waitangi), tikanga was recognised as the paramount law of the land (2011: 257, 264).

${ }^{17}$ Mikaere writes that:

Tikanga is based upon a set of underlying principles that have withstood the test of time: principles such as whakapapa, whanaungatanga [relationships], mana, manaakitanga, aroha [affection], wairua [spirit] and utu [reciprocity]. While the practice of tikanga has adapted over time to meet new contexts and needs, it has nevertheless remained true to those foundational concepts, which some have called 'conceptual regulators', others 'kaupapa'. Justice Durie has pointed out that allowing for the adaption of practice while protecting the fundamental norms underpinning it 'enabled change while maintaining cultural integrity' (ibid: 254255).

${ }^{18}$ Mara's joke makes me think of Elizabeth A. Povinelli's work on the 'limits of recognition' (2002), where indigenous people are expected to be culturally different, but not in ways considered 'repugnant' by the dominant culture. Povinelli is 
'There was one Māori guy who came,' Kura says, 'he's from Dunedin or something. He came up to 128 one day and was like: "Oh, this place is really interesting, I've just moved to Wellington and I'd like to get involved in a place like this". This is while I was living there and I was asleep and someone came and woke me up and was like: "There's a Māori here who wants to join the collective". I was like: "That's nice".' As we all crack up, Kura goes on, '“Cool. One day, when I'm not in bed, I'd like to meet him". But pretty much it was like: "Here's your Māori team mate".' 'So you quickly threw together a pōwhiri for him?' Francis says and the laughter keeps building as Te Awanui calls out, 'Come up, come up. Come up the stairs!' 'That sounds like a really sensitive and thoughtful way of dealing with that,' Francis says.

'Yeah,' Kura says. 'It's quite the same with lots of Māori related stuff. People's way of being sensitive is: "This is primarily Māori issue, so-". You know, it's like they're saying you have more say, but ultimately they're saying you should have the responsibility.' The room hums with recognition and she concludes, 'Yeah. It's weird.'

'Yeah, often it's either one extreme or the other,' Amiria says. 'Like you take responsibility, or I'm just going to totally forget that you're Māori while we talk about this.'

I totally felt like that the time I asked that Helge not speak for us when we went somewhere,' says Francis. 'Like if I didn't want Helge to speak for us, I had to come up with some other plan, other than: "Let's not have a speaker".'

'I was going to ask you about that,' Mara says. 'I remember I heard about it and I said: "What? He can't do that!" and it was like: "Well, apparently Francis said it was

particularly interested the irresolvable position nonindigenous liberal Australians find themselves in when confronted with morally 'repugnant' cultural difference, summed up by a feeling of: 'I should be tolerant but you make me sick; I understand your reasoning but I am deeply offended by your presence’ (2002: 5). Would 128 embrace 'dirty' practices if they were Māori customs? 
alright". I said: "What?! Francis can't do that!"” That gets a big laugh from the rest of us.

'That's the other thing,' Te Awanui says. 'You are always in the position-if you are the Māori person in the group, you have to vouch for the rest of the group not being racist and stupid. And it's like: "I'm not going to do that!"

'I can't vouch for that!' Amiria exclaims and sets us all laughing with her.

When Māori are not treated as invisible and are listened to, they are often expected to take full responsibility for 'Māori issues'. This may not be a responsibility Māori members of Pākehā dominated groups want, but they may feel obligated to take it on, in part because they cannot trust other members not to do something 'stupid'. Furthermore, they know that the weight of the groups' mistakes will fall heavier on their own shoulders.

'It's like even at that Concerned Citizens thing, ${ }^{19}$ Amiria says. 'I was feeling really uncomfortable and really Māori all of a sudden. ${ }^{20}$ They were talking

\footnotetext{
${ }^{19}$ This refers to the opening of a fundraising exhibition organised by a community of New Zealand artists, the Concerned Citizen Collective, for those arrested under Operation 8 (June 3, 2011).

${ }^{20}$ In addition to the ideas about insiders experiencing instances of oppressions (Narayan 1988) or racial micro-aggressions (Sue et. al. 2007) through emotional reactions, discussed in the previous chapter, this recurring expression of feeling 'uncomfortable’ calls to my mind Sianne Ngai’s (2005) discussion of 'irritability’ in response to ubiquitous racism. Ngai notes that this affective state is not as easily politically mobilised as anger, yet she goes on to argue that while anger in response to injustice is widely valued, ‘its justifiability seems always in question’ (ibid: 182. Emphasis in the original) and there is an expectation that the response to racism should be 'neither in excess nor lack of the violence inflicted (ibid: 188. Emphasis in the original). Ngai's discussion of irritability unsettles this expectation that the emotional response of those who experience racist oppression will be as recognisable
} 
about Tūhoe this and that. It just seemed really superficial, like they weren't actually thinking about the issues underlying the terror raids.'

'No,' Mara agrees. 'Nicky Hager was saying how police acted was racist, the way they locked down Rūātoki and the way they engaged with Māori was a racist act. Then they opened it up for discussion and I was just like: "Ooh, should I say something?" I put up my hand and said: "Hello".' Her small, pained voice tells of the awkwardness of just this. 'I said: "What l'd like people to take away with them today, is to think about not just what happened in Rūātoki and how the police were racist, but how this has affected race relations, or Māori throughout the country, for decades to come". And then I was like: "I want to say more, but it's not coming out".' We laugh and groan sympathetically. 'And then it was all quiet, 'Amiria says, to more laughter. ${ }^{21}$ and unambiguous as righteous anger. Instead, irritability captures a more diffused affect that seems close to the discomfort Amiria is describing.

${ }^{21}$ Amiria often points out uncomfortable silences in Pākehā dominated spaces. In her thesis The Invisible Whiteness of Being: The Place of Whiteness in Women's Discourses in Aotearoa/New Zealand and Some Implications for Antiracist Education (2006), Helen Gibson offers detailed analysis of the various kinds of silences that occur when Pākehā women are asked to reflect on their own racialisation. This includes 'polite silences'-in which people struggling to find something 'acceptable' to say may not be able to say anything. Interestingly, Gibson also notes that 'privileged' and 'veiled' silences may occur, even as white people continue to speak, disguised with a 'colour/power evasive'. Gibson makes the important point that:

The belief that 'race'/difference should not matter underpins the dominant colour/power evasive discourse. A corollary to this belief is that since 'race'/difference should not matter, everyone should act/speak as though it does not. An important rationale associated with this discourse is that anyone who does act/speak as though 'race'/difference matters, is prejudiced and divisive (2006: 170. Italics in the original).

This cultural norm that 'race' or difference should not be commented on may sit behind much of the discomfort, awkwardness and silence that occurs when Māori raise issues of difference in white majority spaces. 
'And then was everyone like: "No we want something we can cheer at the end of"? Te Awanui jokes.

'But, yeah Mara!' Amiria says with admiration. 'Because I was standing there going: "Oh shit, I should maybe say something, this is really uncomfortable".'

'I got a couple of: "Mhm mm mm"s,' Mara mimics the performance of thoughtful affirmation and Amiria cracks up. 'It was strange... That was weird anyway, because Ruru ${ }^{22}$ - who is one of the arrestees-was there. I went up earlier to talk to him, just introduced myself and I got into a big chat with him for quite a while, which was really interesting. And also because I thought this has got to be uncomfortable for him and his wife, with a whole bunch of young, Pākehā hipsters.'

'There were so many hipsters, eh?' Amiria says.

'So I thought maybe I'd try and make it a little bit less uncomfortable for them,' Mara says. 'But, I mean it's good. Money is good. People seeing the film is a good thing. There's just always that underlying: "Let's not talk about this real basic shit".' '"Stick to the positive things, raising money and that kind of thing", ' Amiria says. 'I think a lot of people wanna put themselves on one side of the divide too, eh?'I say. 'Like: "There are the racist police, or state, and then there are us nice, friendly Pākehā, who are doing what we can and don't want those two things muddied".'

'Well, it seems to me,' Te Awanui says, 'that there is just real common stuff that happens in groups that's stupid. I mean going to that Queer organising thing, I was like: "Well, it's going to be a completely different scene than the people I'm used to working with. And maybe some of it's bad and some of it's good, but it will be whole different thing... Or will it?"' We laugh and Te Awanui continues, laughing all the way through, "It was different, no one said: "I propose that we do this, do we all have consensus?" So it was a little bit different. But it was just the same.'

'The first one was really interesting,' Kura says, 'because I knew there would be a lot of people there and I was really hoping there would be some other Māori people-I was really excited, like: "Yeah! Let's make a queer Māori group"-but there wasn't.

\footnotetext{
${ }^{22}$ This is a pseudonym.
} 
None that identified themselves anyway, or that I could identify. They didn't do a name round or anything like that, which was really odd. And they started talking about Destiny Church ${ }^{23}$ a lot and it was getting a bit funny, nothing really particularly offensive. But there was this Pākehā guy who got up and did his mihisaid that he was Pākehā-and he had a really cool analysis about Destiny Church, about it being really a race and class thing as well, and he just warned people to watch what they said. Which was really cool, because he managed to do it in a way that wasn't offensive to me. He wasn't speaking for Māori, but it meant that I didn't have to get up and say it, which I was really dreading. I had the shakes, I was like: "Oh god, I'm going to throw up. There's like sixty people in here and I don't think any of them are Māori. Fuck!" So yeah, that was really cool. But then straight afterwards a whole lot of people all got up and said: "Yes!"' Kura puts on a bright, teacherly voice. '"Because before colonisation Māori weren't sexist or racist or homophobic or-"'

We all burst into laughter.

'We were pretty much perfect,' she concludes. 'But nobody really picked up on his points. He was saying that it was just a really odd way of running a meeting. We weren't saying who we were and weren't letting anybody speak, or really establishing anything. It was basically just the loud people yelling over top of each other. Everyone was like: "Oh, good point - blah blah blah",' Kura yells and we laugh. 'The next meeting was exactly the same.'

'If you are having a meeting, which is supposed to be an inclusive discussion,' Mara says, 'you can't presume this is a way people are going to make decisions. It makes it harder to counteract all of that other crap. And, once again, I'm sure there's lots of reasons why there weren't more Māori or Pasifika or others.'

'Yeah, I texted Kayla ${ }^{24}$ and was like: "Is there going to be child care?" She was like: "Ah, no. That's a really good idea, maybe in the future",' Te Awanui laughs loudly.

\footnotetext{
${ }^{23}$ Destiny Church is a Pentecostal fundamentalist Christian organisation, led by Brian Tamaki. It has a predominantly Māori and Polynesian membership and came to notoriety when it launched the 'Enough is Enough' campaign against civil unions in 2004.

${ }^{24}$ This is a pseudonym.
} 
'Then I texted her for the second one: "Is there going to be child care?" and she was like: "Aaaah, no. Sorry".

We all join Te Awanui's laughter.

'Isn't that gross though, eh?' I say. 'The way that there are structural reasons why there aren't more Māori and Pasifika in, say the anarchist scene or at a queer meeting like that, but that makes it real easy for the people who are there to sit around and talk about Māori being sexist or Destiny Church being homophobic or whatever, and assume that all the Māori and Pacific Islanders aren't there because they live in some sexist, homophobic world that prevents them from queer organising or something.'

'Yep,' Kura says. 'Like what Clara said about how there were no queers in the Māori world. Or, you know, they were all about the male and female element. And me and Te Awanui were like: "Ah, we're Māori!"' Another explosion of laughter. 'Here's two queer Māori right here!' says Te Awanui.

Speaking up in Pākehā dominated groups can be very uncomfortable for Māori, yet again they may feel a responsibility to do so. This shows that challenging people is difficult work. This work is made more difficult in meetings where little attention has been paid to decision-making processes, allowing those most comfortable with speaking to dominate discussions. There are, however, ways that non-Māori can share some of the responsibility for this challenging work respectfully.

'You talked ages ago about her response to it,' Francis says, 'how for a while Clara didn't want to talk about it because she found it really traumatic.' Francis summarises a debate on a feminist blog she read and concludes, 'Some of the trans $^{25}$ people were pointing out that people were acting as if the trauma from

${ }^{25}$ Transgendered. 
being called on anti-trans language was as bad as the effect of their language. And I might be naive, but it was the first time I had heard that really well articulatedthat you make that bigger than the actual thing you did. ${ }^{26}$

'Yeah!' Kura says, among a general rush of recognition from the group. 'And it's really self obsorbed,' Mara says.

'That reminds me of the story I was thinking of telling,' I say. 'We were at a working bee at the animal sanctuary-and I don't know if you were in ear shot, Te Awanuibut I remember you being in the lounge with me and Jac, ${ }^{27,}$ I say to Kura. 'I was telling Jac about how when I met this Māori academic (who I went to see to ask about how the sanctuary could work with local iwi), she told me that Moana Jackson didn't want to work with the anarchist scene, because of how they acted around October $15^{\text {th }}$. I was just telling her like: "This is full on, eh? Obviously we need to sort our shit out". Well, that was my intention, but all I said was that he had pulled out of all these public meetings when I was in that group, because he had tangi, but now I realise that he also just didn't want to work with us. And she went on this big rant like: "He's this fucking powerful academic and he should have told us!" The October 15th group had done a similar thing, all about his behaviour, but when I talked to them I had gone in prepared for an argument. I guess it kind of caught me off guard with Jac. She was talking about how: "Anarchists get such a hard time because we actually do stuff and it's just because we're trying. Other people don't try, so they don't get the shit that we get". It was this real 'poor me' rant.

${ }^{26}$ In relation to racism, this tendency has been popularly labelled 'white women's tears’ by bloggers such as Julian Abagond (2010). Narayan explains this emotional response in more sympathetic terms, when she notes that well-meaning 'outsiders often react with honest bafflement and anger' (1988: 41) when challenged on their oppressive behaviour, because this clashes with their self-image as allies (much of this is covered in the previous chapter, see also my final discussion, 'Processes of Pākehā Change: 'learning to be affected').

${ }^{27}$ This is a pseudonym. 
'Part of the reason I thought this was a good story to tell is my response. I didn't agree or disagree, I just sat there in shocked silence and said nothing. And I've never talked to her about it. Because I was really angry. And people have different responses, when Jac is angry it comes right out straight away. For me, I'm just stunned. So I didn't say any of the stuff that I said to the October $15^{\text {th }}$ group, like: "Well I think that we should focus on our own behaviour", or the simple fact that: "poor Pākehā people!" You hear that so much like: "Oh, we tried and we got told off and so we aren't even going to try anymore". You know, all that trauma of being told off, and it's like: "What, Māori people don't tell each other off?"' 'It's like, what's the purpose of those kinds of statements?' Te Awanui says. 'It's to avoid being told off, right?'

'Yeah, that lack of being able to hear criticism,'I say. 'But again, part of the reason I am telling this story is because I knew: "This is probably quite shit for Kura and I could be saying something here", but I wasn't. So, that lack of being able to get your shit together enough to say something useful, when somebody says something really stupid.'

'Sometimes it's hard to respond, eh?' Te Awanui says.

'And when it's someone you care about as well,' I say, 'and you weren't expecting $i^{\prime}$

'Yeah,' Kura says.

'That reminds me,' Te Awanui laughs, 'of telling a boy that some sexual thing we did together, I wasn't real into and I tried to make that clear and they didn't pick up on it. And them being like: "Oh my god! That is so not something that I do! Oh, but I did do it, oh! But oh my god, this is so terrible, I'm going to have a big break down over it," and me being like:... "There there".'

"'This isn't making it easier for me to deal with the initial thing now, turning it into a big drama",' Mara adds.

'Which is why it was hard to say something at the time,' Te Awanui says, and we agree, 'because I thought their reaction to me making a big deal out of this is gonna 
be worse than just doing it. That should be obvious, actually. Don't make this about yourself!'

We all laugh.

'It's exactly the same stuff that happens in groups,' Kura says.

'There was a really cool post on a feminist blog recently,' Francis says, 'about a trans woman in Knoxville, Tennessee, calling her grandfather and her mother on not very inclusive behaviour. And how hard that was for her to do, and the reason why she felt like she had to do it. Like, we call each other on behaviour because we want to maintain relationships. It's this thing we do so that we can stay in contact with each other, not to make you feel bad. ${ }^{28}$ Just thinking about that in relation to Moana-why does Moana care? For that solidarity group?'

There is a lot of laughter from the rest of the group.

'That's exactly what Mara said when I told her the story,' I say. 'She was like: "Pft, it's not his responsibility to teach you guys to sort your shit out".'

'Oh yeah,' Mara says.

"How many people within the group had told you that?"' Francis says and there is more laughing.

'Yeah,' Te Awanui says, 'every time you have to call someone out on their behaviour, that's work of theirs that you are doing.'

While challenging oppressive behaviour can be seen as important and difficult emotional labour, undertaken in order to maintain relationships, people who have been 'called out' often respond by acting as though that

\footnotetext{
${ }^{28}$ Matthew Palmer makes a similar comment while explaining his relational approach to the Treaty of Waitangi:

Maintaining a serious relationship will always have its ups and downs. Anyone who has experienced difficulties in any ongoing relationship understands that. The parties can expect to experience conflict if they are genuinely prepared to say what they think - yet that is the essence of the clear communication that is necessary to ensure the ongoing health of the relationship (2008: 23).
} 
challenge is the same as-or worse than-their own behaviour. This strategy can be used to make it more difficult to challenge people and puts an extra burden on Māori.

'With the October $15^{\text {th }}$ group,' Hayley says, 'some of the stuff I found hardest to deal with was the stuff that would have been impossible to call someone out on. Like I used to get so wound up about Helge, for example, saying: "Oh yeah, I'm from Taranaki"29 $^{29}$. Possibly that would be one thing I could make a point of calling him out on, but just the vibe of: "I'm down with the Māoris". That kind of atmosphere, I found real hard to name.'

'Yeah, and if people were real clear about not speaking for Māori, some of that would change,' Te Awanui says. 'If someone is acting or talking like: "I'm in with the crew", perhaps they need to make a point of saying: "I'm not Māori. And I'm not going to be speaking for Māori". Period. Not: "But, blah blah blah". Just: "I'm not going to do that". Then it's a humility thing or something, eh? People just want to say stuff, which is cool, and they have good intentions, which is cool. But actually, people need to not get all full of how awesome they are! Or how "in" they are. It's nice to feel accepted and I can understand that it's like: "Yay, it's cool these people I think are cool like me", but-'

'I think there's another underlying problem with the anarchist scene, that made me think of Helge,' Mara says, 'because a friend who knew him quite a while ago was really angry when I was talking about him. All I said was that he's moved to Taranaki, staying in Parihaka, and she was like: "Hgr!"' Te Awanui laughs loudly at this and we all join in. 'She's like: "God! Rr, he used to fuck me off. What an arrogant little shit". And I started to think, that's how it works-young people come into the scene, they're not challenged on their arrogence. No one tries to guide them to be less jerky. And probably because they are quite arrogant, or confident, they get put up to do speaking. And then there is the whole issue of power-we start

\footnotetext{
${ }^{29}$ Helge is a foreign national and a fluent speaker of the Māori language, so he is presumably familiar with Māori conventions of naming one's place of origin (rather than where one lives currently) as where one is 'from'.
} 
being reliant on them and they start getting away with shit all the time because no one is willing to say something. And more often than not, they are making really bad comments around Māori. Around Palestine. Gender. Women.' 'Leading chants in te reo,' Hayley adds and we laugh.

'Yeah, that's such a good point, Mara,' I say. 'People tend to focus on certain people, but everyone in that room-in that meeting or whatever-is involved in that situation, eh?'

'Yeah,' Mara says. 'But it's really hard when you're a newbie and you're like: "Aaw, everyone must respect them".'

'Yeah, totally,' says Te Awanui. 'And it seems like not a lot of people make it past being a newbie unless they are that person.'

'So,' Mara says, 'I guess putting out the challenge for people who have been there for a little while to speak up if they think something is wrong. Even just say-' 'Like: "I don't agree",' Kura offers.

'"I don't agree",' Mara says, 'or: "I don't know how to voice it, but I don't feel comfortable with that". So it's not setting up that on-going cycle of ego.'

'That's the thing about power though, eh?' Hayley says. 'How many people challenged Paula? I don't know how many people challenged Helge, I know Francis has. And it's like, if they've got power, then they have the power to ignore you.'

'I completely agree with you,' Francis says, 'but I think the culture of the scene also comes in there. Like, I never confronted Helge or Paula about their behaviour in front of the group.'

'No,' Mara agrees. 'Yeah, same. I've had Helge up on stuff heaps of times and it's always on a one-on-one level. I'd just say: "What did you say that for?" or: "What are you doing? Dick!'” Mara quotes in a laughing, matey voice.

'I've tried to wrap my head around the culture of the scene so much,' Francis says. 'It's bitchy, but it's kind of not. You can bitch about someone to everyone, you can 
say something to their face, but you can't bring it up in a group. And if you bring it up in a group, people back away. ${ }^{30}$

'Yeah, that's a good point!' Te Awanui says. 'It's a huge deal to bring something up in a group, eh? Even if it's something that affects the group and is something the group should be dealing with.'

'It's like you become responsible for any dramas that come up in that group,' Mara says.

'Yeah, and if there is a conflict in a group between two people, about people's behaviour,' I say, 'the rest go silent and it's left to those two people to deal with, eh? I've been in those situations, when I've been one of the silent people watching. And it's hard because you don't wanna feel like you're all ganging up on someone, I suppose...' I am trying to honestly dig into those feelings, but perhaps I sound like I am trying to justify them, because I feel Francis go a little prickly. I hurry to add, 'I guess it's about learning language or something?' 'Yeah,' Francis says.

'To support people, without it feeling like it's a big attack or something?' I say.

${ }^{30}$ Eleanor Wilkinson also notes a similar repression of open conflict in her work with queer people in 'non-queer' autonomous spaces in the UK (2009). Wilkinson argues that 'hidden hierarchies' in collectives are supported by 'feeling rules' dictating what can be expressed during meetings. This mirrors the discussion in the previous chapter about assumptions that emotional expression hinders rational arguments, as Wilkinson's interviewees recognise that their feelings of anger and frustration are 'not seen to be appropriate in autonomous space' (ibid: 39). Wilkinson writes:

At times it seems that the emotionally supportive environment that has been created to foster participation, has sometimes led to the reverse; some people may not want to block decisions for fear of causing trouble and disrupting group harmony. At times it appears what we are left with is a very simplistic dual emotional framework—consensus $=$ good $/$ conflict $=$ bad' (ibid.).

She also notes that while consensus organising 'should be about working through conflict rather than avoiding it entirely' (ibid: 40), the practice of consensus often differs from the theory. 
'Yeah, but the problem is,' Te Awanui says, 'it becomes how the 'someone' reacts to being told off. You know how it is, they get all upset about being called out and then it's a bigger deal than it needs to be.'

'And it becomes about the 'abusive' behaviour of the person who said something,'31 Francis says. 'Maybe they didn't go about it in exactly the right way. Then no one wants to stand beside them. ${ }^{32}$ But I think it's such a big deal and we are so bad at it, because we don't see it done. And we don't do it. And you can't get good at something if you never see it or try it.'

'True,' Kura says.

A culture of conflict avoidance makes it difficult to confront and resolve power issues within collectives. It is difficult to challenge people, because some oppressive behaviour is subtle and tied to a person's power, while those raising concerns may be labelled 'abusive'. Lacking the skills to deal with these challenges collectively, we often allow-and even foster-abuses of power.

${ }^{31}$ Indigenous scholar Aileen Moreton-Robinson noted a similar tendency in her research with white feminist academics, finding that when she took an 'interventionist' approach to interviewing she got 'highly emotive responses' from an interviewee, whose 'use of language and turn of phrase equated black women's critique of white feminists with violence and abuse' (2003: 81). This shows that a focus on the 'abusive' behaviour of the person who has been wronged is closely related to the 'trauma' response of the person challenged about their oppressive behaviour.

32 That people do not always raise their concerns in 'exactly the right way' is also acknowledged by Narayan, who writes that when outsiders to oppression are dismissive of insiders' concerns:

The insider will most often respond emotionally to such attempts to negate her understanding - with anger, tears etc. The issue, to the insiders, is not a purely theoretical one, and their anger and pain at what they have to endure become exacerbated by the seeming inability of even well-intentioned outsiders to see their point of view (1988: 41). 
'That reminds me,' Hayley says, 'I was very briefly part of an 'intentional living' group with Martina ${ }^{33}$ and some other people.'

'Yeah, Martina's good at it,' Francis says.

'Yeah!' Hayley says. 'And I was like, 'Oh my god, it's a cultural thing!'

'German, eh? She's direct,' I say.

'Yeah,' Hayley says, 'we were in this group, planning and getting to know each other for a year or so, before buying land together. And Martina was like: "The first excercise we are going to do is go around the room and say what we don't like about each other". ${ }^{34}$

'Wah, woah!' Mara cracks up.

'That's what she wanted to do,' Hayley says. 'She said: "It's really important to put out there what issues you have with everyone in this room".'

'Oh my gosh...that's so cool,' Kura says hesitantly.

'Well, we didn't do it!' Hayley says and I laugh loudly. 'And I'm really glad we didn't because, for one, what are the chances of the group getting anywhere? Do we really need to do this really full-on, traumatic thing right at the get-go? But yeah, that's a really different cultural place to be coming from, where that seems like a cool way to start a group.' 35

${ }^{33}$ This is a pseudonym.

34 This is a clear example of the cultural clash Brigitte Bönisch-Brednich notes between a German belief that 'directness and a frank expression of opinion are undeniable virtues' and the cultural imperative among New Zealanders to remain polite, even at the expense of clarity (2002: 171).

${ }^{35}$ In 'Watching the Kiwis: New Zealander's Rules of Social Interaction - an Introduction' (2008), Brigitte Bönisch-Brednich (following Kate Fox 2004) writes about the English rules about conflict and face-saving that middle New Zealand has inherited. In contrast to the German cultural norm to talk about differences openly, Bönisch-Brednich writes that: 'One of the characteristics of rules about conflict is that a straightforward complaint has to remain the last resort; complaints are dangerous because they potentially tip the balance in an already unstable relationship, 
Francis says, 'I've been in some groups, where Martina's been like: "I just want to put on the table that there is some really bad power stuff going on here. There's an informal hierarchy, and you know, I can go around the room and tell you each where you are on that hierarchy and I bet you could do the same too. But we won't talk about it". ${ }^{36}$

'Ahh-haa! Wow,' Kura says as she and Te Awanui burst into a fit of giggles.

Amongst all the laughing, Francis says, 'Yeah: "That's cool. And I'm a little scared of you right now".'

'If you bring anything like that up,' Kura says, 'it becomes your responsiblity to deal with what you're saying. So it becomes a huge burden, like, 'What the fuck did you bring this up for in a meeting? Now we all have to fix this. When are we going to get some work done? ${ }^{\prime 37}$

are often read as an insult and are usually ineffective’ (2008: 9). Bönisch-Brednich notes supressed complaints are replaced with 'cathartic moaning', where it is more acceptable to complain to anyone other than the person with which one has the actual complaint.

${ }^{36}$ Bönisch-Brednich connects notions of egalitarianism to 'this carefully developed Kiwi system of playing down differences, denying hierarchies or at least acting them out in a more backstage kind of way, applying various tactics of disguising difference and constantly creating a social plateau’ (2008: 7). Bönisch-Brednich points out that this is confusing for newcomers to New Zealand, who have to learn that 'there are, as in every society, boundaries, social classes, status systems and signs and indicators for them; they are just harder to detect because these rules are written in a code' (ibid.).

${ }^{37}$ Kate Fox makes the observation that the notion of 'consensus' is very important to English working culture, yet English people are always moaning that they hate meetings - they want to get on with the 'real work' (2004: 198). It is interesting that this is equally true in the anarchist spaces, despite a commitment to consensus being a defining feature of the movement. Irihapeti Ramsden acknowledges that these kinds of negotiations take a huge amount of time, yet she argues that: 
'Yeah,' Hayley laughs. "We will just schedule that for after our discussion about gender and whether or not we support tino rangatiratanga and what are we going to do about this abusive man? and-"'

We all laugh with her.

Difficulties with confronting personality clashes and informal hierarchies in the anarchist scene can be connected to wider cultural norms in Aotearoa New Zealand. Within this culture, direct criticisms can in fact be experienced as 'traumatic'. Naming these power dynamics is also made more difficult because it is seen as a 'burden' on the group, a barrier to 'getting work done'.

'When I think about groups I've been in that have tried to discuss tino rangatiratanga,' Hayley says, 'it makes me think it's a sign of how little me and the other people in the group know about it. The fact that in multiple collectives, it has been something we try and do, and try and do, until it's just too hard and then it falls off the agenda and we forget about it. It never becomes like everyone understands where they stand well enough that it's integrated into everything we do. It's only when it's scheduled separately on the agenda, and then no one knows what to say. And it's so hard.'

'Yeah,' says Kura.

'It was so like that at the sanctuary, eh?' I say and Te Awanui agrees.

[P]ower sharing involves reallocation of all resources, including time... Consensual negotiation does take time, but time is also saved once consensus has been reached, resistance is removed and the group functions as a whole. Because continued cooperation is ensured the process balances out in favour of the consensual model and can actually save a great deal of time. The Maori model has proved extremely workable and efficient (2002: SI-2). 
'It's almost like by labeling it: "Do we support tino rangatiratanga?"' Hayley continues, 'it misses the point a bit. Maybe if you are making a group statement or whatever you want to know that, but it misses the point of: "What does it mean for us? Doing this particular work, in this particular collective, in this country?"' 'Yeah,' Mara says, 'and maybe people need to frame it differently. Not to put 'tino rangatiratanga', but talk about colonisation. And say: "We don't practice tikanga within this group-because we don't feel like we're in a position to talk about what Māori should do with their tikanga or their tino rangatiratanga-but we should challenge colonialism" or something.'

'Yeah,' Hayley says, 'and: "If we are planning on doing this particular demo, how does that fit with our beliefs about this?" Or: "Are there any things we are going to do that are possibly going to be offensive?"'

After a little laughing and agreeing, Hayley asks, 'What were you saying about the sanctuary? Was it that it was really separate?'

'Yeah, well we tried,' Kura says. 'It was really like we just had this little lobby group, on the side, that was constantly trying to force tino rangatiratanga on an unsuspecting group.' Te Awanui bursts out laughing and we all join in. 'So we'd talk about it a little bit at the start of every meeting. And we would schedule separate meetings, that no one else would ever show up to. But it really was like you said, we wouldn't go back to it for anything. Yeah, it wasn't integrated into what we were doing everyday, it was like: "Here is this big fat annoying thing on the side"., 38 'And then if it did get brought into the regular thing,' I say, 'like the gravel issue, then suddenly-'

'Burgh!' Kura shudders and Te Awanui says, 'But didn't that just get done behind our backs?'

'What was the gravel issue?' Hayley asks.

\footnotetext{
${ }^{38}$ This seems to reflect the lower end of what Mason Durie identified as a 'bicultural continuum': where we see the 'introduction of a Maori perspective into the culture of the institution but as an addition to the overall culture of the organisation rather than as integral to its core business’ (1995: 36).
} 
'Uh, it was a really polarised example of animal rights versus tino rangatiratanga. Because there is a quarry there and they wanted some gravel to do the roads and we'd already agreed that were weren't going to quarry anymore. And my dad and his partner had come up and had a look at the place" and he said: "This is unsightly, blah blah blah" and Jac said something to them about how we weren't going to touch the gravel anymore. But then it was like: "But, if we spend money on gravel then the animals lose out!" So it was really like-'

'Well, because they wanted to use the gravel to make pathways,' I say, 'up around the house and stuff. Which was quite separate from the road, which the gravel had to be used for.'

'Yeah yeah,' Kura says, 'those pathways.'

'But when making the decision whether we were going to use the gravel for the pathways, it was framed like: "What does the decol group think about that?" It was like we were this consultation group, eh?'

'And they didn't actually listen to what we said anyway,' says Te Awanui.

'And it had to be decided at that meeting, as well,' I say. 'It's not like we could talk about that stuff in some broader way. There was heaps of things that were hideous about that.'

'And the impetus was on us to find a solution that wouldn't use the gravel as well,' Kura says, 'if we were objecting.'

'Or the money!' says Te Awanui. 'The money "being taken away from the animals".'

'But the other thing was the way it was talked about,' I say. 'With any of the things you guys suggested, there was this general argument that Māori value taking care of the environment and it's the most environmental thing to use the gravel that's already here. Rather than shipping it from somewhere else. And the word 'kaitiakitanga,40 was used. So it was this usurping-like: "We're just going to take vague things we know about Māori principles and try to do it the best we can and

\footnotetext{
${ }^{39}$ Kura's father and his partner were our main link to Raukawa. They visited the animal sanctuary to talk with us about how we could build a relationship with their iwi. This intimate connection put Kura in a difficult position.

${ }^{40}$ Guardianship.
} 
then the mana whenua ${ }^{41}$ won't be able to hassle us, because we will have done it". That was the tone. ${ }^{42}$

'Yeah, definitely,' Kura says. 'It was a covering our arses, how can we-'

'Do what you want to do,' Hayley offers, 'but make it look like-'

'It's Māori friendly, yeah,' Kura says. 'Pretty much.'

Te Awanui laughs at this and says, 'The annoying thing was that we had talked about the quarrying. We had extensive conversations about it, and decided that until we knew whether or not we should be moving the earth, we would leave it where it was. But then, someone wanted to make some pretty paths and it was just like: "Oh, let's not worry about what we've decided before".'

'But even if you are going to go along that sustainability path,' Mara says, 'well, what about the water table? What about the soil structure? What about all these other things?'

'"No no no, let's just not talk about that",' Te Awanui jokes and gets a giggle from Amiria, "'because then we would be able to save less animals".'

'But it's an animal rights group, right?' Francis says. 'It's not an environmental group or a tino rangatiratanga group?'

'Obviously not,' Kura says sardonically.

'Well, what are we actually about anyway?' Te Awanui exclaims. 'Didn't we all agree that we were about animal rights?'

\footnotetext{
${ }^{41}$ The people with power from their tribal land.

${ }^{42}$ My understanding of this as 'usurping' local Māori roles as hosts and guardians of their land comes from my reading of Lucy Pickering's 2010 article, 'Past imperfect: Displacing Hawaiians as hosts in a 'drop out' community in Hawai'i'. Mikaere makes a similar point regarding the Crown demonstrating a commitment to the Treaty through including elements of tikanga into certain laws, 'but clearly the accommodation of tikanga values within a Western legal framework is a totally different prospect from the acknowledgement of tikanga as the supreme law of the land' (2011: 267).
} 
'We had built this kaupapa,' Kura says.

'But that was the weird thing about that group, eh?' I say. 'One of the stated intentions was to build partnership with Raukawa and actually do something there. ${ }^{43}$ But because not everyone in the group even necessarily agreed on that, or maybe agreeed-'

'In theory,' Kura says. ${ }^{44}$

'But it wasn't really their vision,' I say.

'It's a shame that people didn't realise," Francis says, 'that is working with tangata whenua exactly the same way that the government does. Like: "We'll be in partnership with you when you agree with us. Then we'll consult with you and if you disagree, we've consulted. ${ }^{45}$ And when I say 'you', I mean the people we are going to bother contacting."

${ }^{43}$ This aim was based on Paula's reading of a chapter in Carol Archie's Maori Sovereignty: The Pakeha perspective (1995), which outlines Tanya Cumberland and Charmaine Pountney relationshipbased approach to buying a lifestyle block within the traditional area of the iwi Ngāti Te Ata.

44 This tendency for Pākehā to support tino rangatiratanga 'in theory’, so long as it does not threaten material resources, can be seen in Chris G. Sibley and James H. Liu’s study, which concludes that: 'Pakeha students support biculturalism in principle but were opposed to resource-specific biculturalism’ (2004: 96).

${ }^{45}$ Richard Hill's Maori and the State: Crown-Maori relations in New Zealand/Aotearoa, 1950-2000 shows that despite rhetoric of 'true' or 'equal partnership', Māori are always treated as the junior partner and the Crown's sovereign authority is continually legitimated at the expense of Māori rangatiratanga (glossed by Hill as 'autonomy'). Hill argues that: 'Defeat of autonomist aspirations was always the preferred Crown goal, especially in the long assimilationist period from the beginning of the colony until the early 1970s. But where that proved untenable, the state sought to appropriate organisational expressions of autonomy for its own purposes, often attempting to turn them into vehicles for the assimilation project' (2009: 275). Within this model of 'partnership', the Crown can at any time decline from meaningful consultation and make decisions unilaterally (ibid: 284).

${ }^{46}$ Annette Sykes has shown how the National Iwi Chairs Forum has become 'a Maori issue one-stop shop... which the Crown then resources as part of its specific 
Tino rangatiratanga is not well understood or integrated in many anarchist groups, even those that have had ongoing discussions about it. A focus on whether or not the group supports tino rangatiratanga may act as a distraction from looking at one's own behaviour, or the decisions of the group, and truly challenging colonisation. When tino rangatiratanga and decolonisation are treated as side issues (often seen as competing with other core issues such as animal rights) there is little room for negotiation or genuine partnership.

'That's what I tried to say to that group about Jac,' Te Awanui says. 'The meeting I ended up leaving, they said: "Let's go back and revisit our hopes and dreams, because it's not working". I was like: "This is stupid, we've done this, we've had extensive talks about what everyone wants. The problem is the power

dynamics. The problem is that Jac has all the power and makes all decisions and is fine with everyone having a say as long as everyone agrees with her and as soon as they don't, she just does what she wants. The people who do agree with her support that and the rest of us just don't get a say. ${ }^{47}$ That's really obviously the problem, these fucked power dynamics that we're not talking about". It's the same. The same stupid thing. That group sucked!

consultation requirements in the expectation it will generate an acceptable Maori view' (2010: 13).

${ }^{47}$ Jonathan Purkis outlines some of the ways 'activists in possession of significant cultural capital might pose problems for the organisational philosophy' of anarchist collectives (2001: 173). Purkis argues that this power imbalance is 'broadly acknowledged by the movement' and particular strategies are used to counteract these problems, however, he also notes that these strategies rely on a high level of self-policing and responsiveness by the 'core group', who, possessing higher cultural capital, may easily drop these strategies in favour of 'pragmatism' when they become frustrated by the constraints of consensus decision-making. 
'I hate now, when someone says something to me about how cool the sanctuary is. Or when I'm at the op shop and I see that written about "Respecting Papa-tū- $\bar{a}-$ nuku" ${ }^{48}$ and all this. I'm like: "Those are my words!" and they are not doing that. The people who actually came up with any of the ideas about tino rangatiratanga have been racistly excluded from that group! Actually, all that shit-all that racist, not respecting-it's the reason I left and I think it's the bloody case for a lot of us. It's real bullshit that they're still putting it out there that that's what they're all about.'

'Yeah,' Kura says, 'I would just like them to take it off the signs, just stop using those words. It's just offensive.'

'I think it still says on the website that it is collectively run, as well,' Hayley says. 'Well,' I say, 'I think it is still, technically, a collective.'

Hayley says, 'So, it's run by consensus, meaning that if you don't agree, the group continues to get smaller and smaller and smaller? ${ }^{49}$

As we laugh Kura says, 'That's exactly what happened! People just kept dropping out. If you had a problem in the group, you would eventually end up leaving and then the next person who had a problem would end up leaving, yeah.' 'And then we just got kicked out though!' I say and everyone laughs. 'It wasn't just dropping out.'

'No! I left the day before you got kicked out!' Kura says and there is a lot more laughter as she adds, 'I could see it coming though.'

'Ridiculous, eh?' Te Awanui says.

\footnotetext{
${ }^{48}$ The Earth mother. All living things originate from the union of Papa-tū-ā-nuku and Rangi-nui (the Sky father) in Māori cosmology.

${ }^{49}$ This mirrors the pattern of 'exaltation followed by burn-out' within the anarchist movement, described by David Graeber, where once eager members become disillusioned as groups fail to live up to the initial promises of autonomous organising (2009: 332). This leads to a high turnover of members, which Purkis (2001) notes is one of the reasons a ‘core group’ of more experienced people retain greater power, creating a 'self-fulfilling prophecy'.
} 
'It makes me think of interventions I've heard of in the States,' Francis says, 'in anarchist stuff. I think it was a CrimethInc ${ }^{50}$ conference, there was going to be a ball or something, and a bunch of activists of colour marched into the ball and started shouting about what a racist and exclusive organisation Crimethlnc was. It caused physical fighting, but I think sometimes those confrontational interventions are really useful for just getting rid of the silence. Like: "If you want to use these words and still be exclusive, I'm going to make sure everyone knows you're lying".'

'Yeah, SO,' Te Awanui laughs mischievously, 'maybe there could be a petition, to say that those cats need to go! Or they need to be made to not kill native birds, like have collars with bells or be in an enclosure.' Te Awanui is referring to some halfdozen rescued wild cats that Jac brought with her when she moved to the animal sanctuary. Jac objected to them being collared, because they might strangle themselves on tree branches. Because Kura's father had expressed concerns about these cats, this issue came to represent the group's failure to listen to Māori. 'I just think it would be really funny,' Te Awanui says. 'Because imagine if you cut and paste all this shit from their website, like: "We support tino rangatiratanga", "We wanna build relationships", "We wanna listen to what Māori have to say". We could be like: "We're a bunch of Māori people, how about you stop bringing all these cats out here? And putting them into an area right on the path where they are trying to get native birds to regenerate. How about you just fuck off with all your cats or start doing something about it? Or admit that you're racist and you don't support tino rangatiratanga!"' Te Awanui is laughing throughout this and we start to join in as they add, 'Put that on your website: "We are racists, who don't support tino rangatiratanga".'

'"We support cats over all sorts of natives".' Francis says and we all crack up.

'I think that cat example,' I say, 'even more so than the gravel, shows that you guys were only really listened to if it was really obviously "Māori stuff", eh?'

\footnotetext{
${ }^{50}$ CrimethInc is a decentralised anarchist collective, with autonomous cells throughout the USA.
} 
'That's pretty obviously Māori!' Te Awanui says.

'I know,' I say, 'but anything that could be a little bit about other issues as well was-'

'Yeah, but animal rights is a Māori issue,' Te Awanui says. 'It's almost like everything else is by default a Pākehā issue, unless you can prove it's Māori.' I laugh, 'Yeah!' and Kura says, 'Exactly.' 'If it's not just some cute cultural practice,' Te Awanui says, 'it's a Pākehā issue. ${ }^{, 51}$ 'I think that comes back to the stuff with 128,' Francis says, 'about tikanga. What it means to be supporting tino rangatiratanga-means not washing tea towels with underwear and not wearing shoes inside. And that's it. Personally, I couldn't care less about washing tea towels with underwear, but I do really care about tino rangatiratanga. And it's a much harder question.'

Power-sharing is clearly a central issue that needs to be addressed for those claiming to support tino rangatiratanga. Lax decision-making processes and informal hierarchies can allow anarchist groups to reproduce power relations that exist at the national level-with Pākehā in positions of power making the decisions and having no time for real engaged partnership. This power imbalance is supported by a tendency to reduce Māori realms of influence to 'cute cultural practices'. This allows tino rangatiratanga and tikanga to be contained within simple customs, rather than challenging power or core values.

\footnotetext{
${ }^{51}$ Mikaere makes a similar point when she writes: 'We were free to practice our quaint rituals within the boundaries of our homes or our marae, so long as we did so in a manner that did not offend any Crown laws' (2011: 260-261).
} 


\section{A Black Rainbow Story}

In chapter three, 'Black Rainbow (August to October): Identity', I drew on Uma Narayan's notion that insiders' epistemic privilege is based on lived experience and tied to identity, and also pointed to how Māori identity is not always recognised. In chapter four, 'Black Rainbow (November to March): Relationships', I expanded on Narayan's assertion that insiders' epistemic privilege is experienced through emotional reactions, to reflect on how Māori ways of expressing emotion are not always validated. I returned to Narayan once again in the chapter before you to discuss how insiders to oppression can validate each other's epistemic privilege. I look here at how Black Rainbow was a place this could be done through sharing stories, telling jokes and creating meaning as a group.

Through tracing the meaning made in this discussion, I suggest that this 'Black Rainbow Story' could be summarised as follows: stories of how people in Pākehā dominated autonomous spaces relate to the Māori principles of tino rangatiratanga and tikanga expose failures at power-sharing. Several things get in the way of true power-sharing, such as ignorance, informal hierarchies and cultural norms against challenging people directly over mistakes or abuses of power. This leads to several situations where Māori find themselves uncomfortable, bearing a greater responsibility, but lacking decision-making power. Tino rangatiratanga and tikanga remain limited to lip-service and simple customary practices in this environment and the burden of the discomfort of working across difference remains largely with Māori members of groups. 


\section{Processes of Pākehā Change}

\section{'Learning to be affected' while working across difference}

This thesis is a collaborative exploration of how Māori and Pākehā work together. As well as responding to these issues within my own anarchist community, this thesis also questions how we work together in research, in response to criticisms presented by Kaupapa Māori researchers. For both the anarchist scene and for methodology, as well as wider society, I am interested in the questions: 'how do Māori and Pākehā work together across difference?' and 'how can Pākehā work better with Māori?' Answering these questions together with Black Rainbow, I have employed anti-oppressive methodologies and written about this collaboration in a way that shows the progression and relationship-building of the group (how we worked together) as well as telling the members' stories and tracking the meaning we made together as a group in response to these stories.

Moving chronologically through our time together, I looked first at how complex identity is for both Māori and Pākehā living within colonisation, in chapter 3, 'Black Rainbow (August to October): Identity'. Through the 'where we come from' stories shared in this chapter, I came to appreciate how life experience and identity inform insiders' epistemic privilege (Narayan 1988), giving Māori a heightened understanding of racism, while Pākehā tend to find racism and white dominance more difficult to 'see'. This gap in understanding can especially be seen through the use of humour and 'who is laughing'. Outsiders' lack of insight into oppression also impacts on Māori identity, as Pākehā unintentionally push notions of who are 'real' and 'not real' Māori onto the Māori members of our community. 
After our early meetings Black Rainbow went through a period of relationshipbuilding and this became my focus for chapter 4, 'Black Rainbow (November to March): Relationships'.

This chapter also looked at how our relationships were threatened, particularly through my failure to appreciate Māori responses to 'micro-aggressions'. The discussion about intimate cross-cultural relationships at the heart of this chapter showed how relational identity is and how power impacts on relationships-even while that power is not fixed. I was particularly struck in this discussion with issues around how emotional expression is valued differently in Māori and Pākehā culture. This called me to consider that a Pākehā tendency to dismiss Māori emotions as inappropriate can hinder an acceptance of insiders' epistemic privilege, which, Narayan has argued, is largely experienced emotionally.

In the final stage of the Black Rainbow meetings, we had a more focused discussion about difficulties within the anarchist scene, which became the centre of chapter 5 , 'Black Rainbow (April to June): Power-sharing'. The humour used in these discussions can be seen as insiders asserting epistemic privilege, in the face of that privilege often being denied. This allowed the group to investigate some of the reasons for failures at power-sharing, including Pākehā ignorance about tino rangatiratanga and tikanga, Pākehā claiming indigeneity, and a culture that avoids conflict and sees criticism as an attack.

A conclusion of these discussions could be that the Pākehā dominated communities are difficult for Māori to participate in-because Pākehā often undermine or tokenise Māori identity, deny the complexities and subtleties of their insiders' epistemic privilege, respond insensitively to Māori concerns and resist powersharing. By all accounts, the stories we tell in response to the question "how do Māori and Pākehā work together across difference?' are pretty grim. Having told 
the story of Black Rainbow and tracked some of the meaning that was made in that group, I want to end with a final discussion about the learning I have taken from this experience and how it might go some way toward answering the second question: 'how can Pākehā work better with Māori?' My intention in this is to focus my analysis on my own experience, rather than laying further analysis over that of the other members of the group. Instead I will discuss the impact their stories, analysis and friendship have had on my thinking - as an ally and an academic. In this, I build on work from Ingrid Huygens on 'processes of Pākehā change' within the Treaty educators' movement, which focuses on the emotional processes of change (2007). Yet, in this turning towards myself and my emotional reactions, I am aware of how this returns the focus to Pākehā, perhaps re-centring white experience. Therefore, I also respond to criticism of whiteness studies, particularly those put forward by Sara Ahmed (2004), who writes about the non-performativity of anti-racist claims that express white 'pride' about 'shame', and may actually prevent white people from hearing the exposure of racism. In this final discussion I am, therefore, interested in how learning to be attentive to my own emotional processes of change has helped me to sit with the discomfort of hearing racism exposed. Two major things I learnt in Black Rainbow was the importance of simply listening to Māori and the power of accepting criticism. Relating these to emotional experiences of discomfort and trust, I discuss the change working across difference has worked in me.

\section{Processes of Pākehā change}

In this focus on my own experience of working with Black Rainbow, I have been particularly influenced by Ingrid Huygen's thesis: Processes of Pākehā change in response to the Treaty of Waitangi (2007). I hope that by reflecting on my experience of change I can contribute to a growing body of literature on Pākehā identity and consciousness raising. I will therefore begin with some discussion of Huygen's thesis. 
In a very interesting piece of collaborative research, Huygen's thesis taps into the institutional knowledge of the Pākehā Treaty education movement. This movement developed in response to Māori activism around the New Zealand state's failure to uphold the Treaty of Waitangi, as well as requests from Māori activists that Pākehā educate their 'own' about the Treaty. The Treaty education movement therefore attempts to change the dominant Pākehā culture, largely through adult education. Huygens' research collected the co-theorising of these educators around how Pākehā change, with a mind towards how that change can be facilitated in educational practices. With an emphasis on Pākehā working with Pākehā, these Treaty educators clearly have a different experience than I have had working in a Māori majority group. However, their theorising about Pākehā change still offers many useful insights into my own change experience, as well as some of the resistance to power-sharing within the anarchist scene that Black Rainbow discussed.

\section{Emotional responses to learning}

Based on their own personal change, as well as their experience with educating others, the Treaty educators employed several metaphors to describe change processes. The first involved the individual's experience, understood as 'sequential stages of change - from ignorance to awakenings and awareness, and thence to learning and action' (Huygens 2007: 180). Huygens stresses that these shifts involve the heart as well as the head, as people respond to 'disorientating information':

As they described it, a learner "goes backwards after each shift in worldview to what is known, especially under pressure. Therefore, a person needs a number of shifts". Furthermore, educators did not theorise the process of adopting new constructions of the world as primarily rational in nature, nor was increased rationality implied as a destination of such learning. On the contrary, a key factor in adopting new constructions of the world was the person's emotional response (ibid: 181).

The acknowledgement that this change is not a purely rational progression was also represented by metaphors of spirals or returning cycles. This cyclic nature of 
change is influenced by emotional reactions, as well as the connections between conscious and unconscious processes. The Treaty educators recognise that change cannot be a purely conscious process over which Pākehā individuals have control, because so many cultural values have been unconsciously absorbed during childhood, within 'the white fog of colonisation' which obscures dominance (ibid: 188).

Huygens employs the term 'epistemological discomfort', to discuss how the emotional shock of hearing challenges to the 'standard story' of New Zealand colonial history may either motivate change or cause resistance to learning (ibid: 182). Challenges (and support) from Māori are seen as one of the most important factors facilitating Pākehā change, while 'both extreme fear and extreme comfort' are seen as inhibiting factors (ibid: 175). Therefore, Treaty educators try to strike a delicate balance between challenging and reassuring participants. They recognise some positive emotions are part of the 'awakening' stage, such as hope, excitement and joy, as well as several painful emotions:

Pākehā appear to share with oppressed groups many of the emotions associated with critical conscientisation - anger and blame at how much has been hidden, grief at loss of innocence, and shame at the implications of a lifetime of labouring under illusions and collusions, or equally fear of change to a known world, and anger at those who are suggesting change (ibid: 197).

Where Pākehā emotional responses differ significantly from Māori is around feelings of guilt over complicity in the dominant culture, as well as denial or defensiveness. This can make change difficult, as people may 'become stuck in cycles of alternating emotions such as guilt and denial' (ibid: 183).

\section{Collectively preparing for relationships}

As a counter to the immobilising affects of guilt and denial, the Treaty education movement takes up a consciously collective approach to change. The metaphor of a collective journey is employed to emphasise a movement away from the 
hegemonic 'individualised Pākehā cultural identity', in which emotions-such as anger and fear-become a site of social control, as Māori are presented as a threat to the limited interests of individual Pākehā (ibid: 184). Therefore, rather than focusing on racism as personal prejudice, the Treaty educators understand racism as 'a set of processes enacted by Pākehā as a collective' and deliberately employ collective processes to move away from it (ibid: 198). What this journey is moving towards is a Treaty based, 'radically different' future, which requires a letting go of colonial power and privileges to be open to a fully negotiated relationship with Māori. Huygens likens this to Freire's understanding of utopian hope as 'engagement full of risk' and emphasises a 'consistent focus on Pākehā developing a sense of connected destiny with Māori', through which Pākehā may find 'cycles of rekindling positive emotions' (Huygens 2007: 186).

Therefore, Huygens points to this 'concept of Pākehā preparing for a mutually agreed relationship with Māori' as one of the major contributions of the Treaty educators' co-theorising (ibid: 199). This preparation is understood to include the development of 'unfamiliar skills' required for building relationships with Māori: "being able to "name the gift we receive from Māori", learning how to agree on new values and processes, and relaxing about a negotiated, connected destiny' (Huygens 2007: 199). Huygens suggests that the processes through which Pākehā Treaty educators have developed relationships with Māori activists offer examples for relationship-building between colonisers and indigenous communities. Huygens describes a series of stages in this relationship_beginning with individual Pākehā being unaware of Māori political organising, then becoming aware and attempting to 'access Māori cultural knowledge' but finding some boundary setting in Māori spaces, finally turning to other Pākehā activists for validation and support in a collective change journey. 'As a result, a more strategic way of relating to each other was established that follows a more negotiated, co-intentional path', with 'Māori asserting their rangatiratanga and Pākehā experiencing conscientisation' (ibid.). 


\section{Responding to and extending Huygens' theorising}

I find the theorising that Huygens has presented very useful, especially the naming of the emotional processes Pākehā go through when learning about the Treaty. This emphasis on the emotional aspects of change resonates with the emotional themes that have also come out in the Black Rainbow discussions. The notion of 'epistemological discomfort' is especially useful, as a parallel to insiders' 'epistemic privilege'-which members of Black Rainbow have shown is often experienced through discomfort. Therefore, this discomfort experienced by Pākehā learning about this land's colonial realities could be seen as a shifting of some of the burden of discomfort from insiders onto outsiders. Huygens' description of feelings of fear, guilt and denial that create resistance to change, seem to explain some of the 'traumatised' response to challenges that Black Rainbow members note in the anarchist scene. Further, Huygens' discussion of these affects resonates strongly with my own experience of discomforting change (which I will discuss in greater detail below).

Where my work differs from Huygens' is that she is describing Pākehā change in the context of white dominated spaces (in both formal Treaty workshops and among 'groups who are changing' together within the educator's network), while I want to elaborate on the change that occurs for Pākehā in a Māori dominated group (from my own limited experience). While the Treaty educators speak about 'preparing for relationships' with Māori, I am interested in the change that happens within those relationships. I have reservations about Huygens' suggestion that the Treaty educators' experience of moving from ignorance through to collectively working on a 'co-intentional path' with Māori could be seen as a model for relationshipbuilding in wider society. I agree that Pākehā need to find clear and collective roles in relation to Māori, especially to resist tendencies of many concerned Pākehā to try to 'be Māori' or 'claim indigeneity' (as discussed in the previous chapter). Yet, it seems as though this model only describes the positioning of Pākehā in those 
relationships with Māori, rather than focusing on the actual processes of relationship-building itself.

A metaphor employed by some Treaty educators, which seems less developed in Huygens' thesis, recognises the different paths Māori and Pākehā walk; although it complicates them, by presenting them as 'an interacting and tangled web of connections between people committed to the Treaty, each involved in myriad processes of change' (Huygens' 2007: 191). This 'web of change' seems to offer a shift in focus from 'preparing for relationships' to an acknowledgement of existing complex relationships. A major advantage of this more complex metaphor is that, rather than focusing solely on Pākehā change, it shows all of the people that are moving in response to the Treaty-Māori, non-Pākehā immigrants (notably Pacific peoples) and Pākehā-and the dynamic connections between them. This 'web' is made up of various, always shifting, competing directions of change, which make it difficult to quantify or predict. While this points to a lack of control over change, the role of the 'spider' as the-potentially frightening-weaver of the web symbolises the active role of those working to create connections. Huygens' explanation of this agency focuses on Treaty educators 'weaving in additional material so as to cast the knowledge in a new light' in their workshops, however this metaphor of the weavers of the web could also be extended to relationshipbuilding with others (ibid: 192).

Jen Margaret picks up some of the same questions I have about how Treaty educators actually develop relationships with Māori in her article, 'Capacity development processes within a social movement: Pākehā Treaty Workers' movement'. Here Margaret looks at how Treaty educators learn to work with Māori tino rangatiratanga activists, highlighting that at an individual level this learning was unintentional-'primarily informal and experiential, happened in a range of ways from direct instruction to listening and osmosis, and occurred primarily in the context of action and reflection' and especially involved 'learning what not to do' 
(Margaret 2010a: 70). Margaret therefore argues that because of the complex nature of this on-going informal learning, experienced Treaty educators found it difficult to articulate this learning and pass it on to others within the movement, leaving a gap in collective capacity development. She explores factors that inhibit this collective capacity development, including: the tendency for social movements to prioritise action over reflection, difficulties with conflict and relationship break down within the movement, people (especially newer members) lacking the confidence to share their learning, a tradition of rigid and prescriptive capacity development, the impacts of wider societal forces on the movement, and finally, a focus on the technical details of Treaty education rather than the practice of working with Māori. Margaret's discussion of all these factors is interesting and relevant to the anarchist scene, though, I am particularly interested in this final point. Margaret writes that compared to practice of Treaty education:

[T] he practice of working with Māori activists involves working in diverse relationships external to the movement. These relationships are dynamic; so the practice being learned is not fixed...As it is dynamic, relational and contextual, the practice is difficult to share. There is not one common practice or collective approach. This complexity is characteristic of all relationshipbased work and has clear implications for how we approach capacity development (ibid: 73).

What I take from this is that Pākehā primarily learn how to work with Māori activists through direct experiences of working with Māori activists. This is not learning Treaty educators can do by themselves in workshops. Nonetheless, Margaret suggests that this learning can also be greatly enhanced by reflecting on those experiences with other Pākehā:

In sharing about practice in diverse relationships and contexts, it may be useful to be explicit that the aim is not to generate a collective practice but to strengthen the practice of the collective through learning from one another. This encourages openness to listening for the similarities and differences in experiences which can enrich understanding of one's own and others' practice (ibid: 74). 
It is in this spirit that I offer my reflections on working with Black Rainbow and the change it has worked in me. This includes both similarities and differences with the Treaty educators' movement. Moreover, the disjuncture between individual learning and collective learning that Margaret describes is also true in the anarchist movement. There are many people in our networks who have done and are doing remarkable work at supporting each other across difference and I want to acknowledge that, while also noting that we have not always been good at sharing our learning with each other. Rather than presenting a prescriptive approach for working across difference here, I want to add to those conversations of diverse experience.

\section{Critiques of whiteness studies and white}

\section{decolonisation workshops}

In sharing my experiences of change through working with Māori, I am also interested in responding to some of the critiques of whiteness studies-which surely the study of processes of Pākehā change sits within. Sara Ahmed in particular makes a powerful argument against the 'self-reflexive turn in whiteness studies' and suggests that: 'we should not rush too quickly beyond the exposure of racism by turning towards whiteness as a marked category, by identifying 'what white people can do', by describing good practice, or even by assuming that whiteness studies can provide the conditions of anti-racism' (2004: abstract. See also Andrea Smith's chapter on confessions of white privilege, 2013). Ahmed argues that declarations of whiteness, of making the 'invisible' visible, expose a 'fantasy of transcendence' - that declaring one's racism will prove that one is in fact not a racist, as racists are unaware of their racism. Ahmed notes that this is especially questionable in an elitist university environment, a 'place shaped by privilege' (ibid: para.40). And she asks whether 'learning to see the mark of privilege involves unlearning that privilege' (ibid: 36$)$. 
This concern is mirrored in the reflections of activist sociologist Michelle O'Brien, who after many years of facilitating decolonisation workshops for white people in autonomous organising, found that being able to name their privilege did not make white people better at listening respectfully to the exposure of racism. She gives an example of witnessing this, which I will quote at length because it is so reminiscent of the Wellington anarchist scene and because it illustrates Ahmed's argument so clearly:

It was a mostly white group. A few people of color in the room started talking. What the people of color said was fairly complex and subtle, and included a few criticisms. All the white people in the room start freaking out inside. None of us know [sic] what to say. Then a white person, clearly remembering some antiracism workshop of some sort, starts bringing up how we should focus on our white privilege, dealing with the racism in our movements. A few other white people perked up, recognizing the language involved, and launch into a lengthy discussion that seems straight out of a white-ally meeting. The statements of the people of color in the room got boxed into the narrow confines of this workshop rhetoric, and the people of color get [sic] erased completely. A dozen utterances of 'our racism' later and all the white people started actually believing the room had only white people in it. The people of color got totally ignored, now totally excluded from the discussion. Whatever challenge or threat they might have posed to white people's arrogance was thoroughly contained, managed and diffused. They were reduced to just the crude caricature of workshop rhetoric. And all the white people, clearly, were feeling great about being so on the ball about racism (O’Brien 2003: para.43).

Both O'Brien and Ahmed note the role of emotions in anti-racist white spaces. Given my interest in the role of emotions in processes of Pākehā change, it is worth considering their concerns. O'Brien lists among her frustrations with white decolonisation the use of:

[E]motionally manipulative workshop activities designed to produce intense out pouring of strong emotions by people involved, often tied up with white guilt... with a systematic attempt to use that white guilt to push white people to admit difficult things and take on new languages (ibid: para.34). 
Similarly, Ahmed argues that declarations of racism often involve a 'cultural politics of emotion: we might feel bad for one's racism, a feeling bad that 'shows' we are doing something about 'it' (Ahmed 2004: para.21). Ahmed digs deeper into what these emotions actually do, by looking at demands for the Australian nation to express collective shame over racism towards indigenous Australians. These demands explicitly relieve 'Australians' of individual 'guilt', in fact, the expression of shame shows that these are 'well-meaning individuals' (ibid: 23). This, then, becomes a nation building project for white Australians: 'By witnessing what is shameful about the past, the nation can 'live up to' the ideals that secure its identity or being in the present' (ibid. Italics in the original). This re-centres white people as the true 'Australians' and again exposes the fantasy of transcending racism.

Ahmed therefore identifies the resulting paradox that 'The white subject that is shamed by whiteness is also a white subject that is proud about its shame' (ibid: para.28. Italics in the original). Ahmed goes on to discuss how the 'happy' anti-racist white identity has been created. She notes that the rationale behind this assertion of happy anti-racism is based in the assumption that racism is the result of negative emotions-seen in the 'widely articulated anxiety that if the subject feels 'too bad', then they will become even worse' (ibid.)-as well as a response to bell hooks and Audre Lorde's writing on white guilt as a self-centred performance, which can 'block' 'hearing the claims of others' (ibid: para.32. See hooks 1989). She argues; however, that turning away from bad feelings does not necessarily mean turning away from the white subject, but rather makes that subject the source of happiness. This allows racism to remain the burden of those who experience it:

If bad feeling is partly an effect of racism, and racism is accepted as ongoing in the present (rather than what happened in the past), then who gets to feel bad about racism? One suspects that happy whiteness, even when this happiness is about anti-racism, is what allows racism to remain the burden of non-white others. Indeed, I suspect that bad feelings of racism (hatred, fear, pain) are projected onto the bodies of unhappy racist whites, which allows progressive whites to be happy with themselves in the face 
of continued racism towards non-white others (ibid: para.34.

Italics in the original).

Reading and re-reading Ahmed's work, I always feel the strong sense of Pākehā paralysis. With expressions of shame and joy both ruled out as suspect, I am often left with only anxiety about what it is 'ok' to feel. Perhaps similar anxieties are expressed in what Ahmed notes is the common 'white response' to her argument, which is to ask: 'but what are white people to do'. This is something that I have often also heard in anarchist context when people of colour share their frustrations. Ahmed reply is very useful for my work:

The impulse towards action is understandable and complicated; it can be both a defense against the 'shock' of hearing about racism (and the shock of the complicity revealed by the very 'shock' that 'this' was a 'shock'); it can be an impulse to reconciliation as a 'recovering' of the past (the desire to feel better); it can be about making public one's judgement ('what happened was wrong'); or it can be an expression of solidarity ('I am with you'); or it can simply [be] an orientation towards the openness of the future (rephrased as: 'what can be done?'). But the question, in all of these modes of utterance, can work to block hearing; in moving on from the present towards the future, it can also move away from the object of critique, or place the white subject 'outside' that critique in the present of the hearing. In other words, the desire to act, to move, or even to move on, can stop the message 'getting through'.

To hear the work of exposure requires that white subjects inhabit the critique, with its lengthy duration, and to recognise the world that is re-described by the critique as one in which they live. The desire to act in a non-racist or anti-racist way when one hears about racism, in my view, can function as a defense against hearing how that racism implicates which subjects, in the sense that it shapes the spaces inhabited by white subjects in the unfinished present. Such a question can even allow the white subject to re-emerge as an agent in the face of the exposure of racism, by saying 'I am not that' (the racists of whom you speak), as an expression of 'good faith' (ibid: para.56-57. Italics in the original). 
Ahmed concludes by arguing that whiteness studies should be about exposing white racism, rather than making the 'anti-racist' white subject. She stresses that to be anti-racist means 'to be in an intimate relation with that which one is against' (ibid: para.47), rather than transcending it, for race 'is sticky; it sticks to us, or we become 'us' as an effect of how it sticks, even when we think we are beyond it. Beginning to live with that stickiness, to think it, feel it, do it, is about creating a space to deal with the effects of racism' (ibid: para.49). Instead of simply turning towards whiteness, Ahmed argues, 'the task for white subjects would be to stay implicated in what they critique, but in turning towards their role and responsibility in these histories of racism, as histories of this present, to turn away from themselves, and towards others' (ibid: para.59).

By reflecting on my experience with Black Rainbow, I want to respond to Sara Ahmed's work to some degree, by drawing out her suggestion that 'hearing' the exposure of racism is something that white people can 'do'. In my experience, being open to this hearing requires a double turn, or a simultaneous turn-towards others, but with an eye on my own emotional responses while listening to others. Rather than simple shame or happiness, a complex mixture of 'positive' and 'negative' affects relate to that 'hearing' - blocking it, allowing it, responding to it, being changed by it. To me, staying with the 'stickiness' of race, means staying with the discomfort of relating across difference, as this discomfort is also intimately related to openness. I will discuss this in terms of two seemingly simple, yet important, lessons I learnt while working with Black Rainbow: the value of listening and the value of accepting criticism.

\section{Learning through listening}

Again, I will begin with a story, which captures the moment when I most fully felt the change that Black Rainbow had worked in me. 
It's Friday, late afternoon, and I am in the university café with Jaime ${ }^{1}$. Our books and laptops are spread out around us, neglected. This is supposed to be a study session, but because it is our first and we haven't seen each other in a long time, we spend most of it gossiping. Even though Jaime is no longer active in the anarchist scene, she has a long history with it and we have many mutual friends. I have not long finished my field work with Black Rainbow and I talk with her a little about what I have been up to. Jaime shifts a little in her seat and asks me what I think about how Te Awanui is always saying on Facebook: 'It's not my job to educate you'. Jaime expresses some of the confusion she is feeling about this, especially when it comes to transgender issues, because someone she cares about has transitioned. She's left asking, 'how else are we supposed to learn?' I want to make it 'alright' for her, but I also feel myself start to tingle and tense up. I say, as gently as I can, that I used to feel more sympathy for that position, but now I realise that there are so many opportunities to learn. Especially online, there are a lot of blogs and YouTube clips where (for example) transgendered people or people of colour, carefully and clearly explain their experiences and how others could be more supportive. ${ }^{2}$ If you really want to learn, you don't have to look far. Jaime looks a little cowed, mutters something about forgetting about 'zines and blogs, and we quickly move the conversation onto safer ground.

After leaving Jaime, I walk home. I drop down behind the gym and stroll past the sports fields, where it hits me that all of those blogs and clips I was talking about were shared with me by people in Black Rainbow. So, while I'm telling Jaime that

\footnotetext{
${ }^{1}$ This is a pseudonym.

${ }^{2}$ See, for example, Natalie Reed’s (2012) 'Five ways cis feminists can help build trans inclusivity and intersectionality', http://freethoughtblogs.com/nataliereed/2012/11/16/five-ways-cis-feminists-canhelp-build-trans-inclusivity-and-intersectionality/. For a more humorous example, which focuses on racism, see Pandie and Takiaya’s Shit White Queers Say to Black Queers, http://www.youtube.com/watch?v=Vy9vM15OMVc.
} 
outsiders can do their own research, I hadn't really spent any time trawling the internet for great pieces on oppression; it had all come to me through friends who experience that oppression directly. Te Awanui actually does a huge amount of 'educating' on Facebook, through sharing these links. Despite their insistence that it isn't their job to educate, Te Awanui has spent hours and hours teaching mesitting on their sunny front porch, smoking, drinking cups of tea and laughing. I begin to realise just how much I have learnt, simply by listening when people wanted to talk.

By sharing their stories and perspectives, in meetings, art galleries and kitchens, Amiria, Mara, Te Awanui, Kura and Francis have all educated me. It is interesting that this thought was sparked by the notion 'it's not my job to educate', because that seems to be closely linked to the boundary setting described by the Treaty educators - the reason for turning towards Pākehā educating Pākehā. Yet, in these Facebook debates, Te Awanui is not responding to cis gendered or non-Māori people who honestly want to understand Te Awanui's experience. Rather, this statement 'it is not my job' is usually made in response to some form of the 'tone' argument (see Derailing for Dummies, especially the sections on 'Derailing using Anger' and 'Derailing using Emotion'). The 'tone' argument is a way of derailing insiders to oppression who are exposing oppression, by claiming that if they were not so 'angry', people would be more open to hearing what they have to say. This is clearly connected to the aversion to overt emotional expression in Pākehā culture (as discussed in chapter four). Te Awanui regularly highlights this use of 'tone' when it appears in online debates. As a group, Black Rainbow also often joked about it. For example, from our meeting on May 28, 2011:

Francis: 'What I found is that no matter what you say about Pākehā needing to be a bit more mindful, it really offends some people.'

Te Awanui: 'Well if you said it a bit nicer, maybe they'd listen!' [Laughing] 
Hayley: 'Yeah!' [The laughter in the room builds]

Kura: 'If you weren't so irrationally emotional about it.' [More laughter and ironic joking]

The 'tone argument' is based on the assumption that in order to learn, and change, outsiders to oppression need to be educated gently (see also Jones 1999). The implication being that those who want change must behave as 'good' educators, including taking responsibility for the emotional response people may have to the new information they bring. This is also the thinking behind the practices of the Treaty educators, who attempt to strike the delicate balance in their workshops between challenging and reassuring their participants. Ahmed points out, however; that the idea that racism is based on bad feelings and therefore people should not be made to feel 'too bad' (least they become 'even worse'), is based on the restorative justice notion of 'reintegrative shame'. This model, which stresses love, respect and forgiveness, 'presumes the agents of shaming are not the victims (who might make the offender feel bad), but the family and friends of the offender' (2004: para.29). In the face of demands for this carefully balanced, loving-shaming education, Te Awanui's response of 'it's not my job' is entirely understandable and appropriate.

Therefore, when I say that I was educated by the other members of Black Rainbow, I am talking about a process quite different from demanding that insiders take on a teaching role, framing their concerns in ways that will 'not make me feel bad'. I am interested in the learning that takes place when we are willing to hear what people say about their experience of oppression, when they want to tell us.

The importance of just listening was continually brought home for me in Black Rainbow. Several times in our discussions, members of Black Rainbow expressed frustrations over not being heard, such as when Kura said, 'It was just really hard to 
get white boys to listen to me' (June 25, 2011). Mara expressed the emotional burden of this when she spoke about the October $15^{\text {th }}$ Solidarity collective:

Even if you sit down and talk to someone, they're not going to listen to you. They're not going to take things on board. They just don't get it. You know, it's one thing to be in the fucked up scene anyway, but to have to carry around all that additional stuff... (October 16, 2010).

I experienced these kinds of comments as clear instruction from members of Black Rainbow in terms of 'learning what not to do' (Margaret 2010a: 70), as failure to listen came through as a major problem.

Alongside these lessons in what not to do, there were also expressions of relief, felt on the occasions when people did listen. For example, Te Awanui says of the Aotearoa Anarcha-feminist Hui, 2010:

[T] hat was the only time I have been in a group of activisty women where I've felt like: "Oh, actually people are listening to me". Not expecting me to come up with all the answers, but listening to me. I was like: "Oh this is how it feels!" (June 25, 2011).

In many ways, this whole thesis is about people not listening to Māori-because they are not seen as 'real' Māori (chapter 3), because Māori expressing concerns are seen as 'too emotional' (chapter 4) or because Pākehā often act as though naming racism is as hurtful as racist behaviour (chapter 5 ). What I hope this thesis does is allow some careful listening.

Aside from the obvious point that listening when people speak about the oppression they experience is the respectful thing to do (and can relieve a great deal of frustration for insiders), listening also offers an opportunity to learn. The greatest learning I have gained through this research, and which I have returned to again and again in this thesis, is the strength of insiders' epistemic privilege. Narayan writes: 
[T] he claim to the epistemic privilege of the oppressed does imply that people who are not members of the oppressed group will have to make a great deal of effort to come to grips with the details of lived oppression. Having members of the oppressed groups as friends, sharing in aspects of their life-style, fighting alongside them on issues that concern them, sustaining a continuous dialogue with them, etc can all help non-members develop a more sophisticated understanding of what a form of oppression involves (1988: 37).

The greatest learning comes to me through listening, not so much in knowing about the details of people's lives, but in understanding more deeply the reality of insiders' epistemic privilege. Hearing this epistemic privilege also broke down notions of 'authenticity' (Bell 2004). I found that, simply by speaking with me about their experiences, Māori members of Black Rainbow shaped my thinking over time to come more in-line with the difference-centred philosophy behind antioppressive theory (see Moosa-Mitha 2005). The people in Black Rainbow continually surprise me, defying or complicating stereotypes or generalised understandings I have about their experience or thinking. Talking with them made a mockery of the idea that I could create a 'check list' to decide what is culturally appropriate and I came to appreciate the importance of staying open to genuine expressions of difference (as suggested by Ramsden 2002 and Bell 2008). I wish to suggest that this kind of openness to difference also brings with it opportunities for genuine power-sharing. At the very least, it allows the exposure of racism (with the, perhaps always frustrated, hope that this will lead to anti-racism. See Ahmed 2004 above).

In short, hearing taught me the value of listening. As an embodied learning by osmosis, this lesson is hard to explain and track; though it has had the greatest effect on my change as Pākehā. The impact of this learning through listening is also the best argument I can make for Pākehā decolonisation through working together with Māori. Responding to Ahmed's arguments above, I suggest that listening to 
insiders speaking about their experiences and hearing the exposure of racism is 'what white people can do'.

\section{Sitting with discomfort}

Even though I am proposing the benefits of simply listening, this is in fact not an easy task. This can be seen in the great deal of resistance to listening to Mãori (both in the anarchist scene and wider society). This brings me back to considering the emotional elements influencing Pākehā change. Following Gayatri Chakravorty Spivak's use of the notion of 'foreclosure', Danny Butt points to the importance of emotional response in blocking white people from hearing the concerns of indigenous people:

It is not just that the idea of the native is rejected, but the feeling that is generated by them is also rejected. So a psychological defense must be made against the idea and the affect returning. This explains why the question of indigeneity or the racial basis of colonisation is not simply a matter for logical discussion about rights. The actual well-being or relative socio-economic or legal status of oppressed peoples has no real bearing on the psychoanalytic functioning of the person that has been raised in racial dominance and expects dominance. The very presence of the discussion also raises in the settler-colonist the spectre of emotions (of fear, for example) that have been rejected, and the lengths to which a psyche will go to avoid bad feelings are profound (2010: para.2).

In this light, a white privilege such as: 'I can be casual about whether or not to listen to another person's voice in a group in which s/he is the only member of his/her race' (McIntosh 1990: para.8), seems to represent the surface manifestation of the repression of deeper feelings that are anything but casual.

Trauma studies researcher Kali Tal gives an excellent illustration of this in her article 'White privilege diary series \#1 - White feminist privilege in organizations' (2011). In this article, Tal discusses her frustrations with white-dominated feminist organisations, based on thirty years of experience facilitating diversity workshops. 
Tal found that, more often than not, once the white core groups of these organisations realised that in order to attract more women of colour to their organisation they would have to share power with them, taking on board their concerns and suggestions, they decided it 'simply isn't worth it' (ibid: para.19):

[W] hite women said that it would make them 'too uncomfortable,' and that, for them, [their feminist organisation] would no longer be a refuge and a place that boosted their egos by affirming they 'did good.' Instead, they'd have to be 'careful' all the time, and would be self-conscious about what the women of color thought of them. In short, given the comfort of racism, and the discomfort of active anti-racism, they chose racism, outright (ibid: para.19).

Clearly this is appalling, but what would it mean to choose the discomfort of active anti-racism?

This discomfort may include a combination of several emotions, such as guilt, confusion, anxiety and shame. I am particularly interested in the disorientating affects triggered by having our worldviews challenged, since this is an unavoidable element of accepting insiders' epistemic privilege. Huygens glosses Bateson's term 'epistemological discomfort' as 'the distress felt by all mammals when the epistemological basis of a learned context for life is falsified in some way' (2007: 182) and she applies this to the disorientation Pākehā experience when exposed to a critical history of colonisation:

For instance, when Pākehā working in social services with longstanding constitutions and ethics based on humanitarian values of compassion and social justice discover the amount of legislative force used to impose assimilationist policies in New Zealand, they may feel deeply distressed... They may experience emotional shock or discomfort as they catch a glimpse of how a standard story was constructed during their childhoods, and who did it - their teachers, the school journals, their parents. They may experience a further shock when they consider the number of people in their current life who appear to actively promote the self-serving story - the government, the media, their employers. A final shock may come as they realise their own complicity in this 'deception', remembering their part in dinner table conversations and staff room arguments. They may well feel angry at the initial 
deception, grieved by the historical impact and ashamed at their ongoing complicity (ibid: 182).

While the disorientation of shifting cognitive constructions is itself emotionally distressing, when this learning is around colonisation, feelings of guilt and shame remain closely tied to this disorientation. This has certainly been my experience, as you can see in my methodology chapter where I write about experiencing Pākehā paralysis around fear of my own ignorance and internalised racism. While I can relate to the series of emotional shocks Huygens describes above, which seems to largely represent reflections on the working of Pākehā society, I felt this disorientating epistemological discomfort most keenly while listening to Māori members of Black Rainbow speaking about their own lives. The emotional cost of recognising insiders' epistemic privilege is this painful sense of not understanding the world I live in. This makes me vulnerable and the temptation to reclaim some sense of myself as 'the knower' is great. I continually found myself attempting this through relating what I was hearing to academic analysis. Even though this is embarrassing to read in the Black Rainbow stories in this thesis, it is telling. What 'saved' me from reproducing the situation O'Brien describes above-with white people silencing and boxing people of colour by talking about their white privilege-was that the Black Rainbow meetings were a Māori dominated space where, invariably, people responded to my abstractions with stories and analysis that complicated them. I was forced to remain with the discomfort of being the 'not knower'.

It is not surprising that in her report, 'Working as allies', Jen Margaret suggests the need to get comfortable with being uncomfortable. She notes the importance of listening 'intently as people are speaking from different worldviews' and suggests that an ally must ' $[\mathrm{b}] \mathrm{e}$ willing to go into emotionally difficult terrain and prepared to sit with the unsettling nature of the work and with discomfort' (2010b: 14). When I first read this, early in my research, I found it an incredible relief, especially as Margaret links this to 'analysis paralysis' - the immobilising effects of 'not knowing' 
what to do-writing: 'If you are feeling uncomfortable it probably means that you are "doing the work"' (ibid: 17). It was easy, in the quiet of my office, to nod sagely when I read that humility means 'being passionately aware that you could be completely wrong' (ibid: 15). I found, however, that it is very difficult, in the moment of contact, to feel like being ignorant and awkward meant that I was being a 'good ally'. More often than not, it made me feel as though I should not even be in the room. This is a crucial and difficult relationship skill that I am still in the process of learning. Yet, becoming used to this disorientation, becoming comfortable with discomfort, and trusting the people in Black Rainbow to accept my limits did become easier over time. I believe that this paradox of becoming comfortable with discomfort differs from the paradox that Ahmed identifies of being proud about shame, because it involves emotional labour rather than proclamation. Recognising the presence of this discomfort and attempting to sit with it, rather than rushing to remove it, also allows more opportunity to listen to the exposure of racism. I have learnt most from staying with the unsettling affects that arise while simply listening.

To return to my discussion of the 'tone argument' above, I want to stress that listening to what Māori say involves me, as a Pākehā, taking responsibility for my own emotional reactions to what I hear, rather than expecting Māori to be careful about their tone while educating me. This is a key relationship practice which helps to focus on what is being shared, rather than re-centring discussions on the experiences of outsiders. Or as Te Awanui puts it: 'Don't make this about yourself!' (June 25, 2011).

Moreover, hearing the exposure of racism involves more than listening to the words that are spoken by Māori people. Some of my most powerful learning has come through seeing the emotional impact of oppression on people in Black Rainbow. This brings me back to Narayan's argument, which I have used throughout this thesis (particularly in chapter 4), that 'a very important component 
of what constitutes the epistemic privilege of the oppressed has to do with knowledge that is at least partly constituted by and conferred by the emotional responses of the oppressed to their oppression' (1988: 38). Naturally, this insider knowledge is often also expressed emotionally, especially when responding to the hurtful or offensive behaviour of outsiders. Narayan writes:

It is very hard for insiders not to react with anger to such insensitivities, for each such insensitivity evokes memories of countless others. Besides, anger is a necessary emotion for those who must constantly exercise vigilance and retain their selfrespect in the face of systematic social prejudice and discrimination. Insensitivities from outsiders one trusts make insiders especially bitter and pessimistic about hopes for change, and anger is often an inevitable corollary.

Besides, revealing one's anger makes one less vulnerable than revealing one's hurt. In revealing one's anger, one seems to react from a position of strength, while revealing one's hurt lacks this quality and seems to open up possibilities of the outsider reacting with either pity or guilt, neither of which the insider can find very palatable (1988: 46-47).

Through witnessing this anger and hurt, and feeling these affects reverberate within myself, I have experienced insiders' epistemic privilege directly and felt changed by an embodied 'listening'. This, then, is a discomfort that comes, not simply from having one's worldview challenged, but rather from responding to unsettling emotions expressed by Māori. The notion of 'sympathetic resonance' employed by Charles Te Ahukaramū Royal and Betsan Martin is useful here:

If we imagine two humans as musical instruments, the idea is that one individual resonates with another in spontaneous and sympathetic ways - not only in the quality of articulated and conscious communication between them but also in the bodily and unplanned way they relate with one another. Here we can see that listening involves more [than] the use of the ears and a focused concentration of the mind - it is 'listening' with all the senses, the body, the emotions, spirit and so on (2010: 48-49). 
It is easy to become lost in the beauty of this image of responsiveness as reverberation and assume that most of what one is relating to are 'positive' emotions. Yet, when relating across difference involving colonial oppression, I find that often it is difficult feelings that are resonating within me. An important part of allowing this listening is learning to manage my own emotional responses to these intense feelings.

Gibson-Graham's notion of bodily 'learning to be affected' is another way of articulating this process of change. It is also useful for thinking about how to deal with difficult emotions. All this talk of 'managing' emotions implies more control than I truly experience, when more often than not my only option is accepting a lack of control. Gibson-Graham's statement: 'We are interested in thinking about learning to be affected as an ethical practice, one that involves developing an awareness of, and in the process being transformed by, co-existence' (2009: 325) helps remind me that it is through feeling this discomfort that change happens.

\section{'Learning to be affected' unmakes Pākehā identity}

\section{and opens opportunities for belonging}

The transformative powers of learning to be affected by discomfort have implications for Pākehā identity and sense of belonging in this place. There is no doubt that listening to Māori speak about their difficulties with Pākehā behaviour, having my worldviews challenged and shifted, has shaken and unsettled my Pākehā identity. As I tried to capture in my story about the hīkoi (chapter 4), involvement with Black Rainbow has often made other Pākehā seem strange to me and increased my alienation from my parent culture. Simultaneously, I have never before felt so white. This unsettling of Pākehā identity is expressed by Butt as being 'taken out of myself... and returned to a refracted version of myself at the same time' (2010: para.18). Butt writes: 'as we do the slow work of finding out who we 
are in another system, I believe that our whiteness becomes both incredibly obvious yet barely possible to discuss in frames that we are familiar with' (ibid: para.15-16). Similarly, Metge argues that '[i]t often takes the shock of encounter with people who are fundamentally different to reveal us to ourselves' (2010: 2). While this may be an uncomfortable revelation, it is also an important part of finding the role Pākehā can play in relation to Māori.

Ani Mikaere raises a number of points about Pākehā attempts at belonging in her article 'Are we all New Zealanders now? A Māori response to the Pākehā quest for indigeneity' (2004). Here Mikaere discusses the claims such as Michael King's statement that '[p]eople who live in New Zealand by choice as distinct from an accident of birth, and who are committed to this land and its people and steeped in their knowledge of both, are no less “indigenous" than Māori' (King 1999: 235). Mikaere notes that this claiming of indigeneity is an attempt by Pākehā to shake off a history of inheriting the colonisers' privileges, as they 'are 'born' post colonisation out of the New Zealand soil' (2004: 2. Italics in the original). Like the Treaty educators, she argues that this covers an 'underlying unease, of unresolved guilt' (ibid: 5). These are attempts to 'settle' the settlers, to remove the discomfort of colonisation. Nevertheless, she takes some hope that this may also signal an acknowledgement that "the key to their desire to feel they "belong" here somehow lies in the relationship between Pākehā and Māori' (ibid.) and that this relationship needs to change. Mikaere suggests that solutions can be sought in tikanga, as the first law of Aotearoa, which has as its 'fundamental purpose' the maintenance of 'appropriate relationships of people to their environment, to their history and to each other' (ibid: 6). Therefore, she draws on the concepts of tangata whenua and manuhiri-it is the tikanga of the tangata whenua that manuhiri follow when they move into their area:

Nor would manuhiri ever assume tangata whenua status in another people's domain. That is not to say that people from outside an iwi area never took up residence within that iwi's boundaries... But arrangements of this type were always carefully negotiated, and the consent of the tangata whenua was 
imperative, as was the fulfilment of any conditions they laid down. And always, it was the relationship between the two parties that mattered most. Both sides were expected to actively nurture the relationship, with the concept of utu or reciprocity operating to bind them together more closely as time passed (ibid).

Mikaere, therefore, suggests Pākehā seek to find belonging in the role of manuhiri, through a negotiated relationship with Māori. Rather than basing belonging to this place on so many generations of settlement, or attempts to 'become' Māori, this manuhiri status offers a defined role 'as we do the slow work of finding out who we are in another system' (Butt 2010: para.15). This is an unsettling of Pākehā identity that ironically offers the promise of greater Pākehā belonging.

I am less interested in this as a part of another Pākehā identity project or attempt at transcendence, but rather to present a positive perspective on the unmaking of Pākehā identity, the experiences of discomfort that come with this and the openness to Māori difference this allows. The emphasis that Mikaere places on this reconciliation being on Māori terms-grounded within a Māori cultural framework cuts to the heart of the unsettling, uncomfortable elements of embracing the unknown across difference. I feel that particularly keenly when reading Mikaere's discussion of the institution of muru as a way of dealing with wrongdoing and restoring mana and balance:

This required the whānau or hapū of the wrongdoer to submit to a process whereby the whānau or hapū of the victim would be free to take for themselves the offending group's belongings, goods or produce. Treasured personal items along with foodstores and other valuable goods could legitimately be taken, houses could be destroyed and in some instances it was possible that lives might be taken or injuries inflicted. The greater the significance of the parties involved, and the more serious the wrongdoing, the greater the extent of the muru that could be expected. It has to be noted that whakamā, the notion of embarrassment or shame, was a pivotal concept in muru. Whakamā was felt, not just by the individual who had committed the wrong, but also by his or her whānau or hapū. The consequences of the individual's actions were suffered by the collective group (2004: 7). 
Clearly the sense in this is plain-why should the process of restoration be in anyone else's terms other than those who experience oppression? The implications frighten me, with the obvious suggestion of violent retribution in this call to employ muru. Moreover, I can quote Mikaere's use of the terms muru and whakamā here, but I cannot really explain or fully understand them, which is key to the disquieting nature of accepting the authority of another's system. Mikaere is sensitive to the discomforting effects of what she is asking and she notes that muru requires a 'powerful element of trust', where the whānau of the wrong doer has to submit themselves to the discretion of the wronged and trust their 'ability to gauge the extent of action required to mend any damage to the multiple relationships affected' (ibid: 7-8). Mikaere compares this to the current state of affairs, in which the Crown dictates the terms of reconciliation, asking Māori to trust it, while perpetuating their oppression. She writes: 'For Pākehā to gain legitimacy here, it is they who must place their trust in Māori, not the other way around' (ibid: 8).

Therefore, Mikaere's article pulls together many of the issues I have been writing about here, as it seems she is arguing that instead of seeking a false sense of indigeneity that covers repressed guilt, Pākehā may find belonging through accepting the discomfort of whakamā, to engage in a negotiated relationship on Māori terms. I find her final point that within this discomfort of accepting the unknown, Pākehā must learn to trust Māori practically useful and I want to connect that to my own experience with Black Rainbow around ideas of accepting criticism.

\section{Accepting criticism, gaining trust}

So far I have been talking about the simple relationship skill of careful listening and sitting with the discomfort that can come from that. This practice of listening is most important and obviously most uncomfortable when it comes to receiving criticism over our own behaviour. Black Rainbow spoke about the difficulties with 
people responding badly to criticism in our discussion about the anarchist scene (chapter 5). Many of the power dynamics we spoke about as a group are also mirrored in our project. An obvious example of this is when I received criticism from Francis about the way I had written chapter 3 of this thesis (the details of this feedback were discussed in chapter two). It is through receiving this criticism that I learnt the most about the power of accepting criticism to work change and build trust. I am also interested in how receiving criticism for me involved a real mix of 'positive' and 'negative' emotions-it was horrible, but ultimately, I experienced it as a 'gift'. Again, let me illustrate this with a story:

The hospital entrance is clean and cavernous and I feel self-conscious as I walk in. Nervous, a little numb, I make my way to the Wishbone café at the back of this huge space. Hayley and Francis aren't here and I worry that there might be another café somewhere in the hospital I don't know about. Anyway, I buy myself a hot chocolate and wait for them in a white booth. Everything looks ultra-sharp and clear, yet I can't focus - I feel that familiar mix of clarity and confusion that always seems to accompany big life events. A little over a week ago (Friday, October 27, 2012) I'd gotten an email from Francis saying she had some concerns about my identity chapter. I wrote her back saying I was really disappointed to have let her down and that I would think about it and get back to her. Then I gave myself a few days to freak out.

Following all the conversations we had in Black Rainbow about people responding to criticism as if it is a 'trauma', I really didn't want to dump all I was feeling onto Francis, especially since she was heavily pregnant, so I thought I'd call her on Tuesday night to talk about it, once l'd calmed down. In the meantime I cried, I lay in bed, I talked with anyone else who would listen and I wrote long explanatory response emails that I didn't send. I felt like a failure - I had read Kim McBreen's review of the film Operation 8: Deep in the Forest, ${ }^{3}$ which pointed out very similar

\footnotetext{
${ }^{3}$ McBreen (2011b). See Wright and King-Jones (2011).
} 
concerns to the ones Francis had with my chapter-how had I not seen I was doing the same thing? I felt like I had damaged my friendships with everyone in Black Rainbow, or at least put them at risk. I hadn't shown the chapter to the rest of the group yet and now I was dreading it. I spent a lot of time trying to work out how I had written something so different from what I intended. I also spent some time thinking about criticisms I have of Francis' work that I have never shared with hera petty, defensive response that I knew even at the time was irrelevant. Tuesday finally came and I felt ready to have a decent conversation with Francis about her comments, but before I could call she went into hospital. Her baby would have to be born premature.

There is nothing quite like the life-and-death stakes of complications with childbirth to remind you just how not life-and-death your PhD thesis is. Still, all of the upset I was feeling has now combined with concern for Francis, her baby and Hayley and become a confusing mess. I have never wanted to be there for them more and yet our relationship has never before felt so uncertain. I know my need for reassurance is a low priority. Do they even want to see me? What can I do to help anyway? It's funny how strong the urge just to wish and hope and will good health upon people becomes when we feel helpless.

Francis' baby was born small and early, but okay. Hayley put out a call for help with food, and here I am with my snap-lock plastic containers, so grateful to be of use in this small way. Relieved and nervous and numb at the same time, I wait in this sterile hospital café. Then Hayley comes down and hugs me and a little while later Francis joins us. They tell me about the wonders of 'kangaroo cuddles', they are much more excited about my vegan macaroni 'cheese' than I expected they would be, and they look good-tired, but happy. They're all okay, I begin to relax. Still, Francis and I are a little awkward with each other and I'm surprised to see she looks as sheepish as I feel. Is she worried I'll be angry with her? Or cry? Did Hayley tell her off for being 'mean' to me? It seems totally unfair that Francis should have to feel 
bad, but maybe I'm also a little relieved to see it-maybe she is worried about damaging our friendship too? I remember Te Awanui saying how scary it is to call your friends out on racism. I think of Francis talking about how we call people out to maintain relationships, not to make people feel bad. I talk with Francis a bit about the chapter, my frustrations and intentions, but I try to make light of it. She is generous and understanding. We both relax a little. I think we will be okay.

What surprised me over the next few weeks and months is that I began to feel more confident and grounded than I had at any other point in this project. A great deal of anxiety I had been carrying began to fall away. Up until that point, I had been learning a lot about 'what not to do' and I was trying not to do those things. I felt a great deal of trust was given to me by the Māori members of Black Rainbow, and a knowledge that sooner or later I would break that trust had gnawed at my side from the beginning. Sadly, this anxiety to 'get it right' leads to a great deal of self-policing, which can suck the sense of humour out of people, usually making us tedious to be around (see O'Brian 2003). Mara points to this when she speaks about people 'just being all earnest' (June 25, 2011). Perhaps being an awkward, wet-blanket is part of the 'burden of care' that Narayan asks outsiders to take on and I had become used to the discomfort of that role-although I was also painfully aware that it also causes a certain amount of discomfort for Māori around me as well. What accepting Francis' criticism reminded me of, however, was how easy it is to get it 'wrong' while trying so hard to 'get it right' and this helped me let go of some of that awkward anxiety and carry my limits with a little more lightness, humour and humility.

This experience also helped me understand how processes of change have to occur through this kind of interaction-as I cannot simply put emotional responses and lifelong patterns 'right' by understanding oppression intellectually. Eve Sedgwick 
explains this clearly, in an interview with Maria Russo about her 'emotional reeducation' through exchanges with her psychotherapist:

[Sedgwick] came to see that the quickness of her mind was actually holding back her progress, because she expected emotional change to be as easy to master as a new theory: 'It's hard to recognize that your whole being, your soul doesn't move at the speed of your cognition,' she told me. 'That it could take you a year to really know something that you intellectually believe in a second.' She learned 'how not to feel ashamed of the amount of time things take, or the recalcitrance of emotional or personal change' (Russo 1999).

Te Awanui often says that criticism is a gift-'every time you have to call someone out on their behaviour, that's work of theirs that you are doing.' (June 25, 2011). The Treaty educators in Huygens' research talk about trying to 'name the gift we receive from Māori' (2004: 89), and criticism seems to me the most important gift to name. One of the reasons I wanted to work with Francis is because I expected she would tell me if I messed up, and it was a relief when she eventually did. Even though it still took a lot of work to figure out how I would solve the writing problems she pointed out (and I am never convinced I have), this gift of criticism helped break down the delusion that I could 'get it right' - that I could work out just what needed doing, and do it. Hearing what Māori made of my writing, how Francis was able to see what I could not, deepened my respect for insiders' epistemic privilege and helped me accept my own limits. I could not expect to get everything 'right', but I could begin to earn the trust I had been given, if only by accepting criticism respectfully.

Thinking about the negative responses people often have to receiving criticism from Māori (which Black Rainbow discussed in chapter five), I can appreciate that I was fairly lucky, in that several factors made it easier for me to accept this criticism. My friendship with Francis was amicable before I received her feedback-if we already had a lot of conflict between us, perhaps I would not have been so willing to hear what she thought. I actively seek feedback from the group on my writing, so I had 
braced myself somewhat for any criticisms. Francis was also able to quickly and clearly articulate the issues that she had-if they had been 'hard to name' she may have needed to spend a period of time thinking and discussing them with other people before she came to me, which may have made me feel hurt that people were talking 'behind my back'. Moreover, the concerns Francis brought to me were framed in language I understood, around matters I care deeply about and have given much thought. Reading Kaupapa Māori literature prepared me for Francis' perspective on my work and I agreed with her. If she had come to me with a criticism which did not make such clear sense to me, I may have had more difficulty comprehending and responding positively. Perhaps if these conditions had not been in place, I would have only felt the sense of undermining rejection. Within these conditions, I felt able to treat it as an opportunity to build trust between us and among the group.

I am also very grateful for the reactions of other members of Black Rainbow. When I told Te Awanui that I had written a chapter that 'looked like the academics knew more about Māori identity than the members in the group did', they laughed heartily and said, 'Yep, that's a thing'. After I explained it to Amiria she simply said, 'So, you fucked up. You're our friend, we will forgive you'. I felt (not for the first time) a sense of the generosity that is extended by insiders to oppression within friendship - who open themselves up for hurt and annoyance from outsiders all the time. These conversations also helped me realise that being a friend across difference means each relationship is up for negotiation, and problems arising must be sorted out within that particular relationship. Too often I have seen (and felt) the tendency for Pākehā who have been criticised by Māori to seek acceptance and a contradiction to that criticism from other Māori friends: 'I'm not racist, right?' This puts those Māori in the difficult position of pressure to reassure their friend, or risk hurting them. It can also lead to situations where new Māori members to the scene are pitted against more established Māori. Many people I spoke to about Francis' comments asked me 'What do the rest of the group think?' and of course there was a small part of me that hoped Mara, Te Awanui, Amiria and Kura could 
offer me some absolution. Instead they were able to kindly let me know that they supported Francis' criticism, while also affirming me and the project. Even if they had not all been so respectful of Francis' criticism, however, I would still have to be open to her concerns-Māori approval is not interchangeable.

In Teaching Critical Thinking: Practical Wisdom, bell hooks writes of her collaboration with philosopher Ron Scapp that maintaining 'intimate intellectual bonding across differences' means that they both have to remain radically open to change and are "frequently "called out" by the other person; asked to stand back and engage in rigorous self-critique; to look realistically at the ways we inhabit a different world' (2010: 38). She links this openness to trust:

We continually focus on the issue of trust because the most common complaint we hear from people of colour about whether they feel able and willing to strive for solidarity across differences is their fear that white people cannot be trusted, especially privileged white males. And it is equally true that racist conditioning has socialized many white people to be suspicious of people of colour, especially when we refuse to stay confined within the limits of racist notions of self and identity. What Ron and I have learned in the constant re-evaluation and reaffirmation of our bond is that trust is not static, that it must be constantly re-enforced by the actions we are willing to take both to own the importance of our bond and to protect it (ibid: 39 ).

For me, accepting criticism has allowed me a chance to earn trust. This is also closely linked to accepting that trust will not be automatic or fixed. Learning to live with mistrust from Māori is, indeed for me, an important element of accepting the discomfort of working across difference. Te Awanui helped me to understand this when they spoke with me about something they had come to realise about acting as an ally to transgendered women. Frustrated over a misunderstanding between themselves and their transgendered girlfriend, Te Awanui came to see that as long as transgendered men generally continue to treat transgendered women disrespectfully, the transgendered women Te Awanui dates will not fully trust them. This in turn helped shift Te Awanui's approach to trans-misogyny away from 
being angry on behalf of transgendered women (in a self-righteous, saviour sense), towards Te Awanui being angry on their own behalf, because that misogyny damages their relationships. This notion of being angry on your own behalfbecause your friends cannot trust you and you cannot trust yourself-can also be applied to racism and is an interesting counter to Ahmed's question over who gets to feel bad about racism, if white people are happy about anti-racism. As racism 'sticks' to all of us, we have reason to be angry on our own behalf and cannot hope for transcendence, as trust has to be built afresh every day.

I have written here about 'earning trust', but returning to Mikaere's argument that it is Pākehā who must learn to trust, over time I came to realise that the sense of grounding and acceptance I came to feel after receiving Francis' criticism arose more from learning that I could trust people in Black Rainbow to see my limits and still be my friend. That this gift of friendship comes with the gift of criticism further muddies ideas of positive and negative emotions around confronting racism, as I have found these affects to be subtly and intimately mixed. Opening ourselves up to criticism and placing our trust in others is scary. It lacks the sense of control that comes from attempting to gain trust, to prove that 'I am one of the good ones'. As Mikaere points out, this need to learn to trust is a key part of the letting go of control the Treaty educators talk about (see Huygens 2007). Again, while this has been difficult, it has been through leaning into the discomfort of this, letting go of

control enough to learn to be affected, that I have experienced first-hand a sense of grounding and belonging. Gaining this trust is the change that receiving and accepting criticism has worked in me.

\section{Reflections on these lessons for methodology}

The flip side of derailing emotional responses that block Pākehā from listening to Māori expressing concerns, overenthusiasm to hear about Māori experience is another way of re-centring Pākehā and placing a burden of education on Māori 
individuals. Mara reminded me of this point when I spoke with her about writing this final discussion about learning through listening. She said that her approach to learning about queer experience (as a straight woman) is to wait until queer people talk to her about their experiences, in their own time, rather than asking a lot of questions about it and expecting people to fulfil her curiosity. This is excellent advice, the logic of it is plain, as seen in Te Awanui's comment about Clara: 'I don't want to be asked: "So you, what do Māori think?" I just want her to listen when I'm talking' (December 11, 2010). Still, it took me a long time to learn this lesson and I still struggle with it. I found it particularly difficult, as an emerging researcher, not to ask a lot of questions. Perhaps I am not alone as a PhD student who found it easy to become a little obsessed with my topic, to want to talk about it all the time, especially in the beginning when I was absorbing a lot of new information and trying to process what I was reading and seeing through talking to the people in my life who were actually interested and knowledgeable about colonisation. On a personal note, I felt a sense of urgency to learn as quickly as possible. There seems to be a common experience among Pākehā who are 'awakening' (to borrow Huygens' term) to want to 'correct' a lifetime of misinformation and remake ourselves as 'good Pākehā'. This desire for 'recovery' clearly echoes that of the Australian nation state as described by Ahmed (2004) and exposes the 'fantasy of transcendence'. I was in this state of urgency during much of the time that Black Rainbow was meeting and I am deeply grateful for the patience and generosity other members of the group showed me at that time, because I know I must have been a little annoying.

This lesson was brought home for me, in a very personal way, when I was sitting at a table full of postgraduate students in the university bar, when the topic of conversation turned to paedophilia. The people around me were discussing this as a philosophical problem and one young woman was quite passionate in her argument, but this connected to childhood pain for me and even though on some occasions I am interested in talking about that intellectually and personally, those experiences were not something I wanted to be reminded about at the end-of-the- 
week postgrad drinks. This moment powerfully allowed me to feel what should be obvious - 'if colonisation is something that has been causing pain and frustration in Māori friends' lives, they may not want to think about it every time they meet me for coffee. Maybe they just want to talk about music or kittens?' When I said this to Amiria, her laughter let me know I was right to be apologetic. I hope that this is something I will continue to mature into as I develop as a researcher, nevertheless I think this raises some interesting methodological questions for how we can conduct research in a way that does not burden participants with the role of educators, but rather allows us to wait for the learning that comes from hearing what people want to say, when they want to say it. This assumes a relationship-based research, which accepts that a lot of time spent with participants in the research will not be 'on topic'.

Mara's lesson of listening when people want to speak, is a typical example of how recognising the 'epistemological discomfort' of change-as the emotional cost of accepting insiders' epistemic privilege has implications for writing this thesis. Ruth Behar wrote about the irony of being vulnerable in the field, only to return 'home' and hold an authority over what one has learnt:

[E]ven though we start by going public, we continue our labour through introspection. And then we go public again, and if the first time we dealt in something that came dangerously close to tragedy, the second time around we are definitely in the theatre of farce as our uncertainty and dependency on our subjects in the field is shifted into a position of authority back home when we stand at the podium, reading our ethnographic writing aloud... (Behar 1996: 9)

The collaborative nature of the Black Rainbow project has not allowed for this total shift in power, however. Even if I was not actively seeking feedback on the chapters I write, any authority I have is shaken every time I see people from Black Rainbow. All it takes is a cup of tea with Mara to remind me how little I know. This makes insider's epistemic privilege powerfully real for me and is perhaps why I have emphasised it so much throughout the thesis. It is through sitting with the discomfort this causes me that I am most able to appreciate insiders' epistemic 
privilege and see some of my own limits. This points to one of the most glaring limitations of this research, which is that it was not carried out by a Māori researcher.

I hope through reading this thesis you (the reader) will have come to appreciate that there are interesting parallels between the ideas raised in the Black Rainbow discussions about the limitations on power-sharing in the anarchist scene, and the limitations of power-sharing within this collaborative research project. Throughout this research, I have found anti-oppressive research methodologies and lessons in collective organising reinforcing and testing each other. I am in a position of power as the instigator and author of this research thesis, and I share many of the same difficulties of seeking consensus and not always finding it, or not being sure if it is found, as some of the people discussed by Black Rainbow in the previous chapters. This was exacerbated, in part, by my inexperience as a researcher. As an emerging researcher, creating my methods as I went and still learning about collaborative research, I was often flustered and hesitant about explaining my proposed methods to the group. My desire to de-centre myself, and push power away from myself, often left the group frustrated and directionless.

Similarly, another limitation of this research is that I am in the middle of my own decolonisation journey, while I carry out this work. My understanding of this has changed immensely over the course of this research and I feel very aware that I write from where I am 'at' right now. This relates to another limit of this research, which is that it looks only at the relationships between Māori and Pākehā, missing the perspectives of other people who are part of the 'web' of people moving in relation to the Treaty and colonisation in Aotearoa New Zealand (Huygens' 2004: 191). People who identify as 'off white' (who experience white privilege, but are not culturally Pākehā), other Pacific Islanders and members of established communities (such as Indian and Chinese) as well as new migrants, are not included in this research and I am aware that I risk alienating those who are not represented 
by the typical 'bicultural' pairing of Māori and Pākehā. This is the unfortunate reflection of my own limits and the realisation that I was unable to do justice to wider 'multicultural' issues at this time.

Someone more experienced with both collaborative research and decolonisation would probably produce a very different piece of work. Yet, through this research I have learnt how difficult truly collaborative work is, especially when only one person is authoring the text. This is a research style I would like to continue to pursue, but with more expectation of 'epistemological discomfort' than I began with. Returning to Abu-Lughod's point that 'we should perhaps be more modest in our claims to radicalism' (1993: 26), I am willing to accept that there are always limits and there is a need to remain hopeful but humble.

Never-the-less, I believe this project was very successful. It was an important change experience for me and it created a space for Māori members to share their experiences with each other. Responding to Ahmed, I believe one of the key things this thesis 'does' is allow the exposure of racism-especially by allowing the people who experience that racism to tell their stories and share their analysis. The form that the thesis takes asks the reader to 'listen' to the participants, as I attempted to write in a way that does not privilege my voice over theirs. I do not want to end this thesis on too much of a triumphant note, but I do want to say that it is 'okay'. Engaging with Māori is often seen as frightening and confusing by non-Māori and many of the things I have talked about confirm that, but ultimately I have found that engagement wonderful and exciting and involving all the relationship skills and work that any friendship does. These help to mature us and allow us to treat each other with grace and dignity.

This brings me back to the discussion I began this thesis with, about 'learning to be affected' by Kaupapa Māori, reflecting on the lessons I learnt working with Black 
Rainbow helps deepen my understanding of this discussion. These lessons translate to 'listening' to Kaupapa Māori researchers, sitting with the discomfort of that, gaining a greater understanding of insiders' epistemic privilege through listening, and accepting the criticism of my work by Māori academics as a gift. I hope that this approach will lead to more trust between the disciplines of anthropology and Māori studies. Building these relationships may be the 'the trick of standing upright here' for Pākehā academics like myself (Metge 2010: 1). Trust, however, is not so much 'trick' as an ongoing process and therefore, I am putting this thesis 'out there', to see what academics and activists will make of it-as part of those ongoing relationships. 


\section{Appendix}

\section{Consent to Participation in Research}

Project: Where parallel lives meet: a personal study of biculturalism in Aotearoa/New Zealand

\section{Researcher Rachael Fabish,}

Cultural Anthropology Programme in the School of Cultural and Social Studies

I have been provided with sufficient information about this project. I have discussed this project with Rachael and have had my questions answered.

I consent to joining this project group. I am very committed to this project and am willing to work with Rachael for the next three years. I will inform her of any problems if they come up during that time.

I understand that as a member of this project group I will be fully involved in the decision making process for this project from this point forward. This means that I will be totally informed about the project at all times and the direction of the group will be decided by consensus from this time forward.

I understand that we will decide as a group by consensus what will be recorded and by what means. I also understand that I will have access to these recordings as one of the participant-researchers in this project.

We will also decide as a group by consensus how those recordings will be stored and what will happen to them at the end of the project.

I understand that I can pull out of this project at anytime. I also understand that I will have a responsibility to the group to uphold the decisions made in the group, especially around confidentiality, after I have left the group.

I understand that I will be given the opportunity to check, make corrections to, and/or withdraw any quotations or discussions attributed to me or images of me before they are used by Rachael in her final analysis. 


\section{CONFIDENTIALITY, please tick one:}

$\square$ I understand that any information I provide will be kept confidential to the collaborative group and Rachael's supervisors - the published results will not use my name, and that no opinions will be attributed to me in any way that will identify me.

OR

$\square$ I prefer that information or opinions which I have given being attributed to me in any reports on this research.

Signed:

Date:

SACS HEC ethics approval Ref. \#17775. Date of approval: 12 July 2010 


\section{Bibliography}

Abagond, Julian

2010 White Women's Tears. Abagond [blog] June 11, 2010.

http://abagond.wordpress.com/2010/06/11/white-womens-tears/, accessed February 16, 2014.

Abu-Lughod, Lila

1993 Writing Women's Worlds: Bedouin Stories. Berkeley: University of California Press.

Ahmed, Sara

2004 Declarations of Whiteness: The Non-Performativity of Anti-Racism. Borderlands e-journal 3(2).

http://www.borderlands.net.au/vol3no2 2004/ahmed declarations.htm, accessed February 17, 2014.

Archie, Carol

1995 Māori Sovereignty: the Pākehā Perspective. Auckland, N.Z.: Hodder Moa Beckett.

2005 Skin to Skin: Intimate True Stories of Māori-Pākehā Relationships.

Auckland, NZ: Penguin Books.

Bargh, Maria, ed.

2007 Resistance: an Indigenous Response to Neoliberalism. Wellington, N.Z.:

Huia.

2009 Going Backwards: The Future of New Zealand Studies. Paper presented at The Future of New Zealand Studies seminar series. Stout Research Centre, Victoria University of Wellington, April 1, 2009. 
Behar, Ruth

1996 The Vulnerable Observer: Anthropology that Breaks Your Heart. Boston:

Beacon Press.

Bell, Avril

1999 Authenticity and the Project of Settler Identity in New Zealand. Social Analysis 43(3):122-143.

2004 Relating Māori and Pākehā: the Politics of Indigenous and Settler Identities.

Ph.D. dissertation, Department of Sociology, Massey University.

2006 Bifurcation or Entanglement? Settler Identity and Biculturalism in Aotearoa New Zealand. Continuum: Journal of Media \& Cultural Studies 20(2):253-268.

2008 Recognition or Ethics? - De/centering and the legacy of settler colonialism. Cultural Studies 22(6):850-869.

2009 Dilemmas of Settler Belonging: Roots, Routes and Redemption in New Zealand National Identity Claims. The Sociological Review 57(1): 145-162.

Biggs, Bruce

1989 Humpty-Dumpty and the Treaty of Waitangi. In Waitangi: Māori and Pākehā Perspectives of the Treaty of Waitangi. I.H. Kawharu, ed. Pp. 300-311. Auckland: Oxford University Press NZ.

Bishop, Russell

1998 Freeing Ourselves from Neo-Colonial Domination in Research: a Māori Approach to Creating Knowledge. International Journal of Qualitative Studies in Education 11(2):199-219.

Bönisch-Brednich, Brigitte

2002 Keeping a Low Profile: An Oral History of German Immigration to New Zealand. Wellington [N.Z.]: Victoria University Press. 
2008 Watching the Kiwis: New Zealander's Rules of Social Interaction - an Introduction. Journal of New Zealand Studies, Oct. 2007-2008. Special Issue: Watching the Kiwis: 3-15.

Borell, Belinda

2005 Living in the City Ain't So Bad: Cultural Identity for Young Māori in South Auckland. In New Zealand Identities: Departures and Destinations. J.H. Liu, T. McCreanor, T. McIntosh, and T. Teaiwa, eds. Pp. 191-206. Wellington, N.Z.: Victoria University Press.

Borell, Belinda, et al.

2009 "It's Hard at the Top but it's a Whole Lot Easier than being at the Bottom": The Role of Privilege in Understanding Disparities in Aotearoa/New Zealand. Race/Ethnicity: Multidisciplinary Global Contexts 3 (1): 29-50.

Brown, Leslie, and Susan Strega

2005 Research as Resistance: Critical, Indigenous and Anti-Oppressive Approaches. Toronto, ON: Canadian Scholars' Press.

Butt, Danny

2004 On 'New Zealand' 'Studies'. Paper presented at the Imagining New Zealand / Aotearoa, 11th Annual day conference of the New Zealand Studies Association, London, July 3, 2004. http://dannybutt.net/on-new-zealand-studies/, accessed February 17, 2014.

2005 Biculturalism as Multiculturalism. Paper presented at the Biculturalism or Multiculturalism? conference, Christchurch, September 1-3, 2005.

http://dannybutt.net/biculturalism-as-multiculturalism/, accessed February 17, 2014.

2010 The Opposite of Whiteness. Paper presented at the Whiteness/Whitemess: Creative Disorders and Hope conference, Wellington, May 15, 2010. http://dannybutt.net/the-opposite-of-whiteness/, accessed February 17, 2014.

Carty, John, and Yasmine Musharbash

2008 You've Got to be Joking: Asserting the Analytical Value of Humour and Laughter in Contemporary Anthropology. Anthropological Forum 18(3):209-217. 
Cram, Fiona

2001 Rangahau Māori: Tona Tika, Tona Pono: The Validity and Integrity of Māori Research. In Research Ethics in Aotearoa New Zealand: Concepts, Practice, Critique. M. Tolich, ed. Pp. 35-52. Auckland, N.Z.: Longman.

Crenshaw, Kimberlé

1991 Demarginalizing the Intersection of Race and Sex: A Black Feminist Critique of Readings in Law and Gender. K.T. Bartlett and R. Kennedy, eds. Pp. 57-80. Boulder: Westview Press.

Curwin, Nick Singhal Sanjay Russell David Elliott Jane dir.

2009 Anatomy of Prejudice: Jane Elliott's Seminar on Race. Films Media Group. Hamilton, N.J.

Denzin, Norman K., and Yvonna S. Lincoln

2008 Introduction: Critical Methodologies and Indigenous Inquiry. In Handbook of Critical and Indigenous Methodologies. N.K. Denzin, Y.S. Lincoln, and L.T. Smith, eds. Pp. 1-20. Los Angeles: Sage.

Derailing For Dummies: A Guide to Derailing Conversations.

http://www.derailingfordummies.com/, accessed February 17, 2014.

Desmond, Pip

2009 Trust: A True Story of Women and Gangs. Auckland, N.Z.: Random House New Zealand.

Devadas, Vijay

200815 October 2007, Aotearoa: Race, Terror and Sovereignty. Sites: New Series 5(1):124-151.

Doerr, Neriko Musha

2009 Meaningful Inconsistencies: Bicultural Nationhood, the Free Market, and Schooling in Aotearoa/New Zealand. New York; Oxford: Berghahn Books. 
Durie, Mason

1995 Beyond 1852: Māori, the State and a New Zealand Constitution. Sites 30:31-47.

1998 Te Mana te Kāwanatanga = The Politics of Māori Self-Determination. Auckland; New York: Oxford University Press.

2004 Exploring the Interface Between Science and Indigenous Knowledge. Paper presented at the 5th APEC Research and Development Leaders Forum: Capturing Value From Science, Christchurch, March 11, 2004.

http://www.massey.ac.nz/massey/fms/Te\%20Mata\%200\%20Te\%20Tau/Publicatio ns\%20-

\%20Mason/M\%20Durie\%20Exploring\%20the\%20interface\%20Between\%20Science \%20and\%20Indigenous\%20knowledge.pdf?CE92AA6ED9817AF4E35467C91584A8A 9, accessed February 17, 2014.

2005a Ngā Tai Matatū: Tides of Māori Endurance. Melbourne; Auckland: Oxford University Press.

2005b Tino Rangatiratanga. In Waitangi Revisited: Perspectives on the Treaty of Waitangi. M. Belgrave, M. Kawharu, D.V. Williams, and I.H. Kawharu, eds. Pp. 3-19. South Melbourne, Vic.: Oxford University Press.

Durie, M.H., T.E. Black, I.S. Christensen, A.E. Durie, E.D. Fitzgerald, J.T. Taiapa.

1995 Te Hoe Nuku Roa Framework: A Māori Identity Measure. The Journal of the Polynesian Society 104(4):461-470.

Ellis, Carolyn

1996 The Other Side of the Fence: Seeing Black and White in a Small Southern Town. In Private Sociology: Unsparing Reflections, Uncommon Gains. A.B. Shostak, ed. Pp. 100-120. The Reynolds series in sociology. Dix Hills, N.Y.: General Hall.

2004 The Ethnographic I: A Methodological Novel about Autoethnography. Walnut Creek, CA: AltaMira Press.

2009 Revision: Autoethnographic Reflections on Life and Work. Walnut Creek, CA: Left Coast Press. 
Ellis, Carolyn, and Leigh Berger

2003 Their Story/My Story/Our Story: Including the Researcher's Experience in Interview Research. In Inside Interviewing: New Lenses, New Concerns. J.A. Holstein and J.F. Gubrium, eds. Pp. 467-493. Thousand Oaks [Calif.]: Sage Publications.

el-Ojeili, Chamsy

2012 Anarchism as the Spirit of Contemporary Anti-Capitalism? A Critical Survey of Recent Debates. Critical Sociology published online 11 September 2012:1-18. http://crs.sagepub.com/content/early/2012/09/04/0896920512452023.abstract, accessed February 2, 2014.

Evans, Patrick

2006 'Pākehā-Style Biculturalism' and the Māori Writer. Journal of New Zealand Literature 24(1):11-35.

Fabish, Rachael

2010 The Impact of Tā Te Māori Rangahau / Methodologies of Māori Research on My Work. Te Kāhui Kura Māori 0 (2).

http://nzetc.victoria.ac.nz/tm/scholarly/tei-Bid00 2Kahu-t1-g1-t3.html, accessed February 17, 2014

2010 Where Parallel Lives Meet: 'Learning to be Affected' and Researching Decolonisation in Aotearoa. Paper presented at the Contemporary Ethnography Across Disciplines conference, Hamilton, November 18, 2010.

Farrell, Michael P.

2001 Collaborative Circles: Friendship Dynamics and Creative Work. Chicago: University of Chicago Press.

Ferguson, Kathy E.

2011 Becoming Anarchism, Feminism, Indigeneity. Affinities: A Journal of Radical Theory, Culture, and Action 5(1):96-109. 
Fine, Gary Alan, and Michaela de Soucey

2005 Joking Cultures: Humor Themes as Social Regulation in Group Life. Humor: International Journal of Humor Research 18(1): 1-22.

Fleras, Augie, and Paul Spoonley

1999 Recalling Aotearoa: Indigenous Politics and Ethnic Relations in New Zealand. Auckland, N.Z.: Oxford University Press.

Foote, David

2009 Anarchists, Punks and Vegans - Oh My! Ethnography of an Anti-Capitalist Community of Dissent. M.A. dissertation, Department of Social Sciences, University of Waikato.

Fox, Kate

2004 Watching the English: The Hidden Rules of English Behaviour. London: Hodder \& Stoughton.

Frankenberg, Ruth

1993 Growing up White: Feminism, Racism and the Social Geography of Childhood. Feminist Review (45):51-83.

Gagné, Natacha

2004 Māori Identities and Visions: Politics of Everyday Life in Auckland, New Zealand. Ph.D. dissertation, Department of Anthropology, McGill University.

2013 Being Māori in the City: Indigenous Everyday Life in Auckland. Toronto: University of Toronto Press.

George, Lily

2008 Articulating the Intellectual Tūrangawaewae of an Indigenous Anthropologist. Proceedings of the Māori Association of Social Scientists Conference: 55-64. 
Gibson, Helen Margaret

2006 The Invisible Whiteness of Being: The Place of Whiteness in Women's Discourses in Aotearoa/New Zealand and Some Implications for Antiracist Education. Ph.D. dissertation, Department of Education, University of Canterbury.

Gibson, Lorena

2011 Hope, agency, and the 'side effects' of development in India and Papua New Guinea, Social Anthropology, Massey University.

Gibson-Graham, J. K.

2006 A Postcapitalist Politics. Minneapolis: University of Minnesota Press.

Gibson-Graham, J. K., and Gerda Roelvink

2009 An Economic Ethics for the Anthropocene. Antipode 41(1):320-346.

Glover, Marewa

1993 Developing Psychologies: An Ethical Necessity. New Zealand Psychological Society Bulletin 76:38-39.

2007 Eroticising Equality, Coming to Power. In Sexuality and the stories of indigenous people. J. Hutchings and C. Aspin, eds. Pp. 58-69. Wellington, N.Z.: Huia.

Godfrey, Morgan

2014 'Anne Tolley: An Agent of Colourblind Racism?' Maui Street [blog] January 31, 2014. http://mauistreet.blogspot.co.nz/, accessed February 16, 2014.

González, Christina M.

2010 'Be(com)ing' Ngāti Kahungunu in the Diaspora: Iwi Identity and Social Organisation in Wellington. M.A. dissertation, Department of Te Kawa a Māui = Māori Studies, Victoria University of Wellington. 
Gornick, Vivian

2002 The Situation and the Story: the Art of Personal Narrative. New York: Farrar, Straus, and Giroux.

Graeber, David

2002 The New Anarchists. New Left Review 13(Jan-Feb):61-73.

2004 Fragments of an Anarchist Anthropology. Chicago: Prickly Paradigm Press.

2007 Possibilities: Essays on Hierarchy, Rebellion and Desire. Oakland, CA; Edinburgh: AK.

2009 Direct Action: An Ethnography. Edinburgh; Oakland: AK Press.

Gwynne, Cat Ruka

2009 Artistic Practices, Representations of Māori Women and the Paradox of Kaupapa Māori. MAI Review 1(Intern Research Report 6):1-11.

Hanisch, Carol

1969 The Personal Is Political. Women of the World, Unite! The Writings of Carol Hanisch. http://www.carolhanisch.org/CHwritings/PIP.html, accessed February 17, 2014

Haraway, Donna Jeanne

1988 Situated Knowledges: The Science Question in Feminism and the Privilege of Partial Perspective. Feminist Studies 14(3):575-599.

Harris, Aroha

2008 Concurrent Narratives of Māori and Integration in the 1950s and 60s. Journal of New Zealand Studies, 6/7:139-155. 
Henare, Amiria

2007 Nga Rakau a te Pākehā: Reconsidering Māori Anthropology In

Anthropology and Science: Epistemologies in Practice. J. Edwards, P. Harvey, and P. Wade, eds. Pp. 93-113. Oxford: Berg.

Hill, Richard S.

2009 Māori and the State: Crown-Māori Relations in New Zealand/Aotearoa, 1950-2000. Wellington, N.Z.: Victoria University Press.

hooks, bell

1989 Talking Back: Thinking Feminist, Thinking Black. Boston, MA: South End Press.

1990 Yearning: Race, Gender, and Cultural Politics. Boston, MA: South End Press.

2000 Feminist Theory: From Margin to Center. Cambridge, MA: South End Press.

2010 Teaching Critical Thinking: Practical Wisdom. New York: Routledge.

Houkamau, Carla A., and Chris G. Sibley

2010 The Multi-Dimensional Model of Māori Identity and Cultural Engagement. New Zealand Journal of Psychology 39(1):8-28.

Huygens, Ingrid

2007 Processes of Pākehā Change in Response to the Treaty of Waitangi. Ph.D. dissertation, Department of Psychology, University of Waikato.

Irwin, Kathy

1994 Māori Research Methods and Practices. Sites 28 (Autumn):25-43.

Iti, Tipare dir.

2011 The Half-Caste Broadcast - Hikoi the 2nd. http://vimeo.com/30520002, accessed, February 3,_2014. 
Jackson, Michael

2002 The Politics of Storytelling: Violence, Transgression, and Intersubjectivity. England: Museum Tusculanum Press

Jackson, Moana

2009 Once Were Gardeners. Paper presented at the Cutting Edge conference, Wellington. http://www.youtube.com/watch?v=HfAe3Zvgui4 , accessed 13 February 2014.

Jerram, Kristin

2012 E Kore Te Tōtara e Tū Noa i Te Pārae, Engari Me Tū i Roto i Te Wao-Nui-aTāne: The Symbolism of Rākau and Ngahere in the Huia Short Story Collections. M.A. dissertation, Department of Māori Studies / Te Kawa a Māui, Victoria University of Wellington.

Jones, Alison

1999 The Limits of Cross-Cultural Dialogue: Pedagogy, Desire and Absolution in the Classroom. Educational Theory 49(3):299-316.

2001 Cross-Cultural Pedagogy and the Passion for Ignorance. Feminism Psychology 11(3):279-292.

Jones, Alison, and Kuni Jenkins

2008 Rethinking Collaboration: Working the Indigene-Colonizer Hyphen. In Handbook of Critical and Indigenous Methodologies. N.K. Denzin, Y.S. Lincoln, and L.T. Smith, eds. Pp. 471-486. Los Angeles: Sage.

Keenan, Danny, ed.

2008 Terror in Our Midst? Searching for Terror in Aotearoa New Zealand. Wellington, N.Z.: Huia. 
Kemmis, Stephen, and Robin McTaggart

2005 Participatory Action Research: Communicative Action and the Public Sphere. In The SAGE Handbook of Qualitative Research. 3rd edition. N.K. Denzin and Y.S. Lincoln, eds. Pp. 559-603. Thousand Oaks: Sage Publications.

King, Michael

1999 Being Pākehā Now: Reflections and Recollections of a White Native. Auckland, N.Z.: Penguin.

Larson, Colleen L.

1997 Re-presenting the Subject: Problems in Personal Narrative Inquiry. International Journal of Qualitative Studies in Education 10(4):455-470.

Lawson-Te Aho, Keri

1993 The Socially Constructed Nature of Psychology and the Abnormalisation of Māori. New Zealand Psychological Society Bulletin 76:25-30.

Leonardo, Zeus

2004 The Colour of Supremacy: Beyond the Discourse of 'White Privilege'. Educational Philosophy and Theory 36(2):137-152.

MacLean, Malcolm

1996 The Silent Centre: Where Are Pākehā in Biculturalism? Continuum: Journal of Media \& Cultural Studies 10(1):108-120.

Margaret, Jen

2010a Capacity Development Processes within a Social Movement: Pākehā Treaty Workers' Movement. IDS Bulletin 41(3):68-78.

2010b Working as Allies. Winston Churchill Fellowship Report.

http://www.awea.org.nz/allies north america, accessed February 9, 2014 
Matahaere-Atariki, Donna

1999 A Context for Writing Masculinities. In Masculinities in Aotearoa/New Zealand. R. Law, H. Campbell, and J. Dolan, eds. Pp. 104-117. Palmerston North, N.Z.: Dunmore Press.

McBreen, Kim

2011a Defining Māori. He Hōaka, [blog] January 11, 2011.

http://starspangledrodeo.blogspot.co.nz/2011/01/defining-Māori.html, accessed February 16, 2014.

2011b Operation 8: Deep in the Forest. He Hōaka, [blog] July 27, 2011.

http://starspangledrodeo.blogspot.co.nz/search/label/Operation\%208, accessed February 18, 2014.

McCreanor, Tim

2005 'Sticks and Stones May Break my Bones...': Talking Pākehā Identities. In New Zealand Identities: Departures and Destinations. J.H. Liu, T. McCreanor, T. McIntosh, and T. Teaiwa, eds. Pp. 52-68. Wellington, N.Z.: Victoria University Press.

McDowell, Morag, and Duncan Webb

1998 The New Zealand Legal System: Structures, Processes and Legal Theory. Wellington, NZ: Butterworths.

McGuirk, Emma

2012 Studying Time Banking: Exploring Participatory Action Research in Aotearoa New Zealand. Sites 9(2):142-171.

McIntosh, Peggy

1990 White Privilege: Unpacking the Invisible Knapsack. Independent School 49 (2):31-36. http://amptoons.com/blog/files/mcintosh.html, accessed February 2, 2014.

McIntosh, Tracey

2005 Maori Identities: Fixed, Fluid, Forced. In New Zealand Identities: Departures and Destinations. J.H. Liu, T. McCreanor, T. McIntosh, and T. Teaiwa, eds. Pp. 38-51. Wellington, N.Z.: Victoria University Press. 
Meredith, Paul

1999 Hybridity in the Third Space: Rethinking Bi-cultural Politics in

Aotearoa/New Zealand. He Pukenga Kōrero: a Journal of Māori Studies 4(2):12-16.

Metge, Joan

1986 In and Out of Touch: Whakamaa in Cross Cultural Context. Wellington:

Victoria University Press.

2001 Kōrero Tahi: Talking Together. Auckland, N.Z.: Auckland University Press with Te Matahauariki Institute.

2010 Tuamaka: The Challenge of Difference in Aotearoa New Zealand. Auckland, N.Z.: Auckland University Press.

Metge, Joan, and P. J. Kinloch

1999[1979] Talking Past Each Other: Problems of Cross-Cultural Communication. Wellington: Victoria University Press.

Mikaere, Ani

1994 Māori Women: Caught in the Contraditions of a Colonised Reality. Waikato Law Review 2:125-149.

2004 Are We All New Zealanders Now? A Māori Response to the Pakeha Quest for Indigeneity. Bruce Jesson Memorial Lecture, University of Auckland, November 15, 2004.

2011 Colonising Myths - Māori Realities: He Rukuruku Whakaaro. Wellington: Huia Publishers and Te Tākupu, Te Wānanga o Raukawa.

Mitcalfe, Margaret Ann

2008 Understandings of Being Pākehā: Exploring the Perspectives of Six Pākehā who have studied in Māori Cultural Learning Contexts. M.Mgt dissertation, Department of Communication Management, Massey University. 
Mol, Annemarie

2002 The Body Multiple: Ontology in Medical Practice. Durham: Duke University Press.

Moosa-Mitha, Mehmoona

2005 Situating Anti-oppressive Theories within Critical and Difference-centred Perspectives. In Research as Resistance: Critical, Indigenous and Anti-oppressive Approaches. L. Brown and S. Strega, eds. Pp. 37-72. Toronto, ON: Canadian Scholars' Press.

Moreton-Robinson, Aileen

2003 Researching Whiteness: Some Reflections from an Indigenous Woman's Standpoint. Hecate 29(2):72.

Morse, Valerie, ed.

2010a The Day the Raids Came: Stories of Survival and Resistance to the State Terror Raids. Wellington: Rebel Press.

2010b The Process is the Punishment: Operation 8 two years on. Imminent Rebellion 10:47-51.

Narayan, Uma

1988 Working Together Across Difference: Some Considerations on Emotions and Political Practice. Hypatia 3(2):31-47.

Nettles, Kimberly D.

2008 Guyana Diaries: Women's Lives Across Difference. Walnut Creek, Calif.: Left Coast Press.

Ngai, Sianne

2005 Ugly Feelings. Cambridge: Harvard University Press. 
O’Brien, Michelle

2003 Whose ally? Thinking Critically about Anti-Oppression Ally Organizing. Published on Colours of Resistance.

http://www.coloursofresistance.org/370/whose-ally-thinking-critically-about-antioppression-ally-organizing-part-1/, accessed February 17, 2014.

October $15^{\text {th }}$ Solidarity

2014 October 15th Solidarity: Remember the State Terror Raids.

http://october15thsolidarity.info, accessed February 19, 2014.

Otter, Jacob

2007 Thinking through Biopower: Māori, the Left and the Treaty Worker

Movement. M.A. dissertation, Department of Māori Studies / Te Kawa a Māui, Victoria University of Wellington.

Palmer, Matthew

2008 The Treaty of Waitangi in New Zealand's Law and Constitution. Wellington, N.Z.: Victoria University Press.

Pandie and Takiaya dir.

2012 Shit White Queers Say to Black Queers. Pandiepantherz, YouTube.

http://www.youtube.com/watch?v=Vy9vM15OMVc, accessed February 17, 2014.

Pearson, David G., and Jeff Sissons

1997 Pākehā and Never Pākehā. Sites 35:64-80.

Pickering, Lucy

2010 Past imperfect: Displacing Hawaiians as Hosts in a 'Drop Out' Community in Hawai'i In Local Lives: Migration and the Politics of Place. B. Bönisch-Brednich and C. Trundle, eds. Pp. 49-64. Studies in migration and diaspora. Farnham; Burlington, Vt.: Ashgate.

Pihama, Leonie E.

2001 Tihei Mauri Ora: Honouring Our Voices. Mana Wahine as a Kaupapa Māori Theoretical Framework. Ph.D. dissertation, Department of Education, University of Auckland. 
Pihama, Leonie, and Penehira Mera

2005 Building Baseline Data on Māori, Whanau Development and Māori Realising their Potential: Literature Review: Facilitating Engagement: Final Report. International Research Institute, University of Auckland.

http://www.kaupapaMāori.com/assets/te puna kokiri/facilitating engagement.p df, accessed February 17, 2014.

Potts, Karen, and Leslie Brown

2005 Becoming an Anti-oppressive Researcher. In Research as Resistance:

Critical, Indigenous and Anti-oppressive Approaches. L. Brown and S. Strega, eds.

Pp. 255-286. Toronto, ON: Canadian Scholars' Press.

Povinelli, Elizabeth A.

2002 The Cunning of Recognition: Indigenous Alterities and the Making of Australian Multiculturalism. Durham [N.C.]: Duke University Press.

Purkis, Jonathan

2001 Leaderless Cultures: the Problem of Authority in a Radical Environmental Group. In Leadership and Social Movements. C. Barker, A. Johnson, and M. Lavalette, eds. Pp. 160-177. Manchester: Manchester University Press.

Ramsden, Irihapeti Merenia

2002 Cultural Safety and Nursing Education in Aotearoa and Te Waipounamu. Ph.D. dissertation, Department of Nursing, Victoria University of Wellington.

Rata, Arama

2012 Te Pītau o te Tuakiri: Affirming Māori Identities and Promoting Wellbeing in State Secondary Schools. Ph.D. dissertation, Department of Psychology, Victoria University of Wellington.

Reed, Natalie

2012 Five Ways Cis Feminists Can Help Build Trans Inclusivity and Intersectionality. Sincerely, Natalie Reed: Critical Thinking on Gender, Sexuality and Other Human Maters [blog] November 16, 2012.

http://freethoughtblogs.com/nataliereed/2012/11/16/five-ways-cis-feminists-canhelp-build-trans-inclusivity-and-intersectionality/, accessed February 17, 2014. 
Richardson, Laurel

2007 Last Writes: a Daybook for a Dying Friend. Walnut Creek, Calif.: Left Coast Press.

Richardson, Laurel, and Elizabeth Adams St. Pierre

2005 Writing: a Method of Inquiry. In The SAGE Handbook of Qualitative Research. 3rd edition. N.K. Denzin and Y.S. Lincoln, eds. Pp. 959-978. Thousand Oaks: Sage Publications. Royal Commission on

Royal Commission on Social Policy 1988 The April Report, Volumes I to IV. Wellington: The Royal Commission on Social Policy.

Royal, Te Ahukaramū Charles.

1998 Mātauranga Māori: Paradigms and Politics. Ministry for Research, Science and Technology.

1998 Te Ao Mārama - A Research Paradigm. Te Pūmanawa Hauora, Proceedings of Te Oru Rangahau: Māori Research and Development Conference: 78-86.

1998 Te Whare Tapere: Towards a Model for Māori Performance Art. Ph.D. dissertation, Department of Theatre and Film, Victoria University of Wellington.

Royal, Te Ahukaramū Charles, and Betsan Martin

2010 Indigenous Ethics of Responsibility in Aotearoa/New Zealand: Harmony with the Earth and Relational Ethics. In Responsibility and Cultures of the World: Dialogue around a Collective Challenge. E. Sizoo, ed. Pp. 47-64: Peter Lang Pub Incorporated.

Russo, Maria

1999 The Reeducation of a Queer Theorist. Salon, September 28, 1999.

http://www.salon.com/1999/09/27/sedgwick/, accessed February 17, 2014. 
Said, Edward W.

2003 Orientalism. London: Penguin Books.

Seifert, Miki, and Anahera Gildea

2011 He Rawe Tona Kakahu / She Wore a Becoming Dress: Performing the Hyphen. Ph.D. dissertation, Department of Māori Studies / Te Kawa a Māui, Victoria University of Wellington.

Shamblin, Don H.

1996 Reflections of a White Racist. In Private Sociology: Unsparing Reflections, Uncommon Gains. A.B. Shostak, ed. Pp. 92-99. The Reynolds series in Sociology. Dix Hills, N.Y.: General Hall.

Sibley, Chris G., and James H. Liu

2004 Attitudes towards Biculturalism in New Zealand: Social Dominance and Pakeha Attitudes towards the General Principles and Resource-Specific Aspects of Bicultural Policy. New Zealand Journal of Psychology 33 (2): 88-99.

Smith, Andrea

2013 Unsettling the Privilege of Self-Reflexivity. In Geographies of Privilege. F.W. Twine and B. Gardener, eds. Chapter 11. New York: Routledge.

Smith, Jo

2007 Post-cultural Hospitality: Settler-Native-Migrant Encounters. Arena Journal (28):65-86.

Smith, Linda Tuhiwai

1999 Decolonizing methodologies: Research and Indigenous Peoples. London; New York; Dunedin, N.Z.; New York: Zed Books ; University of Otago Press.

Spectra

2013 Straight Allies, White Anti-racists, Male Feminists (and Other Labels that Mean Nothing to Me). Huff Post: Black Voices.

www.huffingtonpost.com/spectra/straight-allies-white-ant b $3372490 . h t m l$, accessed February 19, 2014. 
Suaalii, Tamasailau M.

2000 Deconstructing the 'Exotic' Female Beauty of the Pacific Islands. . In Bitter Sweet: Indigenous Women in the Pacific. . A. Jones, P. Herda, and T.M. Suaalii, eds. Pp. 93-108. Dunedin: University of Otago Press.

Sue, Derald Wing, et al.

2007 Racial Microaggressions in Everyday Life: Implications for Clinical Practice. American Psychologist 62(4):271-286.

Sykes, Annette

2010 Bruce Jesson Lecture 2010.

http://www.scoop.co.nz/stories/HL1011/S00043/annette-sykes-bruce-jessonlecture-2010.htm, accessed February 17, 2014.

Tal, Kali

2011 White Privilege Diary Series \#1 - White Feminist Privilege in Organizations. Daily Kos [blog] http://www.dailykos.com/story/2011/05/22/957012/-WhitePrivilege-Diary-Series-1-White-Feminist-Privilege-in-Organizations, accessed February 17, 2014.

Tamahori, Lee dir.

1994 Once Were Warriors. Fine Line Features. New Zealand.

Te Punga Somerville, Alice

2011 Neither Qualitative nor Quantitative: Kaupapa Māori, Methodology and the Humanities. Kei Tua o Te Pae Hui proceedings: The Challenges of Kaupapa Māori Research in the 21st Century: 62-66.

Tolich, Martin

2002 Pakeha "Paralysis": Cultural Safety for Those Researching the General Population of Aotearoa. Social Policy Journal of New Zealand (19):164-178.

Trinh, T. Minh-Ha

1989 Woman, Native, Other: Writing Postcoloniality and Feminism.

Bloomington: Indiana University Press. 
Van Meijl, Toon

2006 Multiple Identifications and the Dialogical Self: Urban Māori Youngsters and the Cultural Renaissance. Journal of the Royal Anthropological Institute 12(4):917-933.

Waldman, Ken, and Luis Rubalcava

2005 Psychotherapy with Intercultural Couples: A Contemporary Psychodynamic Approach. American Journal of Psychotherapy 59(3):227 - 245

Walker, Ranginui

2004 Ka Whawhai Tonu Mātou: Struggle without End. Auckland, N.Z.: Penguin.

Webber, Melinda

2008 Walking the Space Between: Identity and Māori/Pākehā. Wellington, N.Z.: NZCER Press.

West, Emma Florence

2012 Manu is my Homegirl: Navigating the Ethnic Identity of the Māori Adoptee. M.Phil dissertation, Te Ara Poutama - Faculty of Māori Development, Auckland University of Technology.

Wilkinson, Eleanor

2009 The Emotions Least Relevant to Politics? Queering Autonomous Activism. Emotion, Space and Society 2(1):36-43.

Williams, Leonard

2007 Anarchism Revived. New Political Science 29(3):297-312.

Winiata, Whatarangi

2005 The Reconciliation of Kāwanatanga and Tino Rangatiratanga. The Rua Rautau Lecture: Rangiātea Church, Ōtaki, January 30, 2005. 
Wright, Errol, and Abi King-Jones dirs.

2011 Operation 8: Deep in the Forest. Wellington, N.Z.

\section{Young, Vershawn Ashanti}

2007 Your Average Nigga: Performing Race, Literacy, and Masculinity. Detroit: Wayne State University. 